

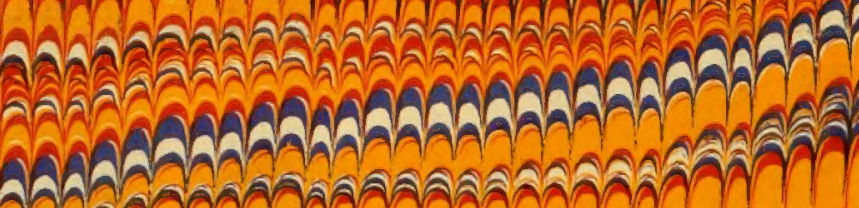

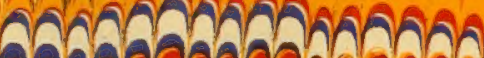

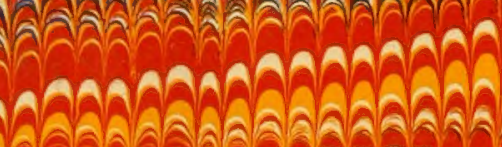




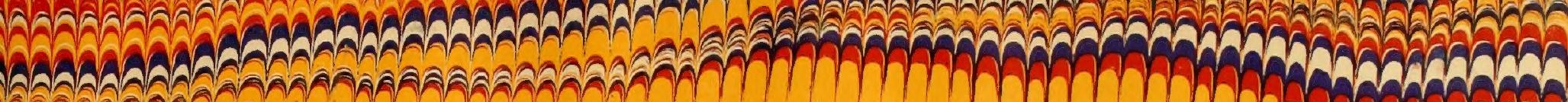
นิน

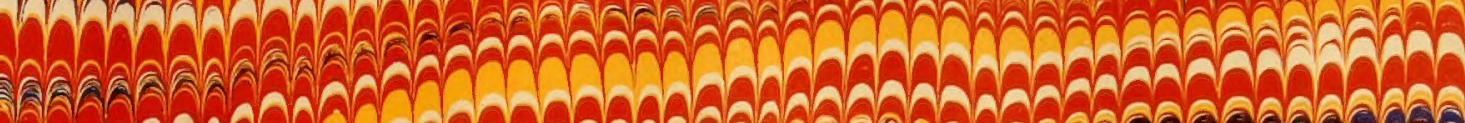

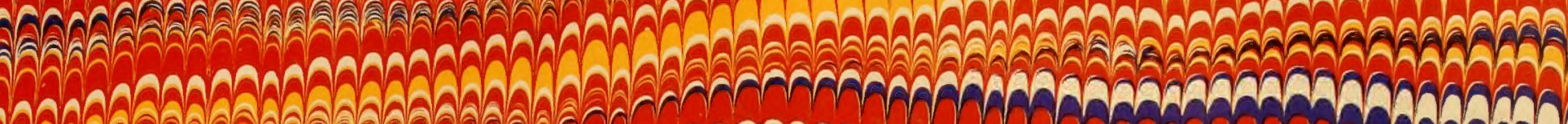
ân

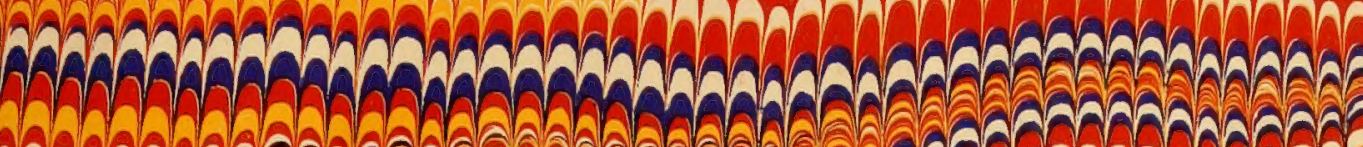

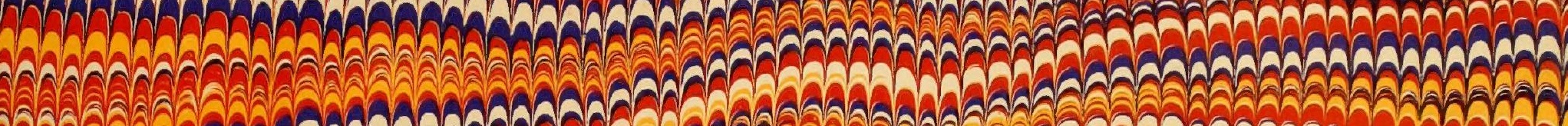

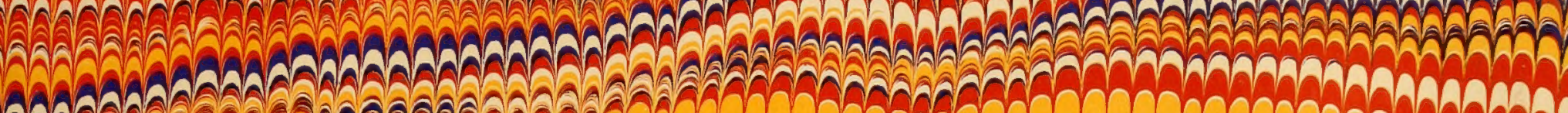

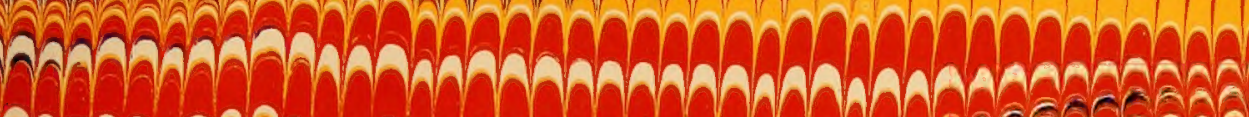

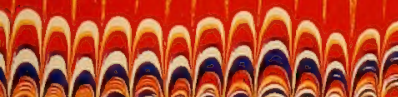

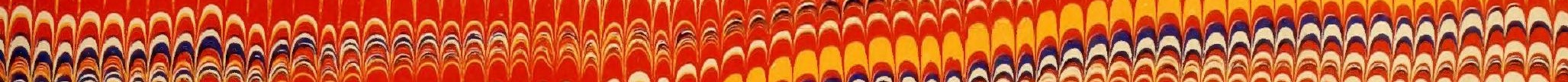

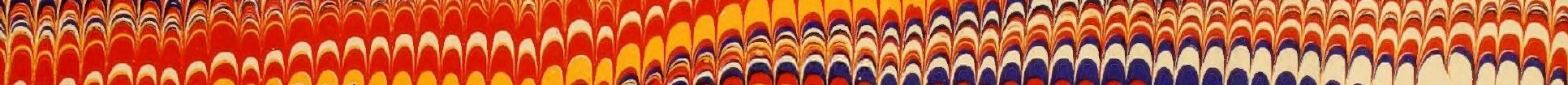
14.

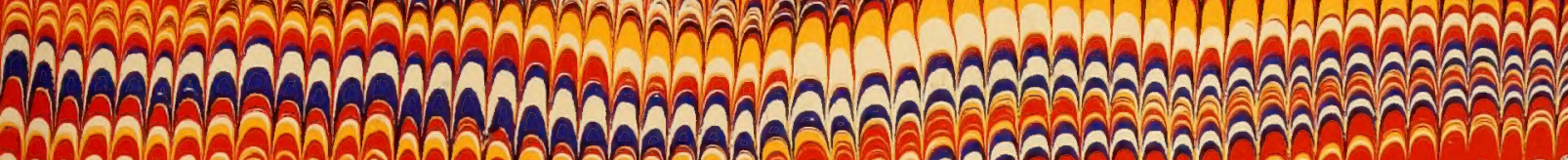
1.

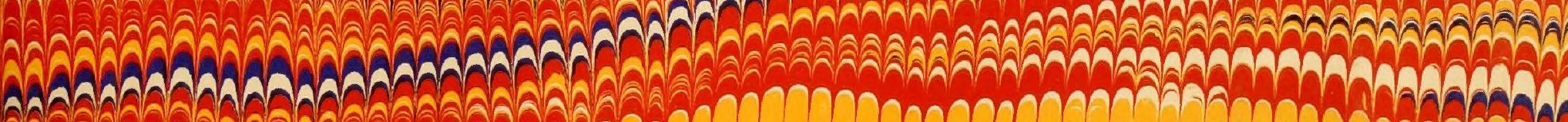
רал

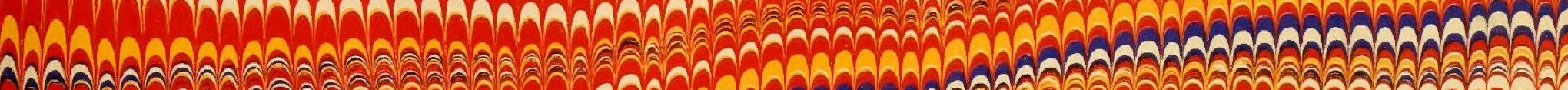
(1)

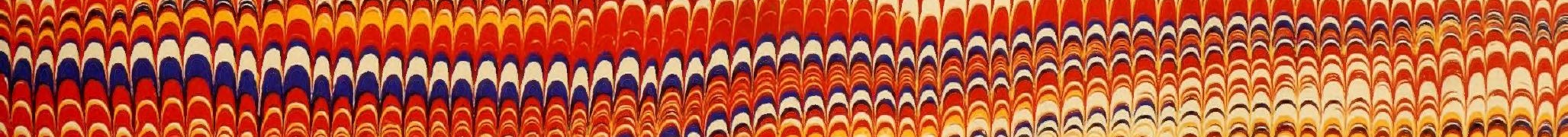
Whath

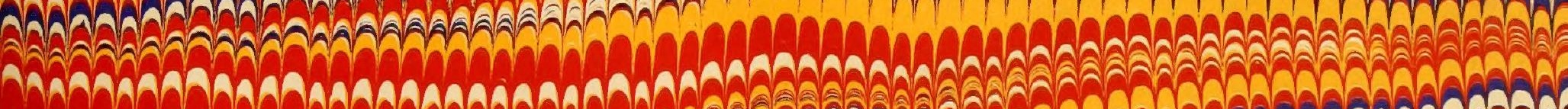

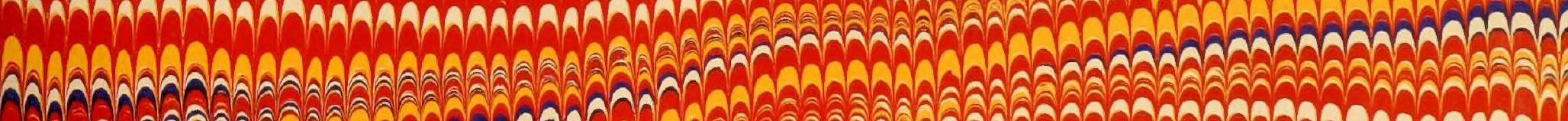
2.

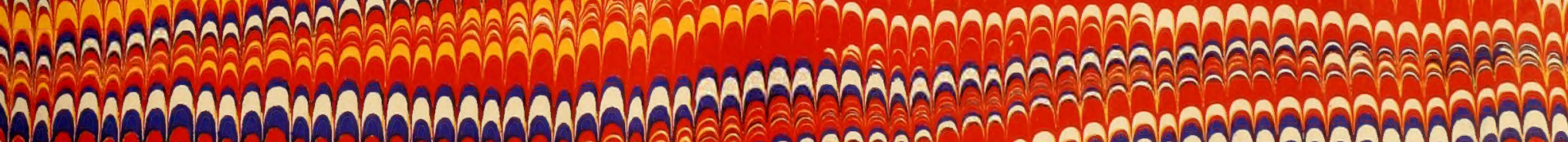

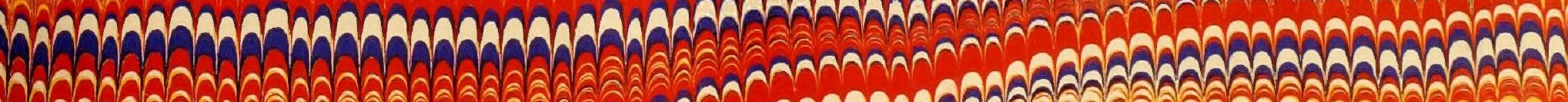
W A

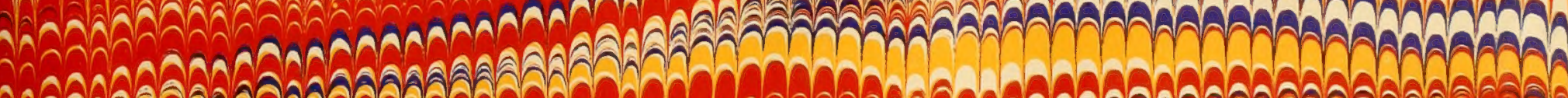

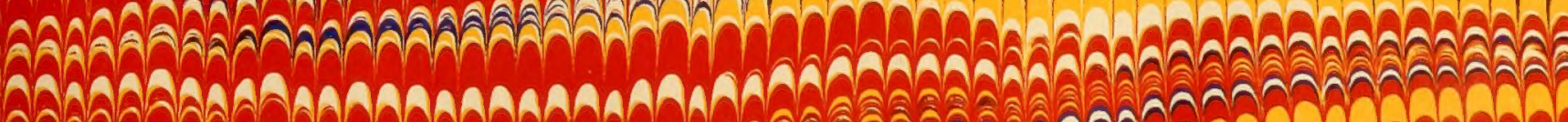

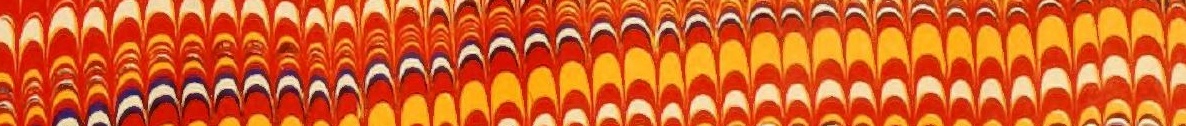

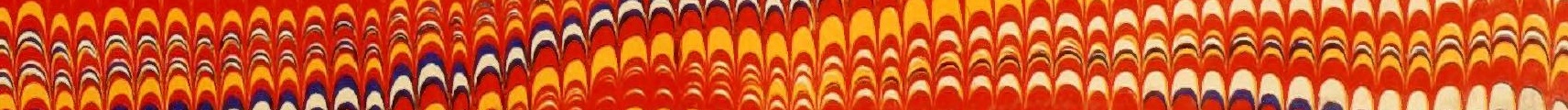

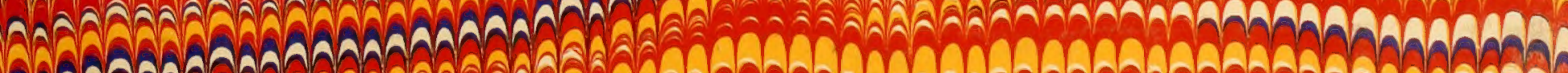

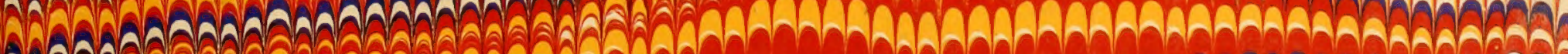






N A T U R A L H I S T O R Y

U N I T E D S T A T E S. 



\section{CONTRIBUTIONS}

\section{THE NATURAL HISTORY}

OF THE

UNITED STATES OF A IEERICA.

BY

L O U I S A G A S I Z.

FIRST MONOGRAPH.

IN THREE PARTS. - I. ESSAY ON CLASSIFICATION. - II. NORTH AMERICAN TESTUDINATA. II. EMBRYOLOGY OF THE TURTLE; WITH THIRTY-FOUR PLATES.

V OL. I I.

B $0 \mathrm{~S} \mathrm{~T} 0 \mathrm{~N}$ :

L I T T L , B R O W A N D C M P N Y.

L ONDON : TRÜBNER \& CO.

1857. 
Entered according to Aet of Congress, in the year 1857, by L OUIS $\triangle$ G A S S I ,

In the Clerk's Office of the District Court of the District of Massachusetts.

C A M B R D G L:

ALUEN AND FARNIIA, PRINTERS 


\section{P A R T I I I.}

EMBRYOLOGY OF THE TURTLE. 



\title{
EMBRYOLOGY OF THE TURTLE.
}

\author{
C II A P T E R F I R S T .
}

DEVELOPMENT OF THE EGG, FROM ITS FIRST APPEARANCE TO THE FORMATION OF THE EMBRYO.

\section{SECTION I.}

THE ORIGIN OF THE EGG.

ON account of the hitherto unknown peculiarities which the earlier stages of growth of the Turtle's egg exhibit, it is necessary to say a few words in reference to the caution which was taken to make sure that these strange features are perfectly normal. A young animal was resorted to, on account of the greater abundance of the smallest sized eggs, and also because the ovary is less opaque, than in the adult. Those of the latter age were nevertheless consulted also, for comparison, and in them it was ascertained that the process of growth is the same as with the younger animals.

In order not to distort the eggs by pressure, tearing, or pulling, the ovary was cut out entire by severing its peduncular attachment, thus avoiding the necessity of touching the eggss. To prevent drying, and also that it might be kept in a natural medium, the ovary was laid in the serum taken from the savity of the body, and brought under the microscope in a watch-glass. If, however, the serum is left uncovered for a longer time, it evaporates and changes its 
density, and in this condition acts upon the contents of the egg, causing great disturbances and a very false state of things. To avoid such an alteration, the serum must be changed often, and that held in reserve kept closely corked up, or, what is still safer, the animal resorted to for fresh supplies, if it has been opened carefully, so as not to allow the blood to become mixed with the fluid in requisition. With these precautions the whole ovary was surveyed under magnifying powers of from fifty to two hundred diameters, and the peculiar features of the eggs of all sizes noted, except those of the very minutest, which, on account of the short focus of the higher powers of the microscope necessarily used for their investigation, required to be observed in thinner portions of the organ carefully cut away.

In no case however was pressure, that great obstacle to all correct appreciation, applied, except to see what the effect might be, and also in certain experiments upon the consistency and elasticity of the contents of the egg. This is mentioned in particular, because the first glance reveals the fact that every egg in the ovary is more or less flattened, the oldest ones least, and those successively younger more and more, till the very minutest ones are reached, which again have the usual spherical form of simple cells. A peculiar brilliancy characterizes the surface of the ovary, which is owing to the circumstance that all the eggs, from nearly the smallest to those about one fiftieth of an inch in diameter, contain, on the side toward the surface of the ovary, a clear and more or less homogeneous fluid, underlaid by a darker and denser, yellowish, granular'substance, facing the centre of the organ (Pl. 8, fig. 3-9). This peculiarity will be spoken of in detail, when describing the progressive stages of growth in the egg.

Now, knowing the features of the eggs of different sizes, when in an undisturbed state, portions of the ovary were carefully cut out, and the stroma dissected away in case of the presence of larger eggs, or thin spots examined for the smaller ones. Although, from their elasticity, eggs removed in this way assumed a natural shape and condition after instances of pressure or pulling with the point of the linife, yet such eggs were avoided in the examination of the contents, not knowing what effect might have been produced upon the ultimate structure of the yolk: This precaution in regard to the yolk was subserquently found to be in no small degree important, as reference to the plasticity and viscidity of the yolk cells will testify. ${ }^{1}$ 'The stroma and the cells of the corpora graffiana are so exceedingly transparent that there is no difficulty in detecting the minutest eggs which may be imbedded therein (Pl. 8, fig. 1, $0^{1}$,

2 Water has a far more injurious effect even than pressure, especially upon the yolk cells, and is most rigorously to be aroided in all cases. But more will be said upon this in detail hereafter. 
$\left.h^{1}, 5,9\right)$; yet the thinnest portions are preferable, because of the greater homogeneity of the transmitted light.

It is beyond the reach of pen or pencil to illustrate satisfactorily the ummistakable physiognomy of the ovarian egrg at that age, when it is smaller than the cells of the Graffian body which surround it. The task becomes more difficult still when the very natural question arises, How is it known that these peculiar forms are eggs? The most direct answer to this question is, by comparison, which is in fact at the base of all inductive reasoning. But the argument here is not to be one of words alone; for every step of the induction shall be illustrated by examples drawn from nature, and words will serve merely to point out their true character.

No one will deny that the most correct and philosophical method is that which follows the development of the life of the eggs, seizing upon and watching the changes and growth of the minutest cells till that period when, by their contents and acknowledged characteristics, they are recognized without reserve to be eggs; although, in an argument upon the identity of an unknown with a known body, our finite senses usually prefer to start from the latter, and proceed toward the former by a series of reductions, tracing embryonic life just as it sometimes apparently develops itself in a series of retrograde metamorphoses. Yet, although we have in a few rare cases seeming examples of this kind, it is, to a mind so deeply imbued with the phenomena of the whole course of development as to follow instinctively in the path of nature, a forced and unnatural mode of interpretation of the phases peculiar to the several successive stages of the genesis of the ovarian egg.

Upon submitting the ovary to the microscope, with a magnifying power of about five hundred diameters, there may be observed in the field, scattered among the larger eggs, quite a number of smaller ones, varying from mere granular, minute, dark specks (Pl. 8, fig. 1, a) to a size about four times the diameter of the cells of the corpus graffianum which inclose them (PI. 8, fig. 1, b-p). These eggs have all one common physiognomy, which at once impels a belief that they are so many different grades in the development of one kind of cells, peculiar in themselves, and very different from the mass of hyaline and colorless cells of unvarying size about them. The thick, dark outline, the peculiarly brilliant and strongly refractive, homogeneous yellowish contents, and the lateral nucleus, ${ }^{1}$ when present, are entirely different from the thin walls, transparent, irrefractive contents, and central nucleus of the neighboring cells of the corpus graffianum (Pl. 8, fig.

- 3 The conflicting views entertained by anatomists upon the formation of cells have rendered some changes necessary in the nomenclature of the cell, its enrelope and contents, which are discussed below. 
$\left.1, a^{1}, l^{1}\right)$. Therefore, since by tracing a series of peculiar cells, from the minutest granular forms to those of a larger size, which have the readily acknowledged characteristics of an egg, there can be no doubt left, that the former are, by nature, the same as the latter, we may proceed to describe the several phases of development in all these bodies, as the progressive steps in the growth of the egg.

The initial form of an egg is a dark, oily looking, granule-like, spherical body, (Pl. 8, fig. 1, a,) situated among the interstices ${ }^{1}$ of the cells of the corpus graflianum. As the latter not only, but even their nuclei, surpass such an egg in size by several diameters, it is superfluous to debate the question, whether the egg may not be the nucleus of a cell of the generating organ. ${ }^{2}$

At this period in the life of an egg, there arises the question, not only of its origin, but also of that of independent cells; for the former is only one of the many variously endowed vesicles by which the animal economy performs its multitudinous functions. Nay, in fact, it is more: the egg, the animal of one single cell, potentially contains the principle of the future phenomena of life; so that the genesis of an egg is neither more nor less than the genesis of one kind of cells, containing within themselves the type of all future cell formations. The granule-like egg, which we have mentioned as the youngest, is a homogeneous mass, from the centre to the surface; the thick outline being not indicative of a wall, but resulting from the strong refraction, which has no such definite internal boundary as obtains in all membranes around limited contents. But yet it must be acknowledged that the superficial particles are determinedly the cell wall, and indeed may have a coherence among each other greater than those situated interiorly, yet not of sufficient density to produce a refraction so different from the latter as to be recognizable by the microscope. There is a warrant for this probability, in known examples on a larger scale; the yolk parent or outer cell, - even when it has reached maturity, (Pl. 9, fig. 11i, $a$; and Pl. 9a, figs. 36-40, a, ) and contains a large nucleus and several nucleoli, - shows this plainly, for it is a mass of excessively hyaline granules, the outer of which are only a little more coherent to each other than those within, but not dense enough to produce a recognizable refraction till water is applied and the contents burst out; whilst the wall, (Pl. 9, fig. 7c, and Pl. 9a, fig. 7a,) by its greater

1 'The first blood corpuscles are yolk-cell nuclei which have undergone changes identical with those of the whole "embryo," and they alone remain free, circulating in the channels hollowed out in a mass of cells illentical with themselves. These are the first cells originating interstitially, but yet, after all, not essentially so, as is the case with the egrg; for each blood corpusele is a segment of an original yolk-cell nucleus, which has gone through the process of selfdivision; whilst the egg originates just as the primary folk cell does, by conglomeration of particles, and the formation of a membrane around the parietes of this coneretion.

2 See 'Thompson's surgestion to that effect in Cyclopadia of Anatomy, article Ovum, p. 136, Oct., $185 \%$. 
tenacity, holds together for a while longer, but finally disintegrates and discloses its mode of origin in the immense number of minute, faint granules, identical in appearance with the extruded ones, which are dancing about in zigzag. At times a granular structure, giving to the wall the appearance of a cellular membrane on a very minute scale, ${ }^{1}$ may be detected, even before it has lost its consistency.

As the egg grows larger, the dark outline decreases in thickness, and the contents become less oily and more transparent, till at last, when it is about $\frac{1}{800}$ of an inch in diameter, a well defined wall discloses itself under the guise of a thin pellicle ( $\mathrm{Pl}, 8$, fig. $1, f, g)$.

The study of a series of eggs, ${ }^{2}$ such as have just been presented, - in which at first no wall is visible, then faint indications of a superficial change appear, in which a gradual differentiation of the parietal from the more internal substance ensues, and the finally well established separation of the two is unmistakable, the latter, the internal, inclosed by the former, which presents itself as a sharply pronounced, extremely tenuous envelope,-leaves no doubt that the egg-cell wall has an origin totally external to all that which is inclosed in it at the time it becomes visible. Whether this wall has arisen by a gradual change in the density of the superficial particles, or by original deposition in its present form, it is impossible to determine; but this much is demonstrated, that at least a small portion of the egg elements exists before its wall has become established, and that this wall, far from being the nidus in which its contents are developed, is more probably the offspring of what it incloses. It would be more proper, perhaps, and nearer the true nature of the operation, to say that the yolk membrane arises synchronically with the concretion of the original yolk particles, as a denser exterior stratum, which, subsequently becoming

1 Indeed, it is no exnggeration to say, that such is essentially a cellular membrane ; for as cells originally are what we have designated as granules, and cells unite to compose a membrane, why may not granules, cells, combine to make a wall around a certain substance? In some respects it is only a matter of size, after all; put on the higher powers of the microscope, and the granules may appear so large that they would be called cells by every observer; and what are minute cells under three hundred diameters, are, to the eye, mere granules with thirty or forty diameters.

${ }^{2}$ In order to preserve the natural relations which exist between the many isolated figures drawn to illustrate the structure of the eggs of different stages of development, it has been necessary to adopt a very peculiar mode of numbering and lettering the figures. Yet, as it is not possible to describe at once all the different features which these figures are intended to bring before the eye, it may facilitate the understanding of the following pages, if the reader will first make himself familiar with the arrangement of the Plates 8,9 , and $9 \mathrm{a}$, by studying the explanation which accompanies them. The student already familiar with Embryology may also read with advantage, Section 5 of this Chapter, before any other.

In the quotations, the reader ought to mark carefully the difference between the letters following the figures without comma, which indicate the whole figure, and those following a comma and are referred to in italics, which designate the individual illustrations belonging to the same objects. 
still more differentiated, stands out as a tenncious layer, capable of loolding in durance the internal, fluid, mobile portion of the conglomeration.

Anterior to this, in some cases, (Pl. 8, fig. 1, $c, c^{1}$ ) but not always, a nucleus, the germinal vesicle, makes its appearance. There is, however, no relation between the size of the egg and the period of the first appearance of the germinal vesicle; at one time we find it nearly filling a small egg (fig. 1, $c, c^{1}$ ); at another, it is not at all present in a comparatively large one (Pl. 8, fig. $1, f, i, k)$. Beyond a certain size, (Pl. 8, fig. 1, l, however, about $\frac{1}{350} \overline{0}$ of an inch in diameter, it is never absent; so that there is a limit, on one side, to the irregularity of its development. It is hardly necessary, after what has been said, to remark, that the nucleus has no part whatever in the formation of the egg cell, but is entirely a subsequent feature of the contents among which it is introduced. True enough, there is a solid substance around which its cell wall arranges itself, just as most observers have of late advocated, but here the parallel ceases; for the basis of this operation is not the nucleus, the germinal vesicle, as they would have it, but the yolk, to all intents and purposes. ${ }^{3}$ The nucleus, in this instance at least, is often a feature of very tardy appearance, and always arises like a swelling, having the concave contour of the egrg-cell wall for a basis. It is always very transparent, but most especially so in the younger stages of the growth of the egg, (PI. 8, fig. $1, m, n, o, p$, fig. 3 and $3 \mathrm{a}$,) when it is often difficult to determine its outline definitely, its transparency arising from the mode of its origin, of which we will speak presently.

The germinal vesicle is always visible to the naked eye, in eggs of from one sixteenth of an inch in diameter to full-grown ones; its presence is indicated by a clear, dark, round spot at the surface, where it originates, as will be shown below (Pl. 9, fig. 9 and 10; and Pl. 9a, fig. $32\left({ }^{2}\right)$ and 32a). It appears very often on the distal side of the egrg, and at other times next to the attachment of the ovum, ${ }^{3}$

1 Barry, (Phil. Trans., London, 1838, p. 308-310,

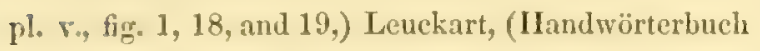
der Physiologie, etc., von Dr. Rudolph Wagner, article Zeugung, p. 815,) and 'Thompson, (Cyclopedia of Anatomy, London, 1854, article Ovum, p. 76 and 77, fig. 53 ,) all hold to the origin of the yolk substance around the previously existing germinal vesicle; but if we mistake not, in many instances the germinal vesicles of these authors were the true ergs, and in others the ritelline sac was conecaled by its close contact with the wall of the Graflian follicle.

2 'The small germinal vesicle of this magnified egro will be perceived on the left side of the figure, about one third from the centre.
${ }^{3}$ Various authors, who hare made more or less special investigations upon this subject, assert that the germinal resicle, throughout the animal kingdom, has a central position in the younger stages of the egg, but that later it approaches, and finally plants itself at the surface. Now, since we have pointed out its superficial position from the very beginning, in Testudinata, and have observed the same feature in the eggs of other animals, as future volumes will show, we have renson to believe that the assertion of these authors, respecting the situation of this vesicle, cannot be sustained by more rigid researches. Such a situation may be only apparent, owing to the position of the egr under the microscope. 
so as to be completely hidden by the peduncle of the calyx. Originally this vesicle is a collection, in a globular form, - against the wall of the eggr cell, (Pl. 8, fig. 1, $j, l$ ) where it always remains, - of a less refractive, lighter, and more albuminous substance than the surrounding medium; yet, until the former has assumed a certain density, dissimilar from the latter, the refraction of the two is so nearly alike that we cannot perceive the difference, but soon there ensues a period when they are faintly distinguishable from each other, and at last every thing.becomes clear and unmistakable. It is not, however, till a much later period that a well defined wall becomes apparent, even after the germinal dots, or, viewing the egg as a cell, the nucleoli of the egg cell, have developed themselves to a certain degree (Pl. 8, fig. 8a); yet we have strong presumptive evidence that a layer of more coherent substance is present at the surface, just as in the case of the yolk parent cells, and also in the case of the dots of the germinal vesicle belonging to a much larger egg, which will be described when speaking of the growth of this vesicle in detail. Again, when water is brought in contact with the vesicle, it swells slightly, and then bursts, just as if a membrane had suddenly given way; whereas, were the mass homogeneous throughout, it would fall to pieces gradually. If it is homogeneous from centre to superficies, why does it not spread and mix with the yolk, as happens after the sudden bursting consequent upon pressure? We can hardly want further evidence, except an actual view of the membrane, to feel satisfied that it is present, although in a less palpable form than it is usual to acknowledge as such.

So far we have followed the growth of the egg, as a whole, up to that point where it has gained all its characteristics, and thus disclosed the mode of its origin, and proved that, what was once a mere granule-like cell, is developed into that which is called an egg, and yet still remains a cell. ${ }^{1}$ 'The further progress of the egg contents, namely, the yolk, the germinal vesicle, and its dots, is so complicated, that each part must be treated separately, in order to avoid confusion, and also to lay particular stress on every one, since the several components have a feature peculiar to each, and entirely different from any other.

1 It is contended, by some investigators, that the egr cannot be looked upon in the light of a cell, because of its subsequent complication. 'True, it is not necessary to insist that it is identical, as a body, with the cells of animal tissues; it is nevertheless a cell, but a cell of peculiar derivation and destination, the simplicity of which, as well as its similarity to those among which it originates, is very early lost in the highly organized nature of its succeeding developments. Again, these authors, Thompson (loc. cito, p. 135) at least, advocate that the germinal vesicle being, as they erroneously hold, the primitive basis of the egg, is more probably the true egg cell, and the whole orum a complex cell. 


\section{SEC'TION II.}

DEVELOHMLNT OF THE YOIR.

In order that the history of the yolk, which follows, may be complete in itself, it is advisable to revert to the first appearance of what is afterwards called yolk, as the original contents of those particular granule-like cells which eventually declare themselves as eggrs.

We have already said, that at first the yolk is a perfectly homogeneous, highly refracting, brilliant, yellowish fluid, which gradually loses its density, and becomes more transparent and colorless up to a certain age of the egg, when the whole begins to appear heterogeneous in its aspect (Pl. 8, fig. 1, $p$ ). At this period, when the exg is about $\frac{1}{1 \frac{1}{6} 0}$ of an inch in dianeter, there ensues a great and very remarkable change; the contents of the egg divide into two very diflerent looking portions, (Pl. 8, fig. 1, p, ) one of which retains the character of the stage just passed, (upper part of fig. 1, $p$ ) whilst the other, which is the larger, assumes a clear, hyaline, and hardly refractive condition, indicative of a greater amount of albumen than in the darker part.

'The germinal vesicle is usually found in the more transparent portion of the eggr, but now and then it lies in the darker region; when in the former it is at times difficult to recognize, because its density and that of the enveloping medium are so nearly alike is to give a very faint difference in refraction.

Soon after this, when the egg has reached the size of $\frac{1}{10} \overline{0}$ of an inch in diameter, the homogeneous fluid of the darker side becomes spotted here and there with very minute granular vesicles, with dark outlines (Pl. 8, fig. 2, 3, 3a). These vesicles are mostly situated near the periphery of that side of the egg; but gradually they appear nearer and nearer to the centre, increasing in size at the same time, till they occupy the whole field adjoining the hyaline region, (PI. 8, fig. 4, 5, when the whole mass presents an opaque, dense, fuscous colored and coarsely granulated appearmce. There is no constant relation, at any given time, between the size of the egrs and the amount of light and dark parts, in definite proportions to each other. One egg may have its denser region but slightly granular, while that of another of the same size will be filled with granules. The same indefinite relation occurs throughout the diflerent parts of the egg, even to quite an advanced period.

But, to retum again to the younger stages, we would note the very remarkable and sharp, straight line of meeting of the two different portions of the egg, 
which, at a certain age, runs in a plane passing through one of its great circles (Pl. 8, fig. 3, and 3a). After carefully dissecting away the envelopes, the eggs can be rolled backward and forward, by tipping the watch-glass which holds them, or by blowing upon the serum in which they swim, so as to disturb its level; and as the several eggs pass by the eye, one is reminded of glass globes whirling along, freighted on one side with golden pebbles. The splendor of such an apparently trifling object needs to be seen to be appreciated. Now follows the encroachment of the granulated portion of the egg upon the clear space, at the time the egg has reached the size of about $\frac{1}{5} \frac{1}{0}$ of an inch in diameter. This proceeds after various modes: sometimes the clear space fills up in a gradual way, as if a deposit was forming in it, (PI. 8, fig. 6, 6a,) till the whole spherical cavity is occupied by a dense, equally distributed, coarsely granular mass; at other times a projection starts out from the darker part into the clear fluid, ( $\mathrm{Pl}$. 8, fig. 10, and divides it into halves, each of which gradually darkens with deposits; again, the granules appear, as it were suddenly, in heaps, (Pl. 8, fig. 9, 9a, 13a, 15,) throughout the homogeneous medium, and, gradually extending their arms to each other, anastomoze, and inclose clear hyaline spaces, (Pl. 8, fig. 15, ) the socalled oil drops ${ }^{1}$ (PI. 8, fig. 7, 16a, 16b); finally, a ring of coarser materials appears near the centre, giving the egg a zonated appearance, (Pl. 8, fig. 18a, 19, ) with the germinal vesicle at times between the dark bands. This last phase is found in eggs of about one twentieth of an inch in diameter, which are easily seen with the naked eye; and we believe it to be peculiar to this age. In fact, the different features mentioned above correspond more or less to a certain stage of the development of the yolk cells. Beyond the last stage, just mentioned, we cannot trace this progressive growth step by step, on account of the opacity and size of the eggs; but thus far it is perfectly reliable that these diverse appearances are normal, since they were recognized, not in one only, but in as many eggs as were examined. By this time the egg has assumed a uniform bright yellow color on that side where the germinal vesicle shines through as a clear (Pl. 8, fig. 17, 17a) but dark spot, immediately surrounded by a very light yellow ring, which shades off into the deeper color beyond. As the egg progresses toward its full development, the yellow color of the yolk grows deeper, (Pl. 9, fig. 4, 5, 6, 7, 8,

I These clear spaces must not be confounded with those which are observed in the spheres of segmentation, though they originate probably in the same manner. That there are egrs containing oil drops, cannot be doubted; they are frequent in the egrs of Fishes, but they differ greatly from the albuminous clear spaces of the Turtle's egrs just described. Much more extensive investigations upon the structure of the egrs of animals of different classes, in their successire stages of development, are still required, before satisfactory comparisons can be instituted between them and the features peculiar to different types pointed out. Comparative Orology is a branch of Embryology yet to be founded. 
9) the light ring around the germinal vesicle becomes still lighter, and the dark spot more sharply defined, until, when full-grown, (Pl. 9, fig. 10, and Pl. 9a, fig. $32,32 \mathrm{a}$, ) the yolk is orange yellow, the ring around the germinal vesicle dead white, and the spot above it a neatly bounded circular area, (Pl. 9a, fig. 32a,) resembling a pinhole over a dark background.

It is important to notice, in this connection, that there is a marked diflerence in the gradation and relative size of the smaller eggs when compared to the larger ones. The innumerable minute eggs which are buried in the folds of the ovary exhibit, up to a certain size, every possible degree of development, from the smallest granule-like egg cells to characteristic eggs visible to the naked eye. There are immense numbers of these small eggs of every size, apparently in the same state of progress; and they seem all to form but one series, in which every successive stage is represented by an indefinite number of eggs. Not so with the larger eggs, from the time they exceed the size of a large pin's head up to their full maturity. These larger eggs appear always in regular sets of a definite number, and, what is particularly important, this number coincides with the number of eggs the different species of Turtles lay at one time. In Nanemys guttata, which lays two or three eggs, each set contains only two or three eggs; in Chrysemys picta, which lays from five to seven eggrs, each set contains from five to seven egrs; and so with every species, even with those which, like Chelydra serpentina, lay more than thirty eggs. Four such sets can readily be distinguished in every ovary, one of which contains mature eggs (Pl. 9, fig. 10); another set contains eggs about half that size (Pl. 9, iig. 8); a third set contains still smaller eggs, (Pl. 9, fig. 5, 6, ) the size of which stands in the same relation to the second set, as those of the second to the first; the fourth is smaller still, in the same ratio (P1. 9, fig. 1, 2, 3). Below these it is difficult to distinguish the different sizes, and impossible to determine which are the eggs likely to start in advance of the others, after the largest set has been laid. But the uniformity of the egrgs of ench set, the conformity of their number with that of the egrgs laid by different 'Turtles, and the absence of eggs of intermediate sizes between those of different sets, can leave no doubt, that, after a certain time, the eggrs of each successive brood are determined in the ovary, and undergo a long development, equal in duration to four times the interval which intervenes between the successive periods of laying. As I have satisfactory evidence that our 'Turtles lay only once a year, it follows, therefore, that an egg requires four years, from the time there exists a marked difference among the eggrs of different sizes, to acquire its full maturity; not to speak of the length of time required for its formation and earlier development. We shall have occasion hereafter to consider the importance of these facts, in connection with the act of fecundation of the egrgs. 
Having thus sketched beforehand, as it were, and described, the grosser changes in the yolk mass up to its maturity, we will now return to the starting point of this digression, and indicate the intimate structural changes which the yolk cells undergo successively, as these changes correspond to each successive feature of the growing egrg.

At the time the granules begin to invade the clear space, (Pl. 8, fig. 6, 6a, ) they are rather coarse and irregular in outline; but the next step beyond this (PI. 8, fig. 8a) in the growth of the egr reveals a diminution in their size, as if they were, as is probable, redissolved by their mixture with the more albuminous fluid which has received them. Soon afterward, in an egg not much larger than the last, or even of the same size, they again appear very coarse, yet dark and irregular, and withal lighted up by seven or eight quite large, clear, albuminous globules, seattered irregularly in different parts of the mass (Pl. 8, fig. 7). These globules, as we have seen above, are the remains of the hyaline region of the younger egg. That they are not oil drops, such as have been described by various authors as occurring in certain stages of the growth of the egg, is easily demonstrated, first, by their very faint refraction, (Pl. 8, fig. 7, and 16a, 16b,) and most conclusively by their mode of origin, as already described. The slightest pressure diffuses them through the yolk mass, whilst oil globules are more tenacious, and if they break up, each fraction at once assumes a globular form.

Another slight advance, in eggs of about $\frac{1}{2} \frac{1}{8} 0$ of an inch in diameter, again brings before us a finely granulated yolk, pretty evenly distributed throughout the egr. A still finer granulation, almost imperceptible, occurs throughout another egg which is hardly larger (Pl. 8, fig. 11a). The application of the extreme high powers of the microscope, however, shows that these granules are spheres of dark, oily globules (fig. 11a, a) closely packed together, which would be perfectly invisible under an amplification of four hundred diameters, and leave one to suppose that nothing but a homogreneous fluid occupied the field. Other eggs, (Pl. 8, fig. 9, 9a,) of the same size as the last, are far from resembling it: hardly one half of the yolk is dense and dark, and amid the finer materials, coarse angular grains arranged in heaps are scattered pretty freely, but as yet few grains appear in each heap; within the lighter space these grains are much less numerous, being only grouped in twos or threes, and even that not frequently. In this portion of the yolk are also very numerous minute but distinct particles, like dust floating in the air across a sunbeam. The clear globular spaces previously mentioned are defined by the anastomozing of these heaps, which form irregulur, sponge-like meshes. A further approach of these heaps to each other is observed in more advanced stages of growth of the egg; but, before considering these changes, we must not pass over an intermediate condition of peculiar features, which has seldom been seen during our investigations. 
In an egg of about $\frac{1}{300}$ of an inch in diameter, the whole central mass ( $\mathrm{Pl}$. 8 , fig. $12, f$ ) is coarsely granulated, whilst a layer of about one eighth the diameter of the egg, resting upon the yolk sac, consists of excessively minute molecular forms, densely packed together, $(e$,$) resembling the entire contents of another egg of$ a somewhat smaller size, described above (Pl. 8, fig. 8a). The only explanation we can give of this appearance is, that it is one of the several modes by which the coarse granular yolk fills up the entire egg, as it resembles, in a certain respect, those phases where the concentric rings occur (Pl. 8, fig. 19).

Returning now to the consideration of the more closely related heaps of coarse, more or less angular granules, in an egg which may easily be recognized by the maided eye, (Pl. S, fig. 13a, we find that, closely set among them, are multitudinous speck-like particles, which moreover extend their sway throughout the clear space. The darker portion of the yolk occupies here about two thirds of the whole egg cavity, and has scattered a few of its granules through the remaining third. Finally, the whole egg is filled by such coarse matter, but not uniformly; it still appears in distinct aggregations, (PI. 8, fig. 15, which, when first seen, dimly resemble so many granulated cell contents, the clear spaces between them representing, as it were, the cell walls. The granules are, again, finer than in the last egg, but more numerous in each heap.

The interspaces of these granular clusters constitute one of the several forms of albuminous concretions which remain to be noticed. In the present case they come nearest to the drop-like form; in fact, a slight approximation of the groups would complete their tendency to a globular arrangement, and end in perfect identity. However, the prevalence of granular cumuli throughout the egg is not always concomitant with the obliteration of the clear space, for at times the latter is still present over at least one fifth of the whole egg, (Pl. 8, fig. 17a,) whilst the components of the former have become dispersed more evenly through the previously clear interstices; and, moreover, they are considerably augmented and intermixed with clearer, less refractive, and less angular cell-like forms (PI. 8, fig. 17b). Even till quite a late period an egg of $\frac{1}{32}$ of an inch in diameter may be found, now and then, spotted with spherical, clear, and very hyaline globules of albuminous matter, (PI. 8, fig. 16a, 16b,) so closely resembling the germinal vesicle, that nothing but their number, their much smaller size, and their easy diffusion by the slightest pressure, marks them as belonging to an entirely different category.

Here, again, it is not irrelevant to insist upon the presence of a wall around the germinal vesicle, as additional evidence for its existence may be derived from the conduct of the clear spaces just mentioned, whose origin and mode of formation we know so conclusively that we can readily foretell how easily pressure would cause them gradually to fade away by diffusion among the neighboring gran- 
ules; whilst the germinal vesicle exhibits considerable elasticity when pressure is removed, and will not burst till the last moment, if we may so express it, and then very suddenly, as if it had sustained great tension in some kind or other of restraining envelope.

There remains but one question to answer respecting the granular period in the growth of the yolk, before we arrive at the turning point, which reveals to us an entirely new and important feature in the life of the egg, namely, the formation of genuine yolk cells. How constant are the denser rings (Pl. 8, fig. 18a) of granular matter, already mentioned above, which may be seen in eggs of about $\frac{1}{20}$ of an inch in diameter? It is not yet possible to answer definitely this question; but this much is certain, that such phases are so frequently met with as to warrant the conclusion that they are to be considered as the prevailing state of the egg at this age. The granules of the rings are rather coarse, but not darkly outlined (Pl. 8, fig. 18b) nor irregularly shaped as heretofore, and the lighter circles exhibit only the faintest traces of minute, dot-like particles. In egrgs considerably larger than this, (Pl. 8, fig. 19b, we may meet with two rings of similar structure, (fig. 19,) separated by corresponding clear spaces.

\section{SECTION III.}

\section{DEVELOPMENT OF THE YOLK CELLS.}

Formation of the Ectoblast. Thus far we have considered the yolk as a whole. We now proceed to describe its cellular development. ${ }^{1}$ The first change noticeable

1 Thus far we have employed, in our descriptions of the egor and its contents, the nomenclature generally in use to designate its different parts, and those of the cell. But this nomenclature, framed to express particular views respecting the mode of formation and the functions, of these parts, is completely theoretical in its meaning. It appears desirable, therefore, now that we are about to consider more fully the origin and successive growth of the yolk cells, to discard every technical expression which may imply a theory, and to adopt such only as designate the natural relations of the objects under consideration, especially since the views to which we hare arrived cannot be reconciled with the theories which the current nomenclature is intended to express. For instance, in the case of a nucleolated cell, the outer envelope is described as formed around a mucleus, in which latter the nucleolus is dereloped. The outer cell membrane would thus inclose, at a later time, a mass accumulated around a nucleus already formed, as its name implies, and the nucleolus would be developed within the nucleus. For similar reasons we shall, hereafter, also aroid the expressions "parent and daughter cells." But, whatever be the mode of origin of cells and of their parts, there is, in a perfect cell, an outer envelope, containing another resicle, in which is seen another smaller borly These parts are therefore designated in the sequel 
in the aspect of the yolk, at the period of initiative cell genesis, is the hyalescence of the coarser granules, ${ }^{1}$ and a rounding of their contours (Pl. 8, fig. 20a). At this time the egg is about one sixteenth of an inch in its mean diameter. (Pl. 8, fig. 20.) The recurrence of a superabundance of albumen is here presented, although in a manner already familiar, namely, in the drop-like form, yet with an essentially different anticipation. The function initiated at this period would lead us to suspect, nay, almost to demand, that something more than an adventitious globular concentration of amorphous substance must be silently working before us. And so easily is this suspicion put at rest, in a positive manner, that we very soon forget that there was once a moment of hesitation respecting the nature of this development. It has already been stated, that there is a difference in the progressive development of the smaller ovarian eggs and those which afterwards appear in separate sets, corresponding to the number of eggs which different species of Turtles annually lay. The eggs which we are now considering belong to the earliest set of somewhat larger eggs, which appear in definite numbers, and may be distinguished from the innumerable mass of smaller eggs scattered through the whole ovary.2 I have further observed, that the youngest Chrysemys picta found in copulation had no larger eggs than these. It is, therefore, plausible to suppose that the changes which now follow, in the development of the yolk, are the natural consequence of a first connection of the sexes, which is repeated twice amnually, for four successive years, before the eggrs are laid; as will be shown more fully in another section.

But, let us return to the eggs in which the formation of the yolk cells is just beginning. The instant that water is allowed to act upon a portion of the yolk,

by the following names: ectoblast is applied to the outer envelope; mesoblast to the so-called nucleus; entoblast to the so-called nucleolus; and, when this contains a still smaller body, this is called entosthoUlast. In the nomenclature of the egg, similar objections may be raised against the use of germinal or germinative resicle and dot, as neither of these parts has the slightest reference to the formation of the germ. We shall therefore designate them, henceforth, as some embryologists do, by the names of the Purkinjean and Wagnerian vesicles. $\Lambda$ pplying our nomenclature to a comparison of the egg with the cell, the yolk membrane is to be considered as an ectoblast, the Purkinjean vesicle as a mesoblast, the Wagnerian resicle as an entoblast, and the Valentimian vesicle as an entosthoblast.
1 By the "hyalescence of the coarser granules," it is not meant that already existing angular, coarse, dark granules become hyaline, but that they disappear now, as they have again and again been changed before, and clearer and round bodies take their place; the action of some novel influence, probably the fecundation, inducing the genesis of new forms.

2 Comp. p. 460. The eggs of intermediate sizes represented on Pl. 9 were observed out of the breeding season. After eggs like that of fig. 10 have been laid, those of the second set (fig. 8) soon grow to the size of fig. 9 ; those of fig. 5 and 6 to that of fig. 7 ; those of fig. 1, 2, 3 to that of fig. 4 ; and a new set, like the egrgs of 11.8 , fig. 20 and 21 , start in advance of the smallest ovarian egges, which cannot yet be distinguished in sets. 
the hyaline masses swell slightly, and the internal portions lose their homogeneity: multitudes of faint granular particles appear suddenly; they dance about their confined sphere in a zigzag quiver, and finally their delicate boundary wall, which by this time has become unequivocally demonstrated, bursts suddenly on one side, and extrudes at a single contractive effort nearly the whole horde of its vivacious motes, assuming itself by this loss a wrinkled, unsymmetrical, much diminished shape, but still holding a. few oscillating corpuscles. It may yet, perhaps, be doubted that there is a cell wall, according to the usual acceptation, embracing these lomogeneous globules of albumen; for the envelope just displayed soon falls and crumbles to atoms, identical apparently with those which not long before rushed from its embrace, whilst a genuine cell wall, so called, disintegrates only under the process of decny. This, however, is only a matter of degree after all: both fall to atoms; the former soon, by reason of its undeveloped nature; the latter holds out longer, because of the greater adherence of its component particles. Moreover, on account of its very slightly changed density and refraction, the former is not recognizable as a separate layer from the mass within; whilst the latter is differentiated by the great predominance of these two features, which are lacking in the young cell.

Here, then, we have essentially, nay, in every sense, a cell, a hollow layer of spherical surface, derived from the lateral adherence of the superficial particles of a homogeneous globule. It is not a cell formation by the hollowing out of a solid substance, forming at first a very thick wall, which would stretch by the increase of the contents, as it gradually surrounds a larger space, till it thins out to the ordinary crassitude of such envelopes. Never, throughout the whole range of cell development in the egg, is there the merest hint at this mode of genesis. From the beginning to the end of the growth of the ectoblast it ever preserves the same thin stratum, apparently of a single layer of corpuscles, and moreover the same tendemess and the same refracting power. Nor can we compare this process to the received mode of cell origin, according to which a wall is condensed around and upon a "nucleus," ${ }^{2}$ for the mesoblast is often absent

I See p. 454 , on the primary cell wall of the yolk.

2 Since the word nucleus implies a body around which something condenses, and nothing of the kind takes place here, the name mesollast is certainly a much preferable designation for that part of the cell which is commonly called nucleus. 'The new names proposed here for the parts of a cell have the further advantage, that they may be applied for the whole body which they are intended to designate, as well as for its envelope. An incipient ectoblast is a homogeneous mass, which afterwards has an envelope distinct from its contents, and so is the mesoblast; even the entoblasts may become resicular and contain one or more entosthoblasts. It is therefore desirable that the nomenclature of the cell should be applicable to these different stages of its development, which the names of cell, cell wall or cell contents, nuclers and nucleolus, are not. 
in quite large cells; in fact, an egg little more than one sixteenth of an inch in mean diameter (Pl. 8, fig. 21) contains numerous cells of considerable size, (Pl. 8, fig. 21a, no one of which contains a mesoblast. Nor can it by any possibility be advocated, that these cells are the contents of other cells, for no others exist; even in a much larger egg, up to full-grown ones, this holds good just as undoubtedly, for in such a mass of yolk as larger eggrs contain, the mesoblasts and ectoblasts have respectively very peculiar and unmistakable properties, not to be confounded with any other cell contents. The resemblance which this mode of cell formation bears to that commonly received is far more apparent than real; yet, paradoxical as it may seem, we must confess that it is very difficult to express the essential character of the difference which separates these two different modes of viewing the subject. ${ }^{1}$

An ectoblast, which, under a power of five hundred diameters, appears about one-eighth of an inch through, in its greatest diameter, (Pl. 8, fig. 21a, has attained its greatest transparency. The ectoblasts preserve this remarkable transparency up to the full accomplishment of their growth, which is not reached, however, till the egrg is fully ripened.

The ectoblast has a remarkable plasticity and resilience, which the mesoblast also shares, existing from the youngest (Pl. 9, fig. Sa, K) to the oldest stages, (Pl. 9, fig. 11h,) in consequence of which the cells may squeeze and worm their way among each other, and yet, when free, return to their original rotundity. Nor is this all; for, besides their impressibility, they have an equally great extensibility, (Pl. 9, fig. 8a, A, M, N, which may best be seen after they have been left in contact for a while and then forced apart, by setting the ambient fluid in motion, when their adherent portions stretch out with long arms. However, beyond a certain extension of these projections the agglutination ceases, and each cell returns to its proper sphericity.

Beyond the fact that the slightly irregular rough surface of the smaller cells becomes, in the larger cells, a remarkably smooth, polished, yet not glittering superficies, presenting on the whole the appearance of a beautiful sphere of glass, we have nothing further to add as regards this special part of their organization, except to mention the action of heat, which collapses the cell wall upon its mesoblast, the latter remaining undisturbed, whilst the entoblasts are fused into a

\footnotetext{
1 Properly to consider this subject, it should be introduced when investigating the mode of origin of the mesolulast, as we view this process. Since the growing ectoblast, apart from its mesoblast and entoblast, varies but little, excepting in size, from the
}

time of its birth, we may now complete the description of its phases in a few words, and then proceed to describe the development of the primary alteration of its homogeneity, that is, the initiative step in the formation of the mesoblast. 
single mass, which but faintly shadows forth the parietes of its constituents (Pl. 9, fig. 11f, a, b, 11g).

Formation of the Mesoblast. We have already mentioned, that there is no constant size at which the ectoblast develops its mesoblast. A minute ectoblast may be seen with a well defined mesoblast, (Pl. 8, fig. 22, c, d, and Pl. 9, fig. 8a, $\mathrm{F}$, b) and another four times its diameter (Pl. 8, fig. 21a) without any, and so on, at various intermediate magnitudes. Some cells have even their entoblasts (Pl. 8, fig. 23b, $a, b, 23 \mathrm{~d}, d, e$; Pl. 9, fig. 8a, D, E, F) at a diameter, which, in others, presents only a homogeneous content. However, to give, with some sort of precision, an idea of the limit of the development of the mesoblast, we would state, that, under a magnifying power of five hundred diameters, there cannot be found a single cell, except perhaps with rare exceptions, which presents to the eye a diameter beyond one eighth of an inch, that is, $\frac{1}{4000}$ of an inch in actual size, without a mesoblast.

As a natural consequence of this diversity of size in relation to the appearance of the mesoblast, this body may be much larger in one cell, than in another of the same diameter; for as soon as it is defined it begins to grow, and continues to increase in size, along with the ectoblast, till the egg drops from the ovary to enter upon a new phase of life. Unlike other mesoblasts, the mesoblast of the yolk cell is not arrested in its development when the ectoblast has reached a certain size, and does not remain as a mere indication of past activity, but ever persists in manifesting very active internal changes within its constantly increasing bulk. With the exception of the germinal vesicle, the mesoblast of the yolk cell, when at its full development, is the largest known, at times measuring about $\frac{1}{6} \overline{0}$ of an inch in diameter. With these preliminary remarks, one may be forewarned to expect here a mode of development of mesoblasts hitherto unnoticed or disregarded in other centres of cell evolution.

The earliest indication of a mesoblast is manifested by a slight haziness at one single point within the ectoblast, close against its wall (PI. 9, fig. 8a, J, $\mathrm{L}^{1}, b$ ). At first undefined and vanishing at its border, it gradually assumes a sharp, spherical outline and a pearly opacity reminding one of the primary physiognomy of the ectoblast; but yet it is of a denser nature than the latter. The size at which it gains its definiteness of contour varies in different cases, the hazy state of one often exceeding the clearly limited mass of another by several diameters. The attachment to the wall of the ectoblast is at times loosened almost as soon as the outline is perfected (fig. 8a, J); however, not long afterwards, every mesoblast becomes free, and may be found, for the rest of the interovarian life of the egg, at the centre of the sphere, whence it is derived.

In the case of the formation of a mesoblast in a most minute ectoblast, the 
appearance produced is as if the latter originated round the former, instead of the reverse, which is the natural process, as we lave lately demonstrated; and this, no doubt, has given rise to the prevailing view of their genetic relation. This appearance may, however, very readily be accounted for, with the object in sight; but to put the pieture before another's eyes in the mien of words, introduces an element in the demonstration always difficult to overcome, and most tryingly umprecedented in the present instance, not only from the intrinsic novelty of the subject, but also because a totally different interpretation of the cell genesis, in other bodies, has swayed the minds of nearly all previous investigators. Hence we must beg an unwonted indulgence wherever, in our descriptions, there appear an unusual redundancy of words, and repetitions of the same idea under different guises.

If there had ever been found a free cell which in the least resembled the mesoblasts already developed in other cells, then the office of originating around itself a certain more transparent spherical substance, such as we call ectoblast, might possibly have been attributed to it. But in no instance has such a cell been discovered, nor any one at all approximating its feature; on the contrary, as we have already shown, all homogeneous cells which appear after the irregular gramular state of the yolk are endowed with the physiognomy of ectoblasts. The nearest approximation to such a mode of cell formation is exhibited in those instances where the mesoblast nearly fills the ectoblast; but this occurs not in the minutest cells only, (PI. 9, fig. Sa, K, F,) it is equally seen at all stages of yolk cell growth, (Pl. 9, fig. 8a, A, B, C, D, fig. 6b, fig. 11d, a, and fig. 11e, even in the largest eggrs. Always, wherever a so-called nucleus is found, there is present a clear enveloping substance of lesser or greater thickness. It would, therefore, be just as reasonable to argue that the largest cells originated full-grown around this nucleus, which nearly fills them, as it would be to assert that this obtains in the minutest cells which present such features, excepting perhaps for the fact that these last are nearer related to the dimensions at which the like are generated; for, in truth, as far as argument from appearances is concerned, there is no difference, except in size; and it requires but a moment to magnify the smaller to such an amount that they will appear identical in every respect with those actually far exceeding them in bulk (Pl. 9, fig. Sa, K and C, or fig. 7d). How easily may we, on the contrary, trace the converse mode of grenesis! How naturally can one follow the steps of the various stages, from a simple, clear cell, at first condensing a portion of its contents into a cloudy mass, till the cloud grows more and more defined in outline and globular in shape, and at last displays itself as a perfect sphere, which finally proceeds to grow, till, by the time the egg has a shell, it absolutely fills the ectoblast (II. 9a, fig. 33b, 
$39 a-39 d)$ ! Now it is in these latter stages that the development of the mesoblast may most readily be mistaken for the primary cell genesis; - a well matured cell for one just forming! Such an error however is excusable only in one who has taken but a glance at the yolk in certain stages of its development, nay, hardly even then. But when the whole series of phases is followed with patient eye and thought, it is impossible to fail in recognizing the true and only prospective system of cell growth, the plan according to which each and every yolk cell has originated, advanced, and finally received the last touch, to fulfil the end for which it was intended, from the beginning, by its projector.

It is only during the beginning of its life that the mesoblast preserves uniformly any thing like a spherical shape. As soon as it has defined its outline clearly, growth ensues, and a more or less irregular, and very often angular, contour bounds its contents, throughout the interovarian life. As regards the lastmentioned shape, were it not for the peculiar reaction which water produces in its contents, causing a condensation in a network form, with less or greater meshes upon its wall, (Pl. 9, fig. 2a, $a, b, d$ ) it might be mistaken for an entoblast; but the entoblast is not at all affected by such a reagent. Moreover, mesoblasts with crystalline configuration are often met with, which contain entoblasts bearing every characteristic of those observed in older phases of development (Pl. 8, fig. 23d, $c, k, l)$. However, it is only at about this age, when the egg measures from one tenth to one eighth of an inch in diameter, that such an unusual angularity of the entoblasts obtains; the subsequent stages, up to those of the full-grown ovum, are characterized by irregular oval or spheroid shapes, and, rarely, with here and there a perfect sphere (Pl. 9, fig. 6a, a, b, $c$, g, and fig. 11i). Contemporaneously with irregularity of form it assumes also a change in color, till very soon, at about the most angular phase, it has passed from a faint to a dark yellowish tint, which it ever after retains as a characteristic complection, distinguishing it from the brilliant, clear, golden yellow of the crystalloid entoblasts.

With reference to the reaction which water produces upon the contents of the mesoblast, we may add a few more remarks in detail, in order to bring the changes thus produced to bear upon the question of the existence, if not of a wall, at least of a denser exterior layer surrounding the entoblasts. Indeed, the presence of such a layer cannot be questioned; for, whilst it forms the basis upon which the contents collapse in wrinkles of coarser (Pl. 9, fig. 2a, d, 3a, c, d, $12, a, b, c)$ or finer folds, (PI. 9, fig. 2a, $a, b, 3 \mathrm{a}, a, b, g, 7 d, 7 \mathrm{e}, 7 f$, ) mastomozing with each other like the meshes of a network, it yet preserves exteriorly its form intact, except in some cases, where the cause of the shrinking within has distorted (Pl. 9, fig. 12, a, b, c) the foundation upon which it has impelled 
the more central material. In this state, very little pressure is required to crush into angular fragments the now brittle shell of the mesoblast, and, by a trifling disturbance of the yolk fluid, the broken parts may be made to roll over till they display their imner surfaces covered with ridges, (Pl. 9, fig. 12, $\left.d, d^{1},\right)$ or present a profile of their thickness, showing in an indisputable manner that this thickness is uniform throughout the whole extent of the spheroid mass, to which it bears a very small proportionate diameter. Now, the very fact that the water passes through the exterior of the mesoblast, leaving it intact, and powerfully reacts upon that which it last comes in contact with, is of itself evidence enough to show that the acknowledgment of a cell wall here depends merely upon our interpretation; and whether a denser layer, inclosing a more fluid substance, can be called a wall, or is to be considered only as the extreme of a mass gradually increasing in density centrifugally, from centre to superficies. The latter view, fortunately, cannot be sustained without the help of questionable reasoning, when we refer to the manner in which the entoblasts, as they gorge the parental matrix, press outwards, in angular prominences, (Pl. 9, fig. 6a, $c, d, i, j$ ) the thin resistant layer which bounds their field of development, and persist in restraining them from projecting uncovered into the hyaline fluid of the primary cell. ${ }^{3}$

Again: the existence of entoblasts, without a cell wall to contain them, would be an unprecedented phenomenon; yet here such an envelope is denied, inasmuch as there does not appear any visible differentiated layer of protein compound corresponding to the usually received definition. But, as it has been shown regarding the wall of the primary cell, (which wall, as likewise here, is not visible at first on account of its lack of refractive powers, ) there is a thin stratum, sufficiently tenacious to restrain the more fluid contents, and this stratum sustains a very different reaction from the latter when immersed in water. To such an envelope, whether visible or not, most certainly the title of cell wall belongs; and under this mode of consideration we may extend the definition of a cell wall beyond the hitherto stereotyped bounds, and embrace a broader and more general view of its essential nature, characterizing it as a hollow, more or less spherical, layer, of indefinite density, tenacity, and refraction, which surrounds the field of some definite, though isolated and homogeneous, function.

When speaking of the plasticity and resilience of the ectoblast, we have already

1 As the entoblasts of the yolk cells have generally been described as crystalloid bodies, swimming either free in the yolk or surrounded by a transparent cell wall, (J. Mǘxer, Ueber den glatten Hai des Aristoteles, Ak. d. Wiss., Berlin, 1842, p. 37, and Rathke, Entwick. d. Schildkrüten, p. 5,) and as the mesoblast which incloses them las been overlooked by all previous observers, we have not been tired in accumulating proof upon proof, in order to slow that they are, in every instance, actually inclosed in a sac, and that this sac, and not the crystalloid body, is the mesoblast of the yolk cells. 
mentioned a similar peculiarity in the mesoblast; but it is proper to revert to the same subject in this place, especially as some more details are necessary in another point of view. It is to the homogeneous fluidity of the contents of the mesoblast that we would now call particular attention.

Let any one glance at a quantity of yolk cells squeezing their way among cach other, and observe the easy mobility of the entoblasts as they oscillate in the mass of now constantly changing, unstable shaped matrix, flying from side to side almost as if they were thumping about in an empty space, and then say, whether the mass within the mesoblast which surrounds the entoblast is a connatural fluid, equidense throughout, or, centrifugally denser, as the collapsing upon the cell wall by aqueous reaction might suggest. To the latter view we have no inclination whatever; but to the former we must give our unqualified assent. We have characterized so particularly the movements of the entoblasts under disturbing influences, in order to render more prominent the fact that these bodies return with unerring certainty to their proper position at the centre of their parental domain, as soon as they are relieved from the contact of neighboring cells similarly affected. Whether this phenomenon is to be ascribed to the same centripetal power that influences the origin of the entoblasts in a central rather than a lateral position, we can only conjecture; but it seems natural to suppose that there must be some unknown relation between the two, and that perhaps the one may be the complement of the other. One word more in reference to the conduct of the mesoblasts, after water has burst the parent cell. Under such circumstances the mesoblasts become easily agglutinated to each other by the slightest pressure, and their parietes are totally obscured, so that one might suppose the yolk cells had contained immense irregular mesoblasts (Pl. 9, fig. 12, e, f).

From the time of the origin of the mesoblast up to that age when the egg measures about one sixth of an inch in diameter, the mesoblast seldom exceeds the semidiameter of the ectoblast, (Pl. 8, fig. 23d; Pl. 9, fig. 6a, $c, d, e, f, g, h, i, j$ ) and often falls short of even that extent, especially just after that exceptional state, when the rather minute cells, ectoblasts, rapidly amplify their mesoblastic progeny (Pl. 8, fig. 23b and 23c) till they are nearly filled with them, and then just as quickly outstrip them in increment of bulk. At the latter end of this stage the ectoblast begins to fail in maintaining its greatly superior size, (PI. 9, fig. $6 a, a, b$, fig. $7 d, 7 e$ ) and the mesoblast from this time forward gradually encroaches upon the fostering matrix, till the latter, in a full-grown egg, is impersonated by a moderately thin layer, resembling, in its beautiful transparency, a halo about a cluster of golden brilliants. Thus terminates the career of the mesoblast in yolk cells, as far as its activity in the life of an interovarian egg is concerned; but another more remarkable phase is still to be gone through before 
it ceases to be independent. This feature of the life of the mesoblast, however, more properly belongs to another chapter, in which it will be shown, that the once free cell may finally be recognized as entering bodily, but not in its present entity, into the formation of the embryo.

We now proceed to consider the origin of the crystalloid entoblasts, of which we have already so often spoken in connection with the mesoblast.

Formation of the Entoblast. ${ }^{1}$ In the same egg in which a mesoblast first appears, the entoblasts also begin to develop, but singly at first (Pl. 8, fig. 23b, a, b, 25, d). Their number very rarely amounts to more than two or three in each mesoblast, (Pl. 8, fig. 23d, $e, j, l$, fig. 25, a, ) until the egg is from one eighth to one sixth of an inch in diameter. Casting the eye over the field of the microscope, there may be seen here and there a few of the minuter cells, containing mesoblasts, which are rendered more conspicuous by the presence of a dark dot in the centre of each (Pl. 8, fig. 23b, a, b, 23d, d, f, $y$; Pl. 9, fig. 3a, 6a, n, o, p): this dot is the nascent entoblast. Unlike the faint looming up of the mesoblast, the entoblast, minute as it may be in its incipient state, shows itself clearly and well defined, and usually with an irregular angular outline. The central orientation of this body, and its fac-simile repetition, in the same focus of centripetal influence, have been noticed before as a remarkable and unusual feature in concentric cell development; and now we would, in this its proper place, follow more in detail the elaboration of the design involved in its peculiar mode of growth.

Rarely is a single entoblast permitted to attain any considerable size alone; but, soon after the declaration of the first, two or three more appear in the field, (Pl. 8, fig. 23d, $e, j, k, l, 25, a$; PI. 9, fig. 3a, $e$, fig. 8a, D, fig. 6a, m, ) and thus, forming a cluster, proceed together in adding to their bulk. Soon, in a little older egg, more are added to the cluster, (Pl. 9, fig. 6a, $d, f, g, h, i, j$, ) and again still others, $(a, e$,$) until their number is beyond estimation, and the meso-$ blast is surcharged with them to its very wall $(b)$. By this time the mesoblast has usually exceeded in diameter the radius of the ectoblast $(a, b, e)$. In two mesoblasts of the same size, ( $a$ and $b$, also $c$ and $e$, or $j$ and $f$, ) the entoblasts differ both in number and size; those in one being oftentimes equal in length to the diameter of their parent, $(a, j$,$) whilst those in another are mere grains in$ comparison. The feature that particularly characterizes the entoblasts, and is prevalent from the beginning up to this period, is a sharp angularity, which at times gives a spiculate appearance to the clusters.

1 'The name entoblast may apply to that part of the cell which is commonly called nucleolus, whether it consists of a single dot, or is made up of a larger or smaller number of such bodies. However, while des- cribing the formation of the individual dots, we shall use it in the plural. We shall also have occasion to use the name of mesoblast in the plural, to designate the parts into which it divides. See Ch. 2, Sect. 4. 
After this comes a great change, not only in the yolk cells, but throughout the whole organism of the egg. The entoblasts begin to decrease in number, and lose their angularity (PI. 9, fig. 7c, 7e); the mesoblast, as we have before mentioned, encroaches upon the hyaline area of the ectoblast; and, to crown the whole, the Purkinjean vesicle changes its complicated cellular structure (Pl. 9, fig. $5 \mathrm{a}, 5 \mathrm{~b}, 5 \mathrm{c})$ into one which is almost perfectly homogeneous, (Pl. 9, fig. Ta, Tb, and this too without the least sign of any new or external influence, so far as we have been able to penetrate the process of this development. ${ }^{1}$

But, to return to the continuance of the entoblastic changes, let us first note the numerical decrease of the waxy crystalloid bodies as the primary indication of any signal divergence from the hitherto uniform line of conduct; and, secondly, the rounding off of their angles. It is a matter of some doubt as to whether the existence of a few entoblasts in each cell is owing to the actual decrease in the number of each cluster, or to the total dissolution of the ectoblast, mesoblast, and entoblasts, and the regeneration of new ones in their stead. Now if the latter supposition be true, it is hardly possible, that, during the evanescence of these bodies, some should not have been found in a transitory state, either a mesoblast without an ectoblast around it, or an ectoblast without mesoblast, or an entoblast totally exposed, or a mesoblast without an entoblast; and, since no such changes are noticed, we are forced to adopt the former conjecture, which has at least a certain amount of evidence in its favor. This we will attempt to support by referring to an egg (Pl. 9, fig. 7) a little older than the last, in which, amid cells as yet containing angulated entoblasts, ( $\mathrm{Pl} .9$, fig. $7 \mathrm{f}, 7 \mathrm{~g}$, ) may be seen, here and there among the largest, some cells in which the sharp edges of the entoblasts have begun to be rounded (fig. 7c, 7e) and the total number of entoblasts has considerably decreased, though they still hold their angular features; but soon these angles are lost and superseded by rounded contours embracing irregular but more equal sided masses, varying from pyramidal to cubical, (Pl. 9, fig. 8a, A, A, A,) or from oval to spherical forms (fig. 8a, B, C, C). In an egg three eighths of an inch in diameter, (Pl. 9, fig. 8, and in which the number of entoblasts may vary from five or six

${ }^{1}$ In view of such a parallelism of changes, we cannot but conceive that there must be some total action, to which each special influence, in the several organisms of the egg, is secondary. Howerer, it is not so much the presence of such a force, as its nature and origin, - whether it is inherently an idiosyncrasy of the region in which it operates, or whether it is generated by some periodic extemal ageney, as for instance the repeated acts of copulation, - that the mind would fain decide upon. Inasmuch as the egg, at this age, is fir from full-grown, but rests unspecialized among many of the same size, it cannot be advocated that it may be subject to any external influence, and that too whilst those a little smaller remain unaffected; and so we must fall back upon the former and more probable explanation, and, for want of additional facts, leave it, about as in the beginning, an unsatisfuctory matter of conjecture. 
down to a single one, these last phases become most frequent; nay, in fact, they prevail to the nearly total exclusion of the others. However, the entoblasts cannot all be traced back to a more angular state, since the minutest, the moderately small, the medium sized, and the largest, indeed, the whole range of cellular developments, display this new character; and among some of these there must certainly be a totally new genesis, or else whence come the supplies that keep up the proportionate number in relation to the increasing bulk of the egg?

This is answered by a survey of the field, where every minute cell will be found in the process of generating, not, as formerly, angular, (Pl. 9, fig. 6a, p, o, $n, l, m, h$, and $6 \mathrm{~b}$, ) but more or less rounded, irregular entoblasts, (Pl. 9, fig. 8a, $\mathrm{D}, \mathrm{D}, \mathrm{E}, \mathrm{F}$,) which in succeeding and older stages are repeated, first, by one, (Pl. 9, fig. 11d,) then by two or three, (Pl. 9, fig. 11e, and so on up to as many as six counterparts (Pl. 9, fig. 11f, 11g, 11h). Yet they do not always iterate themselves correspondingly with the amplification of the generating cell; but as an equivalent, the bulk of a single one or two is enlarged so much (Pl. 9, fig. 11 e, 11f, 11h, a, 11i, c) as frequently nearly to fill the parent. Here we have, then, two distinct modes of originating a new phase in entoblastic life: the one a process of remoulding and fusion, the other a totally new genesis.

In process of time, with the increasing size of the egg, up to the full ovarian growth, the entoblasts add more to their number, or enlarge each one its own proper boundaries, till in the former case a cluster sometimes contains a dozen waxy masses, (Pl. 9, fig. 11g,) and in the latter instance the mesoblast is nearly filled by one, two, or three of its progeny (Pl. 9, fig. 11f). From this time forward, whatever happens to these bodies, as regards multiplication or change of size, belongs exclusively to an extraovarian career.

The thick, dark, oily outline, which characterizes their contour from the beginning, is duplicated in those entoblasts (Pl. 9, fig. 11i,c) which belong to mature ovarian eggs; this may even be seen in younger stages, but not by any mens so distinctly. The distance between the outer and inner lines indicates a very thick wall, composed probably of a substance of a brittle nature, judging by the fissures resulting from pressure; and the dark, thick outlined, golden-yellow contents doubtless are fatty, and more or less fluid or viscid. The latter term appears to characterize more correctly their nature, when we consider, that, after the application of heat, although this causes the waxy masses to blend with each other, they still preserve enough of their solidity to prevent them from losing altogether their irregular outline, as would happen were they in a fluid state.

Let us now glance at whatever characteristics have not been as yet brought to notice. We have already pointed out the insensibility of the entoblasts to the action of water, when speaking of the reaction of the latter upon the mesoblast, 
and on this score need not make any further remarks; but we can very properly instance some particulars in regard to the effect of heat and acids. A full-grown ovarian egg, being thoroughly boiled to the centre by immersion in hot water for the space of three minutes, was opened, and portions of its contents from different depths put in the field of the microscope, when it instantly became evident, that, throughout the whole yolk, every cluster of crystalloid entoblasts had fused its individual components, each one to its neighbor, so that, in connection with the greater transparency that had followed this reaction, it was almost impossible to distinguish any thing but a faintly polygonal light yellow mass. Acetic acid at first swells the ectoblast till it bursts, then produces an effect similar to that of water upon the mesoblast, and finally destroys the same with the entoblasts, after having rendered the whole very transparent. Caustic potash swells the ectoblast enormously, and then dissolves its contents very rapidly. Pressure produces a curious appearance, which has been mistaken by some for a normal feature of the entoblasts, namely, parallel fissures intersected here and there by others obliquely transverse to them. ${ }^{1}$

\section{SECTION IV.}

THE PURKINJEAN VESICLE.

When treating of the egg as a whole, in its earlier stages, the primary phases of the Purkinjean vesicle ${ }^{2}$ were included, as necessary to the understanding of the character of the egg, when viewed in the light of a cell; and now that we wish to make a separate, special study of the Purkinjean vesicle, besides referring to former pages, ${ }^{3}$ a rapid recapitulation is by no means superfluous, in order that there may be continuity in the illustration of the subject. We have already/ spoken of the Purkinjean vesicle as being originally a minute concretion of solid matter against the wall of the primary egg cell, which has no definite size at the time; also of its having no part in originating the egg cell; of its great transparency; of the subsequent existence of a distinct wall around it, under a form sufficient to restrain its fluid contents from intermingling with the yolk; and

1 See-J. Müller, Ueber d. glatten IIai, q. a., p. 38, and Rathke Entw. d. Schildkröten, p. 5.

${ }^{2}$ It has already been stated above why we prefer to designate this part of the egg by the name of P'ur- kinjean vesicle, rather than apply to it the more usual name of germinal or germinative resicle. Sec Sect. 3, p. 463, note 1.

${ }^{8}$ Comp. Sect. 1, 456. 
finally, referred to the special description of its further development in a chapter set apart for the subject. We will now, in continuance of the subject, first consider the wall of the Purkinjean vesicle, which may be characterized as excessively tender, especially in the older eggs; and as regards its thickness, there is hardly any appreciable distance between its outer and inner surfaces till the last days of its interovarian life (PI. 9, fig. 11b).

No two eggs of equal size contain Purkinjean vesicles of the same diameter, and a larger egg may still have a vesicle not surpassing in size that of a smaller one. This disproportion remains constant throughout the ovarian life of the egg. After the Purkinjean vesicle has defined itself, it continues to increase in size for quite a length of time, before any thing appears to disturb the homogeneity of its contents; but at last, about the time when its diameter equals perhaps one fourth that of the egg, a faint spot or two obtrudes upon the clear field (Pl. 8, fig. Sa). Difficult to recognize at first, these spots soon make plain their position (fig. 11a and 12) on the wall, where they remain, as well as those succeeding them, till quite late in the life of the parent. When the Purkinjean vesicle has reached a size but a little larger than that of the last, these spots, the Wagnerian vesicles, ${ }^{1}$ almost entirely cover the wall of their parent, simulating, by their clearness and roundness of contour, drops of dew lining a glass globe (Pl. 8, fig. 14a). It is obviously best to deseribe here, at the starting point of these bodies, the mode of origin of the Wagnerian vesicles, the entoblasts of the egr cell and of the little dots, the Valentinian vesicles, the entosthoblasts of the egg cell, which arise in them. At the same time it will not be amiss to indicate the parallelism which may be traced between their growth and the mode of genesis of the yolk cells.

The clear, transparent nature of the younger states of the Wagnerian vesicles is gradually lost in a certain measure, and superseded by a pearly or milky complection, bounded by a rather dark, soft outline, (PI. 8, fig. 15a, a,) calling to mind the appearance of the denser species of Medusa, or the bluish transparency of boiled cartilage; at the same time there appears a very bright, irrefractive, eccentric spot, (fig. $15 \mathrm{a}, b$, ) the Valentinian vesicle. ${ }^{2}$ The latter increases in size (fig. $15 \mathrm{a}, b, c, d, e, f, f^{1}$ ) at a greater proportionate rate than its parent, the Wagnerian vesicle, till at its final stage it oftentimes occupies three fifths of the diameter of the grenerating medium (fig. 15a, $f$, and $f^{1}$, fig. 22, e, 24b; Pl. 9, fig. 4a); yet even then it refracts so slightly as to be hardly appreciable; but in a certain light, owing to its great transparency compared with the pearliness of the surrounding substance, it appears darker than the latter, and under 
all circumstances flat, as if disciform (PI. 8, fig. 15a, $f^{1}$ ). These latter features obtain at a time when the egg is about from one eighth to one sixth of an inch in diameter; but subsequently, at no very distant period, the Wagnerian vesicles and their contents disappear, and give place to a homogeneous fluidity, which generally pervades the Purkinjean vesicle, and lasts for the remainder of its existence. However, this rarely happens in much smaller eggs; yet an egg with a diameter of one tenth of an inch ( $\mathrm{Pl}$. 9, fig. 1) may have a Purkinjean vesicle, (fig. 1a, b, which, although perfectly free from Wagnerian vesicles, equals in size another Purkinjean vesicle containing numerous Wagnerian vesicles, (P1. 9, fig. 5a, 5b, 5c, ) and even belonging to a much larger egg (fig. 5). Respecting the presence of a wall inclosing the Wagnerian vesicle we have only to mention, that water breaks up its Valentinian vesicles into small, angular portions, which spread throughout its whole extent, though they stop within its outlines, (Pl. 8, fig. 24b, a, a ; Pl. 9, fig. 4b, ) evidently because of a resistant substance which does not yield to the reaction. This certainly is enough to substantiate the existence of a membrane, and moreover of one that has considerable stability, when we see that an hour's maceration, in one instance, did not destroy its entity (PI. 9, fig. 4b). While speaking of the reaction produced by water, we may as well mention also, that heat applied by boiling does not seem to effect an appreciable change in the intimate constituents of the Wagnerian vesicles, but evinces its disturbing power in another manner by loosening them from the wall of the Purkinjean vesicle, and forcing the whole to cluster around the centre of the latter (Pl. 9, fig. 5a, 5b, 5c) in the form of a nebula.

The Purkinjean vesicle during all this time has been rapidly increasing in size, and becoming more and more easily recognizable externally, till, at the lastmentioned size of the egg, namely, when it has one sixth or one fifth of an inch in diameter, it may be taken from the bed of yolk in which it lies, without any other guide than the naked eye. But, on account of the excessive tenderness of the membrane of the Purkinjean vesicle, it is not possible to effect this, unless it be boiled within the egg, when the heat coagulates the albuminous contents to a sufficient consistency to allow its being lifted up on the point of a knife; but even then it hardly holds together, thus evidently evincing the presence of a smaller amount of albumen, and a greater quantity of oily substance, than can be found in older ones. In two eggs of this size that were opened after having been boiled, the side of the Purkinjean vesicle that laid next to the yolk sac was inverted slightly, (Pl. 9, fig. 5b,) probably owing to the contraction of the contents, and the pressure of the yolk. This phenomenon occurs to a greater extent in older eggs, and is obviously due to the increased amount of albuminous deposit, judging from the greater toughness of the Purkinjean vesicle when 
boiled. The homogeneous state of the contents of the Purkinjean vesicle usually appenrs about the time when the egg is one quarter of an inch, or a little less, in diameter (PI. 9, fig. 7). The whole vesicle, as we have said above, is filled with homogeneous contents; but upon closer examination it may be perceived that the mass is composed of excessively minute particles, which the heat of boiling arranges in little clusters (Pl. 9, fig. 7b) that might easily be mistaken for a coarse granulation. This clustering is most evident at or near the centre of the field, where it seems to be denser and darker (Pl. 9, fig. 7a). For comparison with this, we will cite the figures of a larger egg, (Pl. 9, fig. 9,) more than two thirds grown, where the only difference from the last is, that the clusters of particles (fig. 9a, fig. 9c, $a, b$ ) are not so large, but more densely packed at the centre, and the Purkinjean vesicle is more deeply indented (fig. 9b). Another and little older phase (Pl. 9, fig. 10) offers a new feature in the contents of the Purkinjean vesicle; boiling has not had the effect to coagulate into clusters the minute corpuscles which form these contents (Pl. 9, fig. 10c, a); and, excepting perhaps that the central darker and coarser granules (Pl. 9, fig. 10a, 10c, b) whose brilliant refraction renders them so conspicuous are brought more closely together than is natural, there is nothing left but the deep indentation of the vesicle (fig. $10 \mathrm{~b}$ ) to indicate that a contracting influence has been at work.

The next and last step in the life of the Purkinjean vesicle is an almost total vanishing of its clusters, (Pl. 9, fig. 11b, a, ) so conspicuous heretofore in the medium sized eggs when boiled; but, as these clusters grew more and more faint latterly, we are not taken by surprise at their nearly total extinction in the fullgrown egg (Pl. 9, fig. 11). Still a few brilliant, darkly outlined granules, situated centrally, and not so coarse nor so numerous as in the last-mentioned vesicle, serve to cloud the contents which elsewhere are homogeneous. At this age, too, the wall (Pl. 9, fig. 11b) of the vesicle has become of sufficient thickness to allow a distinction between the outer and inner contour; but still we fear it is beyond the power of the pencil to give any idea of its delicacy. The extent of its indentation (Pl. 9, fig. 11a) gives an evidence of very strong contraction, by far more intense than has been known to happen in egrss of a smaller size. But what must be the infinitesimal minuteness of the particles composing the contents of this vesicle, when such powerful contraction only produces clusters of granules (fig. 11b, a) almost unrecognizable with a magnifying power of five hundred diameters!

The large size to which the Purkinjean vesicle has now attained renders its extraction an easy matter, when it has been hardened by boiling; and in this state it may readily be preserved in alcohol. Even the vesicle taken from an egg one fifth of an inch in diameter, after it has been boiled, may be put up in 
spirits and kept for reference, as may be seen in my embryological collection. I mention these trifling circumstances, only the more fully to satisfy the reader that these investigations were made upon parts of the egg duly isolated for a satisfictory microscopic examination.

\section{SECTION V.}

THE GROWTH OF THE OVARIAN EGG, AS A WHOLE.

Thus far we have described in detail the origin, the development, and the maturation of the several constituents of the ovarian egg of Testudinata. Now, in order to arrive at a full and comprehensive understanding of the general relations which exist between the several elements of this complicated structure, among each other as well as with reference to the whole organism of the egg, it is necessary to combine, in one view, all the details which have been before presented as separate and independent features. We have, indeed, up to this time, considered the different parts of the egg as constituting separate organs, as it were, growing each one independently, as regards the peculiar plastic force operating therein. We have shown that each of these parts is distinguishable from every other by dissimilar characters; and yet they are all connected by a superior porver, which holds them in obedience to the one great law of correlation controlling the growth of every organized being.

In a former section ${ }^{1}$ we have followed the growth of the egg as a whole, up to that period when the homogenity of its contents begins to be disturbed by the introduction of the yolk cells in the form of dark granules. At this stage the Purkinjean vesicle is a very clear globule, usually situated in that part of the egg which is most distal from the side where the granules appear ( $\mathrm{Pl}$. 8, fig. $4,5,6,8,9,10$, etc.). The next step brings an encroachment of the granular region upon that which surrounds the Purkinjean vesicle, simultaneously with the appearance of the Wagnerian vesicles in the latter (Pl. 8, fig. 13a, 15, 17, 17a, 18a, 19); thus exhibiting no inconsiderable change in the internal life of the egg. In the succeeding stage, the yolk granules are replaced by mesoblasted cells, (Pl. 8, fig. 22, $a-1,23,23 a-23 d, 24,24 a, 25$, $a-e$, etc.,) accompanied by an enormous increase of the Purkinjean vesicle (Pl. 8, fig. 22, c, 24b); from this time also the differentiation in the size of the yolk cells becomes conspicuous, those around

\footnotetext{
I See Sect. 1, p. 451-457.
} 
the Purkinjean vesicle ${ }^{1}$ being much smaller (Pl. 9, fig. 6b) than those nearer the centre of the egg (fig. 6a); and between these two extremes a gradual increase in bulk from the former to the latter is readily traced. This feature holds good throughout the succeeding phases of the ovarian egg, even to its full development (Pl. 9, fig. 11d-11g). ${ }^{2} \quad$ About this time, also, there appears a whitening of that side of the egr where the Purkinjean vesicle is situated. This whiteness increases in intensity and breadth as the egg enlarges, till in a full-grown ovum it occupies a considerable area. This differentiation of color from the surrounding and gradually deepening yellow is owing to the increasing preponderance of albumino-oleaginous clear cells (Pl. 9, fig. 5c, b, 11c) around the Purkinjean vesicle, intermixed with the usually larger mesoblasted ones. ${ }^{3}$ Again, as the egg comes to maturity, the yolk cells increase to an enormous size, (Pl. 9, fig. 1]g, 11i,) their single yellow mesoblasts nearly fill them, and the waxy entoblasts gorge the mesoblasts. Thus, by the decrease of the clear space, and the filling up of the same by the darker and yellow mesoblasts and entoblasts, the whole egg gradually receives a deeper and more orange-colored hue, excepting, as we have said above, where the space around the Purkinjean vesicle is whitened by the greater predominance of cells with homogeneous contents and a white reflection.

At this time, too, the Purkinjean vesicle has lost its Wagnerian vesicles, and presents pretty uniform homogeneous contents, (Pl. 9, fig. 9c, 10c, 11b, of a highly albuminous nature, so clear and dark as to give the surface of the egg the appearance of having a hole in it (Pl. 9, fig. 4-10; Pl. 9a, fig. 16, 18, 32, 32a). There is never, not even when the egg is matured, the least trace of a separation of a portion of the yolk around the Purkinjean vesicle, to form what is called, in the Bird's egg, the "cicatricula"; on the contrary, as we approach this region,

1 According to Meckel ron IIemsbach, Leuckart, Thompson, and others, the region in the vicinity of the Purkinjean vesicle of the Bird's egg is quite deficient in the "corpuscles" characteristic of the yellow yolk; the space thereabout and the canal leading to the centre of the yolk mass being oceupied by bodies quite different from those exterior to them in the mass of vitelline substance. Yet, from the description of these authors, it would appear that the grenetic connection of these bodics had not wholly escaped them; but that they have laid too much stress upon the extremes of a graduated modification, which is very similar to that which obtains in the egg of 'Testudinata.

2 See the description of these cells, p. 474.

'The clusters of cells on the periphery of the enlarged Purkinjean resicle, represented in fig. $5 \mathrm{c}$ and $11 \mathrm{~b}$, and marked $b$ around fig. $5 \mathrm{c}$, and $11 \mathrm{c}$ around fig. $11 \mathrm{~b}$, are meant to represent a part of the whitened yolk which surrounds these resicles. As the reader may find some difficulty in tracing these references upon the plates, as the cells of the white area are represented on the edge of the figures referred to, which is their true position, a few more remarks are needed. In fig. $5 \mathrm{c}$, the letter $b$, which designates these cells, may be seen on the margin of a cluster bordering on the left upper side of the Purkinjean vesicle which they surround. In the same manner are these cells represented in fig. $11 \mathrm{c}$, as bordering the Purkinjean vesicle of fig. $11 \mathrm{~b}$, which they surround in the same manner as the smaller cells of the preceding figure. 
the yolk cells present a smaller size and are less crowded, and clearer homogeneous cells mix in considerable numbers with them, so that really this is the most fluid part of the egg. From this point the yolk increases in density radiatingly, not only toward the periphery, but also in approaching the centre, which is not at all to be distinguished from the surrounding part by any sudden differentiation in its constituents. ${ }^{1}$

Although, from quite an early period, the cells around the Purkinjean vesicle are smaller than those which are more distant, yet the changes which take plase in their mesoblasts and entoblasts are identical in all the yolk cells throughout the egg. The shape of the egrg also gradually changes, with increasing size and age, from a flattened, more or less disciform, to a perfectly globular, figure, as it becomes more and more detached from the surface of the ovary, against which, in the earlier stages, it is very closely pressed.

Thus we see, that, from the begiming to the maturation of the ovarian egg, there is a constant dissimilarity between its two sides, one of which corresponds to the position of the Purkinjean vesicle, and the other to the opposite portion of the egg. The former contains within and around itself the extreme of albuminous concentration, and the latter the preponderance of oleaginous elements; yet, intermediate between the two sides there is a gradation, both in the proportionate size of the cellules and the relative amount of the above-namerl substances, which unite these extremes into one harmonious whole. How far this antagonism is carried out in the subsequent phases of the life of the egg will be more fully discussed in a future section; but this more we will say here, that, although we have had no opportunity for observing the intermediate steps between the maturation of the orarian phase of the egg and the period of slightly advanced segmentation, we have still sufficient reason to assume that the same diversified portions mentioned above retain the same relative position ${ }^{2}$ during the passage of the egg

1 See note 1, p. 480.

2 The clear space, obserrable in the exer of ravious animals just previous to segmentation, to which the name of "embryo cell" has been giren, (see "Thompson, 1. c., p. 139,) from its supposed intimate connection with the formation of the germ, may be identical with the white area about the I'urkinjean resicle observed in Iestudinata. $\quad W \mathrm{c}$ would take this opportunity to express the opinion, that very probably too much stress has thus far been laid upon the assumption that the Purkinjean vesicle performs a peculiar and exclusive finction in reference to the formation of the so-called cmbryo cells; and, moreorer, that the Purkinjean vesicle is not to be so definitely separated, as regards its essential elements, from the immediately juxtaposed substance of similar appearance, but should rather be looked upon as the crowning point of albuminous concentration, to which the opposite side of the erg stands in the reverse extreme of a highly oleaginous nature. A reference to the mole of origin of this vesicle sluws this conclusively ; for it is developed as a pliase of secondary accession in the egg evolution, and not as the primary basis to a succeeding structure ever after retaining a significunce of superior import, and leading, as some would have it, to its becoming in the end the essential eleurent in 
through the oviduct; nay, even that the ovarian egrg is essentially the animal itself, developed to a certain degree of complication, which, if freed from the parent and cast into the world without passing through the last fecundation, finds itself in an unnatural element, and dies; but, if subjected to this vivifying impulse, is sustained for a much longer period. The antagonism observed between the elements of the egg, during its ovarian growth, is carried out further, during the whole life of the growing animal. The region at first occupied by the Purkinjean vesicle corresponds afterwards to the cerebro-spinal side of the embryo, whilst the vitelline region marks the nutritive or intestinal sphere of the new being.

However much the nature of the immature egg, as described above, may seem to identify it with the budding progeny of some animals, we are not prepared to admit a parallelism between the two; on the contrary, knowing the mode of origin of the former and the totally diverse derivation of the latter, we cannot see any common ground upon which the two processes could be identified.

We hope, in another volume, probably the next, fully to discuss this subject, in connection with another type of animals, the Iydroid Medusa, in which these two modes of procreation obtain in the utmost diversity of combinations.

\section{SECTION VI.}

TIE GRAAFIAN FOLLICLE, AND THE MEMBRANES OF THE EGG.

The Stroma. We have very little to say in regard to the mode of development of this layer, and can only offer a few suggestions, which may lead to further investigations hereafter. An egg hardly yet visible to the naked eye is covered by very faint traces of a semi-fibrous, semi-cellular, exceedingly transpar-

the genesis of the embryo. This mode of origin alone, we maintain, is suHicient to show that the very foundation upon which its importance is laid cannot be tenable, in this light. 'The Purkinjean vesicle, therefore, loses all its adrocated claims to preponderance over the rest of the egr constituents; to say nothing of the fact that it takes no part in the building up of the blastoderm, exeepting that its discharged contents may become absorbed in the endosmotic and exosmotic interchanges of substances between the oily yolk cells, and the albuminous matter in which they
Hoat. 'True enough, the region about this resicle exhibits a specialized nature; it is there that the embryo first develops certain of its characteristics, previous to its further extension: but it does not follow, that, because the P'urkinjean resicle is situated thereabout, it is the basis of this evolution, or in any way causatively connected with it. On the contrary, its presence is itself rather the result of certain tendencies, for instance, the concentration of albumen in that direction; and its disappearance also is the consequence of the consummation of these tendencies. 
ent layer, pressing closely upon the exterior of the "tunica granulosa," and apparently developing by the cohesion of the exterior cells of the latter ${ }^{1}$ (Pl. S, fig. 9). Not long after this, upon an egrg just visible to the naked eye, this layer exhibits faint traces of being doubled, yet withal retains pretty nearly its pristine transparency (Pl. S, fig. 12, a; Pl. 9a, fig. 13, a). Upon an egg one sixteenth of an inch in diameter its fibrous structure has become quite apparent (P1. 9a, fig. 16, 16a, a); and another ovum one tenth of an inch in diameter is inclosed by a double membrane, the inner layer of which (Pl. 9a, fig. $18 \mathrm{a}, a$ ) is as thick as the zona (fig. 18a, e).

On account of the appearance of bloodvessels in the stroma, at this time, by which the thickness of the latter is disguised, we can only say that it becomes a more loose, network-like tissue, the outer layer of which is very movable upon the imner. This is particularly noticeable in full-grown eggs. The bloodvessels of the stroma develop pretty uniformly over the whole of its extent, excepting a circular area at the most distal side, where they suddenly thin out into fine capillaries, anastomozing among themselves (Pl. 9, fig. 5, 7, 8, 9, 10 ; Pl. 9a, fig. 32). Just before the exclusion of the egg from the ovary at the breeding season, the bloodvessels become very much gorged, (Pl. 9a, fig. 32, ) so that the larger eggs appear to be covered by an almost continuous blood-red layer. The bloodvessels, as they come up to this area, the region of the "cicatricula," suddenly bend upon themselves without diminishing their diameter, and commence their returning course. Now it is at this sudden bend that the capillaries which supply the cicatricula take their rise, and into this their return currents empty (Pl. 9a, fig. 32). After the exclusion of the egg, these vessels become paler, and are to all appearances fewer in number; they gradually disappear with the resorption of the corpus luteum.

The Tumica gramulosa. In a former section ${ }^{2}$ it has been shown, that, at the time of the formation of the egg, the cells of the Graafian follicles were not arranged in any particular manner in reference to the body which was developing among their interstices. By and by the egg has grown to such a size (Pl. 8, fig. 1, $h^{1}$; Pl. 9a, fig. 10) that the inclosing cells may be said to form an enveloping layer, although they have not changed in the least as regards their form; nor does this happen even when the eggr has attained to a much larger size (Pl. 8, fig. 1, o1; Pl. 9a, fig. 11). As we have before mentioned in passing, the cells of the follicle, around the younger eggs, are very transparent, of thin contour, with a nearly spherical shape, each containing a central, faint, and comparatively large mesoblast. 
At a much later period, (Pl. 8, fig. 5, 9,) these cells begin to press against each other, and to assume a more or less polygonal shape; yet this chimge does not at all correspond to the age or size of the egg, but appears to exhibit a consiclerable amount of variation as to shape and magnitude, since in a follicle inclosing an ovum invisible to the naked eye (PI. 8, 12, b; Pl. 9a, fig. 13, b, 13a) the cells are closely set against each other, whilst in another and much larger egrg, visible without a lens, (Pl. 9a, fig. 12, 12b, 17,, , ) there is but very little mutual crowding. In addition to their change in shape, the cells last mentioned have also undergone an internal alteration: a darkening of their walls, and a slight increase in the conspicuousness of the mesoblast (Pl. S, fig. 5, 9; Pl. 9a, fig. 12b, 17, c).

An egg about twice the diameter of that represented in Pl. 9a, fig. 12, when brought under the microscope, has the appearance of being covered by a network with polygonal meshes. These meshes, when more magnified, are found to be large, mutually compressed cells, belonging to the innermost layer, or tunica granulosa, of the Graflian follicle. 'Their size has considerably increased, and the contents have become very hyaline, especially the large mesoblast, which it is very difficult to detect (Pl. 9a, fig. 14, 14a). Each mesoblast occupies about one third the diameter of its ectoblast; as usually, before and afterwards, it has a central position, and is remarkable for its thickness $(\mathrm{Pl}$. 9a, fig. 14) when compared with its breadth. The external surface of these cells is more or less flattened next to the imner stratum (Pl. 9a, fig. 14, a) of the stroma, a feature more conspicuous still in older eggs.

When the egg has about one tenth of an inch in diameter, (PI. 9a, fig. 18, the exterior surface of these cells is closely pressed and flattened against the fibrous stroma (Pl. 9a, fig. 18a, b); and the cells themselves have become internally so transparent that even the mesoblast is not visible, except when brought out by reagents. This hemispherical shape, with their rounded surface next to the zona pellucida, they retain for the rest of the interovarian life of the egg (Pl. 9d, diagram, fig. 2, b). What further changes they undergo, after the eggr has been expelled from their embrace, has not yet been investigated, and therefore the subject must be left for further research.

The Zona pellucide. Although the zona pellucida is developed later than the vitelline sac, yet, on account of its comnection with the Grafian follicle, we think it proper to consider it first. The carliest appearance of the zona pellucida which we have noticed is seen at a time when the egg has already become visible to the naked eye (PI. 9a, fig. 12); it is then represented by a layer of excessively liyaline, large, flat cells, (P1. 9, a, fig. 12a and 17,b, $b^{\mathrm{E}}$ ) resting on the outer surface of the yolk sac, and just within the tunica granulosa $(c)$. For want of observations we can say nothing about the origin of these cells, excepting that, from their position, they must be developed from the Grafian follicle, and indi- 
cate, beyond the possibility of a doubt, that the zona, of which they are the constituents, is not a part of the yolk, but an envelope of the egg. ${ }^{1}$

In the next stage, in an egg about one sixteenth of an inch in diameter, we find the cells of the zona so pressed against each other that their outlines are not recognizable, (Pl. 9a, fig. 16, 16a, $c$,) and only a clear, thick band represents the presence of this membrane. Again: in an egg about one tenth of an inch in diameter, this layer is found much thickened and more conspicuous, by reason of the transverse strix which extend from its outer to its imner contour (Pl. 9a, fig. 18, 18a, $e$ ). The nature of these stria is readily demonstrable, by breaking up the zona; when it becomes evident that they are the outlines of columnar cells, ${ }^{2}$ (PI. 9a, fig. 19,) flattened in a direction opposite to that in which we found them in the begimning (Pl. 9a, fig. $17, b^{1}$ ). At this age the zona is a very elastic and flexible yet tender layer, exhibiting a considerable degree of tenacity between the cells of which it is composed. This structure remains unchangeable for the rest of the interovarian life of the egg, $(\mathrm{Pl} .9 \mathrm{~d}$, fig. $2, c$, ) as may be demonstrated by resorting to a full-grown ovum. ${ }^{3}$

Subsequently to the entrance of the egrg into the oviduct, the zona would seem to be gradually resorbed, as the "investing membrane," developing close upon the surface and from the substance of the yolk, becomes more and more defined as a membrane, and takes the place of the former. At what period the zona disappears altogether it is not possible now to say; but, in some instances certainly, not till after the embryo has commenced to form its amnios, when it appears to be very thin, and, in addition to other characteristics, is remarkable for turning suddenly to a nacreous white upon the application of water. This latter peculiarity we have not noticed previously. At a later period it has not been possible to find the least trace of the zona, excepting perhaps a mere film lining the shell, as late as during the middle period of incubation.

The Vitelline Sac. In a previous section ${ }^{4}$ we have already discussed the origin

I See, below, note 1, p. 486 .

2 Thompson, loc. cit., page 83 , says he is inclined to believe that these strix, as seen by Remak (Miiller's Arehiv, rol. 4, p. 252) in the ovum of the rabbit, do not depend on any structure of the zona itself, but rather on the markings produced by the adhesion of the pediculated cells of the tunica granulosa, which, under pressure, leave a radiated appearance on the zona; but we would ask, how are the cells of the tunica granulosa enabled to produce transcerse strix in the considerable thickness of such a membrane as this? We can lardly believe that these cells have such a far-reaching power.

${ }^{8}$ Dr. Martin Barry (Researches in Limbryology, Phil. Trans., 1838, p. 316) says, "In the ovary of Birds, Amphibia, and Fishes, it is, I believe, allowed that there is no membrane formed external to the membrana vitelli," and denies that the zona pellueida ("Chorion," as he calls it, but in Phil. 'Truns., 1839, p. 310 , he says "Zona,") has its parallel in other. Vertebratit than the Mammalia.

4 See Sect. 1 of this Chapter, p. 451-156. What 
of this membrane, the primitive egg-cell wall, and have here only to speak of its permanence up to a certain period, ( $\mathrm{Pl} .9 \mathrm{a}$, fig. $18,18 \mathrm{a}, c$, ) when the egg has attained to a size of about one tenth of an inch in diameter, beyond which, very probably, its function is supplied by the already well developed zona pellucida, whilst it is gradually resorbed; at least, we have observed no trace of its existence after this time. Of its changes, from the time of its origin till its disappearance, little can be said of such a thin, apparently structureless membrane, beyond the mere notice of the gradual thickening and defining of its outline, till there is no doubt left of its perfect distinctness, as a layer, from the yolk which it incloses. ${ }^{1}$

The Embiyonal Membrane.2 On the surface of the yolk, in an egg hardly visible to the naked eye, there is a layer of minute, singly mesoblasted cells, (Pl. 8, fig. 12, $d$; Pl. 9a, fig. 13, $d$,) apparently not yet comnected with each other. On account of their size, and of their color, which resembles that of the yolk in the intermediate neighborhood, it is no easy matter to recognize these cells at first sight; but when once seen, and their peculiarity noted, their presence may afterwards be readily detected by a practised eye. As to the mode of their origin, there appears to be but one explauation, which is, that they are peculiarly modified yolk cells. In confirmation of this explanation we may mention their outline, which as yet is thick,

is now called vitelline sac is the primitive cell wall of the primitive ovarian egg.

1 Thompson (article Orum in Cyclop. Anat. p. 78) compares the early yolk sac of Birds (which he lardly admits as a true membrana vitelli, notwithstanding Meckel's researches) to the zona pellucida of Mammals, (the true primary vitelline sac of these animals, interior to the zona, being totally ignored by him; see also p. 50, where he describes the zona as the original yolk sac, and the only one existing in Mammals, and the secondary yolk sac (the true zona) to the tunica granulosa of viviparous Vertebrates. The secondary yolk sac, he infers, is derived from the cellular lining of the Grafian follicle; but, since at the same time he makes it merely the exterior stratum of a concentric series, the inner of which, he insists, become the true yellow yolk granules, (the primary yolk sac, zona pellucida, as he calls it, having disappeared by deliquescence,) it looks very much as if ho had mistaken the development of the "membrana investiens" for that of the membrana vitelli. Again he says, $($ p. 78,$)$ "the external edge of the layer of prismatic cells, the length of which is considerably increased, is now surrounded by a narrow, pellueid space inclosed by a double line, presenting the appearance as if a small part of the bases of these cells lad been fused together in a homogeneous film." This, probably, is the true zona pellucida of Birds ; he laving failed to see the membrana vitelli, (already disappeared, as he thinks, ) situated between it and the layer of prismatic cells, from which latter he supposes, but without direct research, that the "pellucid space," because of its traces of hexagonal markings, is an immediate development.

2 Until more extensive investigations have proved the identity of this membrane with the "Keimblase" of Bischoff, or the "Umhüllungshaut" of Reichert, which is called "investing membrane" by some Linglish writers, it seems best, in order to aroid confusion, to give it a distinct name. 'That of "embryonal membrane" appears the most acceptable and significant. It can hardly be an objection that it recalls the cmbryonic envelopes, for it is in the end more or less intimately connected with them. 
their oily appearance, their separation from each other, and their position within the vitelline sac. ${ }^{1}$ In an older egg, about one sixteenth of an inch in diameter, (Pl. 9a, fig. 16, 15, ) their contents are granular, and the mesoblast very darkly and thickly outlined, evidently by reason of its oiliness, which, by its highly refracting powers, produces also a dark centre resembling, and no doubt often mistaken for, an entoblast. In an egg one tenth of an inch in diameter, these cells (Pl. 9a, fig. 20, $20 a, a, b$, ) hardly differ from the last, excepting that their mesoblasts are less in size; an irregularity, according to age, noticed elsewhere in regard to the constituents of other membranes. In another egg of this size we have represented this membrane in profile, (fig. 18,$c$, ) as bounded by two lines, the outer being the original yolk membrane, and the inner the line of demarcation between the yolk and the membrane in question.

The manner in which the cells of this layer overlap ench other, in an egg about one quarter of an inch in diameter, (Pl. 9a, fig. 21, 21a, ) shows that they do not as yet all lie in one plane. Here their size, and also that of the mesoblast, is considerably increased.' The latter has moreover a dot, the entoblast, in its centre, and in some instances two dots, with a corresponding elongation of the mesoblast, apparently indicating that a self-division is in progress, which, as will be seen hereafter, (PI. 9a, fig. 27,) is finally accomplished. Upon opening the egg, this layer is found to have such a consistency as to restrain the yolk from spreading rapidly; and moreover it is recognizable by its much lighter color.

In a full-grown egg the cells of the embryonal membrane are considerably larger and more transparent than in the last egg, and exhibit the same double entoblasts (Pl. 9a, fig. 22a). By fixing the focus of the microscope at the horizon of their greatest diameter it will be seen that they are sharply polygonal, (fig. 22, ) the broad light bands between them representing the thickness of two juxtaposed walls, the superficies of which are obscured by mutual fusion, and by the absence of refraction consequent upon the loss of curvature.

Thus far, the embryonal membrane has been traced in its development as a feature of the interovarian egg; whatever else may be said of it hereafter, refers to its more or less intimate connection with the changes of the embryonic envelopes, of which it becomes at least a prominent part, if not conspicuously an efficient member.

In an egg in which the cephalic hood has commenced to form, (Pl. 11, fig. 1, $a^{1}$ ) the cells of this membrane ( $\mathrm{Pl} .9 \mathrm{a}$, fig. 24) are very transparent, especially where they rest closely upon the back of the embryonal area; yet, excepting perhaps the slightly smaller size of the mesoblast and the apparent presence of a dot 
within the highly refractive entoblast, they differ hardly at all, individually, from those of the mature ovarian egg (Pl. 9a, fig. 22). Considering their arrangement, however, we find that here they are all in one plane, forming only one stratum by their juxtaposition. By applying a magnifying power of eleven hundred diameters the mesoblasts and entoblasts are brought out more clearly and appreciably (PI. 9a, fig. 24a): the former, the mesoblasts, appearing to be composed of a stratum of juxtaposed granular bodies; and the latter, the entoblasts, to contain in some instances simply a lateral, dot-like entosthoblast, such as could not be produced by any sort of refiaction, and in others a hollow, vesicular entosthoblast. But the presence of entosthoblasts cannot be of great importance, since, as far as we have been able to see, they are no longer visible beyond this stage.

By the time that both the cephalic and caudal amniotic hoods are evident, (PI. 11, fig. 2, $a^{1}, a^{2}$ ) these cells have become excessively transparent, (Pl. 9a, fig. 25, 26, 29a, $b, b$, ) so that it is almost impossible to recognize them, except by the most careful manipulation, unless they are brought out by a process of maceration in reagents, which it is by no means safe to do, since they are greatly distorted by it. They may be best seen in the area pellucida (Pl. 11, fig. $2, c$,) without disturbing the neighboring layers, and in other regions by carefully removing the subjacent loose cells, or by folding a portion cut away so as to bring them into profile (Pl. 9a, fig. 29a, b, b). In the latter position their thickness may be seen to be considerable, and the superficial contour of each to be distinctly arched, the whole lying close against the germinal layer beneath them. By careful focussing, the mesoblasts may be shown to be attached to the arched surface of its cell, (Pl. 9a, fig. 29, ) and so thin that it cannot be recognized in profile. Owing to their hyaline nature, the entoblasts were not recognized, although they were probably present, since in an older stage (Pl. 9a, fig. 23) they were detected, under more favorable circumstances. In some instances all trace of mesoblasts, entoblasts, and entosthoblasts, was lost (Pl. 9a, fig. 26); but their presence was proved by reagents. The figure just quoted represents the equatorial region of the cells below the horizon of the mesoblasts, so that the double thickness of the walls is shown. Were it not for the presence of granules within the cells, in the profile view, (Pl. 9a, fig. 29, b, $b$, we should suspect that those seen from the outside (Pl. 9a, fig. 25) were components of the layer below them. By this time the embryonal membrane has already such a consistency that it may be lifted up separately from the layer it covers; but, on account of the distortion of its cells, it is not safe to study it after such a process.

At a little later period, when the "primitive furrow" (Pl. 11, fig. 3, b) has commenced to form, the mesoblasts (11. 9a, fig. 23) contain faint entoblasts, which at first appear to be the result of an optical expression, oftentimes noticeable in 
clear cells; but here the lateral position of some of them, and their variable size, testify to their reality, whilst the application of water brings them out more strongly. Our figure gives a good idea of their appearance under this influence.

We have been fortunate enough to recognize these cells in an egrg which had already been laid as long as eighteen days, and in it they were seen undergoing self-division (Pl. 9a, fig. 27). A greater part of the mesoblasts were double, and more or less separated from each other; and here and there were those which, partially constricted, already contained two entoblasts. The size of these double mesoblasts is exactly that which would follow the division of a single mesoblast like those observed in the younger phases of the same kind of cells. The same transparency and angularity as we have formerly observed prevail here, so that their identity is beyond question.

A longitudinal section of an embryo, of about the age of that represented in Pl. 12, fig. 1, shows that this layer (Pl. 9d, fig. 1, ....) follows closely every folding and bending of the germinal layer, (Pl. 9d, fig. $a, a^{1}, a^{2}, a^{5}$, and $a^{6}$,) whether it be over the curved back of the "embryo," or into the furrow which forms the incipient spinal tube, (Pl. 24, fig. 13a, e, e,) or close to its now very much depressed head, or backwards and upwards again with the folds of the amnios.

In later periods, when the amnios is closed over, the embryonal membrane forms an inner lining (Pl. 9e, fig. 7,....) to the amniotic sac; a portion is also inclosed within the spinal tube, as its approaching edges unite above; and, in a transverse section of this tube, totally shut, a thin film (Pl.9e, fig. $6, \ldots .$.$) was apparent, but$ evidently undergoing a change, no doubt tending to resorption. That portion of it, however, which surrounds the whole yolk, remains distinct until the young animal is hatched; but in these latter days it is evidently decomposing, (PI. 9a, fig. 31, a, $31 a, a$, ) at least its cells were more or less separated from each other, and their walls ragged, as well as those of the mesoblasts. In some cells two mesoblasts were still visible.

\section{SECTION VIT.}

FECUNDATION.

Ever since I have known that our Turtles lay only once a year, I have been struck with the fact that the ovary nevertheless contains eggs of very different sizes. I was led by this observation to inquire into the duration of the growth of the ovarian eggs, when I further noticed that these eggs appear in well-marked sets 
of different sizes, each set being equal in number to the average number of eggs laid by the species under observation. It thus became evident that the egras require more than one year for their full development. Once upon this track, it appeared practicable to determine how long a period this growth embraces; for, as soon as it could be ascertained how many eggs different species of l'urtles lay, there was a standard of comparison obtained for the investigation of the ovaries; and, as I early leamed that the species most common about Cambridge exhibit marked differences in that respect, I selected these species for my first studies. Chrysemys picta lays always between five and seven eggrs. I have never observed as few as four, and only occasionally eight. Nanemys guttata lays generally two or three; I have only once or twice found four eggs in its nest, and three times in its ovary. There was therefore no chance of making any mistake, when comparing the number of their ovarian eggs with that of the eggs they lay, after I had ascertained that a few weeks before the breeding season there are the same numbers of mature eggs to be found in the ovary as these species usually lay in the spring. I felt still greater confidence in the possibility of coming to precise results, after I had found again and again the very same number of eggs in the oviduct, ${ }^{,}$and noticed that at that time another set of egrgs could be readily distinguished, of the same number as the larger eggs left in the ovary. Indeed, the difference between this largest set of ovarian eggs and the smaller ones is so great, even at the time when the eggs about to be laid are still in the oviduct, that they are distinguished at the first glance; for, though they have unquestionably to remain another year in the ovary, they are already nearly as large in diameter as those which have just left it.

With a knowledge of these facts, it was easy to arrive at a full understanding of the normal periodicity in the growth of the ovarian eggs. It soon became plain, that shortly before the period of laying there were not only two, but as many as four, distinct sets of eggs in every ovary; and that, after the largest set had been laid, a new small set was started from among the innumerable smallest eggs of variable size. It now seemed that a single question remained to be answered. What is the age at which the Turtle discloses for the first time such differences between its eggs? Upon opening large numbers of young Chrysemys picta ${ }^{2}$ it was ascertained, that, up to their seventh year, the ovary contains only eggss of very small size, not distinguishable into sets; but that with

I It has already been stated above that the emos of one ovary are not necessarily received into the oviduet of the same side of the animal, but may be taken up by the fallopian tube of the opposite side. See I'art II., Ch. 1, Sect. 13, p. 288.
2 Comp. 1'art II., Ch. 1, Sect. 14, 1. 292, where the most prominent characters of this species and the differences in its size, in successive years, arc given approximately, for the first twenty-fire years of its existence. 
every succeeding year there appears in that organ a larger and larger set of eggs, each set made up of the usual average number of eggrs which this species lays, so that specimens eleven years old, for the first time, contain mature eggs, ready to be laid in the spring.

Now another question arose, When are the eggs fecundated? Field observations soon taught me that this species copulates before it is eleven years old; I have even seen those that were not over seven years old already performing the act, though I have never seen any in copulation younger than these. Thus it appears that the first copulation coincides with a new development of the egrgs, in consequence of which, a certain number of them, equal to that which the species lays, acquire a larger size, and go on growing for four successive years before they are laid, whilst a new set is started every year, at the period of copulation in the spring, enabling this species to lay annually from five to seven eggs, after it has reached its eleventh year.

The question was then naturally suggested, whether fecundation is the result of the first act of copulation, or of the second, the third, or the last; or whether the first copulation only determines the further growth of a certain number of eggs, which require a series of successive fecundations to undergo their final development. The second alternative appears the more probable when it is remembered that Turtles were observed ${ }^{1}$ which did not lay their eggs as usual, though the yolk had undergone all the regular changes through which it passes, up to the time the egg has entered the oviducts. This is another fact which tends to prove that fecundation is a successive act. Though Turtles lay only once every year, soon after the period of copulation in the spring, copulation itself does not take place once merely, every year, as in all the animals known to bring forth young once annually; it is repeated a second time, every year, in the autumn, shortly before the Turtles retire to their winter-quarters; ${ }^{2}$ and this takes place without apparent connection with any marked change in the growth of the egrg at that season. So, in Turtles, fecundation does not appear to be an instantaneous act, resulting from one successful connection of the sexes, as it is with most animals. The facts related above show, on the contrary, that, in Turtles, a repetition of the act, twice every year, for four successive years, is necessary to determine the final development of a new individual, which may be accomplished in other animals by a single copulation.

It may be suggested, that, by an investigation of the spermatic particles, additional light would be thrown upon these remarkable circumstances. But such investigations present greater difficulties in these animals than could be supposed 
at first; and notwithstanding the most diligent search, my efforts to trace the spermatic particles through the oviduct, as high up as the ovarian eggs, have been unsuccessful. Turtles do not copulate in confinement; and those which I could catch in coitu in their native haunts have only exhibited spermatic particles in the oviduct. I have, still less, been able to trace the sperm into the egrg itself. Indeed, there is no micropyle in the egr of 'Turtles; and I must confess that I have not yet seen the first fact which could lead me to admit that the spermatic particles penetrate into the egg. I am therefore obliged to abstain from expressing any deciled opinion upon the question of the penetration of the spermatic particles into the egg, which has of late attracted so much attention among embryologists. I can only say, that, notwithstanding the high authority upon which it is asserted as a fact that the spermatic particles do pass into the substance of the egrg through a definite aperture of its envelope, I am still rather inclined to doubt it.

The aperture observed in the outer membrane of the egg, which has been called micropyle, has always appeared to me to be the result of the separation of the sac in which the egg is developed, and by no means to pass through the vitelline sac. Without the most careful examination it is not possible to perceive how complicated the sac is, in which the egg is inclosed; and I suspect that a kind of Graafian follicle, which in many animals drops from the ovary with the egg, has frequently been mistaken for a vitelline membrane. I believe, further, that the scar resulting from the separation of that follicle forms the opening called micropyle, and that this opening does not traverse the vitelline membrane. In Turtles the perforated appearance of the yolk sac arises from the presence of the Purkinjean vesicle near the surface of the yolk, and not from the existence of a real hole. (Comp. p. 456, 459, and 460.) After what has been said above of the lateral origin of the Purkinjean vesicle, it is superfluous to insist upon the incorrectness of the view of those who would ascribe its superficial position to the influence of fecundation. It is formed in that position, and preserves it as long as it exists. 


\title{
C II A P T E R S E C O N D.
}

\author{
DEVELOPMENT OF THE EMBRYO FROM TIE TIME THE EGG IEAVES THE \\ OVARY TO 'THA'I OF THL HATCHING OF 'THE YOUNG.
}

\section{SECTION I.}

THE LAYING OF THE EGGS.

To tell American students that little is known of the habits of Turtles, the laying of their eggs, the growth of their young, etc., would perhaps excite a smile in those who, as boys, have been in the habit of collecting 'Turtles' eggs; egg-hunting being an occupation of which boys are fond all the world over. Yet so it is: what every inhabitant of the country may have seen again and again has not yet been collected in scientific works. I have however availed myself largely of the information circulated from hearsay throughout the community, as it was the best preparation for a thorough study of the Embryology of these animals. Guided by these reports, I could avail myself of the best opportunities for direct investigation, everywhere and at all times. But, though this be the case throughout the United States, it is nevertheless true that this information is nowhere recorded, and that the book-learned are ignorant of what every firmer, living by the side of our ponds and marshes, has known from childhood. I camnot, on that account, allow this opportunity to pass without emphatically calling attention to a point which is of the utmost importance for the farther progress of science in this country, where a desirable object is hardly made known, before its execution is taken into consideration. Had our public and private libraries been better supplied, and arranged with more system, so that their deficiencies in some points might have been as apparent as their completeness in others, the omission to which I have just alluded would certainly 
have been corrected long ago, and I should have been too late with the results of my investigations upon this subject, now published in this volume. And it should be remembered, that a well-marked blank in a library may be as suggestive as a well-filled shelf, and may induce the young naturalist to take up some branch of study which has been neglected. For my own part, I well recollect, that, on my first visit to the University of Ieidelberg, at the age of nineteen, on asking the librarian to show me all that had been published upon the subject of Fishes, he pointed me to a meagre shelf, and on examining its contents I found that many important facts, with which my youthful rambles and my early love of Natural History had made me familiar, were unknown to naturalists. "And is this all?" was my repeated inquiry. But the librarian, as well as the professor of Zoölogy, assured me that these volumes contained all that was then known to the scientific world on the subject of Fishes. Afterwards, I mentioned to Professor Leuckart the facts which observation had taught me with respect to the seasons of spawning, the mode of growth, the geographical distribution, and the habits of the Fishes of Switzerland; and, when I found that they were new and interesting to him, I no longer doubted as to the field in which to commence my labors. That blank in the well-ordered library taught me more, as to the scientific path which I should choose, than shelves crowded with volumes could have done. I mention this aneedote merely to show the importance of systematic arrangement in our libraries, in order that our young students may perceive at once in what departments their investigations are most needed. Otherwise, much time may be lost by toiling in already well-ploughed fields, and valuable facts may be left unrecorded.

For the same reason I would urge upon the consideration of those interested in the progress of science in America the value to the student of well-stored museums, and especially of local collections containing series of specimens of every species of animals, plants, minerals, rocks, and fossils found in the vicinity of every school throughont the country, with precise indications respecting their origin. $^{2}$ With reference to this last topic, too much cammot be said of the impor-

I This was in the spring of the year 1826, two years before the publication of the first volume of the great "IIistoire naturelle des P'oissons" by Curier and Valenciennes.

2 It is a great mistake to suppose that large museums are necessary for the study of Natural History, and that show specimens from distant countries add much to the interest of a scientific collection. I deliberately assert, that there is not a school-house in the
United States, in the immediate vicinity of which it would not be easy to make, in a few years, a collection of native specimens suflicient to illustrate the fundamental principles of any branch of Natural History. Nay, it is not too much to add, that such collections would contribute greatly to the advancement of science, if simple catalogues of their contents were published from time to time. I am satisfied, from my own experience, that every such collection could, in 
tance of correct dates and labels for every specimen. A most valuable collection may be made almost useless from want of attention to these details; whereas if every contributor to public or private museums would furnish precise information respecting the origin of the specimens he has collected, he would confer a real service upon science. Every specimen should be marked with the exact date and place at which it was found, otherwise it may be worthless for purposes of comparison with other specimens. It would not be difficult to show how important are these apparently trifling details. One example may suffice. Thousands of specimens of the Blind Fish of the Mammoth Cave have been brought home by visitors of that interesting locality, and are now scattered throughout the country. They have been examined again and again by naturalists; but to this day the period at which they spawn has remained unknown, even though eggs have been observed in their ovary in an advanced state of development. Had the collectors marked the time at which such specimens were caught, we should know, from that observation alone, what is their spawning season. And so it is with every kind of specimens; without accurate dates we shall learn little from them, of what they might teach us, if they were properly labelled.

With reference to the subject of Turtles, now under consideration, the cause of the discrepancy between the knowledge of the learned and of the field observer lies in the circumstance, that, in the Old World, no Turtles are to be found in the immediate vicinity of the great centres of study, and that most of the information collected upon these animals has been recorded from the casual observations of travellers. In this estimation I do not, of course, include the investigations made upon their structure, which may very well be traced and completed from specimens preserved in alcohol; as every naturalist knows that one of the masterworks upon Comparative Anatomy is that of Bojanus upon the Anatomy of the fresh-water Turtle of Eastern Europe. ${ }^{1}$ Rathke has also published as full an Embryology of that species ${ }^{2}$ as the circumstances under which it was prepared would allow, a monograph, which, with his many other embryological researches, has won for him a place in that constellation of eminent writers whose studies have made Embryology what it now is. But it is felt, on almost every page of his work, that he labored under a scarcity of materials which constantly impeded his progress. As I can plead no such difficulties for the imperfections which my present

less than ten years, be made wortlyy of a careful examination by even the most critical professional naturalists, and would afford to the teachers and pupils a source of ever new interest in their walks, and of ever increasing extension of their knowledge, and ability to observe. In Massachusetts a rexy good beginning has already been made, in several schools; and most successfully by Mr. J. W. I'. Jenks, in Middleboro".

1 Bojanus (L), Anatome 'Testudinis Europare. Vilna and Leip., fig. 1819-21, vol. fol.

${ }^{2}$ Ratnke (II), Ueber die Entwickelung der Schildkröten, Braunschweig, 1848, 1 vol. 4 to. 
work undoubtedly still contains, I feel the more the responsibility I have assumed, in undertaking to write anew the Embryology of that order of Reptiles. But, if I cannot expect to exhaust the subject, I may at least hope to show how instructive this field may become for the American student, and how important it is for science in general. Every Luropean embryologist must envy the opportunities our naturalists have in this respect; and it is the duty of those who possess such advantages to supply fully and freely any additional information which a thorough comparison of the structure and embryology of the different genera and families of our 'Turtles may aflord, and which is not already included in the following pages.

The age at which Turtles begin to lay has been ascertained, with sufficient precision, only for one species, our common Chrysemys picta. By the help of a series of specimens, from those just born up to adult ones, it was possible to trace the progress of growth of the ovarian eggrs till they were ready to drop into the oviduct; and thus the fact was elicited, that the exgrs do not begin to differ in size among each other by any readily appreciable amount until the seventh year, and that the process of reproduction by laying is not commenced before the eleventh year. Several other genera of this and other families were examined in reference to this point, but for want of materials the investigation was not carried on so extensively nor with so much precision as with Chrysemys picta; yet enough has been seen to warrant the assumption, that from the eleventh to the fourteenth year ${ }^{1}$ is about the age at which most, if not all, our native fresh-water Turtles lay their eggs for the first time.

Again: the time of the year at which they lay is the same for both the northern and the southern species, without reference to physical differences, such as temperature, moisture, etc., or climate in general. Graptemys LeSueurii, which lays as early as the first of June, gives the earliest instance of incubation in the year, and this is a western and south-western species. Chelydra serpentina, the species most widely distributed in the United States, at the North lays as early as the tenth of June, and continues to do so till the twenty-fifth: some individuals disposing of their burden as early as the first date, and others as late as the latter.

1 A careful comparison of the relative distance of the successive lines of growth of the scales may satisfy any one that the Turtles grow more rapidly during the first ten or twelve years of their life; and that after the twelfth or fourteenth year the rate of increase is considerably diminished. From the facts observed in our little Clirysemys picta it is certain that this is also the period at which they begin to lay.
There exists, no doubt, some difference between different families; but, judging from the clange in the rate of increase after the twelfth or fourteenth year in different species, there can be no doubt that this is a critical period in the life of all the scaly fresh-water and land 'Testudinata, and Chrysemys picta shows that this is connected with the period of their first reproduction. 
No one of our Turtles makes more than a single nest. They deposit all their exgrs at once. Chrysemys picta las an almost identical period of incubation with Chelydra serpentim, namely, from the eleventh to the twenty-first of June, and even to the twenty-fifth; since eggs were found in the oviduct, as late as the latter date, in a Turtle picked up in the field and opened at once. Thalassochelys Caouana, a southern marine species, lays as late as the fourth of June. Later than the dates mentioned above, no Turtle has been known to lay, except in confinement, where the time of laying is occasionally delayed for a whole month, namely, till the eighteenth and twentieth of July; and yet, in very many instances, the embryo of such eggs was alive, and continued its normal development. A Cinosternum pennsylvanicum, kept confined, did not lay till the seventh of October, and then only brought forth a single egg, which was in all probability not fecundated, judging from the.unnatural appearance of the yolk.

The beginning of the development of the embryo, in the ordinary acceptation of the term, coincides neither with the act of fecundation nor with the laying of the eggrs. But, even if we should extend the meaning of the term embryo to the whole body of the egg, there is no appreciable connection, in 'Turtles, between its developing and the acts just alluded to, such as is known to exist in other animals. The egg is formed, and its development goes on to a certain point, long before the first copulation takes place. After this it continues to increase in size and to undergo a series of internal changes, duxing several successive years, before segmentation takes place; and, though this process follows the last connection of the sexes which precedes the laying of the eggrs, it is hardly legitimate to ascribe it to that act, since copulation has been repeated again and again years before segmentation introduced another phase in the development of the yolk, and eggs were found in which segmentation had begun, though they were not fecundated. It seems to me more concordant with the facts observed to infer that fecundation is another of those organic impulses under which the development of the egg, begrun without it, is now impelled into new phases, concomitant with this act, but not absolutely initiated by it. The autumual copulation, which thus far has not even been found to coincide with any particular movement in the growth of the egg, certainly justifies such a view. But, though I would insist upon this interpretation of the facts, as observed in Turtles, it does not follow, that, in other animals, the influence of fecundation is not more directly connected with the changes the egrgs undergo. In this respect again every type must be investigated for itself, before any general theory of fecundation can be attained. The ouly fict relating to Turtles which remains unquestionable in this connection, is, that the egrgs are still in the ovary when the last copulation takes place, but soon afterwards pass into the oviduct. 
It is not easy to ascertain the length of time during which the egrgs remain in the oviduct after they have escaped from the ovary; from want of direct observation it remains a matter of conjecture. Referring to the tables ${ }^{1}$ inserted

1 'The observations recorded here were chiefly made with the view of ascertaning how long the eggs remain in the oviduet, and also the time of laying. IIundreds of 'Turtles were opened besides, for the purpose of aseertaining the average number of eggs which different species lay, and also to trace the passage of the eggrs from the ovary of one side to the oviduct of the other side; but the ficts ascertained in that way were not tabulated, and are simply mentioned in the text. The queries indicate simply that the eggs were not counted.

\section{CHELYDRA SERPENTINA.}

\begin{tabular}{|c|c|c|c|c|c|c|}
\hline \multirow{2}{*}{ DATE. } & \multicolumn{2}{|c|}{ OFaries. } & \multicolumn{2}{|c|}{ ONIDECTS. } & \multirow{2}{*}{ Lasin. } & \multirow{2}{*}{ REMARES. } \\
\hline & 'Right. & Left. & Right. & Left. & & \\
\hline June $10, ' 55$ & 一 & - & - & - & laid & \\
\hline June 12,54 & 一 & - & $40^{\circ}$ & - & - & In confinement. \\
\hline Iune 12,55 & - & - & - & - & laid & \\
\hline June $13,{ }^{2} 55$ & - & - & - & - & laid & \\
\hline June 15,54 & - & - & & - & - & $\begin{array}{l}\text { Cicatrices, } 21 \text { in the left } \\
\text { and } 15 \text { in the right } \\
\text { ovary. In confinement. }\end{array}$ \\
\hline June 18,55 & - & - & $-1 *$ & - & laid & \\
\hline $\begin{array}{l}\text { June } 18,75 \\
\text { Jume } 19, ' 55\end{array}$ & $=$ & - & $71^{*}$ & Z & 二 & $\begin{array}{l}\text { Taken from two anmats. } \\
\text { Out of seven animals }\end{array}$ \\
\hline Dente 19, wo & & & & & & $\begin{array}{l}\text { opened, two had not yet } \\
\text { laid. }\end{array}$ \\
\hline June $20,{ }^{5} 5$ & - & 一 & - & - & - & $\begin{array}{l}\text { This was opened July } 20 \text {, } \\
\text { and found to contain } \\
\text { egrs. See that date. }\end{array}$ \\
\hline June 20,36 & - & - & - & - & laid & \\
\hline Inne 21,55 & - & - & - & - & haid & \\
\hline $\begin{array}{l}\text { June } 22,74 \\
\text { June } 23,54\end{array}$ & - & 二 & 二 & 二 & $\begin{array}{l}\text { laid } \\
\text { linid }\end{array}$ & $\begin{array}{l}\text { In continement. } \\
\text { In confinement. }\end{array}$ \\
\hline June $23,-65$ & - & - & - & - & lilid & \\
\hline June 23, , 54 & - & - & - & - & liaid & In confinement. \\
\hline Tune 25,55 & 一 & - & - & - & laid & $\begin{array}{l}\text { Seen laying, but eggs not } \\
\text { conlecterl. }\end{array}$ \\
\hline July $20, ' 55$ & 一 & - & ? & - & - & $\begin{array}{l}\text { Embryos alive. In con- } \\
\text { finement. }\end{array}$ \\
\hline
\end{tabular}

CINOSTERNUM PENASYLVANICUM.

\begin{tabular}{|c|c|c|c|c|c|c|}
\hline \multirow{2}{*}{ D.TE. } & \multicolumn{2}{|c|}{ OVARIES. } & \multicolumn{2}{|c|}{ Ovinucrs. } & LAID. & IREUARES. \\
\hline & Iight. & Ieft. & |Right. & Left. ' & & \\
\hline July 3,36 & - & - & $4^{*}$ & - & - & All specimens of this spe- \\
\hline July 30,35 & 3 & - & 1 & - & - & $\begin{array}{l}\text { Three of the egrs just rea- } \\
\text { dy to enter the oriduct. }\end{array}$ \\
\hline$" 4$ & - & - & 1 & 2 & - & \\
\hline$"$ & $\begin{array}{l}1 \\
2\end{array}$ & 1 & 二 & - & - & \\
\hline 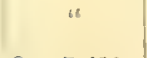 & 2 & & - & 1 & - & $\begin{array}{l}\text { Two of the efgs just ren- } \\
\text { dy to enter the oviduet. }\end{array}$ \\
\hline Oct. 7,756 & - & - & - & -1 & laid & $\begin{array}{l}\text { ['rouably not feeundated. } \\
\text { No enibryo visible. }\end{array}$ \\
\hline
\end{tabular}

O\%OTIECA ODOLITA.

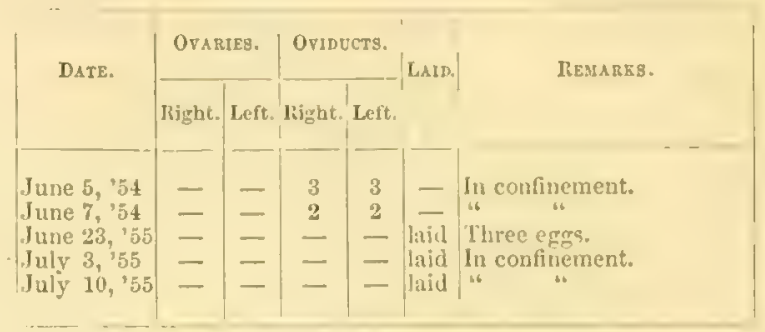

CHRYSEMYS PICTA.

\begin{tabular}{|c|c|c|c|c|c|c|}
\hline \multirow{2}{*}{ D.TE. } & \multicolumn{2}{|c|}{ OVARIES. } & \multicolumn{2}{|c|}{ Ovidects. } & \multirow{2}{*}{ LAID. } & \multirow{2}{*}{ RemaRes. } \\
\hline & Right. & Left. & hight. & Left. & & \\
\hline May $12, ' 54$ & 4 & 2 & - & - & - & In confinement. \\
\hline Mny 15,54 & 3 & 2 & - & - & - & $\because 4 \quad$ " \\
\hline May 16,54 & 2 & 3 & - & 一 & - & " \\
\hline May $20,5 t$ & 3 & 2 & - & - & - & 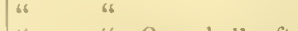 \\
\hline June 3,52 & - & - & $7 *$ & - & - & " " One, shell soft. \\
\hline June $11,{ }^{2} 55$ & - & - & - & - & Inid & In confinement. \\
\hline June $14, " 55$ & - & - & - & 一 & laid & "6 " \\
\hline June 16, '65 & - & - & - & - & lnid & 6 \\
\hline $\begin{array}{l}\text { June } 20, ' 55 \\
\text { June } 21,55\end{array}$ & $=$ & 二 & - & $\bar{z}$ & $\begin{array}{l}\text { laid } \\
\text { laid }\end{array}$ & 4 \\
\hline June 21,52 & $7 *$ & - & - & 二 & - & In confinement. \\
\hline June $25, ' 55$ & - & - & ? & - & - & Opened as saon as caught. \\
\hline
\end{tabular}

GRAPTEMYS LESUEULII.

\begin{tabular}{|c|c|c|c|c|}
\hline DiTF & Ovaries. & OvInects. & $16+00$ & KEYYRKS \\
\hline & Ikight.| Left. & Right. Left. & & . \\
\hline 1,56 & $-1-$ & - & laid & Natchez, Mliss. \\
\hline
\end{tabular}

PTYCHEMS CONCINAA (Foridana.)

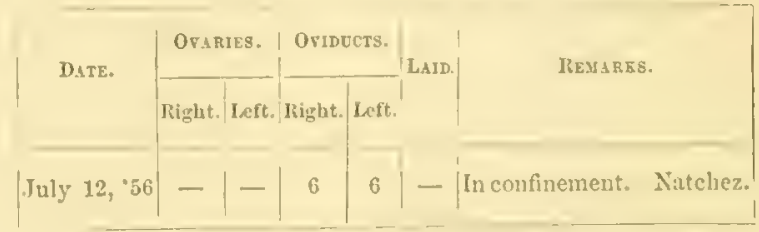

MALACOCLEMIIYS PALUSTIIS.

\begin{tabular}{|c|c|c|c|c|c|c|}
\hline \multirow{2}{*}{ Date. } & \multicolumn{2}{|c|}{ Orants. } & \multicolumn{2}{|c|}{ Orinects. } & \multirow{2}{*}{ Latr. } & \multirow{2}{*}{ REMARES. } \\
\hline & | Right. & Left. & Right. & Left. & & \\
\hline $\begin{array}{l}\text { July } 2,55 \\
\text { July } 3,95 \\
\text { July } 12,55\end{array}$ & E & E & $\overline{3}$ & $\overline{-}$ & $\begin{array}{l}\text { laid } \\
\text { lainl } \\
-\end{array}$ & $\begin{array}{l}\text { In confinement. } \\
\text { " } \\
4\end{array}$ \\
\hline
\end{tabular}


below among the foot notes, for the times of laying, which indicate also when the eggs were found in the oviducts and when in the ovary, it may be possible to form some idea of the difficulty which the solution of this problem presents, when we see, that, for instance, Cinosternum pennsylvanicum in one case had egrs in the oviduct by July 3, whilst in another they were still in the ovary as late as July 30 , and in still another of the latter date they were partly in the ovary and partly in the oviduct. Again: on the 21st of June, 1856, six specimens of Nanemyss guttata were opened, and all found to have already laid; whilst on the 25th of June, 1855, this same species had not finished depositing its egrss; thus showing nearly a week's variation, no inconsiderable amount of time when we reflect, that, with this species, the laying season lasts but a week. This observation loses much of its importance, however, from the fact that it relates to broods laid in two different years.

EMYS MELEAGRIS.

\begin{tabular}{|c|c|c|c|c|c|c|}
\hline \multirow{2}{*}{ DATE. } & \multicolumn{2}{|c|}{ OTARIEs. } & \multicolumn{2}{|c|}{ Ovidects. } & \multirow{2}{*}{ Lam. } & \multirow{2}{*}{ ReMarEs. } \\
\hline & Right & Left. & Right. & Left. & & \\
\hline $\begin{array}{l}\text { June } 30, ' 54 \\
\text { July } 17, ' 55\end{array}$ & $\overline{4}$ & $\overline{3}$ & $\underline{4}$ & 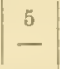 & - & $\begin{array}{l}\text { In confinement. } \\
\text { Next year's brood. }\end{array}$ \\
\hline
\end{tabular}

NANEMYS GUTTATA.

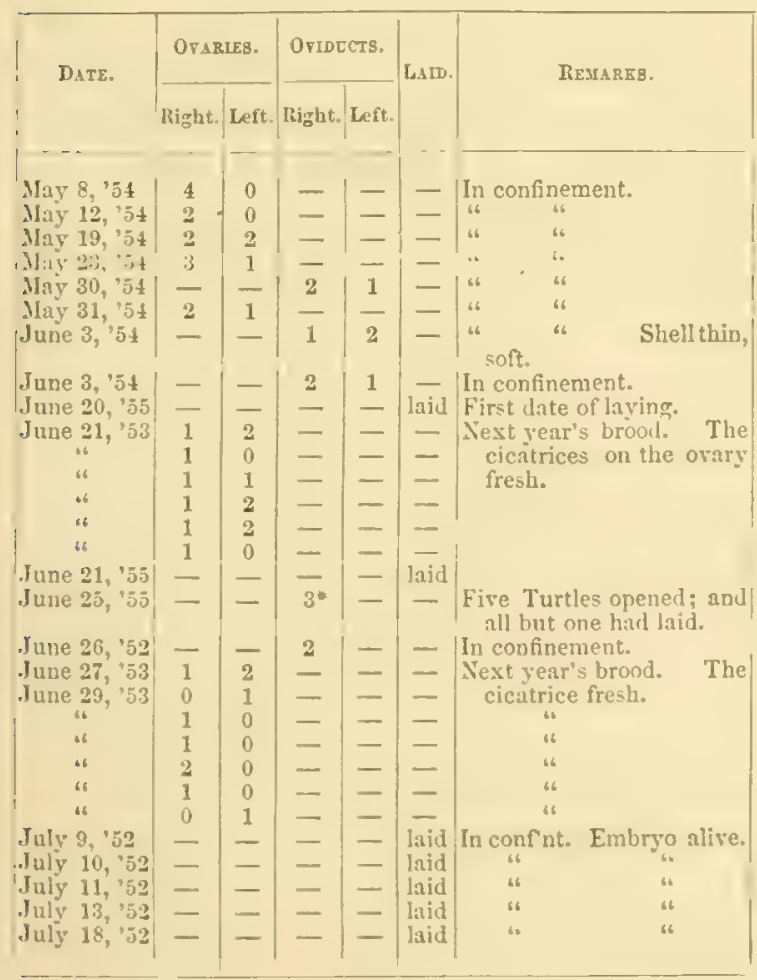

GLYPTEMYS INSCULPTA.

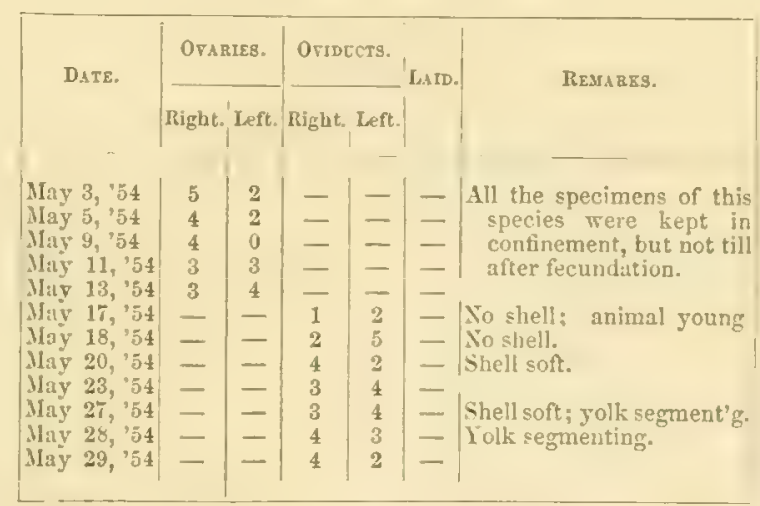

CisTudo VIRGINEA.

\begin{tabular}{|c|c|c|c|c|c|c|}
\hline \multirow{2}{*}{ DATE. } & \multicolumn{2}{|c|}{ Otaries. } & \multicolumn{2}{|c|}{ Onidect8. } & \multirow{2}{*}{ Lain. } & \multirow{2}{*}{ REsarEs. } \\
\hline & Right. & Left. & light. & Left. & & \\
\hline $\begin{array}{l}\text { June } 5, ' 54 \\
\text { June } 6, ' 54 \\
\text { June } 25, ' 55 \\
\text { June } 30, ' 54\end{array}$ & $\frac{-}{2}$ & $\frac{\overline{2}}{-}$ & $\frac{2}{6^{*}}$ & $\frac{3}{2}$ & $=$ & $\begin{array}{l}\text { Tiather soft shell. } \\
\text { In confinement. } \\
\text { Opened ss soon as caught. } \\
\text { In confinement. }\end{array}$ \\
\hline
\end{tabular}

IEROBATES CAROLINUS.

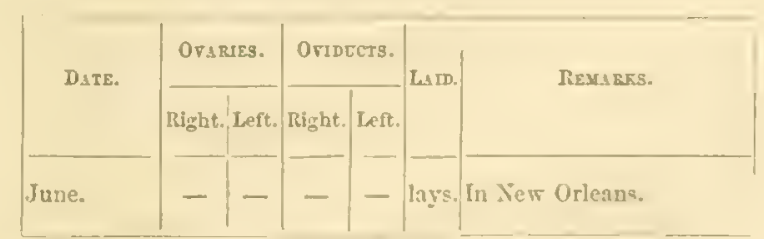

The * mark the eggs the position of which, on the right or left side, was not noticed. 
Now, unless one spends day after day and week after week in the fields in the neighborhood of the breeding grounds and catches each day a great number of 'Turtles of different species, in order to ascertain the presence of egrgs in the oviducts, (as may very readily and confidently be done by inserting the finger between the shield and the plastron, just in front of the hind legs, and then having marked them lets them go amain to remain free and in a natural and untrammelled state until they can be taken up again perhaps within the next few hours or the next day, it is utterly impossible to determine when the egrgs cnter the oviduct, and how long they remain in this organ. Although we have seen many 'lurtles laying their eggs in confinement in a large yard where they were kept well fed and furnished with plenty of water, which is very essential to some species, and although these eggs developed their embryos, still they were always retarded, both as to the time of their being laid, and to the advancement of the young itself. By reference to the tables, ${ }^{1}$ it will be seen that in two instances the egrss of Nanemys guttata and of Chelydra serpentina were retained in the oviduct nearly a whole month beyond the usual time of laying, in consequence of the confinement of these animals. The former having dug, as usually, a hole with its hind legs, at last dropped its progeny into the excavation, and covered the same so as to leave no trace of its operations; but the latter was opened, and found still retaining its brood.

As to the time of the day at which Turtles lay, there have been not more than three different species of so many distinct genera observed throughout the laying season; but, as a great many were seen always laying in the same part of the day, there can be no doubt that different species lay regularly at different times. Chrysemys picta and Nanemys guttata deposit their egrss in the evening, from six to half-past eight o'clock, and Chelydra serpentina in the moming, from four to twelve midday. Ozotheca odorata was seen laying but once, namely, at half-past eight in the evening.

In this comnection it will be most proper to give some account of the kind of nests which these animals make, and of their manner of proceeding in the for mation of the same. We have already alluded briefly to the laying of one species, (Nanemys guttata,) in confinement; but would say in addition, that this species, as well as Chrysemys picta, digs a perpendicular hole, whereas Chelydra serpentina excavates at first directly downwards and then laterally, so that the widest part of the hole, in which the eggs are deposited, is on one side of the external opening of the nest. Hence a stick thrust straight into the mouth of the nest would not touch the eggs, which are laid in the lateral dilatation of the 
excavation. The fuct, that these animals oftentimes dig several holes before selecting one for deposit, shows that they exercise a discrimination with regard to the fitness or unfitness of these several spots for the encouragement and rapid development of their young. When engaged in digrging or laying, notwithstanding their habitual shyness at other times, they seem utterly unconscious of any intruder, but proceed in their occupation till it is finished, and then, trampling down and smoothing over the errth, so that when dry the place of the nest may not be noticeable, leave the spot and disappear among their usual haunts.

\section{SECTION II.}

DEPOSITION OE THE ALBUMEN AND FORMATION OF THE SHELL.

Before proceeding to describe the successive deposition of the albumen and shell around the yolk, a few words in reference to the functions of the various regions of the organ in which these deposits take place, will not be inappropriate. At the time of breeding, the bloodvessels of the ovary are unusually full, as if gorged with blood; and the black pigment cells so much increased, that the fold of the mesentery, to which the ovary is suspended, appears blackish, and black streaks accompany and overlie each bloodvessel ${ }^{1}$ (Pl. 9b, fig. 9, 9a). Though numerous Turtles were opened from day to day, at the time when the eggs were passing from the ovary into the oviduct, (fig. 10, yet so rapidly does this process go on, that not only was it impossible to catch the egg dropping from the one and entering the other, but even to find a single egg in or near the anterior part of the lastnamed organ. In one instance, however, the Fallopian tube was found in a state of turgescence, immediately after fecundation, and the trumpet gaping, as if open to receive the eggs dropping from the ovary. In all cases where the eggs had entered the oviduet, (fig. 11, they were found in its lower part, some with shells, and others without this covering, and again a few with but little albumen around them. This we might almost have conjectured, had the thin, semitransparent nature of the pavilion and the immediate neighboring portion of the oviduct been considered from this point of view.

However, there need be no doubt now that at least one half, if not more, of the oviduct serves for just what its name indicates, merely to conduct the

1 It will be shown in another connection, that the formation of pigment cells precedes everywhere the appearance of bloodressels, and stands in direct relation to their formation. 
eggs from the embrace of the ovary to the last third of its own channel, there to be endowed with an albuminous and calcareous covering, and withal to assume the shape peculiar to each species. In reference to the shape of the eggs of rarious genera, it is important to mention that they vary greatly in form, and that their outline does not answer to the prevalent theory that their passage through the narrow chamel of the oviduct gives them their form, since we have those which are perfectly spherical, and yet sustain as great a lateral pressure from the embracing walls of the shell-forming conduit as those which are more or less oval. We need therefore adduce nothing more against this mechanical theory beyond the statement of such an obviously conflicting fact as the one just mentioned. We would, however, refer to the plastic power which gives to the embryo its typical form while it floats in the midst of a uniformly pressing fluid, in order to answer the question as to what renders some eggs almost cylindrical, others oval, and those of certain species more or less curved, approaching even to a kidney shape, whilst others are broadly oval, and finally, some perfectly spherical.

Since no eggrs were found in the oviduct before the shell membrane had already been deposited, at least partially, it might be presumed as a matter of course that the albumen also had already taken its place around the yolk. This supposition is negatived, however, by the occurrence of eggs, observed especially in one well marked instance in Glyptemys inseulpta, which formed a series of five in one oviduct, situated at the extreme posterior end of that organ, and close to one another, presenting just as many different grades of albumen and shell-lining deposit. The albumen was thicker and the shell lining more opaque for each successively more posterior egg, showing at a glance that not only the albumen, but the shell lining, was depositing at one and the same point of the oviduct; and moreover that the albumen, in order to reach its destined position, must filtrate through the meshes of the fibrous shell lining. There is no disputing this fact, which readily proves the normality of another single case which we have noticed, showing a still greater disparity between the amount of albumen, and the shell lining by which it was covered. 'The egg in question was found in company with another, in the right oviduct of the same animal; it was covered by a shell lining as thick and opaque as the most posterior of the left oviduct, but the albumen was not half deposited (Pl. 9b, fig. 4b); the more tenacious and denser portion, $(a)$ which clings so closely to the yolk sac $(y)$ when a young egg is broken open and the more external and nearly fluid portion drops away, was all that presented itself. Now under such circumstances, in order to allow the albumen to attain its destined bulk, the very elastic shell lining must stretch to a great extent; moreover the former probably solidifies as rapidly as it infil- 
trates, inasmuch as upon opening these egrgs nothing but a thin, hardly consistent, jelly-like albumen pressed its smooth surface against the closely embracing shell membrane.

From the foregoing facts, it is evident that the concentric layers of albumen are not deposited by direct apposition of the glandular wall of the oviduct upon the yolk sac; so that, whatever turns the egg may make in its passage along the channel of the latter, this glairy envelope is not impressed with such a spiral arrangement of its strata as constantly obtains in that of Birds; consequently there are no chalazx. Again: we may justly infer from this structure that there is no spiral motion of the egrg, in its descent from the inlet to the outlet of its conduit, otherwise a simple inversion of the egrg would not injure its contents, as experience has shown to be the case when inadvertently a Turtle was opened whilst laying upon its back, and the eggs were taken out in this abnormal position; ${ }^{1}$ whereas in the albumen of Birds the chalaza are formed early, and serve as axles, upon which the yolk sac swings and keeps its embryonic side uppermost, whilst the more exterior albumen revolves about it. Except to mention that the whole albumen is deposited before the calcareous deposition commences, we will defer any general remarks in reference to the shell until we come to describe its microscopic structure.

What we have just shown in regard to the albumen, the shell lining, and the shell deposit, leads very naturally to the question, What is the essential difference, between the mode of formation and the structure of these concentric layers, which renders them so distinct from each other, and how can they all be the product of one and the same portion of the same organ? The only reply we can make to the latter part of this question is, that it is just as possible for one organ, more or less complicated, to perform diverse functions, as that so simple a structure as an egg can produce, within itself, the multitude of functions which constitute the organic whole of an independent animal; but how this is done still remains among the mysteries inaccessible to our investigations. As regards the first part of the question, we will endeavor to answer it so far as our observations may guide us. We have already proved, by direct ocular demonstration, that the greater part, and, we would suggest, perhaps the whole, of the albumen is at times, if not always, deposited by infiltration through the already partially formed and synchronically developing shell-lining membrane. Now, notwithstanding this substance enters the confines of the lining membrane in a fluid state, yet it by no means continues in this condition, nor does it remain simply, as at the first glance it seems to be, a gelatinous, homogeneous bed, in which the yolk rests.

\footnotetext{
1 On that account, 'Turtles ought always to be opened from abore to cxamine the egross.
} 
The consistency of the fresh albumen of 'T'urtles' egrgs is much greater than in Birds; so much so that the shell and shell membrane may be stripped off; if removed before absorption is fur advanced and the yolk and surrounding glairy envelope remain unchanged, and may even be taken up in the hand without sustaining any injury. It is also a very easy matter to strip off several layers, one after the other, even down to within one or two strata, or sometimes to the very last, which lies close to the yolk, without disturbing the latter in the least; in fict, these innermost layers of albumen seem to have considerably more consistency than those exterior to them.

Upon making a transverse section of the thickness of the albumen, the edge of the cut presents the appearance of several concentric layers divided by dark lines; the distance of the latter from each other, and consequently the thickness of the former, varying according to the region of the mass to which they belong. If in a round egg, (Pl. 9b, fig. 6,) the strata $(a)$ are equal throughout; but in an oval one (Pl. 9b, fig. 3) they are thickest near the ends of the egg, $(\alpha$,$) and$ gradually thin toward the shorter axis, $(e$,$) at which point they attain to the$ minimum of thickness. Their number seems to vary according to the species; for instance, in Chrysemys picta there are six or seven, in Cinosternum pennsylvanicum about ten, and in Platypeltis ferox ten, etc. Further research is needed to ascertain how constant these numbers are in different species. Each stratum is composed of a clear, glairy albumen, in which minute, highly refiacting, granular bodies of a more or less oval shape are densely packed and arranged in lines (Pl. 9b, fig, 3a, 6a); and these lines, as they are successively nearer and nearer the borders of the layers, approach each other, so that finally contact ensues between them; and hence their combination produces the dark zones. It is at these dark zones that the layers of albumen separate when peeled off. Where the strata grow thin, in oval eggs, the lines of granular bodies are closer together, ( $\mathbf{P l}$. 9b, fig. 3a, 6a, ) throughout the thickness of the layer, than elsewhere. It is further remarkable, that in oval eggs the albumen may be pulled off in layers transverse to the long diameter more readily than otherwise. Perhaps this is owing to the uniformity of its density in that direction, whereas it constantly changes toward the projecting ends of the egrg.

When the albumen begins to be absorbed into the yolk sac, these strata are

1 The above statements may be most fully sustained by opening the exrs of Chelydra serpentina, Ozotheca odorata, Cinosternum pennsylvanicum, Nanemys guttata, Chrysenys picta, Glyptemys insculpta, and Cistudo virginea. We have not examined so closely our Western and Southern speeies in this re- spect, nor have we male any experiments respecting the temperature at which the allbumen of 'Turtles coagulates; but would take this opportunity to refer to the interesting paper of Messrs. Valenciemes and Fremy upon the physical and chemical properties of the 'Turtle's ecrg. Comptes-Rendus, 1854, rol. :38. 
resorbed at the upper side of the egg, not from within outwards, but, on the contrary, the most exterior ones first, and successively those more interior; each one, the moment it is perforated, by the loss of its substance at the point of resorption, shrinks away centrifugally, thus allowing the vitellus to rise gradually, till it finally touches the shell. In this condition, the strata appear as if cut across obliquely.

But let us return, and look a little more closely at the structure of this portion of the egg. Upon peeling off three or four strata, and viewing them perpendicularly to their surface, we instantly see that the dark lines mentioned above are the profiles of so many layers of oval granular bodies, and, more remarkable still, that the longer axis of all the oval bodies in one layer trend in the same direction (Pl. 9b, fig. 6b, a); whilst the longer axis of those in the next exterior or interior layer, although running parallel to each other, yet have a different direction from the last, running either at right angles, (fig. $6 b, b$, or at thirty degrees, or with more or less divergence, from them (fig. $6 \mathrm{~b}, c$ ). This peculiarity holds good throughout the whole mass of the albumen; but it is not limited to this part of the egg. Before going further, we would point out the slightly nodular character of some of the oval granular bodies, which appear as if they were composed of two or three smaller ones. These bodies are very minute, comparatively, in some species, as in Glyptemys insculpta, but yet exhibit in their linear arrangement the same relation to each other in the different layers, as obtains in other species where they are much larger.

Those layers of the shell membrane which lie innermost and in contact with the albumen, hardly have a tenacity superior to the inner strata of the latter. This will not seem surprising when the structure of the two is compared, for then we find that they are scarcely to be distinguished from each other. The only difference noticeable is, that the granular bodies of the shell membrane are more elongated, and that each granule seems to be composed of a greater number of smaller granules than obtains in those of the albumen (Pl. 9b, fig. 6c). As in the latter, so also in the shell membrane, the granules of the different layers run in diverse directions, but parallel in the same layer. The distance of these layers from each other is almost nothing, just as is the case among the closest layers of the albumen; but, as there, an excessively hyaline granular film of albuminous matter fills up the interspaces.

Proceeding a little further outward, the oval granules of each layer approximate each other, and lie in contact, end to end, thus forming beaded fibres (Pl. $9 \mathrm{~b}$, fig. 6d); those in one horizon crossing those of another at various angles, as heretolore. Interspersed among them are minuter particles of various sizes and excessive faintness, imbedded in the albuminous film, and evidently arranged in 
lines, thus giving the field of view a striated appearance. As seen with a magnifying power of five hundred diameters, it is impracticable to represent these minute strie with the pencil, except as the fitintest lines possible. It will be noticed that the granules of the nodular fibres are not so large as those of the more interior layers; but this diminution is not constant, as will soon be seen.

In some species the different layers are very distinct from each other, (PI. 9b, fig. 6e,) and keep their components so closely within themselves, that the passage from the one to the other seems almost an interval. This is particularly noticeable in Platypeltis ferox. Again, in others the irregularities of each layer fit into those of its neighbor; so that it is with difficulty that the respective boundaries of one or the other layer can be recognized.

As we advance outwardly, we do not find that the fibrous arrangement becomes regularly more and more apparent; but, on the contrary, here and there may be seen a layer, or rather two or three successive layers, composed of separate granular bodies, oftentimes much broader and coarser than the delicate fibres (Pl. 9b, fig. 6f, $\zeta$ ) of the strata which lie on both sides of them, and still displaying their tendency to trend in particular directions (Pl. 9b, fig. 6f, $a$ ) in their respective layers. It is a very easy matter to peel off these coatings one from the other, and view them separately; yet, where three or four are superposed, there may be sufficient light transmitted to study them as they are naturally related. Iowever, with these breaks in the continuity there occurs in pretty regular obliteration of the nodular appearance of the fibres, their components becoming gradually more and more intimately united to each other, as they are situated successively nearer and nearer to the outer surfice of the shell membrane, till finally each fibre has become uniform and apparently structureless throughout its length. The outermost of these layers, next to the hard calcareous deposit, are composed of the smoothest and most uniform fibres, (PI. 9a, fig. 45, and Pl. 9b, fig. 6 $\mathrm{g}_{9}$ ) resembling at times excessively elongated tabular crystals. Before the shell is deposited, these layers may be recognized by the peculiarly brilliant nacreous appearance which strikes the eye. In Glyptemys insculpta, where this has been noticed most frequently, the component fibres are of excessive tenuity and compactness among each other, the latter feature tending, no doubt, to heighten the polished aspect of the surface of the layer.

The edge of a section made through the whole thickness of the shell membrane (Pl. 9a, fig. 43, c, ll) appears more or less rough and dotted at intervals, where the ends of the fibres have been cut across at various obliquities; but between these the length of the threads may be recognized, and the layers distinguished, with more or less certainty, according to the species.

A few words are necessary in regard to the nature and origin of the gran- 
ular bodies, which, in the shell-membrane, become the components of the fibres Each granule has the appearance of being composed of three or four superposed concentric coatings, reminding one of the structure of starch granules. Now, what these apparent layers are has not been ascertained; but it does not seem possible that they should be the result of refraction, for that, as far as we know, would not produce more than one dark band, or a central dark spot, whilst here we perceive at least two bands within the outline and a central clondiness, so that we feel justified in saying that in all probability they are concentric concretions. But this needs further investigation.

The thickness of the shell membrane varies greatly: in some species it attains to a very great crassitude; while in others it amounts to hardly one third the extent of the first. Thus, in Thalassochelys Caouana (Pl. 7, fig. 30) it is more than one half thicker than in Chelydra serpentina, (PI. 7, fig. 24-26; PI. 9a, fic. $43, c, d$;) but with a quite thin and friable shell; whilst in Gypochelys Temminckii (Pl. 7, fig. 27) the shell membrane equals that of T. Caouana, but the shell is as thick as that of $\mathrm{C}$. serpentina, and rather more dense than the latter, the calcareous nodules being more closely packed together.

Chelydra serpentina (Pl. 7, fig. 24-26) has the next thickest membrane, (Pl. 9a, fig. $43, c, d$, ) being almost two thirds as thick as in Thalassochelys, and a shell $(a)$ equal to that of Gypochelys. Emys Meleagris (Pl. 7a, fig. 26, and 27) and Xerobates carolinus (Pl. 7, fig. 28, and 29) have a membrane of about the same thickness with C. serpentina; but the shell of E. Melengris equals that of C. serpentina, while that of Xerobates is more than one half thicker than in these two species, and far more dense and brittle.

Glyptemys insculpta (Pl. 7a, fig. 15-17) and Ptychemys concinna (Pl. 7a, fig. 20-23) also have shell membranes as thick as the last; but the shell of Ptychemys is two thirds as thick as in Chelydra. Graptemys geographica, (Pl. Ta, fig. 28-30,) Nanemys guttata, (Pl. Ta, fig. 7-10,) and Cistudo virginea, (Pl. 7, fig. 10-14,) have shell membranes hardly as thick as in Chelydra, and the shell half that of the latter.

Cinosternum pennsylvanicum (Pl. T, fig. 1-6) has a shell membrane two thirds as thick as in Chelydra; its shell, however, nearly equals, in this respect, that of Xerobates carolinus, but is more dense and brittle than the latter.

Chrysemys picta (Pl. 7a, fig. 1-3) has a shell membrane and a shell equal to one another, as regards thickness; and both together only equal the shell membrane of Chelydra. The shell membrane of the egg of Platypeltis ferox ( $\mathrm{Pl}$. 7 . fig. 2) is about equal to that of Chrysemys; but its shell is much thicker, about one sixth thicker than that of Chelydra.

The shell membrane of our Ozotheca odorata (Pl. 7, fig. 7-9) is much the thin- 
nest of all known to us, being about one half as thick as that of its congener Cinosternum; and yet its shell is slightly thicker than that of Chelydra.

The annexed table will give a graphic view of the relative thickness of the shell and shell membrane of the different genera of 'lurtles. The line which runs between the columns, marked "shell" and "shell membrane," indicates the junction of the two. The length of the straight lines on the left shows the thickness of the shell membrane magnified to five hundred times its diameter; and the straight lines on the right, the thickness of shell under the same amplification.

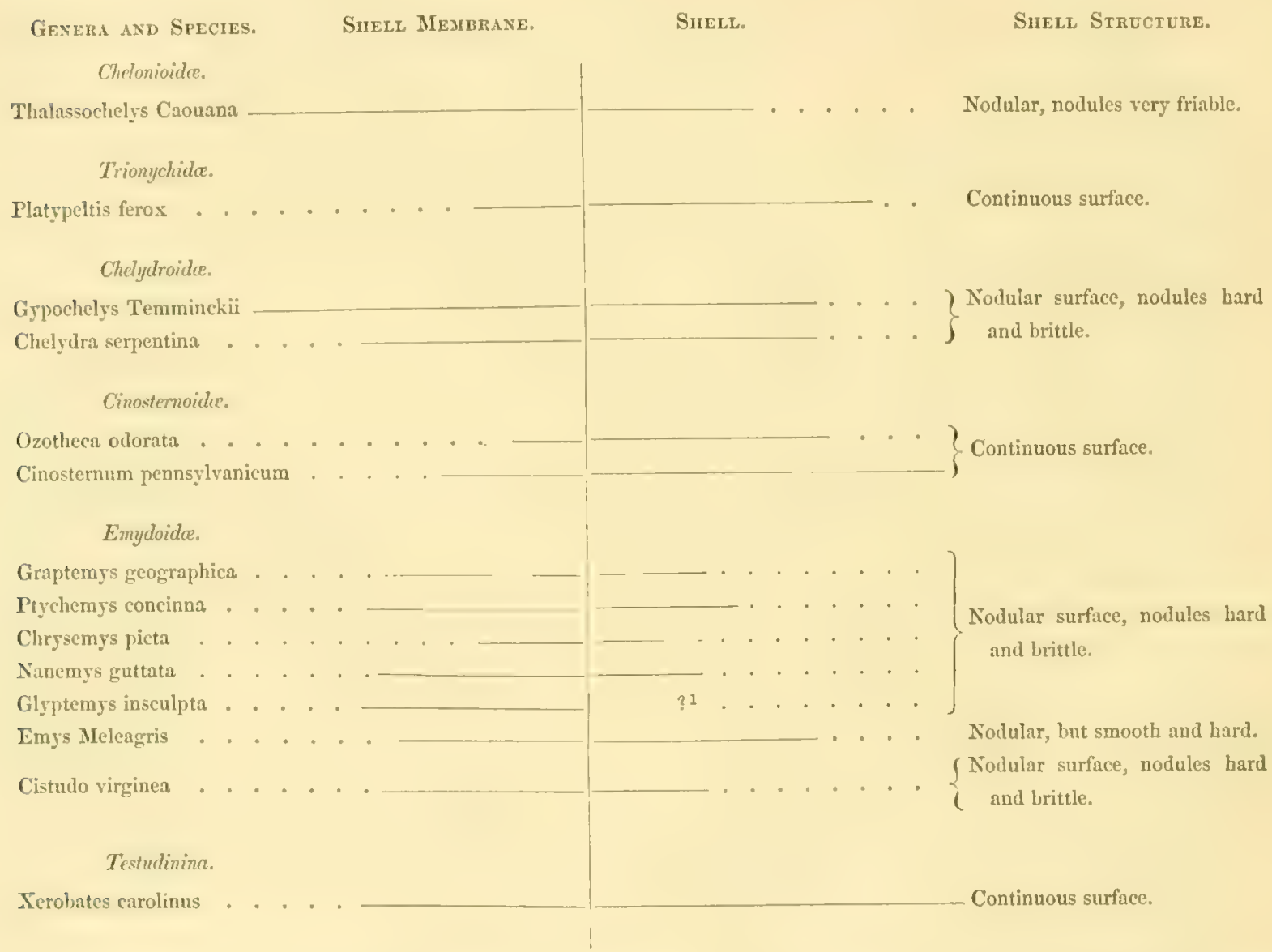

The Shell. As we have already indicated the thickness of the egg shell, when speaking of that of the shell membrane, we will at once pass on to describe the mode of development and the structure of this, the most superficial of the different layers surrounding the egg.

By dissolving the carbonate of lime of the shell with nitric acid, ${ }^{2}$ the basis of

1 The eggs had not yet matured their shell.

2 Nitric acid decomposes the carbonate of lime very rapidly till it becomes saturated, and, upon erap- oration, deposits groups of crystals, (Pl. 18, fig. 11, ) which exlibit the characteristic, long, tabular, rhombohedral forms of nitrate of lime (fig. 11a, 11b, a, b). 
this solid deposit is found to be composed of a fibrous substance similar to, and no doubt identical with, that of the shell membrane, but of a much more tender and less dense consistency, (Pl. 9a, fig. 43c) varying according to the species to which the egg belongs. Thus, in Chelydra serpentina it equals about one third the thickness of each shelly nodule (fig. $43, a$ ) of which it formed the basis; in Platypeltis ferox it bears about the same proportion; but in Cinosternum pennsylvanicum it dwindles down to almost one sixth that of its shell, and is much more tender and transparent than in the two above-mentioned species, indicating that there is far less organic substance for the calcareous deposit in this Turtle than in the others.

In these three species, radiating lines spread out, from the centre of the base of the nodule (fig. $43 \mathrm{c}, b$ ) toward the surfice $a$, just as in the calcareous state (fig. $43, a, b)$; no doubt impressed upon it by the columnar arrangement of the crystals of carbonate of lime, which trend in this same direction, as will be seen presently. In those shells where the structure is evidently nodular, as in Chelydra, (Pl. 9a, fig. 42, 43, $a_{2}$ ) the basis, deprived of its lime, still simulates its former shape, $(43 \mathrm{c}$,) although, as we have said, on a reduced scale; but where the surface of the shell is smooth and uniform, as in Cinosternum and Platypeltis, its basis, when treated as above, is continuous all over the egg as a wavy stratum, each wave corresponding to a group of crystals of carbonate of lime.

On examining an egrg of Chelydra in which the shell is still soft and but very little lime has been deposited, we find that the surface of the shell membrane is striated by lines rumning parallel to the axis of the oviduct, and that these lines are composed of rows of nodules, (Pl. 9a, fig. 44,) which, upon closer inspection, are found to present the characteristic forms in which the crystals of carbonate of lime group themselves (fig. 44a). Every little nodule, viewed from the outside, appears striated concentrically and radiatingly, ench ring between two successive concentric strix representing a stratum of crystals, the sides of which are indicated by the radiating lines. The centres of crystallization vary in their distances from each other: in some instances they are very close together, so that the increasing nodules soon press against their neighbors, forming a straight line of contact; in other cases, where they are further apart, they retain their globular form much longer. Those which are formed early secm to be flattened against each other more thin those formed later, which fill up the spaces between the original series. The earliest indications of these nodules are little, clear, homogreneous, globular masses, seattered here and there, which, as they increase in size, begin to show fiint, radiating, and concentric strix. These strix soon develop themselves strongly, so as to be seen without difficulty, as in the nodules which we have described as armenged in lines. In fully perfected nodules this striation is quite strong and 
sharp, (Pl. 9a, fig. 43a, when seen from the same point of view; and in this case the outline of each nodule is serrated irregularly by the projecting ends of the crystals.

When a section is made through the thickness of a nodule, its centre, at the base, (Pl. 9a, fig. 43, b, ) is seen to be the point from which all the radiating lines proceed to the surface, and the concentric lines, in the view from above, (fig. 43a, ) both at this age and also in the young nodules, (Pl. 9a, fig. 44a,) appear arehed, showing that the lime crystals are arranged as if around a sphere, the centre of which coincides with the starting point ( $\mathrm{Pl}$. 9a, fig. 43, b) of the radiating lines, and that these radiating lines (fig. 43, a, b, 43b) are the long sides of the prismatic calcareous crystals.

It will readily be seen, here, how air and moisture may gain access to the interior of the egg, when we consider that the nodules (PI. 9a, fig. 42, 43, a, $a^{1}$ ) are not soldered to each other laterally. In the case of hard, brittle, and smooth shells, however, such as those of Xerobates, Platypeltis, Cinosternum, and Ozotheca, (in which the groups of crystals become interlocked with each other by the dovetailing of their ends at the basal and younger portions of the nodules, and the later developed and more exterior parts of these nodules so confuse the terminations of their adjoining crystals as to disguise their line of junction, and thus form a continuous stratum from one of the nodules to the other, like a universal bridge over the whole egg;) open spaces must be left in the lime deposit, in order that this may obtain, and we actually find it to be the case. In some species these spaces are quite numerous, as in Ozotheca (Pl. 9a, fig. 46); but in others they are more rare, for instance, in Platypeltis and Xerobates.

From the remarks annexed to the table which we have given, (p. 508,) it will be seen, that, within each family of 'Turtles, the peculiarities of the egg shell are the same throughout. Thus, in the Chelonioidx it is nodular, and each nodule widely separate from its neighbors, and very ragged and friable; in Trionychida it has a continuous smooth surface bounding a uniform, dense, brittle stratum, which equals about one third the thickness of the nodules beneath; in Chelydroida it is nodular, (Pl. 9a, fig. 42, 43, 43a, ) and each nodule is smooth, hard, and brittle, and separable from its neighbor, although at the time of their formation they may sometimes be in contact with each other; in Cinostemoide its continuous surface is wavy or pitted, terminating a uniform stratum, just like that of 'Trionychidie, excepting that here it is about twice as thick, and fully two thirds the depth of the nodular part beneath; in Emydoida it is nodular, the nodules being similar in structure to those of the Chelydroida, but more closely wited to each other, especially in Emys Meleagris, (which by the way belongs to a distinct sub-family of Emydoida, where they are very closely set togrether, so that the shell is quite smooth 
and hard; and, finally, in Testudinina it has a continuous, smooth, wary surface, underlaid by a uniform stratum, as in Trionychide and Cinosternoidx, and similar in structure and hardness with these, but much less in thickness, and only equalling one fifth the thickness of the nodules below.

\section{SECTION III.}

THE ABSORITION OF ALBUMEN TNTO THE YOLK SAC.

In the last section, we have described the mode of origin and deposition, and the structure of the albumen of the Turtle's egg. In this section, we propose to show what becomes of that albumen, and what comnection it has with the yolk mass, around which it is originally deposited. ${ }^{1}$

The youngest and least advanced egg which we have observed, after the last fecundation, was one of Glyptemys insculpta, with an oval shell and a full complement of albumen, in which segmentation had just begun (Pl. 10, fig, 1, 1a). In this instance the yolk mass had already lost the globular form which it possessed in the ovary, and assumed an oval shape. This oval figure would not, at the first glance, intimate that there was any connection between the yolk and the albumen which surrounds it; when, however, we observe besides, that not only the shape of the yolk mass is changed, but its size also is increased, we very naturally infer that this augmentation in bulk is due to the introduction of some substance from without mixing with the yolk, and, as the albumen includes the yolk, that this is the substance in question. Whether the albumen, in this case, was absorbed as soon'as it began to be deposited around the yolk, or not till its deposition had gone on for some time or had even been completed, it is not possible to say definitely; but inasmuch as in the case of a much older egg, (Pl. 9b, fig. 4b,) in which segmentation in the region of the embryonic area was already completed and the embryonic disc well defined; $(e$,$) the yolk sac$ was plainly oval, $(y$,$) and larger than when it left the ovary, whilst the albumen$ was as yet only partially deposited in a thin layer, $(\alpha)$ and no shell was present,

1 Before proceeding to the consideration of this subject, the reader may with alvantage take a retrospective glance at the carlier stages of growth of the oratian egrs, and to that effect compare the diagram of the ergr represented 1'1.9c, fig. 1 with that of fig. 2 upon the sime plate, and also that of I'l. 9d, fig. 3 .
2 This instance shows that the oral shape of the yolk mass is not derived from the impression of the shell acting as a mould upon its contents, since no shell was as yet present; but arises no doubt from the tendencies inherent in the life of the emer and its development. 
we infer that the earliest layers of albumen were at once liquefied and drawn within the yolk sac. This view of the case seems to be warranted by the fact, that the layers of albumen still outside of the yolk sac, are, to all appearances, undisturbed and perfectly symmetrical all around the egg, even after the yolk sac has assumed an oval form. No further alteration of the yolk mass connected with the absorption of albumen was noticed in much older eggs of this species, (Pl. 10, fig. 11a, 11b, up to the time when the embryonic area became a distinct dise (fig. 15a).

The mode of absorption of the albumen mentioned above, and the consequent change in the shape of the yolk sac, have been observed in the oval eggs of several other genera of the family of Emydoidx, namely, in Nanemys guttata, (Pl. 9b, fig. 1a,) Chrysemys picta, and Cistudo virginea (which had the same aspect as $\mathrm{Pl}$. 10, fig. 15a). In these the embryonic area was already a distinct disc, (Pl. 10, fig. 12, 13, 14, and the albumen and shell were complete.

The yolk of the oval eggs of at least two other genera (Ozotheca and Cinosternum) belonging to another family, the Cinosternoida, does not assume an oval form so early as in the Emydoidx. It does not appear even that the albumen mixes at all with the yolk in the beginning, as is the case in the eggs of Emydoida. At least, in all the younger eggs of the family of Cinosternoida which had already a shell, the albumen was arranged in perfect symmetry around the yolk mass; and the latter was perfectly globular, and to all appearances not larger than when it left the ovary (Pl. 9d, fig. 4). In the eggs of the Testudinina, Trionychidx, Chelydroidx, and Chelonioida, which have a globular shell and a globular albuminous deposit, neither an oval form nor an increase in the size of the yolk mass has been observed as long as the yolk remained homogeneous. In fact, the earliest period at which we have known the albumen to enter the yolk sac of the egrgs of the families just mentioned was when the cephalic hood had already began to form (Pl. 11, fig. 1, 1a; Pl. 9b, fig. 5, 7, 7a); and then the albumen bore a very different relation to the yolk mass from that in the cases pointed out before, as will presently be shown.

Notwithstanding the infiltration of a small portion of albumen in some of them, the eggs of all 'Testudinata, whether their shell be oval or round, retain a homogeneous aspect till the cmbryonic disc has assumed a sharply defined outline (Pl. 9b, fig. 1a, e, 4b, e; Pl. 10, fig. 12, 13, 14, 15, 15a). But it is a significant fact, that, at this period, the oval egr shell of the fimily of Emydoidse should contain an enlarged oval yolk mass, whilst the oval egg shell of the funily of Cinosternoida contains a yolk mass which is perfectly globular, and not larger than when in the ovary.

We have already mentioned, that all eggs with globular shells retain, until 
the embryonic disc is sharply defined, not only the same homogeneity, but also the same size, that obtained when they were in the ovary. We would recall this fict again, in order to allude more directly to the similarity in the conduct of the yolk mass in the oval eggs of Cinosternoidse with that of the families which lave globular eggrs.

Immediately after the embryonic dise has become sharply defined, we perceive a remarkable change in that portion of the yolk mass which lies just below the embryonic area (Pl. 9b, fig. 1, $a^{1}, 4, a^{1}, 4 a, a^{1}, 5, a^{1} ;$ Pl. 11, fig. 1a). At this spot, a small quantity of clear fluid makes its appearance. Below, it rests on the great mass of yolk, $\left(y_{9}\right)$ and above, presses against the under-side of the embryonic disc $(e)$ and its continuation, the germinal layer. Seen from above, the space which this fluid occupies appears dark, unless light is admitted through the side of the egg; but in profile it is as clear as glass. This, however, is not seen very readily, unless the slightly opaque germinal layer that surrounds the whole egg is broken through. The embryonic disc is also rendered more distinct and conspicuous by the presence of this dark background. At the same time, a slight enlargement of the yolk sac is noticeable. From these facts, we at once infer that the clear fluid under the embryonic dise does not arise from a liquefaction of a portion of the yolk mass, but that it is introduced from without, and is the cause of the increase in the size of the yolk sac. We are confirmed in this belief when we look at that portion of the albumen which overlies the embryonic area, ${ }^{1}$ and there find that a more or less circular portion

1 The manner in which the allumen is absorbed into the yolk sac in the eggrs of Birds seems not to have been observed with sufficient care. This process is very peculiar, and stands in direct relation to the embryonic area, and to the increase of the yolk sac. Nothing is easier than to ascertain the precise amount of albumen that is absorbed into the yolk at successive periods of incubation, and the clanges of form which the yolk sac undergoes in consequence of this absorption. It is only necessary to boil the eggs slowly, when the albumen discloses at once the changes it has undergone. Its absorption is at first distinctly circumscribed to the area abore the embryonic dise; and the limits within which it takes place are so sharply defined, that, when the albumen is lardened by heat, there may be seen, above the growing germ, a hollow, truneated cone, (PI. 9d, fig. 5 , ) the broad base of which is turned towards the shell, while its truncated apex, turned towards the yolk, corresponds in widtl to the diameter of the embryonic disc. As the embryo increases, the cone appears gradually flatter and flatter and more truncated, until the broad embryonic dise occupies the whole space in the upper part of the egg immediately below the shell membrane. The changes which the form of the yolk sac successirely undergoes are not less characteristic: at first spherical, it is gradually more and more flattened within the limits of the embryonic area, until, by the time the area equals the diameter of the yolk sac, it is rery nearly hemispherical, the Hattened side being only slightly raised in the centre. I intend to publish, on another occasion, a series of drawings representing these interesting changes, as observed in hens' egges meanwhile I would seriously eall attention to these facts, as they show clearly that the changes which the albu- 
in the outermost layers of this glairy substance has disappeared, and that the layers thus aflected have shrunk toward the opposite side of the egg ( $\mathrm{Pl}$. 9b, fig. $3, a, 4, a, 5, a, 7, a)$. In this way the more interior layers of albumen become pressed against the shell, and the enlarging yolk sac on that side follows in their wake. In oval eggs, this absorption usually takes place at the side, midway between the two ends. Sometimes, however, when the egg is laid so as to rest in the nest with one end uppermost, the yolk mass shifts also, and the more buoyant portion, where the embryonic dise originates, faces toward the higher end of the shell; and here, too, the absorption of albumen first finishes: always above the embryonic disc, wherever it may be. In consequence of these changes, the centre of the yolk mass has not remained concentric to the outline of the shell, whether it be oval or spherical, and the layers of albumen appear proportionably much thicker on the under-side of the egg. It is very important to know that the absorption of albumen, and its infiltration into the region below the embryonic disc, commence in the oviduct, and not after the egg is laid; as we are thus enabled to determine at what part of an oval egg the albumen normally first enters the yolk sac.

Upon carefully opening a Turtle from above without disturbing the oviduct, it is possible to ascertain the exact position of every egg within the animal, and its relation to a horizontal plane. The embryonic disc, (that part of the egg which corresponds to the region of the cerebro-spinal axis, is always next to the back of the animal. It is not, however, at all times situated at the highest point of the egg, nor as near as possible to the back of the Turtle, but may be found now and then down toward the side of the egrg (Pl. 11, fig. 4a). The longer axis of oval egrs is usually horizontal, and the shorter axis perpendicular; so that, consequently, the longer curve of the shell is horizontal also, within the animal, excepting, perhaps, occasionally a slight elevation at one end, when the egg happens to be in a part of the oviduct which bends rather suddenly upon itself. Now if, within the oviduct, the embryonic area is always situated next to the back of the animal, it rests, of course, midway between the two ends of the oval egrg, next to its longer curve, at what would naturally be called its side (Pl. 9b, fig. 1, 2, 2a, 3, 4, 4a). 'This, doubtless, is its normal position. The absorption of albumen normally commences above this point, as may readily be seen by opening Turtles just before the laying season. Therefore it is abnor-

men undergoes are intimately associated with corresponding clanges in the embryonic disc and in the yolk sac, and do not take place in a manner to favor the idea that the albumen is merely a mass of nutri- tive substance accumulated around the yolk. On the contrary, these chamges prove that the albumen is organically connected with the yolk, and performs a regrular function in the growth of the embryo. 
mal, that the absorption of albumen should change from the place where it began and go on afterwards near the end of the shell, as is the case when the egrrs were laid obliquely in the nest, as we have mentioned above. However, in this latter instance, the development of the embryo does not appear to be hindered. From these facts, we can very readily see that the longer curve of the oval egg corresponds, in a general way, to the sides of the globular egg, which run parallel with the longer axis of the animal.

The absorption goes on encroaching successively upon the more inner layers of albumen, till all have been pierced in the part which lies above the embryonic disc, and the much enlarged yolk sac touches the shell. There is a considerable degree of regularity in regard to the rapidity with which the albumen is resorbed. At the time it begins to infiltrate into the yolk sac and to occupy a space below the embryonic dise, the cephalic hood has just begun to form (PI. 11, fig. 1, 1a; Pl. 9b, fig. 1, 4, 4a, 5, 7, 7a). Sometimes, however, the cephalic hood does not appear till the yolk sac is almost one third filled with albumen (Pl. 9b, fig. 2, 2a). In the oval eggs of Cinosternoidx, so far as we have observert, the yolk sac becomes half full of albumen before the sac itself loses its globular shape, or the cephalic hood begins to form, or any change comes over the embryonic dise (Pl. 9a, fig. 41, 41a). Soon after this, however, the yolk sac (Pl. 9b, fig. 3, $y$ ) elongates slightly towards the ends of the egg, and becomes broadly oval as the albumen $\left(a^{1}\right)$ continues to be absorbed. When the yolk sac is one third filled, (Pl. 11, fig. 3a, ) the cephalic and caudal hoods are quite deep, and the primitive furrow has just appeared (Pl. 11, fig. 3, b) at the cephalic end of the embryo. Sometimes the primitive furrow has not appeared, (Pl. 11, fig. 4, ) even when the yolk sac is nearly half full of albumen (Pl. 11, fig. 4a). By the time all the layers of albumen have been pierced (Pl. 9c, fig. 2) by the absorption of their substance, and the yolk sac has become more than half filled with albuminous fluid, and its upper side touches the shell, (Pl. 11, fig. 5l, 5c,) the head of the embryo is much bent upon itself, (Pl. 9e, fig. 4, ) and the primitive furrow ( $\mathrm{Pl} .11$, fig. 5, b, 5a, b) extends along more than one half the length of the cerebro-spinal axis. Judging from the large amount of clear fluid alrearly within the yolk sac, a portion of the yolk must have become liquefied, since the infiltrated albumen alone could not take up so much room.

'There remains considerable albumen to be resorbed after this period. Ifter rising so high as to touch the shell, the yolk sac has nothing further to absorb directly from above, and therefore the remainder of the albumen must enter at the side and below. This goes on till, by the time the process is finished, the shell is filled by the distended yolk sac. At what time all the albumen becomes infiltrated into the yolk sac we camnot say definitely, since we have not triced 
the progress of this process to its completion. 'The egg of Chelydra serpentina is that in which we have followed most carefully the successive steps of the absorption of albumen, up to the period when the yolk sac is more than laalf full of clear fluid. At this last-mentioned stage of the resorption of albumen, the egg had been laid about three days and six hours. In an egg of Ozotheca odorata a week old, the albumen was all within the yolk sac. This also obtained in eggs of Thalassochelys Caouana of the same age (Pl. 9b, fig. 8).

In both these cases, however, the embryo was not so far advanced in development as at the last stage to which we have traced this process in the egg of Chelydra serpentina. After the yolk sac is filled, the yellow part of the yolk mass continues to lessen in size, and the space above it, containing the clear fluid and the cerebro-spinal part of the embryo, to increase in magnitude, until the period when the 'Turtle leaves the shell. The older the egg, the more distended does the shell appear, so that, when a mere pinhole is opened in it, a portion of the contents protrude through the aperture. This becomes very troublesome when investigating those eggrs which have a flexible and elastic shell, like that of Chelydra; for, in such cases, the moment an opening is made, the confined fluid tears open the embryonic envelopes ${ }^{1}$ and rushes out in a forcible jet, causing the embryo to assume an unnatural position.

\section{SECTION I V.}

THE TRANSFORMATIONS OF THE YOLK IN THE FECUNDATED EGG.

In the preceding chapter ${ }^{2}$ we have described the mode of formation of the yolk, and its successive changes prior to the last copulation. We have now to consider the changes which it undergoes after this period.

The yolk cells continue to grow, in certain respects, after the egg has entered the oviduct. There is, at this stage, something unprecedented in the unceasing enlargement of the mesoblast, until it finally so fills the ectoblast that the wall (Pl. 9a, fig. 33b) of the latter is hardly to be distinguished from the encroaching surface of the former. 'T'o an umprepared eye, especially if one had not seen the intermediate steps, (Pl. 9, fig. 11f, 11g; Pl. 9a, fig. 2d, 33a, 33b,) the mesoblast would appear destitute of any wall beyond its own (fig. 39a-39e); but

1 This tearing of the ear membranes may be prevented by making a hole in the lower side of the egr and letting out a portion of the yolk, especially in instances when it is not desirable to keep the latter intact for further investigation.

${ }^{2}$ See p. 158-175. 
there cannot be the least doubt that the faint, thin line (Pl. 9a, fig. 33b) which presses closely upon the dark contour of the mesoblast is the wall of the ectoblast; for, even were it not possible to follow with the greatest ease the gradual diminution of distance between the two approaching surfaces until contact ensues, the action of water, which bursts and peels off the outer membrane, would alone serve to prove its existence.

This filling of the ectoblast by the mesoblast is not a feature peculiar to fecundated eggs found in the oviduct, although it belongs in a great measure to that condition of the ovum; for its beginning has been noticed (Pl. 9a, fig. 33a, 33b) in one egg, taken from the oviduct of a female known to have been kept from the male during a whole year. But, just as segmentation of the yolk proceeds to a certain extent in the unfecundated eggs of some animals, so here the filling of the ectoblastic cell may occur as a phase continued up to a limited amount of the yolk; beyond which, however, the stimulus of fecundation is necessary, in order that the process may go on throughout the whole vitelline mass.

But there is a further change, in the nature of the yolk cells, which belongs exclusively to the eggrs found in the oviduct; and that is the sudden multiplication of the number of the entoblasts, (PI. 9a, fig. 1, 2a, a, b, c, 39d, 39e, amounting, in some cases, to hundreds in each mesoblast, and, in most instances, still preserving their rounded form. From what we have sometimes seen in fecundated eggs where more than half the yolk cells were totally destitute of entoblasts and the remainder for the most part faintly entoblasted, as if these waxy masses were deliquescing, we have good reason to believe that this last feature in the life of the entoblast is brought about by a total renascence of entoblasts, after the plan of their first appearance in young ovarian eggs, and not by any subdivision of each crystalloid body into several smaller ones. That this novel conduct of these bodies is intimately connected with the genesis of the embryo there is abundant proof in the fact of its simultaneousness with another still more remarkable and most important phenomenon, hitherto unsuspected as playing a part in the life of the yolk cell of any animal, namely, a self-division of the mesoblast.

IIow long before the segmentation of the yolk this process commences has not been established; but certainly it may take place without the last fecundation, since it was observed in eggs that had not been permeated by this quickening influence within a year $(\mathrm{Pl} .9 \mathrm{a}$, fig. 33). This may readily be proved by confining the females apart from the males during the breeding season, and opening the eggs just as they enter the oviduct, when it may be seen that subdivision of the mesoblast has proceeded to a certain extent without the help of any recent stimulus. In such eggs, this self-division of the mesoblast was noticed and recorded as the earliest observed occurrence of this peculiar phenomenon. This is enough 
to establish its independence of fecundation within a year. But, since the selfdivision of the mesoblast was not remarked as occurring in eggrs just about to drop from the ovary into the pavilion of the oviduct, it must be considered, without doubt, as an intra-uterine phase, commencing before the completion or even before the first appearance of the shell, since the latter was still quite soft and thin in a fecundated egg in which the segmentation of the yolk had but just separated a small area of the surface of the yolk into eight portions, and since it was altogether absent in several eggs whose embryonic disc was well marked.

Moreover, from what we have seen in the yolk of the thin shelled egg just mentioned, and considering also that the segmentation of the yolk was not far advanced, it may be safely inferred that the self-division of the mesoblast begins before the other process. Judging from the heaps of already minute and numerous mesoblasts (Pl. 9a, fig. 35) in the segmenting mass, at the period when segmentation begins, (while but a single mesoblast existed before in each ectoblast, ) and also from their presence all over the superficies (fig. 35a) of the eggr, (their parent envelope, the ectoblast, having disappeared in both cases, we may further say, that the self-division of the mesoblast is in fact a forerumner of the segmentation of the yolk, wherever this occurs, whether it be at the blastoderm, or over the whole surface of the yolk mass, as we shall presently attempt to show.

As we have already mentioned, the earliest period, at which self-division of the mesoblast has been ubserved in an egrg fully fecundated, belongs to that age when the embryonic area is divided into but eight parts, (Pl. 10, fig. 1, 2, 3, ) and heaps of numerous mesoblasts exist, (Pl. 9a, fig. 35a,) which, we can safely affirm, - although we ascertained that in this instance they had lost their parent cell, while its presence (fig. 34, b) around those belonging to a little older cmbryonic disc (Pl. 11, fig. 3) and to that portion of the germinal layer exterior to this was satisfactorily made out, - had evidently originated from a frequent repetition of that same process which at first, in the more internal portion of the yolk mass, simply doubled (Pl. 9a, fig. 33, 36-36c, 37-37d) the single mesoblastic bodies, as exhibited in the figures here referred to. In such instances, the wall of the ectoblast, which in the case of undivided mesoblasts is very obseure, (Pl. 9a, fig. 33a, 39a, 39b, 39d, 39e, was rendered very conspicuous, as it bridged over the constricted portion; but again became more or less indistinct where the mesoblastic masses had inultiplied considerably, as may readily be seen in eggs scarcely older than this (Pl.9a, fig. 7, 9,, 38 , a, 38a, 38b, a, 38c). These last egges presented abundant materials for the investigation of the self-division of the mesoblast, from its begimning, through all degrees of multiplication, until the mesoblasts have become very numerous. We will, however, refer at the same time to figures illustrating this subject in younger, and in some much older, stages of growth. 
At first the mesoblast constricts gently, so as to leave a broad sinus between the separating portions, (PI. 9a, fig. 37, 40,) then a little later its constriction becomes narrower as it grows deeper, (fig. 40a, 40b, 40c, 40d,) till finally it divides into two (Pl. 9a, fig. 36-36c, 37a-37d, 38, 40e, 40f, 40g); then each of these again doubles itself. Sometimes the one division begins before the other, so that there is a triple mesoblast (fig. 40h, 40i); or, in the case of the next phase, one of four doubles previous to the others, (fig. $38 \mathrm{~b}, 40 \mathrm{j}$ ) thus producing a quintuple mesoblast; and so on, again and again, almost to infinity, we might say, when we consider the innumerable quantity of these bodies (Pl. 9a, fig. 9, $a, b)$ in each ectoblast, at the time they have just entered the boundaries of the embryonic disc and become part and parcel of the embryo. In this connection we may express the opinion, that it is very probable that the entoblast also segments, since in some instances (Pl. 9a, fig. 40d, c) it is so large as to make it almost impossible that it should enter entire into either of the two portions of a duplicated mesoblast. In several other cases the entoblast has been observed in the same position (fig. 40, $40 \mathrm{a}, c, 40 \mathrm{c}, c)$ as in the former, directly in the line of the approaching constriction; but in these cells it might, considering its size, be forced into either segment by the narrowing strangulation.

We have good reason to believe, that the phenomenon of self-division of the mesoblast obtains throughout the period of incubation of the animal; at least, it was observed in an egg two months old, (Pl. 9a, fig. 40-40b,) which is half the time required to develop the Turtle; and, on the day the animal left the shell, the still pendent yolk sac contained cells of the largest size, having each but a single undivided mesoblast (Pl. 18, fig. 4a); so that, at best, it cannot be said that the self-division of the mesoblast had pervaded the whole yolk at the time of hatching. Again: this process does not go on uniformly throughout the yolk at one time, but has a centripetal aim, provision for the embryonic dise (Pl. 9a, fig. 7, 35) and the germinal layer (fig. 3, 35a) all round the yolk sphere, being first made, previous to segmentation; then the next more interior portions become the seat of action, and so on, deeper and deeper. ${ }^{1}$

By referring to cells (Pl. 9a, fig. $7,7 \mathrm{a} ; 9, a, b$ ) taken from the embryonic disc and from the germinal layer (fig. 3) after segmentation, we may gain abundant evidence, that, even at this period, the self-division of the mesoblast has not finished its part. This may be confirmed by resorting to an embryonic disc a little older, where the cephalic hood is just about to be formed, the depression all

1 Such cells were observed from the centre of the yolk mass, from the surface, and midway between these points, and found everywhere alike, but in greater proportion near the surface, where they seemed to be quite numerous; those divided into two being by fir the most frequent. Both the mesoblast and entoblast, throughout the yolk mass, are very fintly. yellow. 
round the germ being already present as an indication of the incipient plication of the amniotic membrane; and here the greater part of the mesoblasts are still further and more minutely divided, (Pl. 9a, fig. 4, 5, 5a, 6, 8,) and reduced to that size (fig. 3t, a) which they exhibit when the organs have begun to mark ont their boundaries.

But, let us return and trace more critically the changes through which the yolk cells pass, in order to reach that condition in which they are found when they have become components of the nascent embryo. By the time that the segmentation of the yolk has commenced, not only the cells in the region of the embryonic area, but those all over the surface of the yolk close to the vitelline envelope, have multiplied their mesoblasts to an innumerable number. In this state, they may be recognized as a very light yellowish white layer, which - when the egg is rolled in various directions, the more interior yolk thus falling to what becomes, in succession, the lower side, and this layer is left more exposedresembles a very fragile, sedimentary deposit against the yolk sac, falling away in flakes upon the least flexure or disturbance of its smooth, crust-like arch. Owing to the rapid formation of this layer, and the quickly succeeding ultimate changes in the cells, the latter seem to burst almost in an instant, and leave their mesoblasts arranged in heaps, (fig. 35a,) side by side, thus forming the brittle stratum above mentioned. 'The superficial ectoblastic cells of this layer discharge their mesoblasts so early before the self-division of the latter has been completed, that it is next to impossible to find among them ectoblasts still embracing their progeny; but this may be accomplished in regard to those more deeply seated, especially next to the inner surface of the stratum. We will first make a special mention of these latter, and then return to the former to trace their progress in completing the stare of their fissiparous multiplication, and the comnection of the same with the building up of the embryo.

By cutting out an embryonic dise and laying it upon its back in a watch-glass containing albumen from the same egg, it is very easy to select whatever portions are needed from this body for this purpose; the substance hanging together so lightly that a few cells may be taken up on the point of a knife and laid upon a glass slicle for exammation, or, for those most superficial, the microscope may be brought to bear directly on them in situ. Of course, in the latter case, a strong, concentrated light from above is necessary, on account of the opacity of the embryonic disc, which precludes the possibility of using transmitted illumination. The innermost cells, the ectoblasts, of the germinal lnyer and of the embryonic disc, ${ }^{1}$ are still

If, however, there are those who still incline to believe that these cells are genuine serment balls, then they must, even upon this supposition alone, admit also, without reservation, that segmentation 
found inclosing their mesoblasts (Pl. 9a, fig. 9, $a, b$ ) after segmentation has completed its purpose, and even at the time the cephalic hood has begun to form (fig. 34, b). Almost to the last moment before losing its identity as one of the many belonging to a particular heap, each mesoblast can be recognized and distinguished from the waxy bodies, the entoblasts, which it usually incloses in greater or less numbers, (Pl. 9a, fig. 9, $a^{\prime}$,) by the peculiar mesh-like condensation of its viscid contents upon the inner surface of its wall (fig. 9, $a^{\prime \prime}$ ). This may be seen, even in those which rival in minuteness the cells of a much further alvanced embryonic dise. (Compare fig. 9, $a^{\prime}$, with fig. 8).

Not only the mesoblast, but the ectoblast also, gives the peculiar reaction formerly noted in regard to the cells of the interovarian egg, when water is applied; for, just as in these latter, the ectoblast swells up, and, finally bursting, after the transparent fluid contents in which the mesoblasts float have condensed into a swarm of minute oscillating particles allows them to escape, discharging at the same time its multitude of mesoblasts ( $\mathrm{Pl}$. 9a, fig. 7, 7a).

Going deeper into the substance, and more toward the back of the embryonic disc-or, more properly speaking now, the back of the embryo - and the outer surface of the germinal layer, the heaps of mesoblasts become less and less distinct. owing to the closer application of the wall of the ectoblast against the mulberry-like surface of the mesoblasts, (Pl. 9a, fig. 4,) so that the mesoblasts of adjacent heaps interlock with each other to the confusion of the outline of each mass. Finally, almost at the outer surface of the yolk, the ectoblasts have disappeared entirely, (Pl. 9a, fig. 5a,) though the mesoblasts still remain in heaps, with more irregular outlines than is usual. The disappearance of the ectoblasts is so gradual, so imperceptible, that we have good reason to believe that they are slowly disintegrated and liquefied, the result mixing with the surrounding fluid. The now free heaps of mesoblasts extend their boundaries in an irregular manner, inosculating with each other by the intermixing of their most superficial components (fig. 5, 6). Even here the mesoblasts retain their entoblasts, sometimes to the number of three or four in each, (fig. 5a,) and withal exhibit their vitelline character. The same may be

occurs not only on one side, but all over the surface, of the yolk, for the very reason that these identical "segment balls" are found upon the whole superficial extent of the egg, (P1. 9a, fig. 4, and 34,6 , and, to a certain depth, inwardly. But we think this total segmentation may be proved upon totally different premises, so that what we have just said above may be left for the consideration of those who would hold both to the partial segmentation of the yolk and to the development of a wall around the serment masses, as is said to occur in Birds. By commencing our inrestigation of the subject with these "segment balls," and tracing their development in a retrograde series, beginning with $\mathrm{Pl}$. 9a, fig. 9 , and receding through fig. $\boldsymbol{7}$, $4,34, b, 36-36 \mathrm{c}, 37-37 \mathrm{~d}, 38-38 \mathrm{c}, 40-401$, we find that the first steps toward their formation are taken in the midst of the great yolk mass, the rery spot from which segmentation is excluded by the advocates of partial and superficial segmentation in the classes of Birds and Reptiles. 
said in regard to the superficial or outermost layer of mesoblasts, (fig. 8, which have departed from their cumulated arrangement, and present a uniform stratum all over the surface of the embryonic disc and of the germinal layer.

Everywhere the mesoblasts are now spread uniformly, in unbroken continuity and in close contact, yet not pressing agninst each other so as to assume a polygonal form. Even at this late period, intimately identified as these bodies are with the embryo, their fissuration is in many instances not yet complete, (fig. S, judging from the inequality of their size, when compared with their uniformity in that respect at a later age (fig. 34, a). In fict it is evidently impossible to distinguish between the fissuration of these bodies as yolk cells, and the same operation when they have become the cells of which alone the embryo is composed, at the age to which we have just traced them; for, in the latter case, they have still the same more or less dark, oily outline, with some, here and there, contrining one or two waxy bodies, (fig. 5i, 8,) entoblasts. By the time, however, that the primitive stripe (Pl. 11, fig. 3, b) has begun to form, this heterogeneous aspect has disappeared; and the mesoblasts, the primitive embryonic cells, - as we may now call them, in reference to their being the original constituents of the enbryo, - are of a nearly uniform size (Pl. 9a, fig. 34, a) throughout the upper surface of the young animal, and the exterior of the germinal layer.

IIcre we have, at last, an indisputable series of facts, the succession of which is umbroken, showing the origin and nature of what constitutes the primitive cellular basis of the germ. These facts are enough to establish the identity of the segmented mesoblasts of yolk cells with those cells which are primarily arranged surface to surface to build up the embryo. There is now no room left for the supposition that the Purkinjean vesicle takes a part in the operation. ${ }^{1}$ The idea is negatived without directly referring anew to the mode of development and the final disappearance of that vesicle, when it can be shown, as we have just done, that the embryonic disc is entirely composed of yolk-cell mesoblasts after their most minute self-division. Any further account that may be given of the ulterior changes of these cells belongs more properly to that section which treats of the structure of the tissues, the histology, of the various organs.

1 We have already alluded to the exaggernted importance which has been ascribed to the germinatire vesicle, and to the erroneous impression conveyed by its name (p. 481, note 2, and p. 463, note 1). Ahrer what has been shown in this section respecting the orjerin of the primitive embryonic cells, we maty furly adh, that it is now proved that the P'urkinjen vesicle takes no part in the formation of the embryo, beyond supplying the region in which it originates, as a clis- tinct hody, with a larger quantity of albumen than is found in other parts of the egg. The whole process thus appears like a succession of isolations and recombinations of the oleaginous and albuminous substance of which the yolk is composed, with a prevalence of the albumen at one pole of the ego, where the embryonic dise arises, and a more extensive accumulation of the olcaginous mass at the other pole, where the socalled vergetative systems of organs originate. 
SECTION V.

SEGMENTATION OF THE YOLK.

The morning of the 27 th of May, 1854, was made memorable to us, in our investigation of the embryology of 'Testudinata, by the discovery of the segmentation of the yolk in eggs of Glyptemys insculpta. After repeated trials every day for the space of several weeks upon Chrysemys picta, Nanemys guttata, Ozotheca odorata, Chelydra serpentina, and Cistudo virginea, - which were opened in great numbers, sometimes a little too soon, when the eggs were still in the ovary but just about to drop from it into the oviduct, or again too late, when the embryonic area had already obtained its definite outline and smooth, uniform surface, - it seems rather singular, that a species which is comparatively rare should have furnished the information so long looked for.

From what was seen in the oviducts of one of these animals, it is evident that the segmentation of the yolk proceeds very rapidly, incleed so rapidly, that the space of twenty-four hours probably covers the greater extent of this process. Of three animals opened in three successive days, the first furnished eggs, on the 27th of May, exhibiting the earliest stages of segmentation thus far observed in Turtles (Pl. 10, fig. 1-S); the second, on the 2Sth of May, gave those in which segmentation was almost completed (Pl. 10, fig. 9-11b); and the third, on the 29th of May, contained only eggrs with well defined embryonic dises (Pl. 10, fig. 15, 15a). After all, we were not favored with the view of a primitive furrow, dividing the yolk into two equal portions. There is even good cause to doubt that the yolk always commences segmenting in such a regular manner, if we may judge from the total absence of bilateral symmetry in some of the early stages of this phase ( Pl. 10, fig. 5, 6, 7) in the development of the egg. The youngest and simplest form of segmentation was observed in the most anterior of three eggs, in the right oviduct. About midway between the two ends of the yolk mass, which was already elongated, - as in fig. 1 and la, which represent a similar but somewhat older state, - and parallel to its longer axis, there ran a straight, narrow, and deep furrow, (Pl. 10, ifg. 3, with rounded edges, broadening at each end, and shallowing to a level with the surface of the more eccentric segments. Altogether this furrow equalled in length a little more than one fifth of the longitudinal diameter of the vitelline mass. (Compare fig. la, to see the natural size.) Commencing at two points, a little more than one third the distance from the ends of the first furrow, other furrows of a similar 
nature but only about laalf as long extended laterally and obliquely outward, one on each side of the several points of departure, so as to include between themselves and the terminal thirds of the main furrow, equilateral, triangular spaces, and on cach side of the median third a truncated isosceles triangle, each of which was partially split, as it were, by a short depression, originating from the central part of the principal furrow, and terminating sharply at its ends. 'Thus, on the whole, six segment masses, two of which were again partially divided, were included in the formation of the embryonic area at this early stage. 'The depth of these furrows was not ascertained in a definite manner; yet, judging from appearances and the known thickness of this portion of the germinal layer, they must have penetrated very nearly, if not fully, to the inner surface of the latter.

In another egrg, a little older, and the anterior of four in the left oviduct, the main furrow was not parallel to the longer axis of the egg, running more in a zigzag line, ( $\mathrm{Pl} .10$, fig. 2,) and the lateral oblique furrows trending so as to be more nearly perpendicular to the longer axis of the yolk. Those which terminated sharply in the last egg were here represented by much more lengthened forms, and not exactly symmetrical as to their point of origin as in the former eggs, being nearer to the end of the principal furrow on one side than on the other. So, even at this early period, there is here a considerable want of bilateral symmetry, which still further justifies the doubt, already expressed, as to the constancy of a single furrow, in the beginning of the segmentation. It will also be noticed, that there is some difference in the two figures which are given of this stage from the same egr (Pl. 10, fig. 1 and 2); but this apparent disparity is explained by the circumstance that one view is more superficial than the other; the one (Pl. 10, fig. 1 and Ia) representing only the surface of the embryonic area where the outermost edges of the segment masses more or less overlap each other, and the other (Pl. 10, fig. 2) a deeper view, through the overlapping edges just mentioned: thus showing that the furrows are not perpendicular chasms, but bend, some in one direction and some in another, opening below, in one instance, (Pl. 10, fig. 2, b, ) in a line at right angles to the main furrow, but gaping above, (Pl. 10, fig. 1, b, with edges running quite obliquely to it, or, as in the case of the median transverse furrows, opening above (Pl. 10, fig. 1) in one and the same line, and terminating differently one from the other below (Pl. 10, fig. 2). 'This obliquity becomes more and more evident as the number of segment masses increases, and their contours attain a more rounded outline, just as would happen were a collection of plastic, rounded bodies pressed against each other as they laid spread out upon a convex surface. The embry. onic area of the egg next behind the one first mentioned (Pl. 10, fig. 3) was 
hardly older than the second one, (Pl. 10, fig. 1 and 2,) but much more irregular, (Pl. 10, fig. 4,) evincing a great want of symmetry in the origin of the transverse lateral furrows, so much so that on one side a small segment mass had become totally isolated by a circumvallation.

The embryonic area of the three following eggs, two of which were from the left (Pl. 10, fig. 6 and 7) and one from the right (fig. 5) oviduct, exhibited about the same degree of advancement: all agreed in being very irregular in their segmentation, and in having most of their furrows more or less transverse to the longer axis of the yolk, without any trace of the principal furrow observed in the younger stages. Centrally each possessed two or three isolated masses, and others more or less completely separated. It would be almost a needless repetition, after what has already been shown, to insist here upon the centrifugal character of this process, as the first isolated masses originate always at the centre of the embryonic layer, and those which appear afterwards are successively further and further out of the centre. This is more particularly noticeable in another embryonic area, (PI. 10, fig. 8,) the fourth and last in the left oviduct of the same animal, which is still further segmented, and in which the furrows radiate from a centre occupied by five isolated masses, while the conelike portions included by these furrows are more or less rounded off at their summits. In this same egg, too, we may observe the diversity in size at which the masses originate, two or three being much smaller than some others, that are more central.

On the 28th of May another Turtle was opened, and, as already stated, the eggrs were found in a very advanced state of segmentation, yet not so far beyond those of the first animal opened the day before as to break the linik of connection with them. The segmentation had already extended over a much larger extent than the furrows of the embryonic areas observed the day before had included, and the now numerous radiating cones diverged from a field still more distant from the centre (Pl. 10, fig. 9, 10, 11, 11a, 11b). Of four embryonic areas in this condition, that in the oldest egg, (Pl. 10, fig. 9, ) the fourth and most posterior in the right oviduct, was the least evenly segmented; the centre being still occupied by several masses larger than those embraced in the same region in the other three. However, all four agreed with each other in having the most minute masses in the centre, and the larger ones at the circumference. But the furrowing had not altogether taken place in a perpendicular direction, as we may see by a glance at one of the more magnified views, (Pl. 10, fig. 11, where the masses are heaped one upon the other in stich a manner as ummistakably to evince a horizontal fissuration, such as was partially approximated in the oblique chasms of the earliest segmentation (Pl. 10, fig. 
1 and 2). The embryonic area of the egrg next to that of fig. 9 in the right oviduct was the most minutely segmented (fig. 11b); the one next to it in this respect (fig. 11) was, on the contrary, the most anterior in the same oviduct, whilst another, (Pl. 10, fig. 9,) intermediate in position, in the oviduct of the same side, consisted of coarser masses than the two preceding; and the youngest (Pl. 10, fig. 10) was second from the front, in the left oviduct. This shows distinetly that the progress of segmentation does not correspond to the age of the egrgs.

It is to be regretted that the opportunity was missed of making special investigations as to the nature of the substance which held together the components of the segment masses, and that it was not ascertained from the living egg whether a membrane was formed around each of these masses, as their smooth exterior would lead one to suppose, or whether they were merely enveloped in the albuminous fluid that had already begun to be absorbed from the outside through the yolk sac. After some researches upon this subject, made subsequently upon carefully preserved alcoholic specimens, we are very much inclined toward the latter view. It is true, the altering eflects of the preserving fluid may be objected to; but this much we may say in favor of this opinion, that, in the specimens examined, the ectoblasts of that portion of the yolk which was not yet fissurated, at the lower side of the egg, although of excessive tenuity and tenderness, were in many instances nearly as distinct as ever, excepting a slight wrinkling or flattening by contact with each other, and that the mesoblasts, which are so susceptible of change in a fluid not natural to them, were in this instance very often entirely unchanged. Now, under such favorable circumstances it is quite reasonable to expect that a membrane of tolerable consistency would still be found, if it ever existed, around the segment masses; but, after prolonged search, not the least trace of any such membrane could be discovered. In fact, all indications of furrows had disappeared; and only very faint remnants of heaps among the cells broke the homogeneity of the embryonic area. In all probability the alcohol had dissipated the albumino-oleaginous, glairy substance that inclosed the masses. But, even supposing that such a membrane had been present for a time, it certainly disippears in the natural course of the changes which the vitellus undergoes, since nothing of the kind existed in well defined embryonic dises, where the segmentation had grone through its phases till no two cells were left together. 'This has been specially noted in the description of the progress of the self-division of the mesoblast."

Under a low magnifying power, some of the larger masses of the embryonic

\footnotetext{
${ }^{1}$ Compare p. 521.
} 
area may be seen undergoing further segmentation, (Pl. 10, fig. 11, either by single furrows or by two or three or four or more; and beyond these the cone-shaped bodies radiating around its periphery appear in the act of extending their longitudinal division, and throwing off masses from their apex by transverse constrictions (lig. 9, $a^{1}$, and 11, $a^{1}$ ). We would ask particular attention to these cone-shaped, radiating bodies, as hereafter they will have a special bearing upon the question of the extent of segmentation over the area of the germinal layer. From the earliest stages of segmentation, up to the time when the embryonic dise is perfectly formed and well defined, a yellowish white color pervades its surface; but it becomes more yellow outside of the circumscribed area, where the thimner germinal layer allows the yolk to shine through.

Comparing the size of a smooth and sharply defined embryonic disc, (Pl. 10, fig. 15, 15a,) found in an animal opened on the 29th of May, with that of some of the preceding eggs, (fig. 11by) it appears that here segmentation must have already progressed beyond the boundaries of the embryonic disc, and encroached upon the space devoted to the vascular area. This assertion is borne out, not only by the presence of the above-mentioned cone-like bodies outside of the embryonic disc of an egg from another species (Nanemys guttata) with well marked boundaries, and encircled by a clear, transparent, narrow ring, the area pellucida, (Pl. 10, fig. 12, $a^{1}$ and 13,) but also by the presence, in a similar position, of large numbers of rounded segment masses, (fig. 1t,e, e, in the egrg of Chrysemys picta. There is no chance here to mistake the relation of the parts; and it cannot be doubted, therefore, that segmentation does not belong exclusively to the embryonic disc, but extends also, for a certain distance, to the surface exterior to it. Of this we have ocular evidence; but whatsoever reason there may be to believe that it goes on beyond this must be based upon induction; and yet, even here, to any one who has followed the series of preparatory steps through which the yolk passes in this region, and has noted the peculiar physiognomy which it bears when thus specialized, in a certain manner proper to itself, all over the surfice of the vitelline mass, the almost certain conviction arises, that segmentation must spread over any surface to which this layer extends, and to whatever depth it may eventually plunge, even though, in the end, it included the whole bulk of the yolk.

It may seem an unwarrantable inference from premises of insufficient weight to assert the belief, that, in 'Testudinata, the whole egr undergoes segmentation, and not the surfice only, at a definite point. This much, however, is certain: this process groes on, to a known extent, in the region of the vascular area. But what is the final expanse of this area? It is not limited within a certain circle to the surface of the yolk only; it spreads eventually all over the 
latter, and, still later, plunges into its substance, till the whole yolk mass becomes a great network of bloodvessels, (Pl. 18, fig. 4,) a vascular area, hollowed out in the lamellar partitions (Pl. 17, fig. 1) into which the yolk cells have consolidated themselves. Now if segmentation obtains in a part of the vascular area, and is still apparently progressing externally, it is at least reasonable to expect to find it operating eventually wherever that area may exist; especially as the latter bears with it the identical uniform arrangement and modifications of yolk cells which are found within the circle of its primary development. So confident are we of the soundness of this theory, that we look earnestly forward to another breeding season for an opportunity to demonstrate it in an indisputable series of ocular proofs.

\section{SECTION VI.}

TIIE WHOLE EGG IS THE EMBIRY.

Since we have shown in former pages, that the embryonic disc, and its extension, the germinal layer, are formed by the original apposition of yolk-cell mesoblasts minutely subdivided, and that these yolk cells are all the same through the whole yolk mass from centre to surface, even to the very walls of the superficial Purkinjean vesicle; and, moreover, since it is proved that segmentation obtains beyond the embryonic disc, and very probably all over and throughout the whole yolk, it is evident, that, in the egg of the 'Testudinata at least, the region around the Purkinjean vesicle camnot be separated from the more exterior or inferior mass which constitutes the greater bulk of the vitelline substance, and that the last cannot be homologous to the contents of the Granfian follicle, ${ }^{1}$ which bears no part whatever in the formation of the embryo, but is totally exterior to the mammalian egg. Again, as will be shown hereafter, that portion of the yolk which is originally excluded from the primary circumscription of the outlines of the embryonic disc cannot be separated from the animal as an appendage, ${ }^{2}$ for it very soon

1 Meckel von IIemsbach (Zeitschrift für Wissenschaft. Zool.) and 'Thompson (Cyclop. Anat., London, 1854, article "Ovum," page 77) deny that the whole yolk mass of the lirds and of the scaly Reptiles corresponds to the egg of Mammals. 'The first of these writers compares the I'urkinjean vesicle alone to the mammalian orum, and the yolk surrounding this resicle to the corpus luteum; whilst the latter author includes the granular cicatricula, along with the resicle imbedded in it, as homologous to the mammalian egg, and the yellow yolk to the tunica granulosa of the Graafian follicle. With this latter riew 1)r. Martin Barry (P'hil. 'Trans., London, 1839, p. 309, note, and 370$)$ is strongly inclined to coincide.

${ }^{2}$ It has been customary heretofore, among most authors, to designate the yolk sac as a reservoir of 
afterward becomes an essential part of the "embryo," as the latter extends itself in the form of a germinal layer and a vascular area, not only all over the surface of the yolk, but, in the case of the area vasculosa, through the whole vitelline mass, the latter becoming a great spongy network of bloodvessels, formed by the lateral apposition of the cells composing this large body. 'This vascular mass is finally drawn into the body, and, though gradually disappearing by resorption, remains for nearly six months after birth, as one of the essential portions of the organization of the freely moving animal.

Because a part is more or less separated from the main body, it does not follow that it should be considered as an appendage or an unessential portion of its structure. The bladder, at one time, hangs out in a saccular form as an allantois, extending far beyond its subsequent relations, and yet it is an organ of the embryo. No one would deny that the legs are an integral part of an animal because they extend beyond the bulk of the body; no one would hold that the young teeth, which, after a certain age, are discharged from their capsule, were not essentially a part of the body because they eventually disappear; no one would assert that the menses are not a characteristic physiological phenomenon of the animal system because they cease at a certain age; or that the ovaries, because they are resorbed at this period, were mere transient accessories of the organization. As if life were ever at a stand-still, a stereotyped machine, hewed and hammered out and put up to perform a certain uniform work, never changing from the time it is built till it falls to pieces by wear and decay! No; not so. We may truly say that life is embryonic all through; embryonic, in the sense that changes go on in the adult as in the young, and oftentimes quite as extensively as in the unborn or just born animal. From the moment that the egg is isolated, a new individual life commences; the animal potentially exists. Nor are we by any means to suppose, that the yolk, because it floats freely for a while, is a mere vitelline substance, and not an integral part of the embryo. Does not the blood float freely in the adult body? and does it not originate in the embryo as a loosened mass of yolk-cell mesoblasts, (Pl. 19, fig. 6,) separated from the sides of the channels, which, after having been hollowed out in the thickness of the intestinal layer, form bloodvessels? And yet, who will deny that this fluid

nutritive substance, in contradistinction to the " $\mathrm{em}-$ bryo," which is placed above it, the latter increasing in size as the former supplies the materials. (Comp. Part. I., Sect. 1, p. 181, and Sect. 6, p. 229.) This, we will admit, is true; but only in the same sense that the stomach, as an independent organ of the body, bears the means of existence to the whole organism. In both cases the nourishment is taken up by vessels through the process of endosmosis. The yolk is never appropriated by a process of digestion. There was a time in the history of Eimbryology when the terms "egr" and "cmbryo" were synonymous; we have to go back to it, now that we know how gradually the ergo is transformed into a distinct embryo. 
is part and parcel of the animal system? Then come a series of changes and metamorphoses, at some of which one type stops, while another passes on. One type undergoes certain changes before it is born, another not till a longer or shorter time after birth; one type retains a certain peculiarity of organization for almost its whole lifetime, and this organization forms one of its principal characteristics, while in another, the same peculiarity, lasting but a short time, is too often looked upon as a mere scaffolding and prop-work, which serves to hold the structure in shape while it is perfecting. Because one has a long and the other a short existence, the same characteristics in two different animals are very difierently estimated. Minutely described in the first case, they are perhaps totally ignored in the other as unessential, as having no particular reference to the type in which they occur.

Can this be? Is it not true, that each and every type undergoes a series of changes, not only during its "embryonic period," but throughout life; some following after longer, and others after shorter, spaces of time, so that their peculiarity and periodicity characterize this, or that, or the several different types, as distinct from one another? Different animals shed their teeth at diverse ages, and then acquire other habits. Some shed their epidermis (dandruff, scales, feathers, or slough) at stated periods, and others constantly. Some bear young soon after they are born, and others at two, three, ten, fifteen, twenty or more years of age, and this function ceases in them at diverse ages. And yet this latter change is a normal development just as truly as any which occurs at a much younger age. The long space of time that may follow the period of sterility is quite as prominent a characteristic of the life of an animal as any preceding state. At that period, so great a revolution takes place in the system as sometimes to endanger life when adaptation to its requirements is accidentally prevented. Tet, after such metamorphoses, are not the peculiarities of the functions of some of the organs greatly changed? And so we might go on, enumerating many other progressions and alterations, to show, that life after birth is not fixed to one uniform phase; but that there is a constant and more or less frequent formation and suppression of functions, and a series of alterations going on in the organization, not only from the beginning to the end of the embryonic period, but ever afterwards, through the whole duration of life, till death.

Finally, we must contend that it is a false idea of the physiology of mimal life to suppose that in the egg the animated being is only forming; that its organs are only combining with each other in order to establish regular communications between them for certain ends, and to prepare the way for a variety of functions, the begimning of which is not realized until a definite and unvarying relation of parts with definite proportions has been completed. As if the 
heart of Vertebrates, while a simple, straight tube, - without even smooth internal walls, and while the yolk cells are still dropping from its sides into its cavity and only move backwards and forwards like an advancing and retreating tide, - were not functionally and typically as fully a heart as later, when it has obtained two chambers in Fishes, three in Reptiles, and four in Birds and Mammals; or the lungs, while a simple, cul-de-sac-like dilatation of the wall of the oesophagus, were not truly performing their part as well as in the Fish when they become more isolated as a swimming bladder, or in Lepidosteus when they approach the complicated structure exhibited in Saurians and Chelonians, or in the latter two when they occupy a great portion of the cavity of the body, or in Mammals when they have changed into a uniform, spongy mass of minute bronchioles with their capillaries. And so we might mention the progressive stages of the eye, the ear, the brain, and all the other organs, if so many examples were necessary.

At no time is the whole type exemplified by any particular specimen; nor does any one individual, at the moment when we look at it, reveal to us its whole life. Still less can any alcoholic preparation of an animal, as it hangs inanimate before us, disclose its action, its manner of life, its physical relations, its former embryonic simplicity, its later metamorphoses, or its final mode of passing away. Such objects ought only to be considered as means for our study, as memorials of past life. We collect them, that they may assist us in telling the tale of their organic connections. We may even substitute wax models for the things themselves, and that too with very good success, so fir as a plastic substance may represent the appearance of animal life at a given period; but the wax is a perfect blank as regards the past or the future, and so is the dead animal, when compared to what it has been, or to what it might have become. But when alive, we see in it at the beginning, as an embryo, certain characteristics of its type; when born it exhibits other characteristics, some of the former disappearing, and some remaining throughout life, and again at various periods of its life other characters appear and disappear, so that some individuals, dying before a certain age, never wholly exemplify their whole type, whether it be that of branch, class, order, fumily, genus, or species.

When such views are adopted, and such interpretations have become our standards, it is impossible to hold longer to the inanimate nature of any one portion of a growing body, and consider the others as endowed with all the characteristics of an animate being: it is impossible to assert, if we may revert more specially to what has already been said, that the so-called yolk sac is a mere bag of nourishment, a reservoir of food, for the embryo, which increases in bulk as the former doles out its supplies. What part this organ plays in the progress of the growth of Testudinata will be fully described in a future section; let it 
suflice here to say, that it will there be found to bear a relation to the body and the whole system different from that which has usually been supposed or admitted. When we look at the cellular tissue of the lower branches of the animal kingdom loosely strung together, where we may see every cell of a muscle dilate and contract for itself; where, in the younger but free stages of the same, these cells hardly touch each other, and yet dilate and contract; where the whole animal moves from place to place by the help of these selfsame active vesicles; or where, in the simplest phases of organic structures, we may actually count the number of cells of which the body is composed, as the animal flutters and quivers while falling to pieces before our eyes; - when we see all these phenomena, we need not fear to adopt views contrary to a sound physiology in advocating the animality of the yolk, ${ }^{1}$ notwithstanding the loose connection of its

1 We neel only refer to the researches of Biscrorr, upon the Enbryology of Mammals (Entwickelungsgeschichte des Kaninchen-Eies, q. p. 83 : p. 93 , pl. 8, fig. 40 1, and pl. 16) - BAEr, upon Birds (Cber Entwickelungsareshichte der Thiere, q. 1. 67: Lirster 'Theil, p. 67, pl. 1, 2, $\left.p^{\mathrm{I}}, r^{1}, t, u, s^{1}, q^{1}\right)$ - REvaK, upon IBatrachians (Untersuchungen uiber lie Entwickelung der Wirbelthicre, q. P. 83: p. 81, pl. 10, fig. 1-5, pl. 12, fig. 1-8) - VogT, upon Wishes (Embryologie des Salmones, in Agassiz Ilistoire naturelle des l'oissons d' eau douce de l'Europe centrale, q. 1) 81: vol. 1, p. 38, pl. 5, fig. 116-120) - KöLцLER and Zubrdcri, upon Insects (Külliker, Ouservationes de prima Insectorum Genesi, q. p. 80: p. 3, sect. 4, pl. I, firg. ii., 1, 3, p. 12, sect. 18, pl. 2, fig. ii., 1, 3; Zaldach, Untersuchungen iber die Entwickelung und den Bau der Gliedlerthiere, q. p. 80: I. IIeft., p. 3 and 1 , sect. 2 and 3, pl. 1, fig. 2, 3, and 4, C, fig. 5, İ) - R.tтиke, upon Crustacen (Zur Morphologie, lieisbemerkungen, q. p. 79 : p. 71 and 75, fig. 9, 10, 11) - MrLye-Enwaris, upon Annelicles (Recherehes anat. et zool., \%. 1\%. 92: premiere partie, p. :3-36, fig. 47-50) - Kï̈Lnker, upon Cephalopodar (Entwickelungsigeschichte der Cephalopoden, q. p. 74: p. 165, pl. vi., fig. 1x-1xiii.) - GLeExBacen and Lexpir, upon Gasteropoda (Leyolig, in \%eitchrift fur Wiscenschaftiche \%oülogie, 1. 1) 73: p. 130, pl. xi. fig. 5-8; Gerenhaner Lntersuchungen über P'teropoden und IIeteropoden, 1. 1. 74: 1.66, pl. iii., fig. 9-13, and p. 179 , pl. viii., fig. 3-9) -
Qutrefiges, upon Acepliala (Annales des Sciences Naturelles, 1839, tome xi., p. 208-215, pl. 9, fig. 16-26) - DERises, upon Echinorlermata (Anuales des Sc. Nat., 1847, tome 8, p. 90-92, pl. 5, fig. 6-14) - Sienold, upon Medusa (Neueste Schriften der Naturforschenden Gesellschaft in Danzig, 1839, p. 22-29, sect. 14-28, pl. 1, fig. 12-19), - and a loost of other authors, quoted in connection with a former section, (see p. 68-87,) to furnish abundant evidence of the truly internal pusition of the yolk. This part of the egg is, from the beginning, embodied within the extended layers of the embryo, "the germinal layer." In some instances it even assumes very early an organic form, (see liemak, loc. cit., pl. 10, fig. 1923, dk, and dk, pl. 12, fig. 10, dk; Dr. J. Wyman on the Surinam 'Toad, Sill. Journ., May, 1854, 1. 371, fig. 3; Leydig, loc. cit., fig. $8-12, b, c, d, g$; Milne-Edwards, loc. cit., p. 24-26, 11. 1, 1ig. 8-11, ) although its components are quite loosely attached to each other. It may be said that the extension of the germinal layer around the whole yolk mass does not suficiently imply the identity of the latter with the rest of the embryo; yet, when we see this same mass take the form of an important organ, especially well marked in the Surinam 'Toad, (I'ipa americana,) and so ably described in Wyman's investigations unon this animal, in which the whole yolk is shaped into a spiral intestine, there is no longer any reason to resist the conclusion, that this portion of the living mass is as fully subject to that plastic power which 
cells among each other, and their resemblance to those of an unfecundated exrg, provided we are aware that the changes which it undergoes in its earlier growth essentially belong to a period anterior to the final influence fecundation has upon its development.

As soon as it is once admitted that the so-called nutritive yolk, as contrasted with the embryo, is an essential part of the embryo itself, there is no longer any possibility of tracing a distinction between an embryo, as it stands out from the yolk at a later period, and the yolk, as embryo, before any morphological difference is introduced between the two, their differentiation being clearly the result of a continuous process, initiated very early in the youngest ovarian egrgs prior to the first copulation. It follows, therefore, that the egg itself is, in the strictest sense of its physiological importance, a new being, an embryo, originating in the ovary as a single, specific cell; and that, from its earliest appearance, it is to be considered as the new animal in progress of formation. From this point of view, the names egg, embryo, young and adult animal, are only couvenient appellations to indicate the different periods of growth of one and the same being.

Thus far, we have limited our remarks to facts which are within the reach of our investigations. But the inquiring mind is unwilling to stop at the limits assigned to its progress by the circumstances of the moment. May we not ask, therefore, what takes place at the time when an egg, the germ of a new being, originates? Apparently it is only a concentration of an exceedingly small mass of oleagino-albuminous substance, in the form of a sphere. But, in reality, it must be a very different thing; for that sphere is, from the beginning, the centre of an action that differs from the functions going on in any other part of the parental organism. It is alive, and at once proceeds to develop, in a regular manner, towarls a definite end. From the begiming it assimilates to itself, and for its orm ends, the material supplies it receives from without. Whatever may be said to the contrary, a principle of life is now at work in the egrg which is totally

slinpes the layers of its more superior portions into the cerebro-spinal systems of organs of the body, as any other portion ; or that it is in fict an organ in progress of derelopment, and more or less permanent, according to the animal in which it originates. Indeed, we are inclined to believe, that, upon further investigation, this portion of the body will be found never to disappear entirely, but only to assume successively various guises, cither diminishing its bulk and rotundity and lengthening out into the intestine, as in Mammals, Birds, and the scaly lieptiles, -or, as lappens in some Batrachians, according to Iryman, coiling very early into an intestine, - or, as Remak has shown in Rana esculenta, moulding itself at first into a thick eylindrical digestive canal, which subsequently lengthens and becomes coiled at the expense of its own thickness, - or simply lengthening, and at the same time diminishing its transterse diameter, as in Abramis (Cyprinus) Blicea (Baer, Lintwickel. der Fische, etc., q. 1. 81 : fig. 9-20.) 
different from the chemical or physical properties of its constitutive elements. But what is that principle? It is the same something which distinguishes the parent, as an individual, from every other individual; for that immeasurably small egg grows to be another individual of the same kind, and never produces any thing else. It is the result of an organic impulse, acting as we see thought act in another sphere, when, in consequence of the utterance of a new view or a new truth, a new social organization is called into existence. As truly as the mind of man acts beyond the sphere of its organic functions when it pours forth its conceptions, so truly is the principle of life, characteristic of any parent being, transmitted to the egg when a new individual begins to grow. The comparison may be carried further. The results of the mental activity of one individual may be modified or stimulated by the action of other minds; as the progress of a new individual is modified by the different parts which the parents take in its formation. So the growth of the egg, begun prior to fecundation, is influeneed by that act in a manner similar to the development of an idea which is modified by the influence of other ideas. We feel justified, therefore, in saying, that conception and fecundation must be, in a measure, intellectual acts, in however instinctive a way they may be accomplished.

\section{SECTION VII.}

FOLDINGS OF THE EMIBYONIC DISC.

In a former section of this chapter, ${ }^{1}$ in which are investigated the changes through which the yolk of the fecundated egg passes, it has been shown, that the cells of which this body is composed undergo a series of transformations, ending with their embodiment in the embryonic disc, where each segment of the selfdividing mesoblasts becomes individually a component part of the future cellular tissue. In a succeeding section, ${ }^{2}$ the segmentation of the yolk was traced till this process terminated in shaping out a well-defined disc upon one side of the egg, though its further effects extend to a much greater area, if not all over the surface of the egg.

We will now consider the development of the embryo from a different point of view. This well-defined disc, the so-called "embryonic disc," marks the place where the earliest and the most important organs of the animal originate. It is 
within its outlines, and there only, that, in the order of Testudinata, the characteristic features of the type of Vertebrates are developed. From the beginning, the mode of formation and growth of this disc distinguishes the Turtles from the five lower classes of this type which have neither amnios nor allantois, namely, the Myzontes, the Bony Fishes, the Ganoids, the Selachians, and the Amphibians, ${ }^{1}$ though they belong to the same branch of the animal kingdom to which the order of Testudinata also belongs. Among the classes just mentioned, nothing like an amnios or allantois occurs, and the embryonic disc bears also different relations to the other parts of the egg. 'Thus we see, that, at the outset, this order exhibits characteristic features, distinguishing it from the classes below it, and showing its relation to the other orders of its class, and to the classes above it.

Though prevailing universally, it is a mistaken view that the outlines of the embryonic disc are the boundaries of the animal, and that the yolk beyond and below is a mere appendage to it. We have already endeavored to show the fallacy of this theory in a former section, ${ }^{2}$ where it has been shown that the whole egro is, even from its first appearance, just as truly the animal as that part of the egg which is circumscribed within the region of the embryonic disc, when this disc becomes distinct from the rest of the yolk. We shall, therefore, speak hereafter of the whole $\mathrm{egg}$ as being the animal, and of those portions of the egg which are called the embryonic disc, the embryo, the amnios, the allantois, the vascular area, the area pellucida, the yolk mass, etc., as being so many different organs, or groups of organs, of one great organism. What we have said in a former section warrants us in the belief that we have taken the proper view of this subject; and, under these impressions, we will now proceed to investigate the formation, growth, and changes of the various organs which characterize this type of the vertebrate series. For obvious reasons we will begin with the embryonic disc, as definite organization first makes its appearance there.

The Embryonic Disc. The area over which the embryonic disc extends is not so much marked by peculiarities of its own, as by the circular furrow (Pl. 10 fig. 14, a) of the germinal layer, which lies immediately beyond it; although it is true that between the two there is a slight difierence in thickness, and in the intimate nature of their cellular constituents. Ilowever, the prominent feature that separates these two regions from each other is this intermediate furrow, which, as will soon be seen, is of great significance in relation to the development of an important organ, the amnios. The arching of the embryonic dise, like a blister on the surface of the yolk, renders the yellow color of the latter less visible, and the whiteness of the former more prominent. In some instances, the formation of 
the organs within the embryonic disc begins (Pl. 11, fig. 1, $a^{1}$ ) before its outlines are well marked by the deepening of the circular furrow. Ilowever, we may mention that it is usually the fact that the embryonic disc becomes sharply bounded before any change comes over it.

By the time the embryonic dise has become well defined, (Pl. 10, fig. 12-15, ) there is already a difierence noticeable in the nature of the cellular components of its upper and of its lower side. Those above are by fir more uniform in size, and smaller (Pl. 9a, fig. 34, a) than those below; they form a thin, minterrupted layer (Pl. 9e, fig. 1, a) of so smooth a surface as to give to the embryonic disc that polished aspect mentioned before, while those below are coarser and darker, (Pl. 9a, fig. 34, b, ) still evincing a cumulated arrangement, and, in some instances, even restrained by the parental envelope. ${ }^{1}$ These lower cells form by far the thicker layer (Pl. 9e, fig. 1, o $0^{1}$ ). The upper layer $(a)$ is continued over the whole surface of the yolk; but here it is not quite so thin as on the embryonic disc. The lower layer $\left(o^{1}\right)$ follows the upper, $(a$, ) but is not so distinct from the subjacent more mobile yolk mass $(y / k)$; yet it is sufficiently separated from the yolk to be easily recognizable, even though it forms an intermediate stage between the two. The thimner or upper layer $(a)$ more properly deserves the name of germinal layer, and the other, the thicker or lower, may be considered as a subsidiary layer, $\left(o^{1},\right)$ the upper surface of which is constantly furnishing supplies to the thickness of the upper layer, $(a$,$) and is continually added to from below, \left(y / k_{2}\right)$ for a certain length of time, which varies according to the part of the whole developing mass to which it belongs. We have mentioned before in passing, that, in the vascular area, there is a constant addition to this layer, even up to the end of the period of incubation.

The Amios. We have already noticed the initial steps toward the formation of the amnios, when pointing out the circular furrow which bounds the embryonic disc. 'This furrow (Pl. 9e, fig. 1, e; Pl. 10, fig. 12, 13, 14, a, 15) is not formed by a scooping out of the thickness of the germinal layer. It is, on the contrary, the result of an actual depression of its whole thickness (PI. 9e, fig. 1, $e, c)$; so that, if viewed from below, that region would appear to have a circular semicylindrical ring raised upon its surface. This is the first indication of the folding of the germinal layer to form the amnios.

But soon this uniformity yields to a diflerent tendency. The edge of the embryonic disc becomes suddenly depressed at one point, so that, viewed from above, it appears, as if a narrow segment of a circle had been cut away from its sides (Pl. 11, fig. 1, $\left.a^{1}, 6, a^{1}\right) . \Lambda$ longitudinal section of the embryonic 
disc (Pl. 11, fig. 6a, and Pl. 9e, fig. 2) shows at once the nature of this change, and at the same time discloses a thickening at the part (Pl. 9e, fig. 2, $a^{1}$; Pl. 11, fig. 6a, $\left(a^{1}\right)$ ) where the depression occurs, and also that the subsidiary layer (Pl. 9e, fig. 2, $o^{1}$ ) follows this depression. By this time the yolk mass has begun to recede from this spot, and is replaced by the albunen which has filtrated through the several walls and layers around the yolk. As yet, however, the albumen (Pl. 11, fig. 1a; Pl. 9e, fig. 2, al) occupies but a small segment of the yolk sac. The next older phase has brought the wings of the depression nearer to one another, so that the central part of the latter is bounded, on the side next to the dise, by what resembles a cone confronted by the approximated horns (Pl. 11, fig. 2, $a^{1}$ ) which bounded the formerly lunate hollow. By this time, too, the opposite end ( $\mathrm{Pl}$. 11, fig. 2, $a^{2}$ ) of the disc has become considerably depressed, yet not like the other end, $\left(a^{1},\right)$ but simply by curving down, while keeping its contour ontwardly arched; the right and left sides also are slightly folded in, in a downward direction, carrying with them a broad strip of the neighboring space, and thus forming a deep annular depression all round (Pl. 11, fig. 2, e).

1 Among the eggs which were retained in the oviduct by a female in confinement beyond the usual time of laying, we have found some remarkable instances of monstrosity.

We will first mention one found in the egg of Ialacoclemmys palustris. As the embryo normally develops, the caudal hood, as just stated, commences to form almost immediately after the cephalic hood, but in the instance before us (P1. 11, fig. 7, $a^{5}, 7 \mathrm{a}, a^{1}, a^{5}, 7 \mathrm{~b}$, $\left.a^{1}, a^{5}\right)$ the head is strongly bent upon itself, whilst the candal end (fig. $7 \mathrm{~b}, a^{2}$ ) is not folded in the least. The back of the embryo is also more arched (fig. 7b) than in the normal state.

Another instance, of much more extreme disparity between the two ends of the embryo, was found in the egg of Ozotheca odorata. The embryo, instead of having its normal round or broadly oval form, suddenly narrows behind to half its anterior width, and then terminates in a rounded end (Pl. 11, fig. 9, 9a, 9b). IIere again the cephalic hood alone has developed, and that, too, fir beyond the bounds of normality. After haring bent upon itself as is usual, a portion of the head along the axial line las continued to push still further back in the form of a blind sac, till it has reached the posterior end of the embryo (Pl. 11, fig. $9,9 b$ ). Seen from above, (fig. 9,) the blind sac ap- pears broader behind than at its mouth, and in a longitudinal section (fig. $9 \mathrm{~b}$ ) we see that it is quite flat, and proceeds in a straight line from the head to the tail, and also that the back of the embryo is much more arched than in the preceding case. We hare also made a cross section of this embryo, just behind the head, (P1. 11, fig. 9a,) in order to display the transverse arch of its back and the flatness of the whole width of the blind sac, and the manner in which its mouth expands sideways and joins the more periphe. ric part of the embryonic disc. It will be noticed in this transverse section (fig. 9a) that the sides of the embryo are rather suddenly bent downwards; but at the caudal end there is no folding, (fig. 9), notwithstanding the highly developed character of the cephalic hood.

In another instance, (Pl. 11, fig. 8, 8a, ) the embryo of this same species exhibits the normal oral shape, but otherwise resembles the last in the mode of its development. The blind sic, however, is cylindrical, and does not reach more than three quarters of the way toward the caudal end (fig. 8). At the mouth of the blind sac there is a furrow on its upper side, (fig. 8a, which might be mistaken for the primitive furrow, but it is probably a longitudinal fold.

In another egg, of Malacoclemmys palustris, the embryo appears, at the first glance, perfectly normal 
In consequence of these folds, and owing also to the growing transparency of the ammular depression which forms the area pellucida, (PI. 11, fig. 2, e,) the embryo has a very prominent aspect, underlitid as it is by a dark background.

In an immediately succeeding phase, (Pl. 11, fig. 3,) the homs above mentioned are overlapped by the more prominent central cone, (Pl. 11, fig. 3, $a^{1}$,) and the depression at the candal end is quite deep (Pl. 9e, fig. $3, a^{2} ;$ Pl. 11, fig. 3, $a^{2}$ ) and broad, fully as much so as the cephalic one; the sides also are more depressed ( $P$ l. 9e, fig. 3a, n) than before, and the whole embryo is strongly arched, and tapers towards the end where the three conical eminences crowd together (Pl. 11, fig. 3, $a^{1}$ ). Here the lunate depressions (Pl. 11, fig. 3, c, c) are no longer confined to the width of the original embryonic disc, but extend even to the edge of the area pellucida, so that the latter is divided into four nearly equal portions or fields, mamely, two lateral areas, (Pl. 11, fig. 3, $a^{3}-a^{4}$,) slightly sunk, and two deeply depressed ones, $(c, c$, ) and terminates by a sudden bend ( $\mathrm{Pl}$. 9e, fig. $3, d, d, 3 a, d, d)$ at the outer edge, where it joins the more peripheric part of the germinal layer (PI. 11, fig. 3, d ${ }^{1}{ }^{1}$ The distinctness of these four regions depends upon the greater or less degree of folding of the edge of the embryonic disc, the base of attachment of the ammios. In these last two phases the subsidiary layer (Pl. 9e, fig. 3, $d, d, 3 \mathrm{a}, d, d$ ) is not so thick as before; and does not follow so closely the upward curvature (Pl. 9e, fig. $3, c, c, 3 \mathrm{a}, c, c$ ) of the germinal layer, where it extends over the area pellucida; but, stretching outwardly with a long bend, (fig. 3, $d, 3 a, d$, ) leaves a considerable space $\left(c^{1}, c^{1}\right)$ between itself and the sudden fold of the layer above. This structure, with the thinning of the subsidiary layer and the presence of the infiltrated albumen, accounts for the dark but transparent appearance at this region.

Next, we see the sides of the embryo so folded in (Pl. 11, fig. 4) that the neighboring areas are brought down to a level with those at each end, so that the embryo rests like a dome on a short, broad pedestal in a circular valley. We

(1'. 11, fig. 10). Like the cephalic hood, the candal hoor is well maked ly the sudden bending downwarls of the posterior end of the embryo, and the sides of the body also are curved down. However, upon close serutiny, we find that the cephalic hood las developed just as in the monstrosity of Ozotheca odorata. Here the blind sac is nearly cylindrical (Pl. 11, fig. 10il) and much narrower than that of Ozotheca, lut, like the latter, reaclies to the caudal end of the cmbryo, and expands at the mouth like a trumpet. In a longitudinal section (fig. 10h) we see that the blind sac is not so ftattened as in Ozotheea, (1'1. 11, fig. $2 b_{9}$ ) and that its upper side, nearly tonching the highly arehed back, follows its curve along the whole lengtl. $\Lambda$ view in front ( 1 'I. fig. 10c) shows that the michle of the back is sunk, probably indieating cither a fold, or at tendency to form a regular primitive furrow. In all these examples of monstrosity, the clear dark space, the area pellucida, is as normally dereloped, and appears to be as natural, as in the healthiest cmbryos at this ange. (Compare Pl. 11, fig. 9, and 10, with fig. $2,3,4$ ).

1 In $1 \%$. 11, fig. 3, the letter $a$ should be $d$, in in fig. 2. 
may mention in passing, that about this time the "primitive stripe" appears upon the oldest conical prominence, (Pl. 11, fig. 3, b,) next to the older depression of the embryonic disc, the cephalic hood; and that the albumen has nearly half filled the space underlying the embryo (P1. 11, fig. 4a). A few more hours bring about a considerable change (Pl. 11, fig. 5, and 5a): the sides of the embryo are so approximated as to give it the shape of an inverted lyre.// The oldest conical prominence has broadened considerably, and is folded under "more suddenly; the depression (Pl. 11, fig. 5, $a^{1}$, fig. 5a, $a^{1}$ ) of that side is like a narrow, transverse furrow broadened at each end, and that on the opposite side $\left(a^{2}\right)$ has become also deeply lunate by the sharp downward folding of the middle line of the body.

At this time the "primitive stripe" (Pl. 11, fig. 4, b) extends along two thirds of the length of that portion of the embryo which is visible outwardly; and below it is represented by a sharp median ridge, ( $\mathrm{Pl}$. 11, fig. 5a, b; Pl. 9e, fig. 4a, $0^{1}$ ) which does not belong to the same layer as the primitive stripe, (PI. 11, fig. 5, b,) but is merely forced downwards by its encroachment. The primarily depressed end has become not only much more sunk towards the centre of the yolk mass, but is bent strongly upon itself (Pl. 11, fig. 5a, $a^{1}$; Pl. 9e, fig. 4, $e^{1}$ ) and rolled inwardly at the sides, (PI. 9e, fig. $4 \mathrm{a}, e^{1}$ ) and that portion of the germinal layer which forms the depression now embraces it closely, (Pl. 9e, fig. 4, $a^{5}$ ) nearly as far up as the level of the exterior surface of the body; but at the opposite end the depression is not so deep, and consequently the upward folding is not as extensive (Pl. 9e, fig. 4, $a^{2}$ ). At this age the embryo hangs over a vast albuminous mass, (Pl. 9e, fig. 4, al, and Pl. 11, fig. 5b, 5c, ) occupying more than one half of the yolk sac, the remaining space of which contains the yolk. The changes which the dimensions of the yolk and of its membranes undergo in consequence of this infiltration of albumen will be fully described in another section.

The next stage in the development reveals which is the head, and which the posterior end, of the embryo. It thus appears that that part of the embryonic disc which is first depressed, (Pl. 11, fig. 1, $a^{1}$ ) and which, in the last stage, hung so low below the rest of the body, (PI. 11, fig. 5a, $a^{1}$; Pl. 9e, fig. 4, $e^{1}$ ) is the head, for the development of the brain (Pl. 12, fig. 1a, $e^{1}$ ) is evidently going on here. ${ }^{1}$ The fold of the amnios arising from this part is therefore the so-called "cephalic hood," and the other, at the opposite end, the "caudal hood." The amnios, folding backward and upward, and thus far closely following (Pl.9e, fig. 4, $\left.a^{1}, a^{5}, a^{6}\right)$ the outer surface of the embryo, has now covered a considerable portion of the head and back, - inclosing the head as with a closely fitting cowl, (PI. 12, fig. 1a, $a^{5}$ ) the thickness of which, in profile, resembles a narrow

1 By mistake in lettering this plate, $c^{1}$ was inserted for $e^{1}$. $\Lambda$ sharp pencil may easily correct this oversight. 
ring, and broadening over the back, so fur on each side $\left(a^{3}\right)$ as nearly to reach the borders of the now elongately oval area pellucida $(c)$, - while at the other end (Pl. 12, fig. 1a, $a^{2}$ ) it forms a similar covering, (Pl. 9e, fig. 4, $a^{2}$,) with a similar appearance in profile, and extending up along the back with a much broader expanse (Pl. 12, fig. 1, $\left.a^{2}\right)$ than at the anterior end $\left(a^{1}\right)$. At this time the dorsal vertebra have become conspicuous to the number of three or four, (Pl. 12, fig. 1, $f$, and $1 a, f$ ) and the spinal tube (fig. $1 a, e-e^{1}$ ) is closed over for more than half the length of the body. A longitudinal section (Pl. 9d, fig. 1) of the embryo at about this age may assist greatly to explain the manner of folding of the amnios; and here it will be seen that the cephalic portion of this layer does not bend suddenly upon the head and then upwards and backwards, but, after leaving the head, still keeps on for a short distance ( $\mathrm{Pl} .9 \mathrm{~d}$, fig. $\left.1, a^{6}\right)$ toward the posterior end of the body, then duplicating, passes forward and upward along the back to the edge of the upper fold, (Pl. 9d, fig. 1, $a^{1}$; Pl. 12, fig. 1, $a^{1}$, ) where it turns at a sharp angle upon itself and runs forward, sinking considerably as it traverses the area pellucida, (Pl. 9d, fig. 1, c ; Pl. 12, fig. 1a, $c$ ) but rising again passes over the whole surface of the yolk. The caudal hood, however, (Pl. 9d, fig. 1, $a^{2}-a^{2}$; Pl. 12, fig. 1a, $a^{2}$ ) turns abruptly upon the tail, and then, following its curvisture backwards, upwards, and for a short distance forwards, bends upon itself just as sharply (Pl. 9d, fig. 1, $a^{2}$ above, and Pl. 12, fig. 1, $a^{2}$ ) as the cephalic part, following now backwards its own previous advancing curvature, and, forming a considerable depression ( $\mathrm{Pl}$. 9d, fig. $1, c)$ as in front, finally continues $(a)$ over the peripheric portions of the yolk mass. The lateral portions of the ammiotic zone have not yet altogether risen above the lower edge of the body.

In a subsequent and little older phase, (Pl. 12, fig. 2, it is visible that the anterior or cephalic fold $\left(a^{1}\right)$ incloses the body more rapidly than the caudal one, $\left(a^{2}\right)$ so as to extend backwards beyond the half a dozen dorsal vertebra which have now become apparent. The shape of the space that still remains open in the amniotic fold above is variable, inasmuch as it is circular here; whereas in a little older condition (Pl. 12, fig. 3b, $a^{1}, a^{2}$ ) it is elongately oval; and then again, in a still older instance, it is circular (Pl. 12, fig. 4, $a^{1}$ ). By this time the lateral folds have risen to a level with the surface of the back, (Pl. 12, fig. 3b, $a^{1}, a^{2}$ ) and the lower bend of the cephalic hood (Pl. 12, fig. 3, $a^{6}$, 3a, $a^{6}$ ) has considerably extended backwards, so as to reach nearly to the middle third of the body. The breadth of this fold, reaching as it does. far on each side of the body, indicates that the lateral abdominal edges of the body have not yet folded inwards. What appears to be an anterior fold of the cephalic hood belongs to another layer, namely, the subsidiary layer, which, as we have said before, closely lines the lower side of the 
body: ${ }^{1}$ this layer here follows the bend of the head for a short distance, thus forming a double layer with the amnios in this region; but suddenly ( $\mathrm{Pl}$. 9d, fig. $1, a^{3}$ ) it leaves the track of the amnios, and, forming an angle, (Pl. 12, fig. 3, $a^{3}$, 3a, $a^{3}$,) changes its course, passing more directly forward to join the amnios again (Pl. 9d, fig. 1, d) on its centrifugal passage after the last bend above.

Soon the amnios censes to follow the surface of the body, and may be seen forming bridges (Pl. 12, fig. 6, 9, 9a, 10, 10a, 10b) across the sinuses between the prominent portions of the body, evidently under a high tension, if we may judge by the rapidity with which it contracts when eut in these places. This tension is not due to its being filled with fluid, for it is not yet closed over on the back; but the amnios is evidently kept in this state by the curved body striving to straighten out, which it does the moment it is set free from its restraint. By the time the eyes, the ears, a slightly saccular heart, the branchial fissures, a well developed vascular area, and all the vertebre but those of the tail, have become prominent features of the embryo, the amnios is nearly closed over, (Pl. 12, fig. 10a, $a^{2}, a^{4}$, ) by the gradual contraction of the anterior, posterior, and lateral dorsal folds.

Up to this time the body has hung partly supported by the amnios, and partly by the peripheric attachment of the subsidiary layer. In a view from below, (Pl. 12, fig. 10,) the amnios $\left(a^{5}\right)$ appears like a narrow halo extending over the whole length of the body and forms an aperture below, $(0,0$,$) similar to that$ above the back; but the sides of the aperture are not yet within the width of this region of the body. There are two peculiarities to be considered in the formation of the amniotic sac. 'The first is, that its closing over, above the back, does not take place along an extended line, but by an approximation of its edges towards a point, around which it gradually contracts, till the stratum that envelops the body is attached to the greater bulk of this membrane by a mere hollow neck, which, finally, is severed by the further constriction and union of the edges of the aperture. As would naturally be expected, as a consequence of this proceeding the outer peripheric portion also closes its aperture, and thus forms a continuous closed sac, lying just within the embryonal membrane, which, as we have already pointed out, follows closely every curve and angle of this layer, and consequently shares in the formation of these double saccular envelopes. The other peculiarity of the amnios is, that its folding upwards and concentrically is totally independent of all pressure from the allantoidian sac, which at the present time has but just begun to develop, though it eventually encroaches upon this region, following closely upon the surface of the already complete amniotic envelope. At the time of this change in the relations of the smaller inner, and the 
larger outer, ammiotic sacs, the latter no longer keeping the embryo suspended, this falls on its left side, (Pl. 13, fig. 2,) where it remains till a late period (PI. 13, $14,15,16)$.

As the embryo increases in age and the body bends more and more upon itself, the ammios gradually follows less and less the contours of the lower side, and reaches across broader simuses, namely, from the top of the head to the ventral opening, (Pl. 13, fig. 3; Pl. 14, lig. 4, 5; Pl. 18a, fig. S, $a^{1}$; fig. 13, $a^{1}$ ) and from the caudal region to the posterior edge of the same opening ( $\mathrm{Pl}$. 13, fig. 2; Pl. 1Sa, fig. 8, $\left.a^{2}\right) .^{1}$ 'This separation from the surface, agrainst which it formerly pressed, grows still more conspicuous, and soon the dorsal portion begins to raise itself above the back of the embryo, (Pl. 15, fig. 12, and then the whole amniotic sac swells out, (Pl. 9e, fig. 3; Pl. 14, fig. 1, 3; Pl. 15, fig. 4, 5, 12; Pl. 18, fig. 9a,) as if distended with fluid, far beyond the outlines of the body, and thus becomes very conspicuous. Iere then it is evident, that, at this age, the embryo remains in a curved position, by its own natural tendencies irrespective of its amniotic envelope. The distension of the amnios by the action of the infiltrated fluid would seem to indicate that there is a difference, at least in density, between the latter and that which is exterior to it, outside of the sac; else why should this endosmotic action take place? Unfortunately no investigation of these fluids has been made. Subsequently, in the latter stages of incubation, this distension subsides, and the amnios again closely embraces the body. In this condition it remains till the animal leaves its shell (Pl. 15, fig. 1, 2, 8, 8a, 9, 11; Pl. 18, fig. $10,10 \mathrm{a}, 10 \mathrm{~b}, 10 \mathrm{c})$.

Synchronically with the changes described above, the lower opening of the body gradually narrows, and bears along with it the basis of the amnios, till finally the latter is attached to the ventral surface by a narrow isthmus, (Pl. 9c, fig. :3 Pl. 14, fig. 1; Pl. 1.5, fig. 4, 5, 12; Pl. 16, fig. 5.) springing fiom the trumpet-shaped abdominal projection.

The peripheric portion of the germinal amniotic layer still persists after its separation from its inner fold, the "amniotic sac," and may be observed even to the latest moment before the period of hatching of the little 'Turtle. It is recognizable not only by its relation to the other membranes, the embryonal membrane and the allantoidian sac, but also by its characteristic cellular structure, (compare Pl. 9a, fig. 28 with fig. 31, b, 31a, b,) which will be described in another place, in comnection with the histology of the various organs and of other parts of the body.

Grouth of the Embryo. Immediately after the first steps are taken to bring out

1 'The largest figure of 1'l. 18 a marked 2, ought to bear' the number' 8 . 
more prominently the growing differentiation of the two opposite portions of the cmbryonic dise known as the cephalic and the caudal amniotic hoods, in contradistinction to those parts situated between them and at right angles with them, another feature develops itself, under the form of a sharply marked, superficial, short furrow, begimning near the cephalic end, (Pl. 9e, fig. $3, b$; Pl. 11, fig. 3, b, ) and trending thence backwards; thus dividing the body into two equal portions, which correspond to the right and left halves of the whole system. The elongation of this furrow continues for some time, (Pl. 11, fig. 4, 5, b; Pl. 9e, fig. $4, b$ ) and reaches almost to the caudal end, before any other peculiarity in any way related to its growth appears at the surface. A transverse section of the embryo, at the two periods just mentioned, shows that the longitudinal furrow (PI. 9e, fig. 3a, b, 4a, b, ) is not a hollowing out of a channel in the depth of the germinal layer, but that the whole thickness of the latter is depressed in the form of a sharp fold. which projects like a ridge on the lower side. But, beneath all this there is an important change going on, which has the closest comection with the furrowing above. In the younger of the two embryos just quoted, (Pl. 11, fig. 3; Pl. 9e, fig. 3, 3a,) at the upper side of the thick subsidiary layer mentioned above, (p. 536,) a broad band of its component, loosely packed, granule-like cells, as thick as the germinal layer above it, has become soparated and combined into a more firm stratum, (Pl. 9e, fig. 3, $f^{1}, 3 a, f^{1}$ ) equalling the length, and following the curve, of the whole embryo, but falling considerably short of the breadth of the same, and only occupying about one third of its whole brealth on each side of the middle line or furrow. The anterior and posterior ends (Pl. 9e, fig. $3, f^{1}$ ) of this band still remain continuous with its original basis, the subsidiary layer, ( $\mathrm{Pl} .9 \mathrm{e}$, fig. $3, o^{1}$ ) but laterally it is clearly and sharply separated (Pl. 9e, fig. 3a, $f^{5}$ ). It is important to notice, that, in this instance and in others of a similar kind, this proceeding is not a splitting up into thinner membranes of an already well developed cellular tissue, but a secession, a withdrawal of a certain amount of loose, unconnected cells from a larger bed or heap of the same materials. However, inasmuch as these cells are evidently arranged for a certain purpose, we do not intend to deny that there is a determined relation anong them, though still in an incipient state.

In the older embryo, noticed above, this broad band still follows the curvature of the lower side of the body, (Pl. 9e, fig. 4, $f^{1}$ ) which, up to this time, is greatest, and more folded in, at the cephalic end, whilst it has become more extended laterally (fig. $4 a, f^{1}, f^{5}$ ). Its central axis beneath the furrow appens to be differentiated in structure, since, when seen from below, it presents a sharply defined, narrow strip, having a tint dissimilar from that on each side of it (Pl. 11, fig. 5a, b, and Pl. 9e, fig. 4a, g). This is doubtless the chorda dorsalis, the 
relations of which will presently be pointed out more satisfactorily. The subsidiary layer partakes also of the curvatures of the body, following closely its lower surfice, as formerly (Pl. 2e, fig. 4 and $4 a, n, n, o^{1}$ ); but, instead of bending up with the amnios over the head, the sides, and the tail, it extends almost in a direct line (Pl 9e, fig. 4 and $4 \mathrm{a}, a^{3}, a^{4}$, and Pl. 11, fig. 5a, $a^{3}$ ) to the onter edge of the area pellucida, (Pl. 9e, fig. $4, d, 4 a, d$, ) and there, meeting the germino-amniotic layer, (Pl. 9e, fig. 4, a, and 4a, $a_{2}$ ) follows it closely all over the yolk mass. This conduct of the subsidiary layer causes the embryo to appear as if winged, (Pl. 11, fig. 5a, $a^{3}$,) when viewed from below. Ever since the albumen began to filtrate into the yolk sac, the subsidiary layer (Pl. 9e, fig. 1, o ${ }^{1}$ ) has been growing thimner; yet not rapidly, but only at such a rate that it is now (Pl. 9e, fig. $4,4 a, o^{1}$ ) reduced to about three fifths of the thickness it had in the beginning.

Making another advance of from ten to twelve days, we come to an embryo in which the ammios, both in its cephalic and caudal part, has progressed pretty lar up, on the back (Pl. 12, fig. 1, $a^{1}, a^{2} ; \mathrm{Pl} .9 d$, fig. 1, $a^{1}, a^{2}$ ). The primitive furrow has become a deep channel, (PI. 12, fig. 1, $e, 1 \mathrm{a}, e, e^{1} ; \mathrm{Pl}$. 9d, fig. 1, $e$, $e^{1}$, ) forming, at the head, quite a large cavity, (Pl. 9d, fig. 1, $e^{1}, e^{6}$, ) closed at one point $\left(e^{3}\right)$ by the arching over and uniting of its walls. Along the back, however, this gutter is still open (PI. 9e, fig. 5, e; Pl. 12, fig. 1, e; Pl. 24, fig. 13, $e$, fig. 13a, e); its lower floor (Pl. 9d, fig. 1, $e^{\bar{\gamma}}$; Pl. 9e, fig. 5, $e^{7}$ ) has broadened, and the whole is curved upwards into a round, cylindrical form, the thickness of which is considerably increased; but its edges, (Pl. 9d, fig. 1, $e, e^{2}$; Pl. 9e, fig, 5,e, although considerably turned inwardly, remain at a slight distance apart, and are still continuous by a sudden reduplication with the immediate and more peripheric part of this layer, (PI. 9e, fig. $5, p$, ) which has thickened also, but thins out toward the area pellucida $(c)$. At the posterior half of the embryo, this furrow, which may now be recognized as the initiatory phase in the formation of the spinal marrow, and of its enlargement, the brain, has not become so deep nor so narrow, (Pl. 9d, fig. 1, e; Pl. 12, fig. 1, e; Pl. 24, fig. $13, e, 13 \mathrm{a}, e$,$) but is yet a very broad channel, which gradually grows shallow$ backwards, and its sides become less elevated, till its lower floor is continuous, in the same horizon, with the space about it; so that a considerable part of the caudal portion (Pl. 9d, fig. 1, $e^{4}$ ) of the embryo is not yet endowed with a special spinal nervous system.

The broad band (Pl. 9e, fig. 3, $f^{1}$, fig. 3a, $f^{1}, f^{5}$, etc.) mentioned in former pages, which separates from the subsidiary layer, $\left(0^{1},\right)$ has now (Pl. 9d, fig. 1, $f^{1}$; PI. 12, fig. $1, f^{1} ;$ Pl. 24, fig. $13, f^{1}$ ) become very much thickened centrally, but thins out laterally, and presses closely against the floor of the spinal tube 
(Pl. 9d, fig. 1, $e^{\tau}$; Pl. 9e, fig. 5, $e^{i}$ ) and the contiguous portion on each side of it $(p)$. At about midway between the head and tail, this band is divided transversely, by four or five fissures, into so many block-like bodies (Pl. 9d, fig. 1, $f$; Pl. 9e, fig. 5, f; Pl. 12, fig. 1, $f$, fig. 1a, $f$; Pl. 24, fig. 13, $f$ ). These blocks are the dorsal vertebra; and through them we recognize that the "broad band" of former pages is the vertebral layer or basis, from and by which the backbones, constituting the axis of the skeleton, are formed. The chorda dorsalis along its middle portion is now distinctly separated from the vertebral layer, but remains hardly differentiated from the latter at its ends, (Pl. $9 d$, fig. $1, y, y^{1}$, ) and may be recognized as a long, cylindrical body, (Pl. 9a, fig. $1, y, y^{1}$; Pl. 9e, fig. 5, $y$, ) tapering before and behind, lying between the two halves of the broad band, to which it forms an axis. When seen through the thickness of the spinal marrow, this stylet-like body resembles a long and narrow continuous band, (Pl. 9e, fig. 5, $y-y_{2}$ ) bounded on each side by the abutting inner edges $\left(f^{2}\right)$ of the dorsal vertebre $(f)$ mentioned above.

The next lower and more interior layer, the subsidiary layer, (Pl. 9d, fig. 1, $n$; Pl. 9e, fig. $5, n$, ) is separated from those above by a shallow, open space, (Pl. 9d, fig. 1, $h, j^{2}$; Pl. 9e, fig. 5, $j^{2}$, which extends as far as the length and breadth of the body, and is deeper at the cephalic end, where a considerable portion is almost isolated (Pl. 9d, fig. $1, h$ ) from the rest. It will be seen presently that this is of significant importance in relation to the location and development of the system of circulation. The subsidiary layer, which forms the lower floor of this cavity, is thinner than formerly along its middle line, (PI. 9d, fig. $1, n$ ) excepting at the cephalic end, where it thickens as it follows the backward folding of the germino-amniotic layer (Pl. 9d, fig. 1, $a^{6}$ ). Beyond the outline of the body, however, it thins out again in all directions, and follows for a short distance the amnios 'as it folds upwards, but soon leaves the same and takes a more direct course $\left(a^{3}, a^{4}\right)$ to the edge $(d)$ of the area pellucida $(c)$. At the point where it leaves the cephalic hood to follow its own course forwards, the subsidiary layer makes a rather sudden bend, which, when seen from below, resembles the anterior edge of a broad wing, (PI. 12, fig. 1a, $a^{3}$,) whose posterior edge $\left(a^{6}\right)$ is the line along which the amnios, and along with it the subsidiary layer, projecting from each side of the body, bends upon itself, preparatory to covering the head. In older stages, this is still more prominent (Pl. 12, fig. 3, $a^{3}, a^{6}$, fig. 3̈a, $\left.a^{3}, a^{6}\right)$.

There is, at this time, beyond the body and for a certain distance (Pl. 9d, fig. 1, from $d$ to $i^{1}$; Pl. 9e, fig. $5, d$ to $i^{1}$ ) outside of the area pellucida, a dark, clear space of a strongly marked character, and readily recognizable by the naked eye. (Compare Pl. 14, fig. 12, which, although a little older phase, presents to 
the eye the same appearance.) Upon closer examination of the layers of cells within this space, we find that the subsidiary layer (Pl. 9d, fig. 1, o ; Pl. 9e, lig. 5, $0^{\mathrm{I}}$ ) has undergone a change, both in the closer aggregation and further self-division of its cells, so that it approaches in intimate structure that portion of its expansion (Pl. 9d, fig. 1, $n$; Pl. 9e, fig. 5, n) which lines the lower arch of the embryo. The exterior edge of this layer is thickened below, (Pl. 9e, fig. 5, $i^{1}$, ) so as to present a projecting annular ridge all round. Beyond this, again, the subsidiary layer remains as heretofore.

Another embryo, (Pl. 12, fig. 2,) although two days younger than the last, is considerably more advanced in its development. The amnios is much more closed over, $\left(a^{1}, a^{2},\right)$ and the head more sunk towards the centre of the yolk mass. The spinal marrow, for some distance behind the head, has become a closed tube by the uniting of its upward folding edges, (Pl. 9e, fig. 6, e, ) and its wall $\left(e^{i}\right)$ has increased in thickness. At the posterior third of the body it still remains open, and gradually loses its distinctness from the portion of the germinal layer which extends beyond. 'That portion of the germinal layer which lies on each side of the part of the spinal marrow that is closed over rests at a lower level than in the last, younger, stage which we have just described, and is considerably increased in thickness, $(\nu$,$) but thins out towards its periphery, till,$ at its second duplicature $\left(a^{2}\right)$ in the amniotic portion, it suddenly becomes exceedingly tenuous $(a)$; and so it remains wherever it may be found beyond the embryonic region.

The figure we have last referred to (Pl. 9e, fig. 6) represents a transverse section of the body at the anterior edge of its posterior third, along a line just behind the point (Pl. 12, fig. 2, $a^{1}$ ) where the amnios is still open. It will be noticed here that the vertebral layer ( $\mathrm{Pl}$. 9e; fig. $6, f^{1}, f^{5}$ ) is much thinner than in the section of a younger embryo made at the middle region. In the latter case the dorsal vertebra were already marked out, (Pl. 9d, fig. 1, $f$; Pl. 9e, fig. 5, $f$; Pl. 12, fig. $1, f$, fig. $1 \mathrm{n}, f$, ) and so they are in this embryo at the same place, and also much farther backwards; but, as we have shown in very young stages that the vertebral layer grows thimner backwards, so here the same obtains. 'The posterior ends of the spinal and vertebral layers appear to expand into broad, spatulate figures (1\%. 12, fig. 2); but this is not so much a peculiarity of these strata alone, as a feature arising from the manner of their partial comnection with the respective layers from which they take their origin. In both cases, as development defines the position and shape of each, the posterior expansions pass gradually farther and farther backwards (Pl. 12, fig. 3, 3a, 3b, 4, 7, 11, 12, 13). The chorda dorsalis (Pl. 9e, fig. 6, g) is large and well marked, appearing darker than the vertebral layer on each side of it, on account of the increased transpar- 
ency of its cells. The subsidiary layer (Pl. 9e, fig. 6, n, $o^{1}$ ) differs in nothing from that of the last embryo, ( Pl. 9d, fig. 1,) excepting that it is not separated from the vertebral layer $\left(f^{1}\right)$ by a hollow space; but this arises, as we have shown before, from the inequality in the development of the different organs.

In another embryo, which in some respects is no farther developed than the last, that part of the spinal tube which forms the brain (Pl. 12, fig. 3, $e^{1}$, fig. 3a, $\left.e^{1}\right)$ is closed over at the most anterior part; but the meeting edges are as yet not obscured, and a slight depression $\left(e^{\mathrm{I}}\right)$ remains at the extreme end of the fold, though it does not appear to amount to a passage-way into the brain cavity. The posterior part of the spinal marrow is much more extended backwards than in the last, and narrowed into a distinct band, still open and spreading at the hind end. The dorsal vertebræ are more marked, both externally and by a growing transparency in the centre, (PI. 12, fig. 3, 3a, 3b,) and the backward extension of the vertebral layer is more defined and distinct from the subsidiary layer. We have already mentioned the wings (P1. 12, fig. 3, 3a, $a^{3}, a^{6}$ ) which stand out on each side of the anterior part of the body, but again call the attention of the reader to this point, in order to explain the singular appearance of that region in another embryo, of about the same age (Pl. 12, fig. 4). Here the inequality of position and configuration of the projections that stand out from the body arise from the slight turning of the embryo upon its axis, and the consequent tension of the wings.

In a phase a little farther advanced, (Pl. 12, fig. 7,) in addition to the increased closing over of the tube of the spinal marrow at the posterior end, the farther multiplication of the dorsal vertebra behind, and the increased backward extension of the anterior edge of the closing over ventral cavity, a new feature appears - a glimpse of which has been given in a younger stage, (Pl. 9d, fig. 1, $h, j^{2}$; Pl. 9e, fig. 5, $j^{2}$ ) - upon the upper surface of the subsidiary layer, in the form of a broad, transverse band, (Pl. 12, fig. $7, i$ ) connected at its middle with a longitudinal one, $(h$,$) which forks (j)$ as it extends towards the head. A closer examination shows that this band is a hollow tube, and contains a movable, gramular fluid, indicating the first steps towards the development of the circulatory system. At this time the circulation is not continuous, but moves simply backwards and forwards, in compliance with the impelling force of the periodical contraction and expansion of the longitudinal portion of the tube, $(h$,$) which is the$ heart, without doubt. Beyond the outlines of the body, this figure represents the dark, clear space $(d)$ mentioned in a former page, (p. 538,) and also the thickening of its outer edge $\left(i^{1}\right)$ in the subsidiary layer. It will be noticed, that, on each side of the body, this thickened ring curves inward towards the transverse portion ( $i$ ) of the circulating system within the body. The meaning of 
this will be readily explained in a little older stage, in connection with the development of the peripheric circulatory system.

Soon the spinal tube (PI. 12, lig. 11, e) loses its spatulate shape at the posterior end, by continuing to close over and growing narrower, till its extremity appears to vanish in a long, slender point. At the cephalic extremity, the spinal tube, constituting the brain, has approximated its upward folding edges, (Pl. 12, fig. $8, c^{3}, 9, c^{3}, 9 \mathrm{a}, e^{3}$, ) so as to form a closed arch for a short distance along the region of the optic lobes, and thence to the anterior end of the head. Behind this closed portion, the spinal tube is yet quite open and broadly gaping, (fig. $8,9,9 a, e^{2}$ ) as far back as a point above the heart (fig. 9, $h$ ).

In connection with the brain, a feature appears which has not been noticeable before. On each side of the ventral portion of the hear, and beneath the region of the optic lobes, a slight protuberance ( $\mathrm{Pl} \mathrm{12,} \mathrm{fig.} 9$ and $9 \mathrm{a}, \mathrm{k}$ ) stands out, and is rendered otherwise more conspicuous by the fict that its component elements are differentiated from the mass of cells about them, so as to appear like a clear, broad ring (fig. 9, $k$ ) imbedded in a darker substance. From its position in the head, and its relation to the optic lobes of the brain, there can be no doubt that this is the eye. A similar differentiation occurs on each side of the head, opposite the posterior part of the gap of the brain, which is still open. Here the clear ring, (P1. 12, fig. 8, 9, and 9a, l, ) when viewed from above, appears to be a cup-shaped depression, (fig. $9 \mathrm{a}, l_{\text {g }}$ ) from the bottom of which a broad band of similar substance runs toward the base of the brain. This is unmistakably the ear. The dorsal vertebra (Pl, 12, fig. 9 and $9 \mathrm{a}, f$ ) are visible, close to the ears, and extend along each side of the whole length of the spinal tube to its end (PI. 12, fig. 11, f). 'The chorda dorsalis, now much elongated, underlies the spinal marrow, from the base of the optic lobes (Pl. 12, fig. 9a, g) to nearly the extreme end of the body (Pl. 12, fig. 11, g). Behind the vanishing part of the spinal tube ( $\mathrm{Pl}$. 12, fig. 11, e) the body is constricted considerably, and then expands into a short, oval termination, which contains the parts of the spinal, vertebral, and musculo-cutameous layers that are not yet isolated. The sides of the body $(p)$ are folded inwardly and downwards, and the anterior and posterior edges of the ventral cavity (Pl. 12, fig. 5, o) are still farther approximated than before, so that, when the body is laid upon its back, it resembles a canoe partly decked over, with an elevated prow.

On each side of the head, opposite the open part of the brain, three or four transverse furrows are visible (Pl. 12, fig. $8, m, 9, m$ ). These extend from near the lower median line of the head upward, almost to a level with the edges of the still unclosed spimal tube, (fig. $S$ and $9, e^{2}$ ) and appear to be superficial incisions in the musculo-cutaneous layer. These are the branchial fissures. The 
heart (Pl. 12, fig. 9, $h$ ) has bent upon itself slightly, assuming a sigmoid flexure, so as to produce a protuberance in this part of the body. The large vessel, spoken of above, in a little younger stage, as a broad, transverse band (see p. 547; Pl. 12, fig. 7, i) which is connected with the posterior portion of the heart, is now bent sharply upon itself, so as to assume a furcate shape (PI. 12, fig. 10, $i$ ). The heart $(h)$ has but a slight flexure laterally, but is bent strongly upon itself as it follows the curvature of the body to join the forked vessels $(j)$ which run towards the head. The clear, dark, circular area, which we have already mentioned above (Pl. 12, fig. $7, d$ ) as surrounding the embryo, still preserves a homogeneous aspect, (Pl. 14, fig. 12, but has expanded considerably, so as to exceed the embryo by one half the length of the latter.

Proceeding to a still further advanced phase, we find the embryo strongly bent upon itself vertically at each end, (Pl. 12, fig. 10, so as to bring the head down towards the heart, and the tail towards the abdominal cavity. The tube of the spinal marrow is nearly altogether closed over (Pl. 12, fig. 10, $\epsilon^{3}$, $\left.e^{4}, 10 \mathrm{a}, e, 10 \mathrm{~b}, e, 10 \mathrm{c}, e\right)$. The apparent gaping in one of the figures (fig. 10a, e) is owing to the circumstance that the view is not taken from the outer surface, but from the deeper parts of the spinal tube, thus showing the hollow passage through and along the organ. The dorsal vertebra (Pl. 12, fig. 10, f, 10a, "f) are more clearly defined. The eyes and ears are not so prominent as in the last-mentioned phase. The subsidiary layer, following the curvatures and the approximating sides of the lower surface of the body, has become a sac, whose broad mouth opens downwards through the abdominal aperture $(o)$ and in contact with it. Thence it spreads out, as heretofore, over the parietes of the yolk mass. The heart, (Pl. 12, fig, 10, h, ) in this animal, appeared still as it has already been described before; but, in continuance of this part of the subject, we may now point out the peripheric extension of the circulatory system. The clear, dark space bounded by an annular thickening of the subsidiary layer, (Pl. 12, fig. $7, i^{1}$ ) which has already been described, (p. 547,) is more or less streaked here (Pl. 13, fig. 10; Pl. 14, fig. 11) by dark, transparent channels, that run radiatingly from the embryo towards the parietes of this transparent area, where a few of them join a broken, irregular circle (fig. 11) of similar channels. The ring bending towards the body, which was pointed out in a former stage (Pl. 12. fig. $7, i^{3}$ ) as curving in elose comnection with the transverse broad band, or vessel, $(i$, ) behind the heart, corresponds here to the circular channels, which also curve inwards towards the same region as above, and join the transverse, or rather now forked, vessel, (Pl. 12, fig. 10, i, ) which enters the posterior end of the heart $(h)$. Within all these chamels, so fir as they are directly in comnection with the heart, there is a backward and forward motion of a granular, 
albuminous fluid, which is totally different in appearance from the blood, containing blood corpuscles, which is usually described as indicative of the earliest circulation. ${ }^{1}$ 'This fluid is set in motion by the impulsive contractions of the heart; as may very easily be seen by the help of a low magnifying power. This clear, dark area, which we now know to be the vascular area, is considerably increased in size beyond the space it occupied when first noticed, (see Pl. 14, fig. 12,) so as to have a diameter of about double the length of the embryo, and equal to one sixth of the circumference of the egg.

At the next step, we find the embryo still more bent upon itself, especially at the anterior part, (Pl. 12, fig. 6, ) where the head curves downwards and backwards so as to approximate the cardiac region $(h)$. A greater definiteness obtains in the outlines of the eyes (Pl. 12, fig. 6, $k$; Pl. 21, fig. 28) and ears (Pl. 12, fig. 6, l; Pl. 21, fig. 27). The spinal tube is still more closed over (Pl. 12, fig. 13, e). The dorsal vertebræ are more marked posteriorly (fig. 12, and $13, f)$. The subsidiary layer is still further contracted at its mouth, by the increased constriction of the abdominal parietes (fig. 13, o). The heart, (Pl. 12, fig. $6, h$, in addition to the sigmoid flexure of the last phase, has become swollen and curved downward towards the ventral surface of the body, carrying with it the superposed musculo-cutaneous layer. ${ }^{2}$ At this advanced stage of growth, the embryo is so transparent that the whole internal organization may very easily be recognized without the help of dissection. This transparency, however, does not amount to that glassy clearness which it obtains among the embryos of Fishes. The further progress in the evolution of the nervous system, the dorsal vertebra, the chorda dorsalis, the eyes, the ears, and the branchial fissures, will be described when treating of the special development of each of these organs; it being sufficient here to have traced their origin and mode of growth up to that period when the nature of each and all of them could be easily recognized. Hereafter we shall merely mention the degree of development of these organs at each phase, without adding any special details respecting the process through which they have passed to arrive at any particular stage, and at the same time describe

1 'This early circulation of an albuminous fluid with minute gramules probably precedes the formation of the blood in all Vertebates. I have observed it in Fishes and Birits.

2 If the embryo is cut out of the egr in connection with the vascular area and inmersed in sugar syrup, it will live, and its heart beat vigorously, for at least twelve hours. In some instances, when the whole egrg was sunk in syrup, after the shell had been taken off, the embryo lived not less than thirty-six hours. We have several embryos of different ages which have been preserved in strong syrup for more than two years, and the blood has just as clear and brilliant a red color as when it flowed through the vessels of the living animal. Caution, however, is necessary in transferring the embryo to the densest syrup in which it is eventually to be preserved, else the animal may shrink and become distorted. 
the mode of origin of whatever other organs may make their appearance in these later stages of embryonic growth.

In a slightly farther advanced stage, (Pl. 18a, fig. 13,) we find the amnios $\left(a^{1}\right)$ lias nearly closed over; the nervous system is about the same as in the last; the eyes $(k)$ have each a distinct crystalline lens (Pl. 24, fig. 8, $k^{3}$ ); the ears are more trumpet-shaped, (Pl. 18a, fig. 13, l,) and extend deeper into the head; and the dorsal vertebræ are perhaps more separated from each other. In this embryo we have been enabled to trace very distinctly the connection of the forked vessel, $(i$,$) which opens into the heart, \left(h_{2}\right)$ with the converging vessels mentioned above, (see Pl. 12, fig. 7, $i^{1}-i$; Pl. 14, fig. 11, which come from the outer edge of the area vasculosa. From the anterior part of the heart, the ventricle, (Pl. 18a, fig. 13, $h^{4}$, ) a large vessel $\left(h^{1}\right)^{1}$ arises and passes along just below the branchial fissures $(m, m)$ towards the head. From the dorsal side of this large vessel, the aorta, (PI. 18a, fig. 11, $\left.h^{1},\right)^{2}$ other small vessels $\left(h^{2}, h^{2}, h^{2}\right)$ proceed between the branchial fissures $(m)$ on each side of the head upwards, and join another large vessel, the dorsal artery $\left(j^{2}\right)$. The dorsal artery follows closely against the median line of the vertebral layer above, till it reaches the posterior end of the body. [See a little older embryo, (Pl. 18a, fig. 14, $j^{2}$, ) to trace its course as seen in profile.] When the embryo is viewed from below, (Pl. 18, fig. 7 , ) the dorsal artery may be seen giving oft to the right and to the left in the abdominal region, numerous vessels, which at once spread and ramify through the vascular area (p. 538). These numerous and minute vessels, the omphalo-meseraic arteries, have a general trend towards the circular channel spoken of above, ( $p$. 549,) the so-called vena terminalis, into which they empty. On each side of the head the vena terminalis converges and joins the forked vessel, (PI. 18a, fig. 13, $i, i$ ) which is connected with the posterior end, the auricle, of the heart. Thus we have a perfect circuit in the circulation of the blood. At the outset, the heart, the first part of the vascular system in which a fluid may be seen in motion, sends the blood forward, through the arteries of the branchial fissures, to the dorsal artery; the dorsal artery sends off currents into the area vasculosa; these currents, the omphalo-meseraic arteries, empty into the vena terminalis; and the vena terminalis returns the blood to the heart, through the forked vessel, the vena afferens.

There are also, within the body, circuits of blood of lesser extent than that

1 Pl. 18a, fig. 13, $h^{8}, h^{1}$. The dotted line, extending in the original drawing from these letters to the parts they designate, has been accidenally omitted here. From $l^{\text {s }}$ the dotted line should extend to the dark holc, in the nearest part of the heart, to that part of the norta which is just below the longest branchial fissure, $(m$,$) which runs from the ear (l)$ downwards.

2 This figure, although representing a little older phase, will scrve to show the direction of the ressels in this region of the body. 
already described. The dorsal artery, which runs along the middle line of the body, (Pl. 18, fig. 7 ) forks as it reaches its posterior termination. Each limb of the fork doubles outwardly upon. itself in a horizontal plane, and then passes forward parallel to, and in the same layer with, the dorsal artery, forming thus an abdominal vein, till it reaches the vena afferens, into which it empties, at a point a little posterior to the heart. 'That part of the dorsal artery which runs forward and forms a cephalic artery (Pl. 18a, fig. 11, j) branches and anastomoses extensively with return currents, the cephalic veins. These veins empty into the vena afferens, near the point where the abdominal veins discharge their contents into the heart. At the middle third of the body, the substance of the subsidiary layer is very much thickened around and above each abdominal vein, the thickening being shaped into a semicylindrical band, with the convex side downwards. Each thick band lies principally between the abdominal vein and the dorsal artery, and is peculiar from its having dark, obliquely transverse stria along its whole length. ${ }^{1}$ The relations of these two bands, one on each side, to the dorsal artery and the abdominal veins, and the peculiar transverse zigzag strix within their thickness, correspond so closely in their relations and appearance to the organs, which, in a more advanced embryo, may be recognized as the Wolffian bodies, that we have no hesitation in identifying the former with the latter, both in name and in function. The sides of the abdominal cavity are more constricted than we have known to obtain before. The branchial fissures (Pl. 18a, fig. 13, $m$ ) extend through the musculo-cutaneous layer, and open into the cavity of the pharynx. The subsidiary layer, by folding together along the axis of the body and bringing the faces of its two opposite halves in contact, forms a double pendent curtain, the height of which equals the thickness of the body above it. The double lower edge of this curtain still remains in connection with the rest of the subsidiary layer, the latter expanding horizontally as heretofore, but at a lower level. In a transverse section ( $\mathrm{Pl}$. 9e, 7) of the posterior third of the body, we do not find the least trace of a curtain; but, on the contrary, the subsidiary layer $\left(n, o^{1}\right)$ expands directly outwards from its basis of attachment. This layer, excepting that the dorsal artery, the abdominal veins, the Wolffian bodies, and the pendent curtain have been formed by it, appears to have undergone no other change than to adopt the shape which the approaching sides of the body have impressed upon it.

Another embryo of the same species, Nanemys guttata, (Pl. 18a, fig. 14,) although one day younger than the one just described, is more advanced.' ${ }^{2}$ The whole body

I See an older phase for the peculiar appearance of this band (1). 18a, fig. 8, 9).
2 The amnios in this figure is represented as torn open along the middle region of the body. 
is more developed. The brain $\left(e^{3}\right)^{1}$ is already slightly three-lobed; the region of the medulla oblongata $\left(e^{1}\right)$ is more closed over; the eye $(k)$ is more isolated from the surrounding parts: the heart is much more enlarged, and stands out conspicuously beyond the ventral surface of the body; the aortic bulb $\left(h^{1}\right)$ is now quite a prominent feature. At a point $\left(j^{5}\right)$ a short distance behind the heart, the dorsal artery $\left(j^{2}\right)$ gives off only a single, but very broad, omphalo-mesmeraic vessel, $\left(j^{\ddagger},\right)$ as if the many vessels of the last phase had merged into one great channel. As this figure, with the exception of the head, is not an exact profile, but rather a combination of a profile view and a view obliquely from above, the dorsal artery $\left(j^{-2}\right)$ appears to be nearer to the ventral surface than it really is, and the dorsal vertebræ $(f)$ seem thicker than is natural.

In a little more advanced phase, ( $\mathrm{Pl}$. 13, fig. 2, and 3,) the spinal marrow is more extended backwards into a distinctly developed tail (wood- Wood-cut 1. cut 1 ). ${ }^{2}$ The dorsal vertebræ (wood-cut $1, f$ ) reach to the root $j^{2} f$ of the tail. The eyes have become entirely inclosed within complete orbits. The heart has become three-chambered; the single auricle of the last phase (Pl. 18a, fig. 14, $h$ ) being now divided into two cavities, thus leaving its fish-like character, and adopting

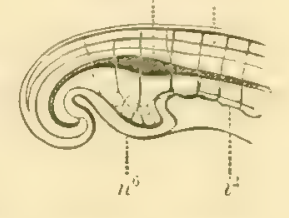
a structure which is peculiar to scaly Reptiles alone. The dorsal artery (woodcut $1, y^{2}$ ) extends to the end of the tail, and the cephalic artery branches extensively in the head. The fork of the vena afferens, which in the beginning originated close to the heart, (Pl. 12, fig. $7, i$, $i$, fig. 10, $i$ ) but later receded (PI. 18a, fig. 13, $i, i$ ) from this organ, is now (Pl. 13, fig. 2) some distance beyond the body, towards the vena terminalis. This embryo presents a feature (wood-cut $\left.1, n^{6}\right)$ in the posterior region, which, at first sight, might be mistaken for the hind foot just budding forth. Upon close scrutiny, however, we discover that this protuberance is in the perpendicular plane of the axis of the body, and is based upon that area close to where the tail arises. This protuberance is a simple hollow sac, formed by the folding together of the two opposite halves of the subsidiary layer, uniting their edges below. The dorsal artery (wood-cut $1, j^{2}$ ) runs close upon and above this protuberance, thus showing that the latter is a later production of the same layer which developed the former, the dorsal artery, upon its middle line. Since we find this protuberance (wood-cut 1, $n^{6}$ ) in such a connection, and moreover see traces of bloodvessels coming from the dorsal artery (wood-cut $1, j^{2}$ ) branching in it, we conclude that this must be the allantois.

I In 1 1. 18a, fig. 14, the first letter to the left of $k$, should be $e^{8}$, instead of $e^{1}$.

2 'This wood-cut corresponds exactly to the parts in Pl. 13, fig. 2 which it represents, and is chiefly intended to point them out more minutely, no letters having been introduced in the original figure. 
There are two vessels to be seen here, one on each side of the body, which rum, from the region of the allantois, forward (wood-cut $1, i^{2}$ ) - as the arrows indicate (Pl. 13, fig. 2) - along the sides of the body, and empty into the heart. That these are the allantoidian veins there can be no doubt, since no other vessels are developed in this region at any time. Between the point of origin of the allantois, on the one hand, and the anterior edge of the abdominal opening, on the other, the subsidiary layer remains in open communication with the mass of yolk below.

As this layer proceeds beyond the edge of the abdominal cavity, it rises gradually, until, at the edge of the area pellucida, it comes to a level with the back of the animal, and with it presses closely against the shell membrane. At the same time it bears along, within its thickness, the vessels of the vascular area, so far as the vascular network extends. The vessels of the vascular area have become very distinct, and run more parallel to each other than heretofore. Those which arise distinctly from the dorsal artery have considerably decreased in number, but are enlarged, as regards the size and capacity of each; moreover, they have a general tendency towards one point (PI. 13, fig. 3, q) of the body. The head and fore part of the body are sunk so much towards the centre of the yolk, that the subsidiary layer forms a very deep hood, (Pl. 13, fig. 2,) as it folds upwards around the cephalic region, and rises to a level with the other portion of the layer. About this time the body turns upon its axis, (P. 13, fig. 2, and 8, ) so as to present its left side towards the centre of the yolk. This change in the position of the embryo has been noticed in a former paragraph, (p. 541,) where it was shown that it is owing to the closing over of the amnios, by which process that portion of the amnios which embraces the body is separated from the peripheric portion of the germino-amniotic layer, and the latter part ceases to support the body in a vertical position.

In the next more developed phase which we have investigated, the embryo is so much bent upon itself as to form a semicircle; but the head and thorax are more suddenly curved than the posterior region of the body. The end of the head is more elongated and pointed. The brain (Pl. 24, fig. $7, c^{2}, c^{5}$ ) is divided into at least three lobes or compartments, by two deep folds trending in the direction of the axis of the body, the deeper one of which $\left(e^{5}\right)$ is behind the eye, $\left(k_{g}\right)$ and the other before it. The eyes (fig. $7, k$, and fig. $7 \mathrm{a}, k$ ) are increased in size. The ears (Pl. 24, fig. $7, l$ ) are very broad, trumpet-shaped. The dorsal vertebre have extended very far into the tail (PI. 24, fig. 14, f, fig. 15, $f$ ); but they are very diminutive there, in comparison with those in the more anterior region of the cerebro-spinal axis, and the vertebral layer (fig. 14, $f^{1}$ ) extends to the tip of the much elongated tail. The heart (Pl. 18a, fig. 11, $h^{3}, h^{4}$, fig. 12, 
$h^{3}, l^{4}$; Pl. 24, fig. $\left.7, h^{3}, h^{4}\right)$ is not sensibly changed; but the dorsal artery (Pl. 18a, fig. $11, j^{2}$ ) has increased in diameter, especially in a horizontal direction. Just behind the heart and close to the ventral surface there is a small, dark. round body, which, in all probability, is the incipient liver. The allantois (Pl. 24, fig. $15, n^{6}$ ) has considerably increased in size, and is transformed into a two-lobed organ, by a longitudinal constriction. From the region of the heart to the basis of the allantois, the subsidiary layer (Pl. 24, fig. 14, n, fig. 15, n) remains broadly open, but not to the extent that obtained in the last phase. The aperture of this layer is limited by the contracted sides of the body, which have reduced the abdominal opening (Pl. 24, fig. 14, o) to one quarter the length of the body. The branchial fissures (Pl. 18a, fig. 11, $m$; Pl. 24, fig. 7, $m$ ) are more or less gaping. On the exterior of the body, at a short distance behind the heart, and also just posterior to the allantois, the musculo-cutaneous layer projects in the form of little bud-like excrescences (Pl. 24, fig. 14, $w^{1}$ ). There are a pair of these in front and a pair behind, corresponding to the position of the feet.

Progressing still farther, we find an embryo with the head still more bent upon the thorax (Pl. 14, fig. 5) than in the last, so as almost to touch the heart; this embryo exhibits also a considerable increase of size. The brain (Pl. 24, fig. 9a, $\left.e^{2}, e^{3}, e^{5}\right)$ is more deeply folded, especially at the sides $\left(e^{5}\right)$. The eyes (fig. $9 \mathrm{a}, k$, fig. $12, k$ ) are perfectly round, and very prominent; the pigment layer is quite black. The front end of the hend is indented, close to the lateral parietes on each side of the middle line, by a deep, broad depression, (PI. 24, fig. 12, v,) the lower side of which is bounded by a diverticulum-like protrusion from the inferior surface of this region. The dorsal vertebre are more numerously developed in the tail (Pl. 14, fig. 5). The heart (Pl. 24, fig. 9, $h^{3}, h^{4}$, fig. 9a, $h^{4}$ ) is much enlarged, and projects so far on the abdominal side, that it renders this region the thickest part of the body; its auricles (fig. $9, h^{3}$ ) are very distinct from the ventricle, $\left(h^{4},\right)$ not only by their position, but also by the peculiar spongy nature of the cavity of the ventricle (fig. $9, h^{4}$, fig. 9a, $h^{4}$ ). The network of peripheric bloodvessels in the head is more numerously developed, especially at its end (Pl. 24, fig. 9a). The fork of the vena afferens (Pl. 14, fig. 5) is now at the rena terminalis; the venæ abdominales ( $\mathrm{Pl}, 24$, fig. 9, $\left.i^{3}\right)$ and the venx capitis $\left(i^{5}\right)$ empty with larger channels into the heart $\left(h^{3}\right)$. The abdominal veins (fig. 9a, $i^{3}$ ) are closely approximated to, but run in a plane a little below, the dorsal artery $\left(j^{2}\right)$. The omphalo-meseraic arteries (PI. 14, fig. 5) spring from one common point of departure, and, by their increased size, render the vascular area much darker. The subsidiary layer has undergone a considerable change at the anterior part of the body, both in front and above the heart, where, in the form of a great, capacious tube, (Pl. 24, fig. 1, $l^{\prime}, I^{\prime \prime}, I^{\prime \prime}$,) it forms the lining of the 
cavity into which the branchial fissures open; its right and left sides are so folded inwardly and longitudinally as to shape the whole into a double channel, one of which $\left(l^{\prime}, l^{\prime \prime}\right)$ lies next to the back, and the other, which is much narrower, $\left(I^{\prime \prime \prime}\right.$,) next to the ventral side of the body. These chamnels communicate with each other by means of a small aperture, $(5$,$) which is situated near the$ posterior end of the longitudinal fold. From the posterior end of the lower chamnel, $\left(I^{\prime \prime \prime},\right)$ two short blind sacs, $(1,1$,$) one on each side, protrude horizontally$ and in a backward direction, pressing against that portion of the subsidiary layer (I') which remains a single tube.

The larger of these chamnels occupies by far the greater part of the cavity in front of the heart; but, behind this organ, it grows narrow, giving place to a larger, globular, dark body, (Pl. 24, fig. 9, r, 9a, r, which occupies nearly the whole breadth of the body next to its ventral side, and close behind the heart; and finally, at the abdominal opening, it flares broadly open, but not so widely as in the last phase, forming a direct communication with the yolk mass below. This is the beginning of the intestinal canal, the broadest part of which corresponds to the oesophagus, and the part that follows behind, to the stomach; the long, thin intestine of the adult being at this age a broad, open layer, excepting at the extreme posterior end, where the allantois springs from it.

The smaller of these channels commences in front, close to the angle where the head is bent upon the neck, (Pl. 14, fig. 5,) and extends backwards as far as the heart, and there, as we have already mentioned, divides into two blind sacs. Every relation which this channel bears to the oesophagus points out its identity with the respiratory system, and therefore the single part of the channel must be the windpipe, and the two blind sacs, the lungs. We have not traced the origin of the large, dark body (PI. 24, fig. 9, r, 9a, r) behind the heart; but from its size, position, relation, and dark color, it must be the liver. It will be noticed that the subsidiary layer, which composes these two channels, is separated into two strata. The interior of these strata, both in the intestine ( $P$ l. 24, fig. 1, 2, $2^{\prime \prime}$ ) and in the lungs and windpipe, $\left(2,2^{\prime \prime \prime}\right.$ ) is no doubt the epithelial layer. The allantois (Pl. 14, fig. 5) is not larger than in the last-mentioned phase, but it shows traces of bloodvessels. The Wolfian bodies, blending closely with the vene abdominalis, (Pl. 24, fig. 9a, $i^{3}$ ) render the latter apparently larger than they really are. The abdominal opening is now contracted to a much diminished space, lying between the liver (Pl. 24, fig. 9a, $r^{*}$ ) in front, and the allantois behind, and narrowed to half the width of the body. 'The feet (Pl. 24, fig. 9a, w) are not further developed than before. The caudal portion of the body, the tail, (Pl. 14, fig. 5,) beyond the allantois, is much longer and more slender than in the last stage; and at its base, close behind the allantois, 
where the anus originates at a later period, there is a deep, transverse fissure, the first indication of the posterior opening of the alimentary canal.

Another embryo, (Pl. 14, fig. 4,) to all appearances identical in development with this, has a considerably larger and much more highly vascular allantois. The allantoidian artery $(o)$ is quite large, and the allantoidian vein $(t)$ has already assumed that wavy course which is so characteristic in older phases. The abdominal artery and the abdominal vein are here very conspicuous along the whole length of the body, even to the end of the tail.

The embryo of another species, Nanemys guttata, (Pl. 16, fig. 6, 6a,) although not more developed than the last two, has an allantois still larger than either of them. It extends its bulk along the whole abdominal region, from the heart to the tip of the tail, and even beyond. The median constriction, which we have already pointed out in a much younger phase, (p. 555; Pl. 24, fig. 15, $n^{6}$ ) is here very conspicuous, yet does not trend in the direction of the longitudinal axis of the body, as at the time of its earliest appearance, but is twisted so as to run obliquely across its former path. This change corresponds with the alteration in the position of the allantois, which, instead of lying symmetrically across the embryo, rests with one part of its constricted bulk next to the head, and the other part in the caudal region. This is the first indication we have of the tendency of this organ to spread over the surface of the animal. After noticing that the line of constriction of the allantois is occupied by the main vessels, arteries and veins, and referring to the youngest phase in which this constriction is visible, but without bloodvessels, it becomes evident that the path of the allantoidian arteries and veins is marked out almost from the time of the origin of the allantois.

We have already pointed out the change in the attitude of the embryo (p. 541, and 554; PI. 13, fig. 2) from a vertical to a horizontal position, with its left side downwards; but will refer to it again now, in connection with a corresponding change which the allantois has assumed in its position. Inasmuch as the right half of the allantois cannot expand laterally, with reference to the embryo, on account of the egg shell, which is closely above, it must take another direction, and consequently the left half also is moved from its former position. It is this change in the direction of its expansion that has twisted the whole allantois upon its axis. Here, too, the sinking of the area pellucida becomes conspicuous, not only in consequence of its having fillen below the general level of the vaseular area, but also because of its bearing upon the expansion of the allantois, to which it gives place. The boundaries of this depression are marked by a sudden bending upwards of the omphalo-meseraic bloodvessels. The bloodvessels of the allantois are very numerous, and anastomoze with each other by a multitude 
of capillaries, evidently evincing a high state of vaseular organization and activity. As regards the other parts of the embryo, we have but little to notice that is new, except to point out the already mimute ramifications of bloodvessels in the head, a feature not represented in the two embryos last mentioned. At this stage, the so-called vena terminalis also merits particular notice, inasmuch as it has now become as distinetly a vessel as it ever will be. In 'Turtles' embryos this vein never becomes a single perfect circular channel, as is the case among Birds. Wherever there appears to be a single large current, it will be found, upon close examination, to be made up of an infinite number of minute anastomozing vessels. (See Pl. 17, fig. 6, which, although a little older, exhibits the same appearance.) It will soon be seen that this peculiarity becomes a more prominent and readily noticeable feature in further advanced stages.

At this age, the diameter of the vascular area of this species, and of all the other species with oval eggs, is broader in one direction than in the other, its greater breadth corresponding to the longer axis of the egg. In globular eggs there are no such differences; but the vascular area always continues more or less circular. In their younger stages of development, oval eggs also have a circular vascular area, as is shown in the case of Nanemys guttata (PI. 18, fig. 7). We have mentioned previously the growing tendency of the vessels of the vascular area to trend in a direct line from the point of their origin towards the vena terminalis. This tendency is now carried out to the utmost in this egg, so as to give to the vessels a stiff and rigid appearance (Pl. 16, fig. 6).

The next older stage (Pl. 14, fig. 2, 2a; Pl. 18, fig. 8; Pl. 18a, fig. 6-10; Pl. 24, fig. 2, 2a; Pl. 9e, fig. 8, 8a, 9, 9a; Pl. 19, fig. 4; Pl. 22, fig. 9) offers some new and remarkable features in addition to a further development of the different organs.

The brain of this embryo (Pl. 14, fig. 2a; Pl. 18a, fig. 9; Pl. 22, fig. 9, b, $\left.b^{1}\right)$ has become strongly lobed, especially in the region above the eyes, where it is so prominent as to give the head a crested appearance. The lower side also projects downwards between the eyes, ( $\mathrm{Pl} .22$, fig. 9, $c$,) where it constitutes the optic lobe. The dorsal vertebre reach to the tip of the tail (Pl. 14, fig. 2a). They have so approximated their opposite halves (Pl. 9e, fig. 8, $f$, fig. $8 \mathrm{a}, f^{\prime}$ ) as almost to inclose the spinal marrow (fig. 8, $e$, fig. $8 \mathrm{a}, e$ ) in a perfect tube. The chorda dorsalis (fig. $\mathrm{S}, \mathrm{y}, \mathrm{Sa}, \mathrm{y}, 9, y, 9 \mathrm{a}, \mathrm{g}$ ) is still very conspicuous, and appears to have increased in diameter. The musculo-cutaneous layer (Pl. 9e, fig. \&, p. $p^{1}$, fig. $8 \mathrm{a}, p, p^{1}$ ) is separated into two portions, namely, an outer (fig. 8, 8a, $p$ ) or dermal layer, and an inmer (fig. 8, 8a, $p^{1}$ ) or musculo-costal layer. The end of the head below the eyes is quite pointed (Pl. 14, fig. 2a). The eyes are very prominent (Pl. 14, fig. 3; Pl. 18a, fig. 7, $k$, and fig. 9; Pl. 22, fig. 9, c). The retina (Pl. 
22, fig. $\left.9, d, l^{1}\right)$ is folded inwardly at several points, a peculiarity which reminds one of the falcate process in the eye of certain Birds, and the flabellum in Fishes. The two deep depressions at the end of the head, noticed in a former page, ( $p$. 555, Pl. 24, fig. 12, v,) are here (Pl. 18a, fig. 9, v) very much broadened, but at the same time the edges are curved inwardly towards each other:

The heart (Pl. 18a, fig. 8, and 9, $h^{3}, h^{4}$ ) is separated into two very distinct portions, the auricle (Pl. 18a, fig. $\left.6, h^{3}\right)$ and the ventricle, $\left(h^{4}\right)$ which are joined by a narrow tubular isthmus. Although the heart is divided into three chambers, the course of the blood is not at all diverted from the channel in which it ran at the beginning. In one of our figures, the heart (Pl. 18a, fig. 10, $l^{3}, l^{4}$ ) is so displayed that its threefold division may be readily seen, and the course of the blood easily understood. From the receiving chamber, the right auricle, $\left(l^{3},\right)$ the blood passes directly into the left aturicle, (the middle chamber in the figure, and from that into the ventricle, $\left(h^{4},\right)$ and thence, through the bulbus arteriosus, $\left(h^{1}\right.$, fig. $6, h^{1}$, ) into the dorsal artery, etc. The vessels which ramify around the brain are becoming very numerous, (Pl. 14, fig. 2a; Pl. 18a, fig. 7, $i^{5}$, ) especially (Pl. 18a, fig. $7, j$ ) in the neighborhood of the medulla oblongata. The dorsal artery (Pl. 9e, fig. 8, $j^{2}$, fig. 8a, $j^{2}$; Pl. 18a, fig. 7, $j^{2}$, fig. 7a, $j^{2}$, fig. 8, $j^{2}$ ) runs to the tip of the much elongated tail. The omphalo-meseraic artery (Pl. 18a, fig. $8, j^{ \pm}$, fig. $\left.9, j^{4}\right)$ is much elongated, and projects as a single vessel, far beyond the lower surface of the body, to where the intestine $\left(x^{1}, x^{\prime}\right)$ communicates with the yolk, and then ramifies, as usual, in the vascular area. The abdominal veins (Pl. 18a, fig. $7, i^{3}$, fig. $7 \mathrm{a}, i^{3}$, fig. $8, i^{3}$ ) appear to be in very intimate connection with the Wolffian bodies (fig. $7,7,7 \mathrm{a}, q, 8, q$ ). The allantoidian artery (Pl. 18a, fig. $7 \mathrm{a}, j^{3}$, fig. $8, j^{3}$, fig. $9, j^{3}$ ) remains single, from its point of origin (Pl. 18a, fig. $8, j^{6}$ ) to far beyond the body. The allantoidian veins (Pl. 18a, fig. $7, i^{2}$, fig. $-7 \mathrm{a}, i^{2}$, fig. $\delta,{ }^{2}$, fig. $10, i^{2}$ ) are remarkably wavy in their course along the sides of the body, and even to the point where they empty (Pl. 18a, fig. $7, i^{4}$, fig. $S, i^{ \pm}$, fig. $10, i^{4}$ ) into the venous sinus. The omphalo-meseraic or afferent vein (PI. 18a, fig. 8, i, fig. 9, i, fig. 10, $i$ ) empties, with the abdominal, the cephalic, and the allantoidian veins, into a common reservoir, the venous sinus (fig. $8, i^{4}, 10, i^{4}$ ). Its course near to and within the body is in contact with and along the lower surface of the intestine, (PI. 18a, fig. 8, $x^{\prime}$, fig. 9, $n^{\prime}$,) and upon the upper surface of the liver (fig. $8, r$, and $9, r^{r}$ ).

The intestine (Pl. 9e, fig. $8, x^{2}$; Pl. 18a, fig. 7a, $n^{1}$, fig. 8, $n^{\prime}, n^{1}, x^{4}$, fig. 9, $x^{\prime}, x^{1}, x^{2}$; Pl. 24, fig. 2, $x^{2}, x^{4}$ ) has become longer than the whole abdominal region, and projects in a fold through the ventral opening. It still remains in open communication with the yolk, but, with a narrow aperture at its posterior end, (Pl. 18a, fig. $8, n^{5}$ ) projects slightly beyond the body, but does not open so as to form 
an anus. The mesenterium, (Pl. 9e, fig. $8, n^{8}$, fig. $8, x^{8}$ ) that part of the intestino-subsidiary layer which keeps the intestine suspended from the median line of the body, may now be recognized as the pendent curtain which was formed by the subsidiary layer in a much younger embryo (see p. 552). That part of the intestine which passes along above and around the liver (Pl. 9e, fig. S, r; Pl. 18a, fig. 9, r) has become considerably swollen, (Pl. 9e, fig. 8, $n^{2}$; Pl. 18a, fig. $9, n^{2}$ ) so as almost to equal the proportions of the full-grown stomach. The respiratory apparatus (Pl. 24, fig. 2, $t, t^{\prime}$, fig. 2a) has separated entirely from the intestine, (fig. 2, $x^{2}, n^{4}$ ) and the lungs have become swollen (fig. 2, $t^{\prime}$, fig. 2a). The liver (Pl. 9e, fig. 8, r; Pl. 18a, fig. 8, r, fig. 9, r) is very dark, and has lost the globular form of earlier periods, (p. 556, Pl. 24, fig. 9a, r, and become more flattened vertically, and lobed on the left side, where it overlaps the stomach (Pl. 18a, fig. 9, $\left.n^{2}\right)$.

The Wolffian bodies (Pl. 9e, fig. 8, q, fig. 8a, $q^{3}$; Pl. 18a, fig. 7 , q, fig. $7 a$, q, fig. 8, q, fig. 9, q) occupy fully one half the length of the body, and exhibit very clearly the zigzag strix spoken of in a former page (p. 557). In a transverse section of the embryo (Pl. 9e, fig. 8) just behind the fore feet, the duct $\left(q^{1}\right)$ of the Wolffian body $(q)$ is shown to be a dorsal channel, and already of a considerable diameter.

The allantois (Pl. 14, fig. 2, 2a, 3; Pl. 18, fig. 8; Pl. 18a, fig. 7a, $n^{3}, j^{3}$, fig. $8, j^{3}$, fig. $9, i^{2}, j^{3}$ ) reaches from the head to far beyond the tail, and laps over upon the right side of the body, so as to cover a large part of the posterior region of the body ( $\mathrm{Pl}$. 14, fig. 2a). In the case of another embryo, (Pl. 14, fig. 2, of the same degree of development in other respects, the allantois overlaps all but the head and shoulders, and extends so far beyond as to cover four fifths of the area pellucida. The bloodvessels of this organ are very large and thick, and anastomoze with each other by innumerable capillaries. It is a remarkable peculiarity of the allantois that its arteries ( $\mathrm{Pl} .18 \mathrm{a}$, fig. 8, $j^{3}$, fig. 9, $\left.j^{3}\right)$ and veins $\left(\mathrm{Pl} .18 \mathrm{a}\right.$, fig. $8, i^{2}$, fig. 9, $\left.i^{2}\right)$ run parallel and close to one another for a long distance, in that part of the organ which is outside of the body. In a view from below, (Pl. 18a, fig. 7a, and 9, ) it is shown how the allantoidian arteries $\left(j^{3}\right)$ arise, one from each side of the dorsal artery, $\left(j^{2},\right)$ and, bending around the intestine, $\left(n^{1}\right)$ converge just below it, and thence run along the narrow peduncle of the allantois out into its great expanded mass.

The abdominal opening is contracted so as to equal about one sixth of the length of the body, exclusive of the tail.

The feet project considerably beyond the body, and have an oval, paddle shape; but, as yet, there are no signs of toes. This is the earliest period in which bloodressels have been seen in the feet (Pl. 14, fig. 2a). 
The area pellucida, (Pl. 14, fig. 2, 2a; Pl. 18, fig. 8,) and the space to a considerable extent beyond it, are much more sunk than in the last stage, (p. 557, Pl. 16, fig. 6,) so as to correspond to the increased size and expansion of the allantois. The area vasculosa covers at least one half of the yolk mass (Pl. 18, fig. 8). The fork of the vena afferens, and the portion of the vena terminalis and of the omphalomeseraic vessels next to it, ( $\mathrm{Pl}$. 14, fig. 2 $\mathrm{a}_{9}$ ) have sunk below the surface of the yolk mass, but yet not so far as to be invisible. In another instance (Pl. 1.t, fig. 2) the vena afferens $(r)$ itself, and at least one half of the vena terminalis, $\left(r^{1}, r^{1}\right)$ have sunk considerably below the level of the vascular area, and retracted within its former boundary. What appears to be a circular vessel in the place of the one that is now depressed is the line along which the vessels of the area vasculosa bend upon themselves, and plunge into the yolk mass, in order to join the vena terminalis $\left(r^{1}, r^{1}\right)$.

The yolk sac has decreased considerably in bulk, and accupies about two thirds of the cavity of the shell, the other third being filled by the embryo and its envelopes. The lungs (Pl. 24, fig. 3, 3a) of an embryo four days younger than this are much more developed; their transverse diameter is much greater at the base than at the apex, so that they resemble in figure the adult state; and the cavity of each is subdivided into two compartments, (fig. 3a, 2, 2, ) namely, the original one, rumning along its whole length, as in the last stage, (fig. 2a, 2, and another, much shorter, which branches from the main channel at the base of the lung, and trends toward the ventral side of the animal. The epithelial layer, (fig. 3a, 2, 2,) which lines this double chamber, is much thicker than in the last phase, not only in the lungs, but also in the windpipe, $\left(2^{\prime \prime \prime},\right)$ especially where the two bronchiæe branch (5). The cavity of the lungs is as yet very narrow, resembling a mere slit along their length.

Up to this period the head has exhibited moderate proportions when compared with the trunk of the embryo, so that its size has not attracted any particular attention. In the next stage, (Pl. 15, fig. 13; Pl. 16, fig. 3; Pl. 18a, fig. 4, 5; PI. 24, fig. 11, however, there appears a great disparity between the different regions of the body. The head has increased to an enormous size when compared with its former proportions, so that it almost equals the whole trunk; in fact, if an outline of the head and neck be laid over that of the trunk, the two will be found to be nearly equal in size. The breadth of the head, including the eyes, far exceeds that of the body, although the latter has broadened also. (See Pl. 6, fig. 25, which, although belonging to a totally different family from that of fig. $13, \mathrm{Pl} .15$, is yet identical as regards the proportions of the body, so far as a small figure may serve for such a comparison.) 'The encephalon, just above the eyes, is much broader than has been noticed heretofore, (PI. 
6, fig. 25,) so that in fact this is the widest part of the head, excepting the region which includes the eyes.

Along a line just above the legs, both sides of the body project with a rather sharp edge, which is formed by a longitudinal fold in the skin, so that, passing from below upwards, the body suddenly broadens, and forms, above, as it were a roofing for the lower side of the animal. When seen from above, (Pl. 6, fig. 25, this roofing appears narrow and ovate, with the broader end towards the head. This is the earliest period at which the shield commences to develop. The wavy surface of the back (Pl. 15, fig. 13) indicates the presence of the ribs, each wave corresponding to a single rib. The tail is also enormously developed, and more than equals the length of the trunk in Chelydroidx and Emydoidx; but in Chelonioidx, Thalassochelys at least, (Pl. 6, fig. 24, ) it is not more than half so long.

The eyes are much further developed, the pupil being now well formed in consequence of the perfect closing of the ring of the iris. 'The broad and deep depressions at the end of the head, mentioned in former pages, (p. 555 and 559; PI. 24, fig. 12, v; PL. 18a, fig. 9, v, have, at this stage, (Pl. 24, fig. 11, v,) become very much constricted at the mouth, so as to leave a very small external aperture. Below these depressions there is a large opening $(x)$ in the head, which leads into the beginning of the intestinal canal, and therefore must be the mouth. This being established, it is easy to see that the two depressions $(v)$ above the mouth are the openings of the nostrils, and that the two fissures which run from the nostrils to the mouth are each the remains of the posterior fold of the depression. The lower jaw has a distinct emargination at the middle.

The region of the heart and liver still remains the deepest part of the body. The anterior part of the intestine, the oesophagus, (Pl. 18a, fig. 5, $n^{3}$,) opens with a nearly horizontal and narrow aperture; the stomach $\left(n^{2}\right)$ is still more bent upon itself as it winds around the left side of the liver $\left(v^{\circ}\right)$; the long intestine $\left(n^{1}\right)$ is more slender, when compared with the stomach and oesophagus, than heretofore, and still remains in open communication with the yolk sac. The respiratory apparatus (fig. 5, $t, t^{1}$ ) is more extended; the windpipe $(t)$ is slender, and projects beyond the opening of the oesophagus $\left(n^{3}\right)$; the lungs (Pl. 18a, fig. 5, $t^{1}$; Pl. 24, fig. 4) are divided into five broad compartments, or bronchioles, one of which (Pl. 24, fig. 4, 7) trends at right angles to the others, and in a horizontal direction as regards its position in the embryo. The epithelial lining (P1. 24, fig. 4, 2) of the lungs is very much thinner than in the last stage, (Pl. 24, fig. 3a, 2,) but the outer layer $(\boldsymbol{I})$ is as thick as ever. The heart (Pl. 18a, fig. 5, $h$ ) retains the spongy nature of former phases; the aortic bulb $\left(h^{1}\right)$ is larger. The efferent vessel, the omphalo-meseraic artery, (Pl 18a, fig. 4 and 5, $j^{*}$,) springs now 
from the same point (fig. 4 and $5, j^{5}$ ) at which the double dorsal artery (fig. 4 and $5, j^{2}$ ) unites to form a single channel in the abdominal region, between the Wolffian bodies (fig. 4, q). The abdominal veins (fig. 4, $i^{3}$ ) are more distinct from the Wolffian bodies $(q)$; the zigzag lines on the Wolffim bodies appear to be in direct communication with the abdominal vein, and, moreover, have a strong red tinge, from which we should judge that they are the bloodvessels of the body in which they are situated. The liver (Pl. 18a, fig. 4 and $5, r)$ is hollowed on its upper side, and on its lower and posterior side a dark body (fig. 5, u) is imbedded, which, from its position and green color, must be the gall bladder. The Wolffian bodies (fig. 4, q) are not quite so long as heretofore. The abdominal parietes are now closed over, with the exception of a small opening for the passage of the neck of the allantois, and the connection of the intestine and the yolk sac.

The allantois not only covers the whole body, but spreads almost as far as the vascular area (Pl. 16, fig. 3). It is most extended on that side which faces the ventral surface of the embryo, and its vessels have attained to a very large size, much exceeding, in this respect, any of those in the vascular area, even the vena aflerens $\left(\vartheta^{1}\right)$. The allantois of one of the figures (Pl. 15, fig. 13) representing this stage of development is very much shrunk by being withdrawn from its area of expansion and crowded up near the embryo. It will be noticed how highly vascular the whole surface of the embryo is; from the end of the head to the tip of the tail, the animal appears like a great vascular organ performing respiratory functions. This peculiarity remains permanent in some adult Turtles, namely, in the family of Trionychida. . The vascular area, as far as it extends superficially, covers about one half the yolk sac, and the vena afferens (Pl. 16, fig. 3, $r^{1}$ ) is plunged deeper than ever into the yolk mass. At the exterior edge of the superficial extension of this area, the downward bend of the vessels resembles very much an irregular vena terminalis, but that part of the area is altogether plunged beneath the surface of the yolk.

The paddle-like shape of the legs is no longer recognizable here; but both the anterior and posterior limbs are now divided into a cylindrical and distinctly: jointed leg, and a terminal, rounded, and expanded foot, yet without the least sign of toes. This obtains not only among the higher families of Turtles, (Pl. 15, fig. 13,) but even among the lowest, the Chelonioida, as the next phase will show more distinctly (Pl. 6, fig. 24). This is rather remarkable as regards the Chelonioidx, since in them the foot and leg become eventually, by a gradual metamorphosis, (Pl. 6, fig. 24, 22, 21, 20, 18, 13, 15, 14, 16, ) apparently fused into one very large elongated paddle. A comparison of the feet of an advanced

1 Comp. p. 281. 
phase of the embryo of Thalassochelys (Pl. 6, fig. 20) with the very broadly webbed feet of any of the 'Trionychidse (Pl. 6, fig. 1-6) may easily show that the dense, tough, and stiff paddle of the Chelonioida is not a retrograde metamorphosis tending to the embryonic simplicity of younger stages, (Pl. 18a, fig. 9, ) but an excessive development of that which forms the soft web in Trionychida, and a hardening of its surface by the growth of closely set scales all over its surface.

In the next phase, (Pl. 14, fig. 1; Pl. 15, fig, 11, 12, 12a; PI. 16, fig. 5; Pl. 17, fig. 4, 4a, 6 ; Pl. 21, fig. 22-26, 30; Pl. 23, fig. 1, 1a; Pl. 25, fig. 11,) the different regions of the brain (Pl. 23, fig. 1, 1a) are very distinctly marked out, with the exception of the olfactory lobe, $(c$,$) which as yet hardly forms a$ sensible swelling. As a whole, the brain has about the same proportions as obtain among bony Fishes, excepting that it is strongly bent upon itself, and the hemispheres $(a)$ are on a much lower level than the corpora quadrigemina $(b)$. The crystalline lens of the eye has already its characteristic cells, (PI. 21, fig. 30, ) arranged in lines $(b)$ and in concentric layers. The proportions of the body hold about the same relations to each other as in the last stage, excepting that the trunk is a little deeper in the region of the ventral opening. The back is more curved, the highest point of the arch being at the middle of the shield. The border of the shield is much lower, and does not run in a straight course from end to end, but curves downward, (Pl. 14, fig. 1; Pl. 16, fig. 5,) reaching lowest just above the heart, and has a rather sinuous outline. The ribs are more apparent, (Pl. 14, fig. 1,) and terminate in a broad, wavy band at the edge of the shield, each wave being opposite to a rib. The breadth of the shield is greater, and has a broader ovate shape (Pl. 6, fig. 23). The edge of the abdominal aperture projects considerably, and simultaneously broadens, so as to form a trumpet-shaped umbilical passage (Pl. 14, fig. 1; Pl. 15, fig. 12; Pl. 16, fig. 5) for the allantois and neck of the yolk sac. The allantois (Pl. 15, fig. 11) is more extended in the dorsal region of the embryo, and covers more of the yolk sac; it also embraces the whole trunk of the embryo, above and below, (Pl. 15, fig. 12, 12a, ) but as yet leaves the head free. 'The parallelism of the arteries and veins of the allantois, mentioned in a former page, (p. 560; Pl. 18a, fig. 9, is here ( $\mathrm{Pl} .15$, fig. 11, 12) particularly noticeable, even to the tips of the smaller vessels. A more highly magnified view (Pl. 17, fig. 4, 4a) shows not only that this parallelism ceases among the very minutest vessels, the capillaries, but that the number of the latter is very large within a small space, and that they run in every possible direction. These two latter peculiarities are very different from what obtains in the superficial portion of the vascular area, (Pl. 15, fig. 11, 12, 12a; Pl. 16, fig. 5; Pl. 17, fig. 6, where the minutest of the bloodvessels run in a more or less parallel direction to each other, and are comparatively far less 
numerous. (PI. 17, fig. 6). The vascular area covers more than half of the yolk mass, and plunges deeply into its interior. (Pl. 15, fig. 11, 12, 12a; Pl. 16, fig. 5). The vena afferens plunges suddenly into the mass of the yolk at a point close to the head ( $\mathrm{Pl}$. 15, fig. 12). The vena terminalis has sunk still further below the surface of the yolk, and at the superficial termination of the vascular area the vessels become very numerous and anastomose freely with one another and with those situated more deeply (Pl. 17, fig. 6).

The feet (Pl. 14, fig. 1; Pl. 15, fig. 12; Pl. 16, fig. 5; Pl. 25, fig. 11) begin to show signs of the toes, and the tissue ( Pl. 21, fig. 22, 22a, 24) in such places has a different appearance from that of the neighboring parts; but as yet the former passes gradually into the latter (Pl. 21, fig. 25.) The form of the feet is changed, either to a broader fan-shaped figure, as among the Chelydroida ( $\mathrm{Pl} .14$, fig. 1; Pl. 15, fig. 12) and Emydoidx, (Pl. 16, fig. 5; Pl. 25, fig. 11, ) or to a more elongated and oar-shaped form, as among the Chelonioidx (Pl. 6, fig. 22). The anus (Pl. 14, fig. 1) is a very prominent feature at this age, just as it is in the adults of some of the lower families, namely, in the Chelonioida and Trionychidx.

In the next phase, (Pl. 18a, fig. 2, 3; Pl. 17, fig. 2, 3, 3a, 7; Pl. 18, fig. 1; Pl. 19, fig. 13, 13a, 13b, 13c; Pl. 20, fig. 2; Pl. 23, fig. 2, 2a, 2b, 2c, 2d, 2e, 2f, $2 \mathrm{~g}, 2 \mathrm{~h}$; Pl. 24, fig. 5; Pl. 25, fig. 4, wood-cut 2,) the former great disproportion between the head and body has lessened very much, the body having grown faster than the head. The embryo has the power to move not only the head and feet and tail, and the lower jaw and tongue, but also the toes, separately, and to roll the eyes. The shield (PI. 18a, fig. 2 and 3) has become a very prominent feature, and the ribs are quite marked.

The brain (Pl. 23, fig. 2, 2a, 2b, 2c, 2d) has its different regions more distinctly marked out; the olfictory lobes, (fig. '2, 2a, '2b, c,) and the cerebellum (fig. 2, 2a, 2b,e) in particular, are more prominent, and the olfactory nerve more lengthened (fig. 2, 2a, 2b, from $c$, to $c^{1}$ ). The more elongated hemispheres (fig. 2, $2 \mathrm{a}, 2 \mathrm{~b}, a)$ are nearly on a level with, and more closely approximated to, the corpora quadrigemina, (fig. 2, 2a, 2b, $b$ ) so as to touch them, and cover at least two thirds of the pineal grland (fig. $2 \mathrm{a}, 2 \mathrm{~b}, \mathrm{~d}$ ). The communications between the different lobes are narrower, both between those of the same side and those of opposite halves. This is especially maked in reference to the opening (fig. $2 \mathrm{~b}, m$ ) between the two hemispheres (a). The medulla oblongata (Pl. 23, fig. 2, $f, 2 a, f, 2 b, f)$ is bent forward and downward at an acute angle upon itself, so that the point from whence the acoustic nerve (fig. $2, l$ ) arises, tonches the lower border of the optic lobe (fig. 2, $k^{\prime}$ ). The bloodvessels of the arachnoid plexus, which terminate suddenly, (Pl. 23, fig. 2b, $g, 2 \mathrm{e}, 2 \mathrm{f}, 2 \mathrm{~g}, 2 \mathrm{~h}$,) have become quite numerous and elongated. The vascular covering to the fourth ventricle (fig. $2 \mathrm{~b}, g^{\prime}$ ) is lighly developed. 
The heart (Pl. 18a, fig. 3, h) has a much greater transverse than longitudinal diameter, and nearly the same proportions as in the adult. The aorta (Pl. 18a, fig. $\left.3, h^{\prime}\right)$ is constricted longitudinally at its base into two channels, the right one of which corresponds to the pulmonary artery of the adult. (See also a little older phase, Pl. 24, fig. 10, pa, 10b, pa.) The blood corpuscles (Pl. 19, fig. 13, 13a, 13b, 13c) are now quite different from the very transparent globular corpuscles (Pl. 19, fig. $7, a-j)$ belonging to the younger phase, described p. 558-560, where they should have been alluded to. They are now fully as large as in the adult, but not so flat, nor have they any entoblast. They are remarkably plastic, (fig. 13, $13 \mathrm{a}, 13 \mathrm{~b}$,) but return to their original shape when relieved of pressure, or after stretching (fig. 13b) by being caught against some object passing on the microscope stand. In these respects they resemble very much the yolk cells of the ovarian egg. The bloodvessels in the neck (Pl. 18a, fig. 2) are very numerous, especially in the region of the medulla oblongata (fig. $2, e^{5}$ ). The omphalomeseraic arteries (Pl. 17, fig. 7 ) are remarkably numerous where they run over the surface of the yolk, and have the same stiff appearance spoken of in a younger phase. The omphalo-meseraic veins (P1.. 17, fig. 3 and 7 ) run in a very irregular course, both horizontally and vertically. The limit of their field of development is a thick stratum of very loosely packed, large, clear, albuminous cells (Pl. 17, fig. 3, 3a).

Wood-cut 2.

At the neck of the vitelline sac the intestine still remains open (Pl. 17, fig. 2); but with a quite small aperture, which does not even equal its own diameter. The anus (Pl. 25, fig. 4, $\left.m^{\prime}\right)$ is quite a long slit in the lower side of the cloaca. The anal pouches (Pl. 25, fig. $4, y, g^{\prime}$ ) are just large enough to be recognized as hollow bodies, opening one on each side of the intestine. The lungs (Pl. 24, fig. 5) are now divided into as many as nine compartments or bronchioles, with a branch of a bloodvessel rumning to each partition. The liver (Pl. 18a, fig. 3, r) is very much flattened, and spread very widely. At its anterior part there is a large hollow, into which the heart $(h)$ fits. The Wolffian bodies (PI. 18a, fig. 3, $q$; Pl. 25, fig. 4, wood-cut 2) are much broader at their middle resion. The excretory duct is well marked, (Pl. 25, fig. 4, c, $c^{\prime \prime}$,) from its beginning to its outlet $\left(c^{\prime \prime}\right)$ in the cloaca $(l)$. On the upper surface of each Wolflian body, next the median line of the body, another similar organ (Pl. 25, fig. 4, b) is developing, seemingly by a gradual metamorphosis of the former. That this latter organ is the kidney we are assured, by finding a great abundance of Malpighian bodies (Pl. 20, fig. 2) within its substance. The uriniferous tubes of the kidneys (Pl. 25, fig. 4, b) are larger and 
more convoluted than those of the Wolffian bodies $(a)$. Already there are numerous pigment cells upon the surface of the Wolffian bodies (Pl. 18a, fig. 3, q). A white and narrow band, of dense substance, tapering at each end, (wood-cut 2, n,) runs along the under-side of the Wolffian body, (wood-cut 2, $a$,) and presses closely against its surface. All the relations which this body bears to the surrounding organs mark it as the genital organ, whether of a male or female is not yet determinable, but probably that figured here is a male, if the long, slender, backward prolongation (wood-cut 2, $f$ ) may be considered a vas deferens. The mouth of the embryo is open as far back as the base of the jaws. The upper jaw, in Chelydroidxe at least, is pointed (Pl. 18a, fig. 3) and slightly hooked. The feet have well marked and movable toes.

In the next phase (Pl. 13, fig. 1; Pl. 15, fig. 4, 5, 5a, 6; Pl. 16, fig. 2, 2a, 2b ; Pl. 18, fig. 9, 9a; Pl. 25, fig. 2, 6, 6a, 6b, 8) the proportions of the body are about the same as in the last. The shield is more projecting at its edges, and the large dermal scales are quite conspicuous (Pl. 25, fig. 8). The ventral side of the body shows a new feature: the sternum or breastbone (PI. 16, fig. 2b; Pl. 25, fig. 8) has made its appearance, and extends longitudinally from the anterior edge of the fore legs to the anus, and laterally, between the anterior and posterior pairs of legs, almost to the edge of the shield. The head is more elongated, especially in front of the eyes, and the upper jaw and nasal region are less curved, being more on a line with that part which lies behind the eyes, so that, on the whole, the head very much resembles that of a bird.

The heart (PI. 25, fig. 2, h) has increased to such a size, that, when filled with blood, it appears very dark and opaque. The vascular area (Pl. 13, fig. 1; Pl. 15, fig. 5; Pl. 16, fig. 2a, 2b) covers four fifths of the yolk mass. The dorsal artery (Pl. 25, fig. 6, h, fig. 6a, $h$, fig. 6b, $h$ ) gives off several vessels (fig. $6, i)$ to the kidneys, $(b$,$) and the abdominal veins (fig. 6, and 6a, d$, fig. 6b, $a^{\prime}$ ) distribute numerous venous currents (fig. 2, $a$ ) to the under-side of the Wolffian bodies. The omphalo-meseraic afferent vessel, (Pl. 16, fig. 2a, $r^{1}$, fig. 2b, $r^{1}$, soon after it leaves the body, plunges in a direct line through the yolk mass, and joins the exterior boundaries of the vascular area on the lower side (fig. 2a). Even at this late age there is sometimes an exception to this, when the vena afferens (Pl. 13, fig. 1, rl) does not sink into the yolk mass till it has reached the periphery of the yolk mass. The allantoidian arteries and veins (Pl. 13, fig. 1, o; Pl. 16, fig. 2; Pl. 18, fig. 9) are very conspicuous; their main stems running parallel, side by side. The liser (Pl. 25, fig. 2, r) evinces a high degree of vascularity, very large vessels rumning from its under-side and branching upon its upper surface. The gall bladder (fig. 2, u) is larger and darker. The Wolffian bodies (Pl. 25, fig. 2, a, fig. 6, a, fig. 6a, a, fig. 6b, a) are considerably shortened and hol- 
lowed on their under surface, (fig. $6 \mathfrak{a}, a$ ) and, in combination with the kidneys, (fig. 2, b, fig. 6, b, are arched on the upper surface corresponding to the arch of the shield above them. The duct (fig. 2, c, fig. 6, c, fig. 6a, $c, c^{\prime \prime}$, fig. 6b, c) of the Wolffian bodies lies in a furrow between the latter $(a)$ and the kidneys, $(b$,$) and is very conspicuous from its size, so that it might be mistaken for an ovi-$ duct, were it not that it is just as large in the male (fig. 6, $c$, fig. 6a, c, fig. 6b, c) as in the female. It empties (fig. $\left(a, c^{\prime \prime}\right.$ ) on the ventral side of the cloaca, $\left(l_{9}\right)$ and at the base of the allantois (o). The kidneys (fig. 2, b, fig. $6, b$, fig. 6a, b, fig. $6 \mathrm{~b}, b$ ) are considerably increased in size, and have a very distinct outlet (fig. 6 , $e$, fig. $6 \mathrm{a}, e)$ on the dorsal side of the cloaca, $(l$,$) and between the bases of the$ anal pouches $(g)$. The uriniferous tubes of the kidneys are very much convoluted, a feature by which they may be very readily distinguished from the Wolffian bodies, in which the uriniferous tubes run parallel from the outer to the inner edge. The genital organs (fig. $6 \mathrm{a}, n, \mathrm{fig} .6 \mathrm{~b}, n$ ) are not so slender and tapering as in the last stage, and each has a distinct vas deferens (fig. 6, $f$, fig. (a), $f$ ) in the male. The anal pouches (fig. 6 , and $6 a, g$ ) are developed into large, deep sacs, which have nearly the proportions of those of the adult. The cloaca (fig. 6, and $6 \mathrm{a}, l$ ) is very broad and deep, and is flattened on the lower side. The allantois (Pl. 13, fig. 1; Pl. 15, fig. 4, 5, 6; Pl. 16, fig. 2; Pl. 18, fig. 9 , 9a) occupies a little more than one half of the egg, and completely envelops the embryo. The umbilical opening is surrounded by a very large and broad trumpet-shaped border (Pl. 16, fig. 2b).

The toes are quite long and prominent, (Pl. 15, fig. 4; Pl. 16, fig. 2b; Pl. 18, fig. 9, 9a; Pl. 25, fig. 8, ) and separate in all those Turtles which are not webfooted when adult.

The yolk sac does not always contain a uniformly yellow mass, but more or less of its superior portion is of a semi-albuminous nature (Pl. 13, fig. 1). In this stage the yolk sac fills the lower half of the egg up to an horizon, $(h$, which is nearly the same with the greatest diameter of the latter. By peeling off the shell and varnishing the shell membrane, the whole internal organization of the egg around the embryo may be as plainly seen as represented on Pl. 13, fig. 1. In fig. 10, Pl. 15, there are two embryos in one egg, but one is much smaller than the other, and considerably less developed; the larger one, however, belongs to the stage just described.

In the succeeding stage (Pl. 14, fig. 13; Pl. 15, fig. 7, 8, 8a, 9; Pl. 18a, fig. 1; Pl. 20, fig. 4, 4a; Pl. 23, fig. 3; Pl. 24, fig. 10, 10a, 10b) the embryo has assumed an erect position, having the right and left sicles of the body on the same plane, and parallel with the horizon. The head is proportionately smaller, more elongated, and narrower; excepting among the Chelonii, in which it remains oblong, the shield is nearly circular. 
In consequence of the elongation of the head, the brain (PI. 23, fig. 3) is also more straightened, especially the olfactory lobes and nerves, $\left(c-c^{\prime},\right)$ so that from the Schneiderian membrane $\left(e^{\prime}\right)$ to the cerebellum $(e)$ there is a long and pretty uniform curve. The olfactory lobe $(c)$ is much more enlarged, and seemingly at the expense of the hemispheres $(a)$. The hemispheres $(a)$ are on a level with the corpora quadrigemina $(b)$. The optic lobes, $(k$,$) in following the$ elevation of the hemispheres, are raised considerably above the floor of the fourth ventricle $(p)$. The floor of the fourth ventricle $(p)$ is much thicker, and the whole ventricle is proportionably larger and broader, than heretofore. The vascular covering $\left(g^{\prime}\right)$ of the medulla oblongata contains more bloodvessels. The entrance to the ear may be recognized externally as a large dark spot just behind and above the corner of the mouth (Pl. 18a, fig. 1). At the tip of the upper jaw there begins to appear a slight protuberance, (Pl. 18a, fig. 1,) the nature of which will be better understood in future stages.

Besides the distinctly developed pulmonary artery, (Pl. 24, fig. 10, 10a, 10b, $h^{\prime}$, $h^{\prime}$,) already mentioned, the heart has now a complete valvular apparatus (fig. 10b, $v o, v l$ ) between the auricles $\left(h^{3}, h^{3}\right)$ and the ventricle, $\left(h^{4},\right)$ and a large venous sinus (fig. $10 \mathrm{a}, v s$ ). The extent of the vascular area is variable, in some instances covering a large portion of the yolk, (Pl. 15, fig. 7,) and in others not more than one half (Pl. 15, fig. 8, 8a, 9) of its surface. The lungs are now many-chambered (Pl. 20, fig. 4, 4a); the partitions are traversed by bloodvessels, $\left(b, b^{\prime}, c^{\prime},\right)$ and new channels of blood are being hollowed in the younger partitions $\left(a^{\prime}\right)$. The allantois extends as far as the edge (Pl. 15, fig. 8, i, fig. 8a, fig. 9) of the vascular area, where it bends upon itself and passes upwards and follows the inner contour of the shell very closely. The characteristic parallel bloodvessels enable one to follow very easily the foldings of this organ (Pl. 14, fig. 13; $\mathrm{Pl}$. 15, fig. $8,8 \mathrm{a}, 9)$.

The skin of the neck has strong folds, (Pl. 15, fig. 9,) indicative of the retractility of the head, which the embryo possesses in a marked degree. This, consequently, indicates the existence of active retractor muscles of the head and neck. Indeed, when the egg-shell is removed, young Chelydras of this age already snap fiercely at any thing that is brought near them.

In a phase but slightly more advanced than the last, the protuberance at the end of the upper jaw (mentioned above, line 13) is here (PI. 16, fig. 1; Pl. 25, fig. $10,6 k$ ) prolonged into a very prominent, sharp beak, covered by the soft and thick epidermis. The eyes are partially covered by movable eyelids (Pl. 25, fig. 10). The terminal joint of each toe (PI. 25, fig. 12, b) is covered with a distinct and thick, transparent layer, $\left(a_{\text {, }}\right)$ resembling horn. The bones of the fingers $(d)$ are broader at the ends than at the middle. The bloodvessels of the feet are well 
developed, and, starting from a transverse vessel $(e, e)$ near the base of the third joint, go in pairs to each finger. In this phase the allantois has almost completely enveloped the yolk mass (Pl. 16, fig. 1).

In the next phase, (Pl. 15, fig. 1, 2, 3; Pl. 9a, fig. 30, 30a; Pl. 18, fig. 3 ; Pl. 19, fig. 9-12, 16b, 16c, 18, 18a, 19, 20, 21, 23, 24, 25, 26, 26a, 32; Pl. 20, fig. 1, 1a, 1b, 5, 6, 7, 8, 9, 9a, 10, 11; PL 21, fig. 1, 2, 3, 4, 5, 6, 7, 8, 9, $14,14 \mathrm{il}, 14 \mathrm{~b}, 14 \mathrm{c}, 14 \mathrm{~d}, 14 \mathrm{e}, 14 \mathrm{f}, 14 \mathrm{~g}, 15,15 \mathrm{a}, 16,16 \mathrm{a}, 16 \mathrm{~b}, 20$ to $20 \mathrm{~d}, 29,31$, 32 to $32 d$, 34, 34a; Pl. 24, fig. 6; Pl. 25, fig. 1 to $1 d$, 5,) the whole contents of the egg are surrounded by the allantois, (Pl. 15, fig. 2,) and no part of the organization, except the blood, is in a loose, mobile state. Even the yolk forms a tenacious sheath about the bloodvessels, (this is figured for the next stage, Pl. 18, fig. 4, 4a, which anastomoze with each other throughout the whole yolk sac. The yolk sac is nearly as small as when the embryo is hatched. The proportions of the body are about the same as when the embryo is born; the head is quite pointed, and the neck proportionally shorter than heretofore. The folds of the skin are more marked and numerous. The lower jaw is pointed (PI. 25, fig. 1a, x). In Chelydroidx (Pl. 15, fig. 3) the shield is marked with a median and two lateral rows of large tubercles, and numerous smaller ones all over the surface, while among Emydoidx the shield is minutely granulated. The head, neck, legs, and tail are covered with small and rather stiff scales. The thick, transparent layer covering the terminal joints of the toes in the last phase is here developed into horny sheaths, forming sharp claws (Pl. 21, fig. 20, a).

The brain is composed of large, globular, transparent cells, each-containing a single mesoblast; and those of the hemispheres, (Pl. 19, fig. 16b, 16c, a, b, $b^{\prime}, c, c^{\prime}$ ) of the olfactory lobes, (fig. 18, a, ) of the Schneiderian membrane, (fig, 19, a, b, ) of the medulla oblongata, (fig. 20,a, b, ) and of the spinal cord, (fig. 21, have all one common physiognomy. Already there are a few slightly caudate cells, (fig. 18, a, fig. 19, a, ) and those of the Schneiderian membrane (fig. 19) are mutually pressed against each other. The eyes have fully developed eyelids (Pl. 15, fig. 3). The erystalline lens (Pl. 21, fig. 29) is covered in front by a large layer of polygonal cells, $(a$,$) the "membrana pupillaris," which is overlapped by the$ anterior edge of the membrana hyaloidea, the zonula Zinnii (c). The zonula Zinnii (c) has the longitudinal plications, the ciliary processes of the membrana hyaloidea, as fully developed perhaps as in the adult. At the anterior edge of the zonula, the pigment layer $(b)$ is quite thick. The cells (Pl. 21, fig. 32a, a, $b, c, d)$ of the fibres of the crystalline lens are so excessively transparent and closely adherent to each other, that it is diflicult to recognize each separately; and, in fact, in some parts of the lens, their walls appear to be obliterated at the point of contact, so that they form a continuous ribbon (Pl. 21, fig. 32b, 
32c). These bands traverse the whole thickness of the lens, and converge toward its two opposite sides (Pl. 21, fig. 31, 32, a).

The shape of the blood corpuscles varies; some are quite flat, (Pl. 19, fig. 12, $a, b$ ) and others are more or less thick, (fig. 10,a, b, $c, c^{\prime}$ ) and even perfectly round when seen endwise (fig. 11, $c, d$ ). The liver is strongly bilobed and very much flattened (PI. 25, fig. 1, r, r) ; and at one point (fig. 1a, r) it clings very closely to the stomach (fig. 1a, $n^{2}$ ). The cells (Pl. 19, fig. 32, $a, b, b^{\prime}, c, c^{\prime}$ ) of the liver are as characteristic as in the adult, with their large mesoblast, coarse, granular contents, and strongly polygonal shape (fig. 32).

The partitions of the lungs are very numerous, (Pl. 20, fig. 5, and have a distinct fibro-muscular structure (fig. 10, b, fig. 11, b); the cells of the epithelial layer (fig. 9, $a$, fig. 11, a) are broad and deep. The surface of the lungs is covered with a layer of very faint, round cells, (fig. 9a and 11,) with minute granules interspersed between them; and, along the courses of the bloodvessels, there are numerous black pigment cells (fig. 5, 8, and 11, $b^{\prime}$ ). The cartilaginous rings of the trachea (Pl. 24, fig. 6) form a nearly continuous spiral; the cartilage cells of this organ are sharply polygonal, and as yet pretty close together (Pl. 20, fig. 6).

The intestine (Pl. 25, fig. 1, $n^{1}, n^{2}$, fig. $\left.1 a, n^{1}, n^{2}, n^{4}\right)$ is very long and much convoluted; its anterior opening is furnished with a well developed hyoid bone (fig. 1a, oh); the neck (fig. 1, $n^{7}$ ) of the yolk sac, where the intestine connects with it, is very small and scarcely perforated. The folds of the internal surface of the cosophagus (Pl. 25, fig. 1b) are broad, and have narrow but deep intervals; but at its posterior part the folds widen considerably as they pass into those of the stomach, where the intervals are very narrow and shallow. Just behind the stomach the folds are very narrow and wavy, and the intervals are broad, but rather deep (fig. 1c). In the thick intestine, close to the clonca, the internal folds (fig. 1d) are almost as narrow as those in the small intestine just behind the stomach, but perfectly straight; and the intervals are very broad. Throughout the whole length of the intestine there is a well-developed, thick epithelial layer of polygonal cells, (PI. 21, fig. 1, 3, 4, 5, a, 6, 14a, 14b, 14c, 14d, 14e, $14 f, 14 \mathrm{~g}$, 34, ) covered with vibratile cilia, and beneath this layer a thick stratum of long, columnar cells, either in a single layer, (fig. 2 and $5, b$, or, in the thick intestine, in two or three layers (fig. 34). The whole surface of the stomach is marked by little apertures, (fig. 14, a, 14a, 14b, fig. 15, 15a, b, leading into quite deep depressions or sacs, (fig. 16, 16a, 16b, which are lined with a continuation of the epithelial layer (fig. 16b).

The uriniferous tubes (Pl. 25, fig. 5,b) of the kidneys are a great deal thicker than those $(a)$ of the Wolffian bodies. The uriniferous tubes (Pl. 20, fig. 1, 1a, 1b) of the Wolffian bodies are composed of very large and transparent cells. The neck 
of the allantois, in the interior of the body, has swollen, and forms a broad, pearshaped sac, (Pl. 25, fig. 1, $n^{6}$, fig. 1a, $n^{6}$ ) the urinary bladder. The tissue of the exterior portion of the allantois is composed of very large and thick-walled but transparent cells, (PI. 9a, fig. 30, 30a ; Pl. 18, fig. 3,) with multitudes of faint granules for contents (PI. 9a, fig. 30). The muscles in various parts of the body are in different degrees of development; those of the foreleg are highly, but not filly, developed, and show a very distinct fibrillous structure (Pl. 19, fig. 25, a, b); those of the dorsal arch (Pl. 19, fig. 23) are as yet composed of more or less elongated cells, $(a, b$,$) each of which contains a single large granulated mesoblast;$ these cells resemble very much the cartilage cells $(c)$ of the dorsal arch. The tendons in the legs have a marked fibrous structure (Pl. 19, fig. 26, 26a).

The cells of the terminal bone (Pl. 21, fig. 21) of the toes are quite large and sharply polygonal, and each contains a large mesoblast and several entoblasts (fig. 21a). The cells of the horny sheath (fig. 20, $a$ ) of the claw are very large, irregularly polygonal, and transparent, and contain a single small mesoblast (fig. 20a, 20b, 20c). The cells of the skin at the base of the claws, (fig. 20, $l^{\prime}$ ) and those $(b)$ which continue under it, are quite large, polygonal, and each contains a single mesoblast and entoblast, besides a few scattered granules (fig. 20d).

The next phase (Pl. 18, fig. 2, 4, 4a, 10, 10a, 10b, 10c, 10d, 10e, 10f; Pl. 25, fig. 3, 3a, 7, 7a, 9; Pl. 19, fig. 27, 27a, 29, 29a, 30, 31, 33, 34, 35, 35a ; Pl. 20, fig. 18; Pl. 22, fig. $5,6,6 \mathrm{a}, 6 \mathrm{~b})$ is the last before the embryo is hatched. A few external features, peculiar to certain families, and not noticed in the last phase, require now to be noticed; otherwise there is not any appreciable difference in the external appearance of the embryo. By this time the shield of many of the Finydoida is covered by a beautiful granular embossment (Pl. 18, fig. 10d, 10e, 10f). The embryo, at the same time, is perfectly straight, in all oval eggs, (Pl. 18, fig. 10, 10a, 10b, 10c,) and not bent upon itself, as happens in round eggs (Pl. 15, fig. 1, 2). In the latter case, at least among Chelydroidx, the embryo has not the power to retract its head or feet, except for a short distance; whereas in Emydoidie only two thirds of the head projects beyond the shield, and the feet are hidden under the latter, and the edge of the shield is very much bent downwards when the embryo is ready to hatch. The beak, (Pl. 25, fig. 9, b7, in all Turtles, is very prominent and sharp. The eyes may be closed as readily as in the adult. The cells of the epidermis ( $\mathrm{Pl} .20$, fig. 18, right half) are large, sharply polygonal, and have thick walls. Underneath the epidermis is a layer of very large, thin walled, excessively hyaline, polygonal cells, each containing a large patch of pigment of a more or less deep black color (fig. 18, left half). The heart, (Pl. 25, fig. $3, h$ ) the liver, (fig. $3, r, r$, fig. $3 a, r, r$ ) the intestine, (fig. 3, $n^{2}, 3 a, n^{2}$ ) and the lungs, (fig. $3 a, t^{\prime}$ ) are in nearly the same condition as in the last phase. 
Soon after hatching, this Turtle discharged from its intestines a glutinous matter with green blood discs, (Pl. 19, fig. 35, ) more or less broken up, and also bodies which appear to be crystals of uric acid (fig. 35a, $a, b, c, d, e$ ).

Each of the lungs ( $\mathrm{Pl} .25$, ing. 3a, $\left.t^{\prime}\right)$ occupies as yet a small space, close upon the back of the liver $(r, r)$ and of the heart. The surface of the lungs is quite dark with pigment cells. The cells ( $\mathrm{Pl} .19$, fig. 31, $a, b)$ of the liver are similar to those of the last phase. The cells (Pl. 19, fig. 29, 29a) of the gall cyst are broad, long, and columnar, each containing a single large mesoblast. The wall of the cyst consists of only a single layer of these cells, which, seen in the direction of their length, appear polygonal. The contents of the gall cyst (Pl. 19, fig. 33, 34) are, in a great measure, minute, dark granules, with bodies that appear to be the different stages of growth of blood corpuscles. The Wolffian bodies and kidneys (PI. 25, fig. 3a, q, fig. 7, 7a) are quite broad and short, with blunt ends; the former are about equal in size to the latter. The kidneys (fig. $7, b, 7 a, b$ ) are supplied with numerous bloodvessels. The generative organs (fig. $7, n$ ) are much broader and shorter than when we first noticed them, and do not equal the length of the kidneys. The cells (PI. 19, fig. 30) of the female generative organ, the ovary, (Pl. 25, fig. $7, n$, are moderately large and sharply polygonal, and each cell contains a large, granulated mesoblast.

The bloodvessels of the omphalo-meseraic system occupy the whole yolk sac, in the form of close meshes, (Pl. 18, fig. 4,) encased in a thick, tenacious layer of albuminous substance, containing innumerable yolk cells of various sizes (fig. 4a). These anastomozing vessels belong to the return currents, and have quite thick walls, (fig. 4a,) which form a striking contrast with the excessively thin walls of the efferent vessels (fig. 2) of the superficial portion of the vascular area. The superior retractor muscle of the head has afforded excellent material to show the serial arrangement of granular bodies in the formation of muscular fibrillæ (Pl. 19, fig. 27, 27a). The central cartilage cells (Pl. 22, fig. 5, 6, 6a, $6 \mathrm{~b}$ ) of the clavicle are widely separated from each other, and, judging from the branching nature of their contents, have begun to form a deposit of lime. The lower jaw (Pl. 9e, fig. 11, 11a) has a considerable amount of lime deposited in its peripheric parts, especially along its upper edge. Upon making an oblique section of its length, (through $\%$ fig. 11a,) a row of small cavities (fig. 11, $b$, fig. 11a, b) are seen proceeding from the upper side of the cavity (fig. 11, a, 11a, a) in which the maxillary nerve runs; and each little cavity is filled by a prolongation of the maxillary nerve. One would suppose that these cavities were the future sockets of teeth, did we not know that Turtles possess nothing of the kind. However, we cannot doubt that they are typical tendencies torird the development of dental organs of mastication. The suture of the branches of the 
lower jaw is very loose; it is formed by four or five triangular projections (fig. 11, l) on one side, dovetailing with a similar number of projections of the opposite side.

In the process of hatching, the young Turtle does not tear open the allantois, but simply forces apart the edges of the folds which inclose the head (PI. 18, fig. 10c); but as the allantois is very tender at this time, it is more or less torn in the struggles of the animal to escape from the shell. The shell always breaks close to the end of the head, corresponding to the position of the sharp, hard beak (Pl. 9c, fig. 6 and 8 ). At this stage the yolk sac occupies about one fourth of the cavity of the shell. Before leaving the shell, the yolk sac is more or less flattened vertically (Pl. 18, fig. 10, 10b, 10c); but as soon as it is relieved of the pressure of confinement by the casting of the egg-shell it assumes a globular form, (fig. 10d, 10e, ) but with less bulk external to the Turtle, a portion having been drawn into the body almost as soon as the hatching was finished. In a few hours the whole yolk sac (Pl. 25, fig. 3, $n^{7}$ ) is drawn into the body, and occupies a large space in the abdominal region. The circulation of the blood in the yolk sac at this time is as active as ever. The extemal remains of the allantois (fig. $3, n^{6}$ ) are soon withered and dried, and finally, in two or three days they disappear; within the body, however, the neck of the allantois persists and becomes the urinary bladder, as mentioned above (p. 571-572). In a previous section (Chap. 1, Sect. 6, p. 486-489) we have already mentioned the persistency of the embryonal membrane, which may be recognized by its cells, (Pl. 9a, fig. 31, $\left.a, 31 \mathrm{a}, a_{2}\right)$ along with those of the amnios $(b)$ and of the allantois, $\left(c_{9}\right)$ till the embryo is hatched.

On account of the great amount of material that had accumulated, and the pressure of time, it was found impossible to investigate the state of all the organs just at the time the young Turtles were hatched. However, this did not interfere with the proper appreciation of the degree of development of these young animals about the time of hatching, since, almost from the time they were born till the space of four months had passed over, they remained in a state of torpor, being kept in a cold room, where at times they were frozen with the water in which they were preserved. During this time they evidently did not grow to any appreciable amount, since, as late as December 13th, two months after they were hatched, the yolk sac was not resorbed, but occupied a large portion of the abdominal cavity. Moreover, specimens were obtained from the fields as late as December which were not even hatched; so that no great dependence can be placed on the age to determine the stage of development. The successive phases of growth must therefore be determined by their sequence, rather than by the time required for their development. The following figures 
(Pl. 17, fig. 1; Pl. 19, fig. 14, 15, 16, 16a, 17, 17a, 17b; Pl. 20, fig. 3, 13, 13̊a, 14, 14a, 15, 16, 17; Pl. 21, fig. 10, 11, 12, 13, 13a, 17, 18, 18a, 18b, 18c, 19, 33, 33a; Pl. 22, fig. 1, 1a, 1b, 2, 3, 3a, 4, 4a, 8, 8a; Pl. 23, fig. 4, 4a, 5, 6, $7,8,9,10,11)$ represent the condition of the young Turtles during a period extending over nearly three months and a half after they were hatched. The organs of but one species (Chelydra serpentina) are represented here.

The cavity of the intestine ( $\mathrm{Pl} .17$, fig. 1) is totally shut off from the yolk sac, but the wall of the former is not detached from it. There are two distinct muscular coats (Pl. 21, fig. 11, d, 18, c, d, 19,,$d$ ) in the intestine, the fibres of which run transverse to each other. The cells of the muscular layer (Pl. 21, fig. 11, d) of the oesophagus are excessively long, and tapering at each end (fig. 13, 13a). The epithelial layer of this part of the intestine is more compact (Pl. 21, fig. 11, a, b). At the base of the tongue there are no vibratile cilia, (Pl. 21, fig. 10, but the cells resemble those at the posterior end of the intestine (PI. 21, fig. 18, 18a, 18b, 19). The glands of the stomach are considerably elongated and convoluted, (Pl. 21, fig. 17,) and the wall $(c, d)$ of each is very thick, being composed of three or four layers of cells, continuous with the epithelial layer $(\alpha)$ of the surface of the stomach. The epithelial layer of the long intestine (Pl. 21, fig. 18, 18a, 18b, 18c) and of the rectum (PI. 21, fig. 19) is now composed of five or six layers of superposed cells. The cartilaginous rings ( $\mathrm{Pl} .20$, fig. $3, b$ ) of the windpipe are much broader than the intervening fibrous tissue $(a)$. The cartilage cells (Pl. 20, fig. 3, b) are widely separated from each other, just as in all permanently cartilaginous bodies. The epithelial cells (Pl. 20, fig. 13, 13a, 15) of the urinary bladder can hardly be distinguished from those of the long intestine and of the rectum. The muscular walls (PI. 20, fig. 16) of the bladder are highly developed; the fibres are very distinct, and run in every possible direction. The cells of the smooth muscles of this organ vary in their proportions at different depths (fig. 14, 14a); those more interior being the longer ones. The contents of the bladder, seen by incident light, have a dead white color, by transmitted light a fuscous color; and consist principally of large, dead white flakes, (fig. 17,) composed of very minute granules, and a few bodies which appear to be epithelial cells, in various stages of decomposition.

The brain (Pl. 23, fig. 4, 4a, 5, 6, 7, 8, 9, 10) fills the cranial cavity as completely as in the adult. It is more elongated, and not so deep, as in the last stage (Pl. 23, fig. 3). The Schneiderian membrane (fig. 4, 11, and woodcut $3, b$, w-c. ${ }^{1} 11, a$ ) is more expanded vertically, and the olfactory nerve (fig. 4,

1 In these references, "w-ce" is the abbreviation for wood-cut. 
4a, w-c. 3, c, w-c. 4, c) is much larger and longer. The olfactory bulb (fig. 4, 4al, 10, w-c. 3, d, w-c. 4, d, w-c. 10, a, $a^{\prime}$ ) is distinctly striated by broad bands of

Wood-cut 3.

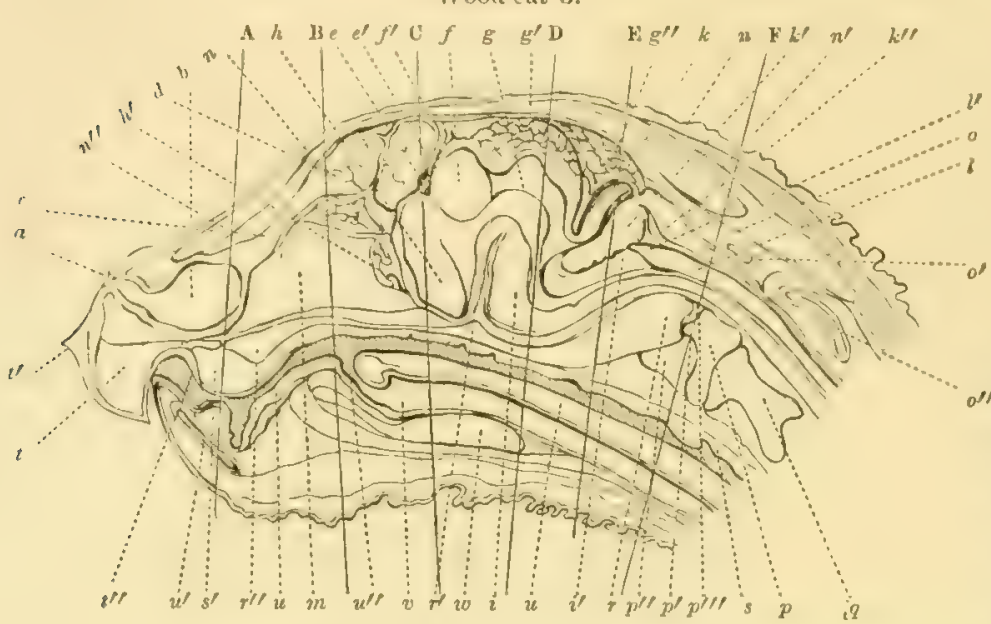

Wood-cut 4.

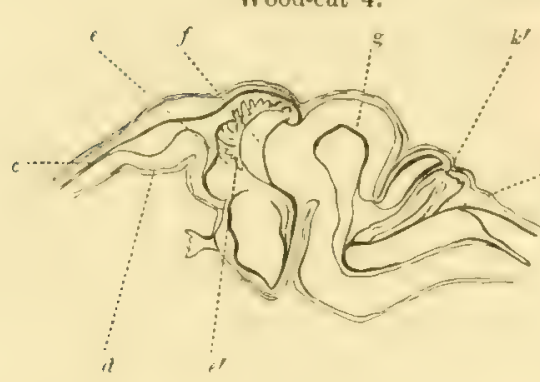
white and gray matter; and it is more enlarged, and encroaches still more upon the rather diminished hemispheres, (fig. 4, 4a, 8, w-c. 3, e, w-c. 4, $e$,w-c. 8, a) than before. The cavity of the latter is nearly filled by the choroid plexus (fig. 4a, 8, w-c. 4, e, w-c. 8, d) ; and the optic lobes (fig. $4,4 a$, 8,9, w-c. $3, h$, w-c. $8, f, f^{\prime}$ ) are again on a little higher level than the fourth ventricle, (w-c. $3, i$ ) and advanced so as to underlie the greater part of the hemispheres (fig. 4, 4a, 8, w-c. 3, e, w-c. 4, e, w-c. 8, a). The optic nerve (fig. 4, 4a, w-c. $3, h^{\prime}$ ) is as yet very short, passing almost immediately from the optic lobe into the eye. The pineal gland (fig. 4, $4 \mathrm{a}$, w-c. $3, f$, w-c. $4, f$ ) is a solid mass, sunk considerably below the upper surface of the hemispheres and of the corpora quadrigemina. The crura cerebri (fig. 8, 9, w-c. 8, $a^{\prime \prime}$ ) are already quite prominent. The corpora striata (fig. 8, 9 , w-c. $8, a$, w-c. $9 a$ ) project con-

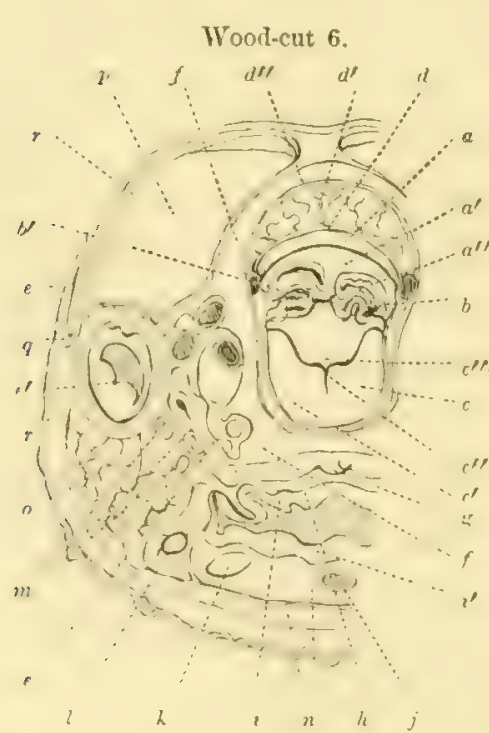
siderably into the cavity of the hemispheres. The corpora quadrigemina (fig. $4,4 a, 7$, w-c. $3, g$, $g^{\prime}$, w-c. $4, g$, w-c. $\left.7, a, a^{\prime}\right)$ have much thicker walls, and are more sunk posteriorly toward the fourth ventricle. The cerebellum (fig. 4, 4a, 6, w-c. 3, k, w-c. $\left.6, a, a^{\prime}, a^{\prime \prime}\right)$ is very much enlarged; it has a much thicker wall, and trends almost perpendicularly to the axis of the brain, upward from its anterior border (w-c. 6, $\left.a^{\prime \prime}\right)$. The arach-

Wood-cut 5.

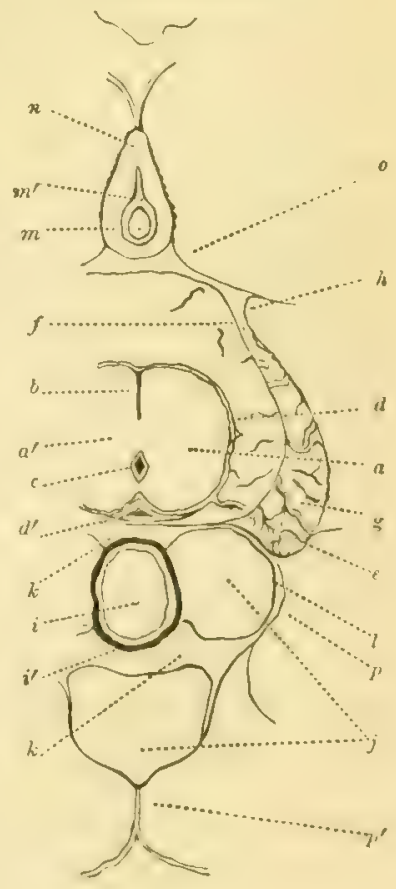


noid plexus has become a large and dense bunch of bloodvessels (fig. 4, 4a, 6, w-c. $\left.3, k^{\prime}, w-c .4, k, w-c .6, b, b^{\prime}\right)$ hanging in the cavity just below the cerebellum. The

Wood-cut 7

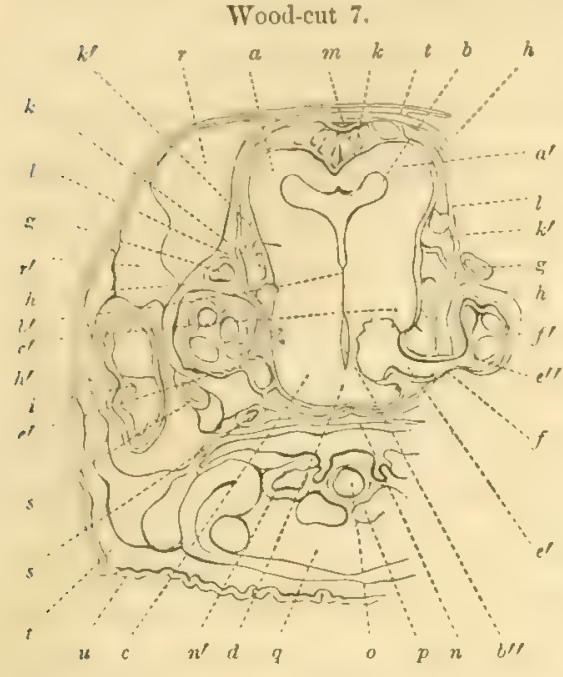
spinal marrow (fig. 4, 5, w-c. 3, l, w-c. 5, a) has closed over, close up to the medulla oblongata, (fig. 4,6 , w-c. $3, i^{\prime}$, w-c. $6, c, c^{\prime}$ ) ) but the latter remains broadly open. The whole surface of the brain, above and below, is covered by a delicate membrane, filled by a dense network of bloodvessels (fig. 4, 5, 6, 7, 8, 9, 10 , w-c. $3, g^{\prime} g^{\prime \prime}$, w-c. $5, d$, w-c. $6, d$, w-c. $7, k$, w-c. $10, e):$ this is the pia mater. The cells of the tissue of the olfactory nerve are beginning to unite with each other in a linear series (Pl. 19, fig. 15) to form nervous tubes. The tissue cells of the base of this nerve, close to the olfactory bulb, are sharply polygWood-cut 8 .

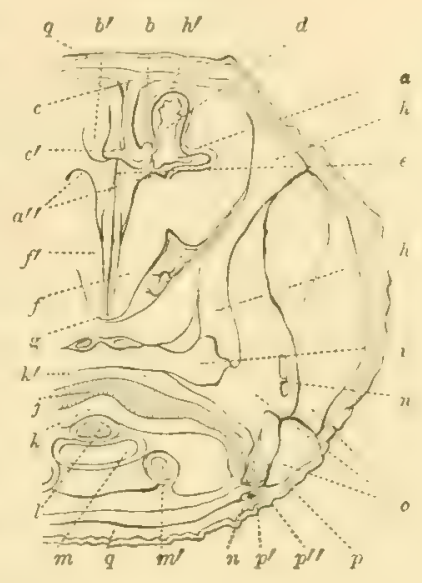
onal (Pl. 19, fig. 17, 17a, 17b) and elongated. The cells of the cerebrum are not so regularly polygonal as at the base of the olfactory nerve, but still retain more or less of their original rounded contours (PI. 19, Wood-cut 9. fig. 16, c, 16a). The eyes are (Pl. 21, fig. 33, 33a; Pl. 22, 。 fig. $\mathrm{S}, \mathrm{Sa}$ ) perfectly developed, as far as the requirements of Wood-cut 10.

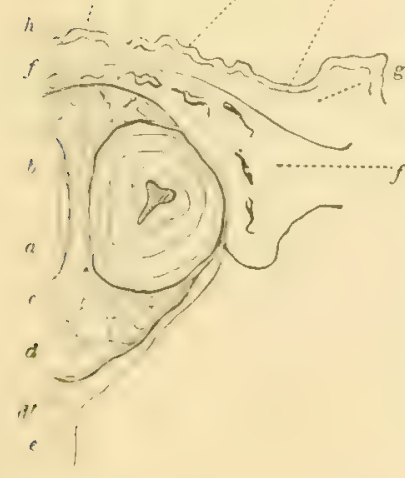
sight are concerned, excepting some features of secondary importance: the bony ring $(\mathrm{Pl} .22$, fig. $7, c)$ in the sclerotica, $(b$,$) and the double membrana pupil-$ laris $\left(n, n^{1}\right)$ before the capsule of the

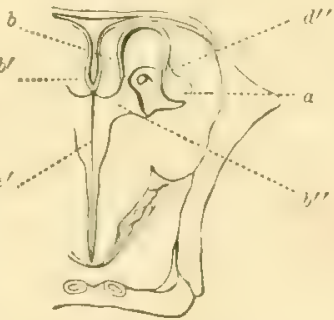
lens, $(l)$ in the adult, are not yet apparent. (See fig. 8, b, the sclerotica, and $n, n^{1}$, the membrana pupillaris.) The ears (Pl. 23, fig. 6, 7, w-c. 6, e, é, w-c. 7, $i, f$ ) Wood-cut 11 . have nearly as complicated a labyrinth as in the adult.

The amount of ossification of the bones is very unequal in different parts of the body. The vertebral column (Pl. 23, fig. 4, w-c. 3, q) and the bones of the sternum are the most advanced in this respect, two thirds of the bone at least being hardened, mostly next the sur-

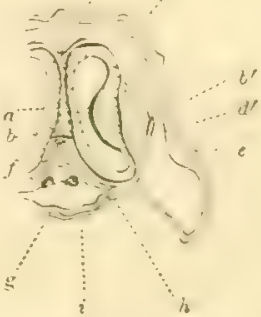
face. The bones of the upper jaw (Pl. 23, fig. 4, fig. 11, w-c. 3, t, w-c. 11, $e$, 
d) are perhaps as much ossified as those of the vertebral column. The bones of the toes come next in the series, the ossification here being principally along the cylinder. 'The other bones of the limbs are much less ossified. The ribs have already a broadly winged margin (Pl. 9e, fig. 12, b); there is only a thin layer of bony substance at the surface, near the base of attachment to the vertebre; the rest of their length is densely fibrous, (Pl. 9e, fig. 12, $b$ to $b$; Pl. 22, fig. 1 , $b, c, d, c$, fig. $2, c, d, e, f$ ) with a cartilaginous interior (Pl. 9e, fig. 12, $a, a^{\prime} ; \mathrm{Pl}$. 22, fig. 1 and 2, $a, a^{1}, a^{2}, a^{3}$ ). The skin, corium, (Pl. 9e, fig. 12, $c, c^{\prime} ;$ Pl. 23, fig. $4,6,7,8,10$; and w-c. $6, r$, w-c. $7, t, w-c .8, q, w-c .10, y)$ is a very dense layer of thickly matted, fine, white fibres (Pl. 22, fig. 1, $g, g^{\prime}, h, h^{1}$ ); it is thickest between the ribs. Throughout its thickness there are scattered groups of pigment granules, and a short distance below the epidermis there is a dense, uniform layer of these pigment granules, (PI. 9e, fig. 12, $h$, ) which seems to be a dividing line between the corium (fig. 12, g) and the epidermis; but this is not so, for the epidermis (Pl. 20, fig. 18) is a very thin film, here (Pl. 9e, fig. 12) represented by a black line, between which and the pigment stratum there is a moderately thick layer of fibrous substance, (fig. 12, $i_{2}$ ) which, to all appearances, is identical with, and merely a continuation of, the corium.

'This is sufficient, in a general point of view, to characterize the young Turtles at the time of hatching; especially if, to avoid repetition, we refer to a previous section, (Part II., Chap. 1, Sect. 14, p. 290, ) on the development of Turtles from a zoölogical point of view, and to another, (Part II., Chap. 3, Sect. 4, p. 386, ) on the comparison of the growth of the Chelonii with that of the Amyda, in which the young of several species, belonging to different families, are described at that age. In the next section, further details concerning the development of several organs will be given, and this, with the section on the Histology of the embryo, will complete the account of our observations respecting the origin and mode of growth of the Turtles. One single general remark, however, may with propriety find place here, before we proceed to these specialities.

The great wonder, in the development of all organized beings, consists in the differentiation of the substance in the different parts of the same body, while it remains under identical influences. This evidently takes place under the action of that principle, in virtue of which every animal is an individual of some special kind of animals, and not in consequence of any physical agency. The living egrg makes its own different substances because it lives, and not in order that a new animal may grow up. This has an important bearing upon the general question of the nature and origin of matter. Without approaching this subject in detail, I would only express my belief, that matter does not exist as such, but is everywhere and always a specific thing, as are all finite beings. 


\section{SECTION VIII.}

FORMATION AND DEVELOPMENT OF THE ORGANS.

While tracing the general progress of the development of the young Turtle, we have described with sufficient fulness the mode of formation and the earlier metamorphoses of many of the organs $;^{1}$ and it would therefore be useless to repeat here many of these descriptions, now that we are about to consider the different organs and systems of organs separately. It will be sufficient for our purpose to refer to the figures and pages, in which much that might be required here has already been said, and then to fill up whatever blanks may be left, in order to illustrate the serial development of each organ. $\Lambda$ s we proceed in the description of these organs, we shall refer to the pages where they are mentioned in connection with the whole embryo; and in this way every student may be enabled, not only to follow the progressive growth of each organ, but also to appreciate the relations which every one bears to every other, at each successive stage of its special development.

The Brain. The formation of the primitive furrow, which is the earliest step taken to lay the foundation for the brain and spinal cord, has already been described (p. 543, Pl. 9e, fig. 3, b, fig. 3a, b, fig. 4, b, fig. 4a, b; Pl. 11, fig. 3, $b$, fig. $4,5, b$ ). This primitive furrow soon becomes a deep gutter, of variable width and depth. In the head it is a very broad channel, from the beginning of its formation; but soon the germinal layer rises on each side of it in the form of a long ridge, in consequence of which the channel (Pl. 12, fig. 1a, $e^{1}$; PI. 9d, fig. 1, $e^{1}, e^{6}$ ) is deepened. Gradually the ridges rise higher and higher, till the channel is as deep as it is broad; they then fold inwardly toward each other till their edges meet, first at one point, (P1.9d, fig. 1, $e^{3}$ ) and finally along the whole length of the head, (PI. 12, fig. 3, $e^{1}$,) thus forming a large, closed cavity (see p. 547). At this period, the cavity occupies the whole breadth of the head, as well as its whole length; the vertebral layer not being developed, except along the lower side of that organ (see PI. 9d, fig. 1, $f^{1}$ ).

At the posterior end of the head, the brain gapes broadly open (PI. 12, fig. S, $c^{2}$, fig. $9, e^{2}$, fig. $9 a, c^{2}$ ) for a considerable distance, as far back as just above the heart, where it again closes over rather suddenly as it meets the spinal tube 
(fig. 9, $e$, fig. 9a, $e$ ). Subsequently, this opening lessens considerably, but is never closed, not even in the adult. At this period, the position of the brain in relation to the spinal cord is remarkable: the whole of this organ, with the exception of a small portion, the cerebellum, (Pl. 12, fig. 8, $e^{3}, 9, e^{3}, 9 \mathrm{a}, e^{3}$,) next to the open region, trends in a direction which is perpendicular to the spinal marrow (fig. 9, 9a,e). At no other time is the brain so strongly bent upon itself. Thus far there is but one fold, that at the cerebellum; the latter forming the angle of junction between the brain and the medullary tube, and all that is to be hereafter - severally, the olfactory lobes, the hemispheres, the optic lobes, and the corpora quadrigemina - is now comprised in a simple, large chamber, which stands in the most deflected position conceivable, at right angles to the longitudinal axis of the body.

Subsequently, the brain suddenly narrows behind, (PI. 12, fig. 10, $e^{3}$,) and folds downward and forward along the median line, so as to give its posterior edge a heart-shaped figure; and thus the posterior boundaries of the corpora quadrigemina are formed. We have given a perfect profile view of an embryo a little older, in order to show the transverse position of the brain as regards the spinal axis (PI. 12, fig. 6 ; Pl. 18a, fig. 13). Soon after this, the superior or dorsal side of the brain becomes indented by two transverse, shallow folds, so as to have an undulated profile (PI. 18a, fig. 14). This produces a slightly three-lobed aspect; one lobe being anterior to the folds, one between them, and one behind the same; the last lobe, the corpora quadrigemina, (fig. 14, $e^{3}$ ) is clearly separated from the open region (fig. 14, $e^{1}$ ) behind by a folding, which we have described in the last phase. These folds increase in depth, and plunge far into the head; the posterior one (Pl. 24, fig. $7, e^{5}$ ) reaching much deeper than the anterior one, which is just in front of the eyes (fig. $7, k$ ). The breadth of the brain, at this stage, has decreased considerably, (Pl. 24, fig. 7a, $e^{2}$ to $e^{3}$ ) and is slightly undulating at the sides, so as to appear four lobed when seen in front: the anterior lobe, formed by the hemispheres, (fig. $7 \mathrm{a}, e^{3}$ ) being the same as the one seen before the eyes in the profile view (fig. 7); the second, the optic lobe, is that which lies just in front of the deepest fold (fig. $7, e^{5}$ ); the third lobe, formed by the corpora quadrigemina, is that which lies close behind the deepest fold; and the fourth and last lobe (fig. $7, e^{2}$ ) is the cerebellum. The lateral constriction, between the optic lobes and the corpora quadrigemina, soon becomes very deep, (PI. 24, fig. 9a, $e^{6}$ ) and the latter body is gradually elevated, (PI. 14, fig. 4; Pl. 16, fig. 6 and $6 \mathrm{a}$, ) so as to give the head a crested appearance. This crest rises at one time very high (Pl. 14, fig. 2a; Pl. 18a, fig. 9). However, the prominence of the corpora quadrigemina does not indicate an absolute preponderance in size or capacity, when compared with the other lobes, since we find, upon 
taking a view of the interior (Pl. 22, fig. 9, b) of this body, that its lower floor is folded inward and upward so as to occupy the larger part of the space included within its superior arch. At this time, the inferior side of the optic lobes has a very thick wall, and is very much compressed; it descends far down between the eyes, (Pl. 22, fig. 9, $c$, ) and has a very narrow space between its opposite walls. The extreme anterior end of the brain, the hemispheres, (Pl. 22, fig. 9, $b^{1}$ ) lias very thick walls and a broad cavity. The two opposite halves of the end of the hemispheres are not intimately soldered together in one continuous layer, but merely touch each other. The superior or rather external edges of these two halves are folded inward, (fig. $9, b^{2}$, so as partially to divide the cavity of the hemispheres. This is the first indication of the development of the two olfactory nerves. Next, the superior wall of the optic lobes begins to bulge out between the eyes, (PI. 15, fig. 13,) and forms a continuation (Pl. 24, fig. 11) of the crest of the corpora quadrigemina, but at a much lower level. The hemispheres are more prominent than before, and encroach upon the anterior portion of the optic lobes, overlapping them at the sides and above.

The hemispheres continue for a while to go on enlarging rapidly, (Pl. 23, fig. 1, a, fig. 1a, a, ) and encroaching upon the optic lobes (fig. 1, k, fig. la, $k$ ). This causes the head to bulge very much just above the eyes, (Pl. 14, fig. I; Pl. 15, fig. 12, fig. 12a, ) and renders it angular in outline. From the hemispheres to the tip of the head, (Pl. 23, fig. 1, $c$ to $c^{\prime}$, ) the brain becomes very much narrowed, and tubular in form, assuming the character of an olfactory nerve, with a suddenly expanded terminal portion, (fig. 1, $c^{\prime}$,) the Schneiderian membrane. In consequence of the bulging of the hemispheres, the anterior part of the brain does not trend at right angles to the spinal marrow, but forms an arch, which, however, may be said, in general terms, to run at right angles with the axis of the body. The olfactory nerves, (PI. 23, fig. 1, c to $c^{\prime}$ ) in this case, meet the hemispheres (fig. 1, a, fig. 1a, a) nearly at right angles. As yet the olfactory nerves are quite short and thick. The folds of the two halves of these nerves, mentioned above, (Pl. 22, fig. 9, $b^{1}, b^{2}$ ) are here closed, (Pl. 23, fig. $1 \mathrm{a}, c$, ) and form two distinct olfactory tubes. This inward folding of the anterior part of the brain is continued backward to the hemispheres, along the median line, so as to divide them into two equal portions, one on the right, ( $\mathrm{Pl} .23$, fig. $1 \mathrm{a}, a_{2}$ ) and another on the left (fig. 1, a). The infolding edges of the hemispheres (fig. 1a, $m$ ) are not closed over at this time, but leave a large aperture on that face of each half which is next to the median line. The superior side of the optic lobes, (fig. 1, k, fig. 1a, $k$ ) where they meet the hemispheres, becomes transversely folded downward and backward, so as to form a small, rounded mass, (fig. 1, $d$, fig. 1a, $d_{g}$ ) attached by a broad base to the superior portion of the 
optic lobes. This new body is the pineal gland, and bears a very large proportion to the bulk of the whole brain, when compared with its size in the adult (Pl. 25, fig. 13, $p g$ ).

That part of the brain which lies close behind the corpora quadrigemina, ( $\mathrm{Pl}$. 23, fig. $1, b$, fig. $1 a, b$ ) and extends at right angles to them, becomes at this time more prominent (fig. 1, $e$, fig. 1a, e) than the region posterior to it (fig. $1, o^{1}$, fig. $\left.1 \mathrm{a}, \mathrm{o}^{1}\right)$. This, unquestionably, is the cerebellum, since just behind it we find that part of the spinal marrow, the medulla oblongata, from which the auditory nerve (fig. 1, l, fig. 1a, l) arises. The medulla oblongata (fig. 1, ol, fig. 1a, $o^{1}$ ) bends downward and forward so as to run nearly in the same direction with the cerebellum $(c)$. The cavities of the corpora quadrigemina, (fig. $\left.1 \mathrm{a}, b_{2}\right)$ of the cerebellum, $(e$,$) and of the medulla oblongata, \left(o^{1},\right)$ open widely into each other; but between the two lobes of the hemispheres (fig. 1, a, fig. la, a) and the optic thalami (fig. 1, k, fig, 1a, k) there is no communication whatsoever, nor between the latter and the corpora quadrigemina (fig. 1, b, fig. 1a, b). The optic thalami (fig. la, 7 ) remain adherent to each other at the lower border by means of a thin commissure, which is continuous with the floor of the fourth ventricle, $(0$,$) and also with that between the anterior border of the corpora$ quadrigemina (b). The floor of the fourth ventricle, (fig. 1a, o, which was formerly spoken of as the lower floor of the corpora quadrigemina, and pointed out as folding upward and nearly filling the latter, (Pl. 22, fig. 9, b, ) has become depressed, so as to leave a very large cavity in the corpora quadrigemina. Presently the olfactory nerve elongates, (Pl. 23, fig. 2, $c, c^{1}$, fig. 2b, $c, c^{1}$ ) and swells at its base, (fig. 2, $c$, fig. 2b, $c$ ) indicating the first step in the development of the olfactory bulb. 'The Schneiderian membranes (fig. 2, $c^{\prime}$, fig. 2a, $c^{\prime}$, fig. $2 b, c^{\prime}$, fig. $2 c, c^{\prime \prime}$ ) are separated by a cartilaginous partition (fig. 2c, $c^{\prime \prime \prime}$ ). The hemispheres (fig. 2, $a$, fig. 2a, $a$, fig. 2b, a) incrense in size in a much greater proportion than the other lobes, and gradually rise until they are on the same level with the corpora quadrigemina. The crura cerebri (Pl. 23, fig. 2d, r) arise by a thickening of the lower wall of each hemisphere along its whole length, close to the median line of the brain. The aperture (fig. $2 \mathrm{~b}, m$ ) next to the median line becomes very much reduced in size. The pineal gland (fig. 2a, $d$, fig. $2 b, d$ ) is about two thirds covered by the hemispheres, (fig. 2, a, fig. $2 \mathrm{a}$, $a$, fig. 2b, $a$, which overlap it at the sides. This body is not solid throughout, but has a slight excavation on its posterior face, in open communication with the cavity of the corpora quadrigemina (fig. 2, 2a, 2b, b). The optic thalami, (fig. 2, $k^{\prime}$, fig. 2b, ) in consequence of the encroachment of the hemispheres, $\left(a_{2}\right)$ have become totally confined to the lower side of the brain. In the brain of the Turtle, at this age at least, and even in the last phase, (PI. 23, fig. 1, 1a, it 
is very evident that the optic nerves (fig. 2, $k$, fig. $2 \mathrm{~b}, k$ ) arise directly from the optic thalami, $\left(k^{\prime},\right)$ and not from the corpora quadrigemina, $\left(b_{,}\right)$as would appear from the figures of the adult brain given by Bojanus. ${ }^{1}$

The corpora quadrigemina (fig. 2, $b$, fig. $2 a, b$, fig. $2 b, b$ ) gradually lose their large, open cavities, in consequence of the elevation of the lower floor, the aquaductus Sylvii, (fig. 2b, o, ) of this part of the brain. The volume of the corpora quadrigemina, (fig. $2, b$, fig. $2 a, b$, fig. $2 b, b$ ) compared with that of the hemispheres, (fig. 2, a, 2a, a, 2b, a, ) is at this time about as two to three, which is a very large proportion, compared with what it is in the adult (Pl. 25; compare fig. 13, cq, fig. 13a, $c q$, with h). The corpora quadrigemina are heart-shaped, with the broader end next to the hemispheres, which have a similar shape, but in a reverse position from that of the former.

The cerebellum (fig. 2, e, fig. 2a, $e$, fig. $2 \mathrm{~b}, e$ ) continues to bulge out behind the corpora quadrigemina, and to gain in bulk, but at a slow rate when compared with the other parts of the brain. The Schneiderian membrane enlarges more rapidly in a vertical direction (Pl. 23, fig. 3, $e^{\prime}$ ) than horizontally, and becomes gradually compressed, at the sides, so as to contain a very high but narrow chamber. The exterior opening of the cavity of this membrane first appears as a narrow channel (fig. 3,9) with a very thin wall. The pineal gland (fig. 3, d) becomes constricted at its base, and thus the first step is taken to form its pedicel. The corpora quadrigemina (fig. 3, b) become more constricted and depressed at the base behind, and in consequence more shut off from the cerebellum (fig. $3, e$ ). The latter, in continuing to increase in size, gradually bends obliquely upward, so as to cover by degrees a considerable portion of the fourth ventricle (fig. $3, p$ ). The fourth ventricle, (fig. $3, p$ ) by bending forward upon itself, allows the cerebellum $(e)$ and the posterior end of the corpora quadrigemina (b) to sink into the angle formed by its approximating anterior and posterior borders. The edges of the opening (fig. $3, e^{\prime}, f$ ) of the medulla oblongata grow thicker, until in time they equal in this respect its lower wall.

At the time the embryo is latched, (Pl. 23, fig. 4, 4a, 5, 6, 7, 8, 9, 10) the brain is far from having that long, slender, and flat shape which obtains in the adult (Pl. 25, fig. 13, fig. 13a). In addition to what has already been pointed out, (p. 575,) it may be added that the Schneiderian membrane is very thick, especially the wall (Pl. 23, fig. 4, fig. 11, w-c. 3, b, w-c. 11, a) facing the median line of the upper jaw. The channel (fig. 4, and w-c. 3, a) leading from the Schneiderian membrane gradually narrows, till, at the nostrils, it opens externally with a

1 L. II. Bojanus, Anatome Testudinis Europex, etc., Vilnx, 1819-1821. Compare his tab. 21, fig.
88, ii., ii. ${ }^{1}$, ii. ${ }^{3}$, with our Pl. 25 , fig. $13 \mathrm{a}$, and the explanation of his figure, p. 91 , with ours. 
small aperture. The walls of the olfactory bulb (fig. 4a, and w-c. 4, d) are very thick, especially at the constriction between the bulb itself and the hemispheres (e). This bulb is, moreover, larger and more distinguishable from the hemispheres than in the adult (Pl. 25, fig. 13, ob, fig. 13a, ob). The walls of the hemispheres (P1. 23, fig. 4, fig. 4a, fig. 8, fig. 9, and w-c. 3, e, w-c. 4, e, w-c. 8, a, w-c. $9, a)$ are very thick, especially below and at the sides, where the corpora striata are forming (fig. 8, and w-c. $8, a$, w-c. $9, a$ ); so that, in the latter case, they equal the transverse diameter of the cavity (w-c. 8, d) which they inclose. The walls of the optic thalami also (fig. 4, fig. 4a, fig. 8, fig. 9, w-c. 3, $h$, w-c. $\left.8, f, f^{1}\right)$ are very thick, fully as much so at the upper part as in the hemispheres, and leave only a very narrow cavity between them. At the inferior commissure (fig. 8 , and w-c. $8, g$ ) the wall is quite thin. The extreme lower end of this lobe is quite pointed; but there is yet no indication of a hypophysis, such as may be seen in the adult brain (Pl. 25, fig. 13a, i). The corpora quadrigemina (Pl. 23, fig. 4, fig. 4a, fig. 7, w-c. 3, $g, g^{\prime}$, w-c. 4, $g$, w-c. $7, a$, $a^{\prime}$ ) have sunk so low that there is only a shallow space (fig. 7 , and w-c. $7, b$ ) between them and the floor of the aquæductus Sylvii. The walls (fig. 4, fig. 4a, fig. 7, and w-c. 3, $i$, w-c. $T, c, c^{\prime}$ ) of the aquæductus Sylvii are very thick, but do not equal, in this respect, those of the hemispheres and of the optic thalami. The view given in fig. 7 , and w-c. $7, c, c^{\prime}$ is that of a transverse section of the brain at a point, in the aquaductus Sylvii, which includes both the lateral and the anterior walls; hence their apparent, great thickness.

The aperture in the upper side of the medulla oblongata is nearly filled by the oblong mass of the arachmoid plexus (fig. 4, fig. 4a, fig. 6, and w-c. $3, k^{\prime}$, W-c. $4, l^{1}, w-c .6, b, l^{\prime}$ ). At the edge of this aperture the wall terminates rather abruptly, (fig. 6 , and w-c. $6, c$ ) except that at the posterior end, where the opposite walls meet, it comes to a sharp edge (fig. 4, fig. $4 \mathrm{a}$, and w-c. $3, l^{1}$, w-c. 4 , $l^{1}$ ). The spinal marrow, although a closed tube with a very small channel, (fig. 5 , and w-c. 5, c,) close up to the medulla oblongata, has yet a deep median dorsal sulcus, (fig. 5, and w-c. 5, b, ) at least as far back as the base of the skull. As regards the spinal marrow, nothing more can be said now beyond what has already been stated above. A few additional remarks respecting its Histology may be found in the next section.

The Chorda dorsalis. Whatever further details are necessary in regard to this body may also be found in the section on Histology.

The Eyje. The eye commences to form by a bulging (Pl. 12, fig. 9a, $k$ ) of the inferior and lateral sides of the optic lobe. When the head is seen from the side, the wall of this protuberance appears as a clear, bright, thick ring (Pl. 12, fig. 9, k). For a short time the hernia from the optic lobe continues to 
increase in prominence, and its wall grows thick, (Pl. 12, fig. 6, k, without any change in its shape, except that its base becomes narrowed, so as considerably to lessen the chammel ( $\mathrm{Pl} .21$, fig. 28, c) of communication with the optic lobe. The pedicel does not meet the hernia at its centre, but at its lower side (Pl. 21, 28, c). At this stage the eyes may be described as pedicellated, asymmetrical, globular hernix projecting from the lower side of the optic lobes of the brain. The musculo-cutancous layer (Pl. 21, fig. 28, b) follows closely the constrictions of the hernia, and in this manner, embracing it closely, forms a shenth about it. Presently the wall at the lower side of the hernia begins to be depressed, as if it were pushed obliquely inward by some external force, thus producing a doublewalled cup, attached by its side to a pedicel. By degrees the depression grows deeper and deeper, and the outer wall (Pl. 24, fig. 8, k) approaches the inner one $\left(k^{\prime}\right)$ till they meet. A thickening of the musculo-cutaneous layer constantly follows the sinking wall, and at the time the two walls meet it forms a spheroidal body, the crystalline lens, (fig. $8, h^{3}$ ) moulded, as it were, in the cup of the eye. The depression at first extends for a short distance along the pedicel, but it is merely a narrow furrow, which has the appearance of being continuous with the channel (fig. $8, l^{2}$ ) of the pedicel; however, it eventually disappears, as the inferior diverging borders of the cup approach each other.

The passage way along the pedicel, the optic nerve of the eye, has by this time become quite small ( $\mathrm{Pl} .24$, fig. $7, k^{2}$ ); and, in consequence of the bending of the pedicel in a downward direction, appears, further inward, totally below the eye, so as to allow a view into its cavity without looking through any portion of the cup. Soon the cup-shaped hernia, the retina of the eye, has approximated its interrupted inferior borders, till they are brought in contact, (Pl. 13, fig. 2 and 3,) and thus the capsule of the crystalline lens is completed. 'The point of junction of the borders just mentioned is not obliterated at once; but after a short time all trace of it seems to be gone. The borders of the sheath or orbit, formed by the musculo-cutaneous layer, have become contracted around the crystalline lens so as to overlap it, except at the fold on the side of the eye, where the optic nerve joins the retina. The fold subsequently becomes very conspicuous as a white band running from the lens toward the posterior side of the eye, in the midst of black pigment (Pl. 24, fig. 11). Soon after this, the eyes become circular, and a layer of black pigment develops upon the exterior surfice of the retina, (Pl. 24, fig. 9a,) and therefore on the inner face of the orbit, the future membrana choroidea. The pigment does not develop over the fold which runs from the crystalline lens to the optic nerve, and consequently a white, broad streak is left on the lower side of the eye (Pl. 14, fig. 5). In a little older phase, what we have hitherto called the crystalline lens turns out to be not only 
that body, but its capsule also. The lens proper (Pl. 22, fig. 9, $c^{2}$ ) is formed by a hollowing of the solid mass which fills the depression in the retina, so as to leave a thin layer or outer wall attached to, and on a level with, the surface of the head, and a deeper layer or wall, from which a thick swelling (fig. 9, $c^{2}$ ) protrudes into the cavity $\left(c^{1}\right)$ between these two walls. The outer wall (fig. 9, c) contains the elements of the conjunctiva and of the cornea, but we have not ascertained what becomes of the inner wall; it may turn out to be the iris.

The two walls of the retina (Pl. 22, fig. $9, d, d^{1}$ ) have separated from each other; the outer one $\left(d^{1}\right)$ remains closely pressed against its orbit, but the inner one (d) forms a partition behind the crystalline lens, $\left(c^{2},\right)$ and separates it from the cavity of the retina, which contains the vitreous humor. The fold of the retina, at the lower side of the eye, continues to grow narrower, but elongates as the eye increases in size, thus forming a narrow, white streak, (Pl. 24, fig. 11, from the crystalline lens to the point of attachment of the optic nerve. The crystalline lens becomes a perfectly independent body, and develops its cells in a shape and with an arrangement peculiar to itself (Pl. 21, fig. 30, $a, b$ ). As yet there are no eyelids, (Pl. 15, fig. 13, ) and the eye is unprotected, as in Fishes. In a little later phase, (Pl. 1Sa, fig. 3,) the skin adjacent to the eyes begins to encroach upon their anterior surface, in the form of a narrow rim. At this time, too, the white streak on the lower side of the eye has disappeared; at least, it cannot be seen externally, since several new coatings have-been developed over it. The narrow rim around the eyes grows broader, (Pl. 18a, fig. 1,) and assumes more distinctly the appearance of an eyelid, and the eyes become less prominent. Soon the rim ceases to broaden at two opposite sides of the circle which it forms, but contimues to increase in the intermediate space, (Pl. 25, fig. 10, so as to produce a broad, oval opening between the approaching opposite edges, the upper half of the rim forming the superior eyelid, and the lower half the inferior eyelid. The eyelids continue broadening until they touch each other, and may be opened or shut at the pleasure of the embryo (Pl. 15, fig. 3). They never become agglutinated to each other, as happens among Birds and Mammals. The state of the membranes of the eye at this stage has already been sufficiently described (p. 570, Pl. 21, fig. 29, 31, 32-32d). Beyond this we have not had time to trace the development of the eye, and must leave the subject for future investigation.

At the time the Turtle was hatched, a very full examination of the structure of the eye was made, the results of which we will now proceed to give. On account of the softness of the different parts of the eye at that age, it was thought advisable to begin with some preliminary studies upon specimens hardened 
in alcohol. In this manner the topography and relations of the different membranes and layers can be made out quite easily, and, once familiar with the general structure of the eye of the Turtle, it is possible to dissect fresh specimens knowingly, and readily to detect any misplacements or distortions caused by the dissection. The outermost coat or covering of the eye is the conjunctiva (PI. 22, fig. 8, $a, a^{1}$ ); that portion of it which lies exterior to the boundaries of the cornea $\left(c^{1}\right)$ is a very thick, soft, and flabby membrane $(a)$; but where it passes over the cornea it becomes very thin. Here it presses very closely upon the cornea, $\left(c^{1},\right)$ and is changed in its nature to a very tender and friable membrane, $\left(a^{1},\right)$ the conjunctiva of the cornea. The sclerotica $\left(b, b, b^{1}, c^{1}\right)$ totally envelops the eye, except where the optic nerve $\left(h^{1}\right)$ enters. In front of the eye it forms the cornea, $\left(c^{1},\right)$ a very tough, elastic, and transparent membrane, considerably thicker than the conjunctiva $\left(a^{1}\right)$ which covers it. At the base of the iris, $\left(e^{1},\right)$ the cornea suddenly thickens, and, passing backward all over the eye, constitutes the sclerotic coat, $\left(b, b^{1},\right)$ which is a tough, dense, bluish membrane, much thicker than any other of the coats of the eye, and pressing pretty closely upon the choroidea $(e)$; but it is not in actual contact with it, being separated from the same by a layer of black pigment $(d)$. This pigment layer $(d)$ extends from the edge of the cornea backward, over the whole eye, but disappears $\left(d^{1}\right)$ at the point of entrance of the optic nerve $\left(h^{1}\right)$. The choroidea $\left(e, e^{4}\right)^{1}$ is a very thin membrane, of uniform thickness throughout its whole extent, excepting where it passes along the optic nerve $\left(h^{1}\right)$; there it thickens considerably $\left(e^{4}\right)$. At its anterior border it begins again to thicken, just where the posterior edge $\left(\epsilon^{3}\right)$ of the ciliary processes $\left(e^{2}\right)$ terminates, and continues to increase in thickness until it reaches a point opposite the junction of the cornea $\left(c^{1}\right)$ and sclerotica, $(b$, where it thins out as it plunges into the aqueous humor. Here it constitutes the membrana iridis, $\left(e^{\mathrm{P}},\right)$ a very spongy and loosely fibrous structure, resembling an irregular network. At this age, the iris $\left(e^{\mathrm{I}}\right)$ does not hang perpendicularly to the axis of the eye, but projects very obliquely forward, as it must necessarily do, because the crystalline lens presses upon it from behind, and forces it to slide over its convex surface, or rather that of the membrana pupillaris, $\left(n_{9}\right)$ when contracting and expanding. Even in the adult, this peculiarity (see fig. $7)$ obtains to a slight extent. The ciliary processes $\left(e^{2}, e^{3}\right)$ extend from the free border of the iris $\left(e^{1}\right)$ along its posterior surface, where it forms a thick posterior lining, and, thinning out rather abruptly about opposite the anterior edge $\left(i^{1}\right)$ of the retina, continues for a short distance backward, and then terminates suddenly in a sharp edge, which may be ensily separated from the choroidea, although

1 In P1. 22, fig. 8, the letter $e^{1}$ nen: $h^{1}$ should be $e^{4}$. 
it is closely pressed upon it. That part of the ciliary processes $\left(e^{2}\right)$ which covers the posterior surface of the iris $\left(c^{1}\right)$ is very probably identical with that which is said to "exist over the posterior surface of the iris and the projecting ends of the ciliary processes" I in the human eye. Between the membrana iridis (fig. $S, e^{1}$ ) and its posterior lining, $\left(e^{2}\right)$ there is a layer of black pigment, which extends backward till it reaches the posterior border $\left(e^{3}\right)$ of the ciliary processes, where it becomes one with the pigment layer $(f)$ which lines the choroidea proper (e). It is evident, that, whatever may be their connections in the higher inimals, in the Turtle, even when full grown, the ciliary processes (see Pl. 22, fig. $T, c^{2}, c^{3}$ ) are not an integral prolongation of the choroidea, but a separate layer, with a layer of pigment between the two membranes. 'The pigment layer (fig. $8, f$ ) just mentioned as lining the choroidea, $(e$, ) and its prolongation, the membrana iridis, $\left(e^{1},\right)$ constituting the so-called pigmentum nigrum, forks at the posterior edge $\left(c^{3}\right)$ of the ciliary processes, and sends oft' a layer along the inner surface of the latter $\left(c^{2}\right)$. The pigmentum nigrum is loosely coherent to the choroiden, yet presses very closely upon it. It disappears where the choroidea sheathes the optic nerve.

In specimens preserved in alcohol, this layer, the pigmentum nigrum, has a leaden aspect with a peculiar lustre, and clings to the membrana Jacobi $(g)$ in preference to the choroidea, $(e$,$) when the former is lifted off from the latter.$ The papilla of the outer surface of the membrana Jacobi, plunging into the pigment layer, adhere to it much more firmly than the smooth surface of the choroidea. Next within the pigmentum nigrum $(f)$ is the retina, $\left(g, g^{1}, h,\right)$ which, in a section of its thickness, appears transversely striated over nearly its whole extent, ${ }^{2}$ and seemingly divided into three layers. These apparent layers are the expressions of so many different strata of peculiar nervous cells, which will be described in detail hereafter; it may suffice here to say that they are not distinct layers. The outermost stratum $(y)$ separites so easily from the inner one, that it has, until within a few years, been considered as a distinct membrane, under the name of "membrana Jacobi." In the Turtle, this peculiar stratum projects singly beyond the anterior edge $\left(i^{1}\right)$ of the rest of the retina, and, pressing against that part of the pigmentum nigrum which covers the anterior extension of the ciliary processes, $\left(e^{2}\right.$, extends half-way to the edge of the iris $\left(e^{1}\right)$. It is much thimner here than where it is comnected with the imner strata of the retina; in the latter position it is quite thick, and uniform throughout $(g)$. The exterior surface of the membrana Jacobi has a beautiful golden orange color, of

1 Sharpey and Quain's Human Anatomy, London, 18.18, vol. 2, p. 921.
${ }^{2}$ By mistake these strix of the retina were not drawn perpendicular to its thickness, in front. 
variable degrees of intensity. This color is situated totally within the large mesoblasts of the columnar cells which compose the stratum (see PI. 21, fig. 33, $h, i$, fig. 33a, $a, b, c$ ). 'The combined strata of the retina (Pl. 22, fig. 8, $h$ ) with the membrana Jacobi (g) have a uniform thickness throughout, except at the anterior border, where they suddenly thin out and come to a sharp terminating edge, $\left(i^{1},\right)$ at a short distance behind the base of the iris. Opposite the entrance of the optic nerve, $\left(l^{1},\right)$ the retina preserves the same uniformity as elsewhere, nor do there appear to be any nervous fibres prolonged through it from the optic nerve; but this point wants further special investigation. 'The optic nerve, $\left(h^{1},\right)$ as well as the whole retina, is hardly consistent enough to hold together, when separated from the surrounding envelopes. Just within the retina, there is a very thin, striated layer, $\left(i_{9}\right)$ composed of wavy fibres, which apparently radiate from the optic nerve $\left(h^{1}\right)$ in every direction, and extend to the anterior edge $\left(i^{1}\right)$ of the retina.

In another place it will be shown in detail, that these fibres are not prolongations from the optic nerve, but belong to the inner layer of nervous cells, of which they are tail-like prolongations (see Pl. 21, fig. 33, 6). Next within the layer of wavy fibres (Pl. 22, fig. 8, $i$ ) is the nembrana hyaloidea, $(k, k$,$) forming a closed$ sac, and lining the whole internal surface of the retina and the back of the crystalline lens (l). This membrane lies close against the retina over its whole extent, even to within a very short distance of the anterior edge of the membrana Jacobi, $\left(g^{1},\right)$ where it folds backward and passes $\left(h^{1}\right)$ close behind the crystalline lens, $(l$,$) where it may be traced as readily as at any other part. The soft,$ thick, and tender nature of this membrane readily distinguishes it from the excessively thin, tough, glassy, glittering, and elastic triple membrane which forms the capsule $(m)$ of the crystalline lens. The three membranes composing the capsule $(m)$ of the crystalline lens adhere very closely to each other, so that it is very difficult to separate them. At the spot where the membrana hyaloidea comes in contact with the crystalline lens, the membrane of the capsule sends off a layer forward and centrifugally, which joins the hyaloidea as far as its first bend, $\left(\hbar^{2},\right)$ and thence, turning suddenly upon itself, passes forward and centripetally before the edge $\left(n^{1}\right)$ of the membrana pupillaris, $(n)$ ) by which it is closely overlapped, and to which it adheres very tenaciously, and terminates a little behind the free edge of the iris. This portion of the membrane of the capsule clings so closely to the hyaloiden, especially at the angle $\left(h^{2}\right)$ where it reverts to pass before the membrana pupillaris, that, were it not for the great difference in structure between the two, as we have pointed out above, it might easily be mistaken for a continuation of the membrana hyaloidea, as it has been asserted to be, in the eye of Mammalia.

'The crystalline lens, $(l$, ) when seen in profile through a line perpendicular to 
the axis of the eye, has a symmetrical, oval outline, the anterior and posterior surface being of equal curvatures. The membrana pupillaris $\left(n, n^{1}\right)$ presses pretty closely upon the anterior surface of the crystalline lens, $\left(l_{g}\right)$ being kept in its place by its attachment (at $n^{1}$ ) to the free portion of the capsule of the lens, and extends behind the free edge of the iris nearly half-way $\left(u^{1}\right)$ to its base. It is nearly as thick as the conjunctiva, $\left(a^{1},\right)$ and has something of the same brittle, soft, inelastic, dense nature. By these properties it is easily distinguished from any other membrane near it. Under the influence of alcohol it retains its shape and smoothness, whilst the membrana hyaloidea becomes very much shrunk and shrivelled. The membrana pupillaris does not disappear in the adult, and very probably remains through life, since it was found in the eye of a specimen of Trachemys scabra which was about twenty years old. In this case the membrane was double, (Pl. 22, fig. $7, n, n^{1}$ ) and very thick. The vitreous humor, at the time the Turtle is hatched, is so soft and so little consistent that it may be poured out of the eye almost as easily as if it were water.

The Ear. The earliest indications of the presence of the ears that have been observed are two cup-shaped depressions, (Pl. 12, fig. 8, 9, 9a, l, ) one on each side of the base of the head, in the musculo-cutaneous layer, and a narrow band or projection running from the median line of the under-side of the medulla oblongata to the bottom of each cup. The cup, or meatus auditorius, gradually broadens at its mouth, (Pl. 12, fig. 6, l, ) and grows narrow at the bottom (Pl. 18a, fig. 13, l) till it assumes a very broad trumpet shape, (Pl. 24, fig. 7, l,) which it retains, with slight modifications, for the rest of its life. Eventually the mouth of the meatus becomes covered by a thin, transparent membrane, (Pl. 18a, fig. 1,) the membrana tympani, which finally assumes an opaque and dense nature in the adult, and is covered by the still denser and tough epidermis. The narrow band, the auditory nerve, (Pl. 12, fig. 9a, p. 548 ,) which passes from the brain to the meatus, becomes in the end very broad, (Pl. 23, fig. 1, l, fig. 1a, l, fig. $2, l_{2}$ ) and is situated higher up on the side of the medulla oblongata; and, finally, by the time the Turtle is hatched, its end expands into a large, convoluted, hollow hernia, (Pl. 23, fig 7, and wood-cut 7, $e^{\prime \prime}$, p. 577) which fills a considerable portion of the vestibule. Each convolution, of which there are three, is very broad, and opens widely into the main cavity, the alveus of the hemia. The pir mater extends as a sheath (w-c. $7, f$ ) from the brain all over the auditory nerve, and its expansion (W-C. $7, f^{\prime}$ ), in the vestibulum. The vestibule (T-C. 6, $e$ ) is very high, reaching from below the level of the medulla oblongata (w-c. 6, $c, c^{\prime}$ ) to a point as high as the posterior end (w-c. 6, $a^{\prime \prime}$ ) of the corpora quadrigemina; and antero-posteriorly, from the anterior wall of the fourth ventricle ( $w-c .3, i$, W-c. $7, c, c^{\prime}$ ) backward to the posterior end (w-c. $6, a$ ) of the cerebellum. 
The ante-restibulum, or the cavity of the tympanum, (fig. 6, fig. 7 , and w-c. $6, e^{\prime}$, w-c. $7, i$ ) which contains the bone, the stapes of the ear, is very large, and is divided into two compartments, one nearly globular, the mastoid sinus, (fig. 6, and w-c. $6, e^{\prime}$ ) opening forward into a larger one, the true tympanic cavity, (fig. 7 , and w-c. $7, i$ ) which is very high, and narrower than the other. The ante-vestibulum extends much further, both before and behind, than the vestibulum. The stapes, the only bone of the ear that the 'Turtle possesses, is a short and thick cartilaginous cylinder, (fig. 7, and w-c. $7, i$ ) with very broad exterior and interior ends.

The Nostrits. Whatever may be necessary to the understanding of the formation and development of the nostrils has already been mentioned above. (See p. 555, Pl. 24, fig. 12, v, p. 559; Pl. 18a, fig. 9, v, p. 562; Pl. 24, fig. 11, v.)

The Vertebral Colum. The process of the origin of the vertebral layer, and the mode of formation of the vertebrx from this layer, have been quite fully described, when treating of the earlier stages of the embryo as a whole. (See p. 543 and 545.) There are a few points, however, which need separate notice, in regard to the special growth of the vertebræ. After the vertebra are clearly defined, (Pl. 12, fig. 3 , $3 \mathrm{a}, 3 \mathrm{~b}$, ) the centre of each changes in its appearance, and becomes more transparent than the periphery. Upon investigating this peculiarity in a little later stage, (fig. 9, $f$, fig. 9a, $f$, ) it was found that each vertebra, or rather each half vertebra, is composed of cylindrical, wedge-shaped cells, forming a very thick wall, (Pl. 19, fig. 3,) inclosing a large, clear space. By following the development of the vertebra through their progressive stages, we find that this clear space finally loses its sharply marked boundaries, and gradually blends with the surrounding wall (Pl. 24, fig. 14, $f$ ). The centre remains for a while transparent, probably in a fluid state; but between this centre and the walls a more solid substance seems to be filling in. What the nature of this substance is, was not ascertained. Finally, the whole half vertebra appears, under a low magnifying power, homogeneous thronghout ( $\mathrm{Pl}$. 24, fig. 9, $f$ ). In the latest stages, at the time of hatching, when the vertebra have become partially ossified at the periphery, (Pl. 22, wood-cut 12. fig. 3, and w-c. 12, $a^{2}$, ) the centre $\left(a^{1}\right)$ of each half is again very clear, and is composed of large cartilage cells, (Pl. 22, fig. 4,) identical with those found in the centre of the ribs (see Pl. 22, fig. 1, a, fig. 2, a). How these cartilage cells are developed in this instance has not been at as as ascertained, nor have we any data upon which a supposition can be founded. The chorda dorsalis has disappeared at this agre, and the two halves of the vertebra have united at the middle line, (w-c. $12, a^{3}$, ) so as to leave no sign of their point of junction. The vertebre may be traced to the very tip of the tail; and their number, fifty-five, equals that found in the adults. 
The Skull. It is not till much later than the appearance of the vertebrx that the cranial portion of the vertebral column makes its appearance. 'The earliest period at which we have noticed it was after it had risen from below, so as to envelope the whole brain in front of the cerebellum, (PI. 24, fig. 7, $c^{2}$, ) and had gained considerable thickness, almost twice as great as the skin just exterior to it. It rises gradually at the posterior part, and grows proportionally thimner, except at its base, (Pl. 23, fig. 3, $\boldsymbol{I}_{\text {) }}$ ) where it becomes very thick. At this point it is merely cartilaginous, and extends in a uniform layer from the nose (fig. 3,4 ) to the posterior opening at its base, (fig. 3, 1,) including the elements of the vomer, $(5$,$) which underlie the Schneiderian membrane \left(c^{\prime}\right)$ and the space between the eyes, the ethmoid, $(\boldsymbol{3}$,$) the sphenoid, (\boldsymbol{6}$,$) the$ basal occipital, $(2$,$) the occipital crest, (\boldsymbol{I}$,$) and several other bones, not indi-$ cated in the figures. The supermaxillary or upper jaw bone (fig. 3, 8) forms a separate cartilaginous layer. At the time the Turtle is hatched, the different bones of the head are generally marked out, but in very different degrees of ossification. The os incisivum, (Pl. 23, fig. 4, and w-c. 3, $t$,) or intermaxillary bone, although as yet very spongy, is the most ossified, and is probably the one most needed of any for the purposes of feeding. The upper maxillary, (fig. 11, and w-c. 11, $d^{\prime}$ ) the ethmoid, (fig. 4, fig. 11, and w-c. 3, $x^{\prime \prime}$, w-c. 11, $d$,) and the frontal bones (fig. 4, and w-c. 3, $n$, fig. 10, and w-c. 10, f) are hardly less ossified than the mandibles. The parietal (fig. 8, and w-c. 8, $h$ ) and the sphenoid bones (fig. 8, and w-c. $S, i$ ) come next in hardness. The crest of the occiput (fig. 4, fig. 5, and w-c. 3, $n$, $n^{\prime}$, w-c. $5, m, m^{\prime}$ ) has only an extemal layer (w-c. 3, $n^{\prime}$, w-c. 5, $m^{\prime}$ ) ossified, the rest is cartilaginous; the basilar portion (fig. 4, and $w-c .3, r^{n}$ ) of this bone begins to be hardened internally. The same may be said of the sphenoid bone (fig. 4, fig. 8 , w-c. 3, $r^{\prime}$, w-c. 8, $i$ ). The other bones of the head are, as a general thing, merely cartilaginous. The basilar part (fig. 4 , and $w$-c. $3, r^{*}$ ) of the occipital bone does not trend in the same line with the sphenoid, $\left(r^{\prime},\right)$ but is elevated to an angle of at least thirty degrees above it. In the adult, these two bones trend in the same line.

The Shicld. Very few investigations have been made respecting the development of the different elements which compose the shield. ${ }^{2}$ The manner in which the roof-like dorsal shield originates has already been described, (p. 562, Pl. 15, fig. 13, and the changes in form through which it passes have been pointed out. We are not prepared to say any thing more in respect to its internal metamorphoses, until the time when the young Turtle is hatched. At that time the shield

1 Comp. Part II., Chap. 1, Sect. 4, 1. 255, and Sect. 5, p. 263-265.
2 For more details, see Rathke, Entwickelung der Schildkrüten, p. 84, 101, 105, and 177. 
consists of the vertebral column already described, the fibrous corium, (Pl. 9e, fig. 12, $c$, and the ribs $(a, b)$ imbedded in the latter. The ribs do not touch each other laterally, as in the adults of many genera, but their margins (Pl. 9e, fig. 12, b) are flattened, and run out into a thin edge. At the surface of the ribs, the passage is so gradual from the fibrous bony layer (Pl. 22, fig. 1, $b, e, d, e, f$. fig. $2, b, c, d, e, f$ ) into the fibrous corium, (fig. 1, $y, g^{1}, h, h^{1}$, fig. $2, h$, that it is impossible to distinguish the one from the other. In fact, since the ribs are developed from what was once a uniform layer of corium throughout the whole extent of the shield, it is not at all to be expected that the line of demarcation should be very definite at this age. The true cartilagino-osseous matrix of the ribs is in the interior of each rib (Pl. 9e, fig. 12, $a, a^{\prime} ; \mathrm{Pl}$. 22, fig. 1, $a$, $a^{1}, a^{2}, a^{3}$, fig. 2, $\left.a, a^{1}, a^{2}, a^{3}\right)$.

The Limbs. The changes through which the limbs pass, as far as their external configuration is concerned, have been sufficiently described in the last section. At first they are lateral protrusions (Pl. 24, fig. 14, w $w^{1}$, p. 555) of the musculocutaneous layer from the sides of the body, and are composed of a solid mass of cells, identical with each other throughout the whole limb. The bone, or rather the matrix of the bone, is formed by a certain portion of the cells in the axis of the limbs becoming differentiated from the others, by increasing in size and assuming a less elongated sliape, (PI. 21, fig. 22, 22a, 24, ) and at the same time separating from each other. This arrangement produces a different effect upon the light from that of the cells in the surrounding parts, so that the position of each bone-matrix may be recognized without much trouble ( $\mathrm{Pl} .25$, fig. 11). The matrices are not sharply defined, because the passage from the elongated cells of the unossifying portion to the broad cartilage cells of the matrix is not sudden, but gradual. Later, however, the bone matrix becomes more definite in outline, (Pl. 21, fig. 21; Pl. 25, fig. 12, $b, c, d$,) and differs very much in appearance from the surrounding portion of the limb (Pl. 21, fig. 20, b, $b^{\prime}$; Pl. 25, fig. 12, a). About the time of hatching, the bones are all well developed, and have in a great measure the characteristic shape of those of the adult, but the ossification is only external, the central part of the bones being occupied by almost pure cartilage (Pl. 22, fig. 5, 6, 6a, 6b). The bones of the feet are the most ossified, especially the terminal ones; and not only is the fibrous layer hardened, but also a considerable thickness of the cartilaginous basis contains lime. The femur comes next in amount of ossification, but this occurs only along the cylinder, and not at all on the ends. The scapula, and its process, the acromion, are but a little less ossified than the last. The other bones have a very thin external fibrous ossified layer, the rest of each bone being highly cartilaginous.

The Nuscles. During our investigation of the development of the Turtles, our 
attention has chiefly been devoted to those points which are less fully illustrated in Rathke's monograph. 'The minuteness with which he has described the muscular development of a number of young 'Testudinata belonging to several distinet fumilies ${ }^{1}$ has induced us to enter into fewer details upon this point, especially since the muscles of the adults are fully described in a preceding part of this work. On that account, we have taken more particularly into consideration the Histology of this system, for which we refer to the next section. (See also p. 592, 1'l. 19, fig. 25.)

The Heart. The heart, and in fact the whole circulatory system, is a development of the dorsal surface of the intestino-subsidiary layer into a vast network of anastomozing chamnels, through which the blood runs in certain determined directions. It is within the boundaries of the central propeller of the circulation that the blood first makes its appearance, surging backward and forward. At first, circulation is a mere tossing of elementary cells and albuminous fluid from one side to the other of the simple saccular heart (p. 547; Pl. 12, fig. $7, h$ ). After the vertebral layer ( $\mathrm{Pl}$. 9e, fig. $4, f^{1}$, fig. $4 \mathrm{a}, f^{1}, f^{5}$, fig. $4 \mathrm{~b}, f^{1}$ ) has divided off from the subsidiary layer, (fig. $4, o^{1}, n$, fig. $4 \mathrm{a}, o^{1}, n$, fig. $4 \mathrm{~b}, o^{1}$, ) the latter becomes separated from the former to a considerable extent, so as to leave a cavity ( $\mathrm{Pl}$. 9d, fig. $1, h, j^{2}$; Pl. 9e, fig. $5, j^{2}$ ) of variable depth between the two. This cavity is deepest along the median line of the body, and grows shallow on each side till its upper and lower walls meet along the sides of the embryo. At the anterior part of the body, the largest and deepest portion (Pl. 9d, fig. 1, $h$ ) of the cavity is nearly altogether shut off from the rest; this is the heart. As yet there is no circulation in it, there being no walls proper; in the beginning it merely marks its position, just in the same way that the primitive furrow indicates the site of the spinal marrow. However, in order to avoid confusion, we will at once designate it as the heart, and speak of it as such during its formation, as well as afterwards. In the beginning, the heart lies at the inner angle of the curve of the head, so that it is partly in the dorsal and partly in the ventral region, and is essentially more anterior than the brain (fig. $\left.1, e^{1}, e^{6}\right)$. This latter feature would be more readily perceived if the embryo were represented in a straightened position.

On account of the absence of a circulating fluid of any consistency, the heart is not perceptible in a general view of the whole animal. It requires a longitudinal section (Pl. 9d, fig. 1) of the embryo, in order to lay it open to view. On this account it is not seen in several of our figures representing external views of some older stages, (Pl. 12, fig. 3, 3a, 4, ) where the anterior bend (fig. 3, $a^{6}$, fig. 3a, $a^{6}$ ) of the body has receded toward the abdominal 
'region. Soon, however, the subsidiary layer forms a wall around the cavity of the heart, partly by a direct hollowing in its own thickness, thus constituting the lower wall, as we may see by the thimness of the layer at this spot (Pl. 12. fig. $7, h, i)$; and partly by elevating the edges of the channel and closing them over, so as to form an arch, or superior wall. Thus, in the beginning the heart is a simple, straight tube, (fig. $7, h$, trending in the same direction with the axis of the body. The posterior end of the heart becomes connected, or rather contimuous, with a transverse channel (fig. 7, $i$ ) which is formed in the same way. and the anterior end with two other channels (fig. 7, j) of similar origin, which pass, one on the right, and one on the left, up along the sides of the head. Presently the heart bends upon itself at two different points; at one point, behind, it curves to one side, (PI. 12, fig. 10, h, ) and at the other, before, downward, as it joins the branchial aortæ (fig. 10, $j$ ). About this time, too, it begins to swell in its middle region, (fig. $6, h$, ) and curves outward; moreover, it has become separated from the subsidiary layer by a kind of longitudinal constriction; but the rest of the channels of circulation remain as they originated. These curves grow stronger until there are three quite distinct chambers, one in front of the anterior curve, the aortic bulb (Pl. 18a, fig. 13, $h^{1}$ ); another, the ventricle, $\left(h^{4},\right)$ just behind, trending in an obliquely transverse and backward direction toward the right side; and the last, the auricle, $\left(h^{3},\right)$ running from right to left and obliquely forward and downward. The communications between these three cavities, and also between the last and the vena afferens, $(i$, are still verv broad. The wall of these cavities, especially that of the auricle, $\left(h^{3}\right)$ has become very thick. At this time there is a complete system of efferent and afferent vessels throughout the body, so that the blood passes in a perfect circle from and to the heart.

Another chamber is subsequently formed, by a median transverse constriction of the auricle, making in all three distinct compartments, (PI. 13, fig. 2,) communicating with one another by narrow channels in the heart proper, and a fourth, just in front of it, the aortic bulb. The relative positions of the three chambers become changed at this time: the anterior one, the ventricle, (Pl. 18a, fig. 11, $h^{*}$, fig. 12, $h^{4}$; Pl. 24, fig. $7, h^{4}$,) falls to a lower level, which is the same, or nearly so, with that of the middle chamber, the left auricle (Pl. 18a, fig. 11, $h^{3}$, fig. 12, $h^{3}$; Pl. 24, fig. $\left.7, h^{3}\right)$. The inversion of the heart goes on till the relative positions of the auricles and ventricle are totally opposite to what they were at first; the auricles (PI. 24, fig. 9, $h^{3}$ ) being situated next to the back and directly above the ventricle, (fig. 9, $h^{4}$, fig. 9a, $h^{4}$ ) which occupies the ventral region, to the total exclusion of the other chambers of the heart. This is the position which the heart holds in the adult. The ventricle, (fig. 9, $h^{4}$, fig. $9 a, h^{4}$, ) at the same time 
that it sinks toward the ventral side, increases very much in size, so as to equal in bulk both auricles, and, moreover, undergoes a remarkable internal change, which consists in the formation of a thick network of high and narrow semipartitions on its imner surface, occupying nearly the whole cavity of the chamber.

The figures of the next stage, (Pl. 18a, fig. 8, 9, 10,) which, by the way, have already been sufliciently described, (p. 559,) apparently contradict the statements just made in regard to the relative size of the chambers of the heart; but this is readily explained by the fact, that, during the contraction of the ventricle, (fig. $8, h^{4}$, fig. 10, $h^{4}$ ) the auricles (fig. $8, h^{3}$, fig. 10, $h^{3}$ ) become very much distended and enlarged. Now that the heart has assumed a position which it ever after holds, the only further changes which it undergoes relate to the comparative size of the different chambers, the narrowing of their channels of communication, and the formation of valves at the mouths of these channels. The ventricle (Pl. 24, fig. 10, 10a, 10b, $h^{4}$ ) finally becomes twice as large as the two auricles combined (fig. 10, 10a, 10b, $h^{3}$ ); the meshwork of semi-partitions disappears, and is replaced by a very thick wall, (fig. 10b, $l^{4}$, ) traversed by irregular canals. It can hardly be doubted, from the appearance of the wall of the ventricle, that the semi-partitions have become obscured simply by thickening until they touch each other, except at a few points, which correspond to the irregular canals which pass from the internal nearly to the extemal surface of the wall.

The manner in which the valves (Pl. 24, fig. 10b, $v^{l}$ ) are formed has not been ascertained by tracing their development; but, as they are simple projections from the edge of the opening (fig. $10 \mathrm{~b}, v^{\circ}$ ) of the passages from the auricles $\left(h^{3}, l^{3}\right)$ into the ventricle, $\left(h^{4},\right)$ it is very probable that they originate by a gradual elevation of this edge until it constitutes a lappet, or fold, sufficiently broad to extend across the whole diameter of the opening. These two valves are properly within the ventricle, (fig. $10 \mathrm{~b}, h^{4}$, ) and, when inactive, hang loosely into its cavity; but upon the contraction of this chamber they are pressed upon by the blood, and apply themselves over the apertures to which they respectively belong, and prevent the regurgitation of blood into the auricles (fig. 10b, $h^{3}, h^{3}$ ). The valves at the opening of the venous sinus (fig. 10a, r's) are mere protrusions of the lips of a transverse fissure into the right auricle The passage of the blood through the heart at this phase is very irregular; first entering at the venous sinus, (fig. $10 \mathrm{a}, 2 \%$ ) it passes into the right auricle, and thence, in part, directly into the ventricle, $\left(h^{4},\right)$ and in part into the left auricle, and from that into the ventricle, $\left(h^{4},\right)$ thence again to pass out through the right ${ }^{1}$ and left (fig. 10,

1 'The right aorta, unfortunately left by mistake unlettered in the figures, doubles at a little distance from its point of origin, and may be recognized here as the shortest vessel in the firgure. 
$p a, 10 \mathrm{a}, p a, 10 \mathrm{~b}, p a$ ) aorts and the pulmonary artery (fig. 10, 10a, 10b, $h^{3}, h^{2}$ ). Our investigations in regard to the relations of the heart to the different vessels which pass to and from it are quite defective, and, like other points in the development of the organs, must be left for future research.

The Bloodresscls. All the principal bloodvessels originate, like the heart, as chamnels, hollowed in the superior thickness of the subsidiary layer. We have already (p. 545 and 594; Pl. 9d, fig. 1, $h, j^{2}$; Pl. 9e, fig. 5, $j^{2}$ ) pointed to the fact, that the subsidiary layer becomes more or less separated from the layers above it; but, with the exception of the tracks along which vessels are formed, this gap is afterwards filled up again. After the initiatory steps are taken to form the heart, the anterior pair of the branchial aorte (Pl. 12, fig. $7, j$ ) are developed: they appear as channels rumning obliquely forward and upward, one on each side of the head, from a common point of origin, the heart, $(h$, ) toward the dorsal region (p. 547). At the same time, the branches (fig. $7, i, i$ ) of the afferent vessel, the omphalo-meseraic vein, commence as nearly transverse channels opening into the posterior end of the heart. $(h)$. These transverse channels $(i, i)$ are exactly in that bend of the subsidiary layer which forms the anterior edge of the abdominal cavity. Exterior to the body, the omphalo-meseraic vessel first appenrs as a broad and thick band, $\left(i^{1}, i^{1}\right.$, ) which subsequently becomes hollow, and constitutes the vena terminalis.

At the time the branchial fissures (Pl. 12, fig. $8, m$, fig. $9, m$ ) are formed, the three other branchial aortæ (Pl. 18a, fig. 11, $h^{2}$, and note 2, p. 551) are developed between, and run parallel with them. A little later, the branchial aorta empty into the two branches of the dorsal artery (Pl. 18a, fig. 11, $j^{2}$, also fig. $7, j$ ). Beyond this we have nothing more to say in regard to the branchial aorta themselves besides what has already been stated in the section on the general development of the embryo.

The aorta dorsalis, or descendens, originates as a forked vessel, one limb of the fork rumning along the right side, (Pl. 18a, fig. 11, $j, j^{2}$ ) and one along the left, (Pl. 18, fig. 7,) of the dorsal region, just behind the head, and uniting into one median channel (Pl. 9e, fig. $7, j^{2} ; \mathrm{Pl} .18$, fig. 7 ) at a short distance behind the heart. From this point it runs singly along the axis of the body to its posterior extremity; and finally, when the tail is developed, to the end of that organ (Pl. 13, fig. 2, w-c. 1, j2, p. 553). The anterior ends of the two branches of the fork of this vessel rum forward into the head, (Pl. 18a, fig. 11, $j$ ) and eventually branch there very extensively (PI. 13, fig. 2). Soon after the forming of the aorta, lateral branches (Pl. 18, fig. 5, 7) rum out from its right and left sides and pass into the vascular area, and its posterior end forks, and joins the two lateral abdominal veins. Presently the allantoidian arteries (PI. 13, 
fig. 2; w-c. 1, $n^{6}$, p. 553) also arise from its posterior end. After a while its abdominal portion has less numerous outlets, (Pl. 13, fig. 3, q,) all of which finally merge into one, the omphalo-meseraic artery (PI. 18a, fig. 14, $j^{4}, j^{5}$ ). This is very easily understood, if the very loose connection of the cells of the subsidiary layer is borne in mind; the channels for the blood, having no wall, readily change their course, and merge into each other, and finally form one large stream for the exit of the arterial blood. Around this single, large channel a distinct wall is eventually formed.

In the beginning, the omphalo-meseraic artery, or rather arteries, are mere lateral diverticula of the dorsal artery, (Pl. 18, fig. 7,) but do not originate from it as a starting point. It is rather singular, but nevertheless true, that the first indications of this system of vessels appear at the extreme edge of the subsidiary layer, in the form of a thickening (Pl. 9d, fig. 1, $i^{1}, i^{1}$; Pl. 9e, fig. 5, $i^{1}, i^{1}$ ) of the periphery of the latter. This thick border goes on broadening for a while, till it becomes quite conspicuous (Pl. 12, fig. $7, i^{1}$ ) as a well defined ring surrounding a broad space bordering on the abdominal region of the embryo. One portion of it, that nearest to the head, curves inward, and lies in close connection with the transverse vessel $(i)$ which leads into the posterior end of the heart. For a short time, this ring gradually expands, and incloses a large area, (Pl. 14, fig. 12,) without exhibiting any other change; but finally little, dark, hollow spaces appear, (Pl. 14, fig. 11,) arranged in one, two, or three irregular rows or concentric circles. These are collectively called the vena terminalis; but it is impossible at this stage to separate them from the arterial vessels which commingle with them here, so that it is quite proper to say that the omphalomeseraic arteries, and the veins also, originate first at the circumference of the vascular area.

Almost synchronically with these circular vessels the true omphalo-meseraic arteries appear as dark streaks, more or less continuous, converging from the vena terminalis toward the body. Presently both the interrupted channels of the vena terminalis and the external omphalo-meseraic system anastomoze completely with each other, (Pl. 18, fig. 5, 7,) and form continuous channels for the circulation of the blood. The channels are very irregular at diverse points, (PI. 18, fig. 6, both as regards breadth and depth, some appearing very shallow, as if just forming. In the latter case, there is no mistaking that they are hollows in the upper surface of the subsidiary layer. It is difficult to say at what stage walls are formed around these channels; but certainly not till some time after they originate (Pl. 14, fig. 5; Pl. 17, fig. 5). Finally, however, they are endowed with a very thin wall (Pl. 18, fig. 2). At the first glance it would appear as if the walls of the vessels must be constantly resorbed, and new ones formed as 
the vascular area enlarges; but we do not believe that this occurs extensively, nor that the vascular area expands beyond a certain limit. By the time these walls are formed, the yolk begins sensibly to diminish in bulk, and the vascular area gradually folds around this shrinking mass; thus essentially covering a greater proportion of its circumference, but by no means a wider extent of actual surface. Toward the end of the period of incubation it even diminishes in area, till finally it disappears altogether, within a few months after the Turtle is hatched.

A peculiarity, which, until quite a late period, distinguishes the omphalo-meseraic arteries from the veins, is that they run, even to their outermost extremities, (Pl. 17, fig. 6, fig. 7,) in a very shallow stratum, the subsidiary layer, without plunging into the yolk mass beneath. Finally, however, they extend into the mass of the yolk, (Pl. 17, fig. 1,) and anastomoze with the branches of the omphalovenous system (Pl. 18, fig. 4). The irregularity of development of the vascular area is particularly noticeable among the other inequalities of the development of the organs. Pl. 13, fig. 11, Pl. 14, fig. 6, 9, 11 are all drawn, on the 10th and 11th of July, from eggs laid by the same Turtle, on the 18th of June; and yet, in Pl. 14, fig. 11 the vena terminalis is partially formed, in Pl. 13, fig. 11 it is a little more advanced, in PI. 14, fig. 9 it is complete, and the vascular area covered with bloodvessels; and in Pl. 14, fig. 6 the omphalo-meseraic arteries are still more numerous. Another, laid on the 13th of June, (fig. 8, ) is not so far advanced as one laid on the 18th of June, (fig. 6, ) whilst the latter is less advanced than one (fig. 7) laid on the $23 d$ of June. Compare also Pl. 13, fig. 4 and 5 with fig. $6,7,8,9$, all of which were laid on the 12th of June, and opened July 11th. Within the body, the changes in the omphalo-meseraic arteries are very simple. At first they are numerous, (PI. 18, fig. 7,) and spring from along the whole length of the dorsal artery; but after a while they become concentrated within a certain area, (Pl. 13, fig. 3, q,) midway between the head and tail, and finally merge into a single thick vessel, (Pl. 18a, fig. 14, $j^{4}$, ) which branches beyond the body as it passes into the vascular area. It soon begins to elongate, at the same time lessening in diameter, (Pl. 18a, fig. 8, $j^{5}$ to $j^{4}$, fig. $9, j^{4}$ ) and passes down between the anterior (fig. $8, n^{\prime}$, fig. $9, n^{\prime}$ ) and posterior (fig. 8, $n^{1}$, fig. 9, $n^{1}$ ) limbs of the curve of the intestine, where the latter protrudes beyond the body, in the shape of a $U$; it then forks, one branch passing on the right, and the other on the left, of the curve. Each branch of the fork divides again, almost as soon as it leaves the main vessel, and these branches give rise to others, and these to still others, and so on until they become very numerous. At last, the efferent artery gives off branches, within the body, which ramify extensively over the intestine (Pl. 17, fig. 1). 
The vena terminalis, as has already been shown, develops first in its peripheric portions, and finally joins the vena afferens, which at the time is a transverse and very short vessel (see Pl. 12, fig. $7, i$ ). The vena terminalis gradually embraces a larger area, up to a certain extent, (Pl. 13, fig. 2, fig. 12, ) and then begins to sink below the surface of the yolk, (Pl. 14, fig. 2, 2a, $r^{x}, r^{r}$ ) following the vena afferens, until, finally, it is lost in the maze of anastomozing vessels which empty into the vena afferens (PI. 9c, fig. 3). At the same time, however, the vascular area continues to expand superficially, until, at last, it embraces the whole yolk mass. At first, the vena afferens apparently lies within the body of the embryo (Pl. 12, fig. 7, i); but it is really as much without as within, being at the bend (corresponding to the point $a^{6}$ in fig. 1, Pl. 9d). where the vascular area joins the body. This transverse vessel (Pl. 12, fig. $i, i, i)$ corresponds to the fork of the vein, there being as yet no intermediate portion between it and the heart $(h)$. Soon, however, it assumes a furcate shape, (Pl. 12, fig. 10, $i$ ) and a little later it retreats from the heart, becoming still more decidedly forked, (Pl. 18a, fig. 13, $i, i$ ) and empties into a short but distinctly developed single vein, the vena afferens (fig. $\left.13, i^{\prime \prime}\right)^{1}$ The vena aflerens elongates rapidly, and its fork retreats still further, till it comes in a line with the vena terminalis (PI. 18, fig. 7). After a short time it begins to sink into the 'yolk, (Pl. 14, fig. 2, 2a, $r$,) and then branches very extensively, until in time it passes directly ( $\mathrm{Pl} .16$, fig. 2a, $r^{\prime}$, fig. 2b, $r^{\prime}$ ) through the vitelline mass, and the latter becomes filled by anastomozing vessels, (Pl. 9c, fig. 3; Pl. 17, fig. 3, fig. 7,) constituting, not as before, a superficial vascular area, but a globose, vascular plexus, an extension of the vascular area, throughout the whole breadth and depth of the yolk. ${ }^{2}$

The Abdominal Tein. (See p. 552, and PI. 18, fig. 7, etc.)

The Allantoidian Artery. (See p. 553, Pl. 13, fig. 2, and w-c. 1, $n^{6}$, etc.)

The Allantoidian Tein. (See p. 554, Pl. 13, fig. 2, and w-c. 1, $i^{2}$, etc.)

The Branchial Fissures. (See p. 548, and Pl. 12, fig. 8, $m, 9$, $m$, etc.)

The Intestine. The digestive system begins rather late to develop, but its foundation is laid by the subsidiary layer ( $\mathrm{Pl} .9 \mathrm{~d}$, fig. $1, n$ ) quite early, in the form of two blind sacs, one just behind the heart, $\left(h_{g}\right)$ and the other, at the opposite end of the body, immediately inclosed by the incurved tail. As the abdominal aperture grows narrower, these sacs consequently increase in length, without undergoing any other change for some time. Of the two, the posterior one first loses its simplicity by the development of a hernia, the allantois, (Pl. 13, fig.

1 The letter $i$, nearest to the letter $h^{8}$ in fig. 13 , P'l. 18a, should be $i^{\prime}$.
2 For further details upon this point, see p. 527, 528 , and 529. 
2 , w-c. $1, n^{6}$, p. 553,) from its lower side; the remainder constituting the true intestine, called the thick intestine, in this region of the body. Not much later, the anterior blind sac becomes changed, by the folding together of the two opposite halves of its superior arch, to form a pendent double curtain, or support of the intestine, the mesenterium, and, by the separation of a portion of its lower side, to form the windpipe (Pl. 24, fig. 1, $1^{\prime \prime \prime}, 2^{\prime \prime \prime}$ ) and the lungs $(1,2)$. The greater portion, $\left(I^{\prime}, I^{\prime \prime}, 2^{\prime}, 2^{\prime \prime}\right.$,) however, remains, and develops into a double-walled channel, the oesophagus $\left(\boldsymbol{I}^{\prime \prime}, \mathscr{2}^{\prime \prime}\right)$ and the stomach $\left(\boldsymbol{I}^{\prime}, \mathscr{2}^{\prime}\right)$. 'The inner wall $\left(\mathscr{2}^{\prime}, \mathscr{2}^{\prime \prime}\right.$, and fig. 1a, $\mathscr{Y}^{\prime} 2^{\prime \prime}$ ) constitutes the epithelial layer, otherwise called the mucous membrane, and is continuous with the inner wall (fig. 1, 2, 2'", fig. 1a, 2, 2'") of the lungs and windpipe. Exterior to the embryo, the continuation of the outer wall (fig. $1, l^{\prime}, l^{\prime \prime}$ ) of the intestino-subsidiary layer is very thin, and the inner wall (fig. 1, 2, $2^{\prime \prime}$ ) loses its compactness, and becomes continuous with a rather thick layer of large hyaline cells, (see Pl. 17, fig. 3, and p. 566, which underlie the vascular area. The double pendent curtain, or mesenterium, soon forms along the abdominal region, still retaining its thick, double walls ( $\mathrm{Pl}$. 9e, fig. 8, $n^{8}$, fig. Sa, $n^{8}$ ) after the intestine (fig. $8, n^{2}$; Pl. 18a, fig. 7a, $n^{1}$, fig. 8, $n^{1}, n^{\prime}$, $n^{4}$, fig. $9, n^{1}, n^{\prime}, n^{2}$ ) has become so long as to protrude through the abdominal opening.

The Glands of the Stomach. (See p. 571, and Pl. 21, fig. 14-16, etc.)

The Lungs. (See p. 555, and 556, and Pl. 24, fig. 1, 1a, etc.)

The Liver. (See p. 555 and 556, and Pl. 24, fig. 9, r, fig. 9n, r, etc.)

The Gall Bladder. (See p. 563, and PI. 18a, fig. 5, u, etc.)

The Wolffian Bodies. (See p. 552, and 560, and Pl. 18a, fig. 8, etc.)

The Kidneys. (See p. 566, and Pl. 25, fig. 4, b, and w-c. 2, b, etc.)

The Ocaries and Spermaries. (See p. 567, and $w-c, 2$, n, etc.)

The Uinary Bladder. (See p. 572, and Pl. 25, fig. 1, $n^{6}$, etc.)

The Allantois. (See p. 553, and Pl. 13, fig. 2, W.c. 1, $n^{6}$, etc.)

\section{SECTION IX.}

HISTOI,OGY.

In a former section ${ }^{1}$ we have demonstrated beyond question, that the embryonic disc, at the time of its formation, and the peripheric portion of the germinal layer, are composed of a uniform layer of consimilar cells (Pl. 9a, fig. 
8, fig. 34, a, p. 522). This is true, as far as their appearance is concerned; but inasmuch as some are destined and tend to form one kind of organ, and assume features peculiar to the cells of that organ, and others form other organs and assume other very diverse features, it is impossible to deny that these apparently identical cells are at this time, respectively, very unlike in their intimate nature. 'The cells of the ammios, for instance, which we are about to describe, are totally different in appearance, at a certain stage, (Pl. 9a, fig. 28,) from all the other cells of the body, and retain their peculiarities throughout the whole period of the existence of the organ to which they belong; and yet these cells were once apparently identical with all the other cells in the embryo. Thus, premising that all the cells of which the embryo is composed have at one time a perfectly similar appearance, as far as our senses can perceive, we will proceed to describe the different changes through which these cells pass in the origin and development of the several organs.

The Amios. At the time the amnios is nearly closed over, its cells (Pl. 9a, fig. 28) are arranged in a single layer. These cells are of moderate size, sharply polygonal, quite transparent, and nearly filled by a large, oval mesoblast; and the latter has perfectly homogeneous, clear contents, with a small, hollow, sharply defined entoblast in the centre. The mesoblast is not quite so transparent as the contents of the parent cell about it. These peculiarities are constant as long as the amnios exists, and by them the amnios may be recognized even at so late a period as when the 'Turtle is hatched; but then the cells are beginning to decompose, (Pl. 9a, fig. 31, b, fig. $31 \mathrm{a}, b$,) and are slightly swollen.

The Spmal Marrow. The cells of the spinal marrow were not made the subject of a particular study, except at one stage, a short time before the Turtle was hatched, (PI. 15, fig. 1, 2, 3,) and then only in one part of this organ, namely, just behind the medulla oblongata. These cells (Pl. 19, fig. 21) are very similar to those of the medulla oblongata, (fig. 20, ) but some are more hyaline. No caudate cells were observed here, as in the medulla oblongata (fig. 20, a, a). The smaller cells are not mesoblasted.

The Mcdulla Oblongata. Our investigations of the cellular structure of the medulla oblongata, and of parts of the whole brain, were not commenced earlier than in the case of the spinal marrow. At this stage, the cells (Pl. 19, fig. $20, a, b)$ are irregular in ontline, but more or less globular, and some have tail-like prolongations, forming the so-called caudate cells $(a, a)$. The contents are light and finely granular, and surround a mesoblast, of variable size, which sometimes almost fills the cells (b).

The Inemispheres. The cells in this portion of the brain are variable in size and closely packed togrether, (Pl. 19, fig. 16b, 16c, ) but not mutually compressed, 
so as to render them polygonal. At the surface (fig. 16b) of the hemispheres, they exhibit a pretty uniform contour. They have a perfectly globular shape, very transparent, faintly granular contents, and a single mesoblast, varying in size so as either to fill two thirds of a small cell, (fig. 16c, $a_{9}$ ) or a small proportion of the larger ones. At the first glance, the mesoblast appears to be granulated; but closer scrutiny shows that this is owing to the granular contents of the parent cell, which lie in its immediate neighborhood. By the action of water, the cell wall becomes very irregular, (fig. $16 c, b, b^{\prime}, c, c^{\prime}$,) and the thickness of the wall of the mesoblast more sharply defined, and collapsed. At the time the Turtle is hatched, the cells (Pl. 19, fig. 16, e, 16a) are slightly polygonal, and mutually compressed. Each one has faint, granular contents, a large, single, clear mesoblast, and a minute, sharply defined, dark, oily-looking entoblast.

The Olfactory Lobes. The cells of the olfactory lobe, of the earliest stage noticed, were taken from the same brain as those of the medulla oblongata, the hemispheres, and the Schneiderian membrane. They are not so large as those (Pl. 19, fig. 16b, 16c) of the hemispheres, nor are they transparent, and the granular contents are darker (PI. 19, fig. 18). The large, single mesoblast is perfectly homogeneous, but darker than the granular contents about it. A caudate cell $(\alpha)$ may be seen here and there, but very rarely. The action of water renders them irregular, like those of the hemispheres.

The olfactory Nerve. At the time the young Turtle is hatched, the cells at the posterior end of the olfactory nerve, close to the olfactory bulb, are rather large, slightly elongated, and sharply polygonal (Pl. 19, fig. 17, 17a, 17b). They are very transparent, and have homogeneous contents, and each has a single, large, faint mesoblast. The walls have considerable thickness (fig. 17b). The elongation of the cells is in the direction of the axis of the nerve; this seems to indicate a tendency among them to arrange themselves in a linear series previous to the formation of nerve tubules. This tendency is carried out at the anterior end of the nerve, where there is no mistaking the relation which the nerve cells (PI. 19, fig. 15) bear to the future nerve tubules. Here the cells are arranged in parallel lines, and have a more or less cylindrical shape, according as they are more or less united end to end, with the longer diameter running in the same direction as the axis of the nerve. Between the united ends of some of them, (fig. 15, $a, b$,) the walls are nearly obliterated, so that conjointly they form perfect tubules, the mesoblasts in some cells remaining distinct, to mark the position of the metamorphosed cells; whilst among others the walls stretch half-way across; and again others, though very seldom, have entire walls. They are quite transparent, although filled by scattered granular contents. The mesoblasts are identical with those at the other end of the nerve, but much fainter. 
The Schneiderim Membrane. A short time before the 'Turtle is hatched, the cells of the Schneiderian membrane are very irregular, (Pl. 19, fig. 19, a, ) and small, when compared with those of the olfactory lobe (fig. 18). They are very fintly and minutely granulated, and contain a comparatively large, irregular, clear, homogeneous mesoblast. In water they readily swell up to a much larger size, (fig. 19, and b,) and become more globular; but the mesoblast still retains its homogeneity and clearness.

The Pia Nuter. At the earliest stage mentioned above, (p. 603,) the surface of the olfactory lobe was covered by a thin layer of elongated, fusiform, faintly granulated cells, in which no mesoblast was visible (Pl. 19, fig. 18a). Although these cells differ very much from those of the pia mater, over the hemispheres, at the time the young is hatched, (see Pl. 19, fig. 16, $a, b, c$,) yet, as they lie close upon the olfactory lobe, they cannot belong to any other membrane than the one in question. At the time the animal is born, the pia mater is quite thick, at least where it covers the hemispheres, and is composed of three layers of cells. The outer layer (Pl. 19, fig. 16, a) is quite uniform, and consists of large, pyriform, and excessively hyaline cells, each containing a large, very faint, homogeneous mesoblast. The two lower layers $(b, c)$ consist of much smaller cells than the last. 'These cells are broad and irregularly prismatic, with faint, granular contents, but withal transparent. There was no mesoblast to be seen. At the point where this section was made, a bloodvessel $(d)$ with an excessively thin wall, belonging to this membrane, passed along its lower surface close against the hemispheres. The blood corpuscles are slightly altered by the action of water.

The Chorda Dorsalis. At the stage when the dorsal vertebre have developed along nearly the whole length of the body, (Pl. 12, fig. 5, 8, 9, 9a, 11, and p. 548 ,) the chorda dorsalis consists of elongated, fusiform, and very transparent cells, (Pl. 19, fig. 5c,) so arranged that their longer diameters trend transversely to the axis of the chorda. Their wall is very thin, but yet sharply defined. Soon, however, the walls increase in thickness, (Pl. 19, fig. 22, ) and the cells broaden and become irregular in outline. At the time the brain begins to divide into lobes, (Pl. 18a, fig. 14, p. 552, 553,) and just before the heart has become three chambered, the cells of the whole length of the chorda ( $\mathrm{Pl} .19$, fig. 5d) are very large, and more or less irregularly polygonal. Those at the surface (fig. 5, 5a, 5b, a) are very irregular, and in many instances as broad as long; they have a moderately thick wall, and mutually follow each other's outlines. In this way, lying close together, they form a continuous, smooth membrane, which incloses the looser interior cells. Where the wall of a single cell is in profile, (fig. 5, a, fig. $5 a, a$,$) it is clear that there is no membrane exterior to the one formed by their$ 
own combination; and, again, it would seem that at the free surfice of the cells $(a)$ the wall is very thim, like that of the interior ones (fig. $5 \mathrm{~b}, b$ ). The interior cells are nearly globular in shape, and do not appear to press against each other. The walls are excessively thin, and their contents, as well as the contents of the superficial cells, are perfectly homogeneous, and hyaline. At no time, as far as we have investigated the cells of the chorda, could the least trace of a mesoblast be detected in them. No reagents were used in this investigation.

The Vertebre. At the time the vertebre have appeared along nearly the whole length of the embryo, and the branchial fissures have begun to develop, (see PI. 12, fig. 5, 8, 9, 9a, 11, and p. 548, each vertebra is composed of a single layer of cylindrical, wedge-shaped cells, (Pl. 19, fig. 3,) having their broader ends outward, and the narrower ends pointing towards the square, hollow, clear space in the interior. (See also p. 591, and Pl. 19, fig. 3.) Their contents are perfectly homogeneous and hyaline, without any trace of a mesoblast. At the time the Turtle is born, the peripheric portion (w-c. 12, $a^{2}$, p. 591) of the vertebre is ossified to a certain depth. The outer, very elastic layer (Pl. 22, fig. 3 , a) can hardly be distinguished from the unossified, fibrous lining of the shield; in fact, not at all, except by its hardness. These hardened, calcified fibres lie close to each other, but leave here and there numerous elongate-oval, clear spaces, which trend, with the fibres, in the same direction as the axis of the vertebra. They consist of rows of minute granular bodies, containing, or in fact made up, of lime (fig. 3a). Transverse to the fibres of the outer layer, those of another layer (fig. 3, b) may be found lying closely pressed upon them, and similar in the arrangement of the fibres and of the clear spaces. A third fibrous layer (c) has clear spaces, the longer diameter of which trends in the same direction as in the third layer. The clear spaces of the second and third layer are more or less broud and irregular, resembling the very large and jagged, broad, oval, or round openings in the spongiform, innermost mass $(d)$ of the bone. The fibres of the third layer (c) cannot be made out at all, and those of the second layer are very faint, whilst those of the first $(a)$ are easily recognized. The meshes or interspaces of the spongiform, calcareous, innermost layer are very clear, and appear perfectly amorphous when seen in this position. From the manner in which the fibres of the torn edge of the first $(a)$ and second $(b)$ layers bristle out, each one supporting itself, it is made clear that the granules composing the fibres (fig. 3a) are the recipients of a calcareous deposit. This deposit gradually fills up the minute interspaces between the fibres, and thus forms a uniform, apparently homogeneous layer, $(e$,$) with clear spots, scattered here and there, throughout the stra-$ tum. The appearance of the third layer $(c)$ is so similar to the two outer ones, and to the second one. in particular, - which only differs in showing very faint, 
granular lines, as if they were becoming obliterated, - that it can hardly be doubted that all three are similarly constituted, and that in the innermost one the fibres are totally obscured by the uniform deposit of lime. The same would naturally be said of the fourth, $(d$,$) were it not that in a transverse section (fig. 4) of$ this layer an irregular, coarse, granular deposit $(d)$ may very easily be seen. From this we should infer that the third layer (fig. 3, c) is, very probably, the basis of a transition state between the fibrous and amorphous. modes of calcareous deposit. In respect to the mode of deposit of lime among the true cartilage cells, (fig. 4,) we would say, that, interior to the calcareous deposit $(d)$ already present, the cells $(\alpha, b)$ have partial, granular linings, which extend over greater or less portions of the cells, and are seen either in profile $(a)$ or with the outer or inner surface next to the eye $(b)$. The fact that the granules are arranged along the wall of the cell would seem to indicate that there is a preparation going on for forming the meshes of calcareous matter. This is confirmed, in some instances, where the granular lining is in direct commumication with the lime granules already deposited, at the edge of ossification $(c)$. Since, however, nitric acid does not dissolve this lining, and moreover since a similar lining is disclosed when the lime is dissolved away from the cells in the already ossified portion, $(d$,$) it is evident that it serves merely as a framework or basis, in which the$ lime is deposited. The large, single, homogeneous mesoblast may be seen not only in the unossified cells, $(a, b, c$,$) but also (c)$ in those which are ossified $(d)$. To show that the hardening of the vertebra is due to lime, the nitric acid which was used to dissolve the coarse granules in this section was allowed to evaporate slowly, and the result (fig. $4 a, a, b$ ) proved to be the characteristic crystals of nitrate of lime.

The Rills. The intimate structure of the ribs was not investigated until at the time the Turtle was hatched. By making a very oblique section ( $\mathrm{Pl}$. 22, fig. 1) of one side of a rib, from the surface to its centre, portions of the surface of all the layers of which it is composed were displayed very clearly. A transverse section (fig. 2) displays the thickness of the cells at right angles to the axis of the rib. The central cartilage cells (fig. 1, a, fig. 2, a) have a quite thick and dark wall, and contain each a sharply defined but faint, large, clear, homogreneous mesoblast, and a heap of coarse and fine granules. A little distance from these, the cell is flatter, (fig. 2, $a^{1}$, ) and the wall, $\left(a^{1},\right)$ as well as the mesoblast, is fainter, and the heaps of granules more spread throughout the cell. Still further outward the cell is yet more flattened, (fig. 2, $a^{2}$,) and the wall is very faint (fig. 1, $a^{2}$ ). Finally, at the surface (fig. 1, $a^{3}$, fig. 2, $a^{3}$ ) of the cartilaginous mass, the cell wall is invisible, but the granules still retain a faint, cumulated arrangement. This layer is quite distinct from the mass of cells 
beneath it. Some of the cartilage cells do not fill the cavity in the matrix; and in such cases (fig. 1a, fig. 1b) the thick cell wall (b) may be seen passing across the cavity, sometimes at one end and sometimes at both. Close upon this, there rests a dense, fibrous lnyer, (fig. $1, b, c, d, e, f$, fig. $2, b, c, d, e, f$, ) containing cells in various stages of development. The innermost of these cells (fig. 1, c) are irregularly round and very flat, (fig. 2,c, ) so as to appear almost like dark lines in a transverse section, and each contains a rather faint, granular mesoblast; otherwise the contents are homogeneous. The irregular, wavy processes from these cells connect here and there with those of neighboring cells, and appear to be spaces in the fibrous substance; but whether they are direct prolongations from the cell could not be made out with certainty, although it appeared very probable that such is the case. A little further toward the surface of the bone, these cells are found to be elongate-oval $(d)$ or oval, and not quite so flat (fig. $2, d$ ) as those last mentioned, and the wavy processes are shorter, but the mesoblast is the same. Still further outward, the cells (fig. 1,e) are very much elongated, irregular in outline, and are as thick (fig. 2, e) as they are broad. Their mesoblasts have altogether disappeared, and the wavy prolongations are very faint. At the surface of the middle line of the rib, the cells (fig. $1, f$ ) are very long and slender. At the edge of the rib (fig. 1, g) the surface cells are like those at the middle line, but they are much more slender. They cannot be distinguished very readily from those in the soft, fibrous corium, except that the latter are in a yielding matrix, whilst the former are surrounded by a hardened substance. The fibres $\left(g^{1}\right)$ of this outermost layer, as well as those $\left(h^{1}\right)$ of the corium, are composed of rows of minute granules. The fibres of the more interior layers are very faint. As these investigations were made upon perfectly fresh bones, and no reagents were used, it is clear that the mesoblasts of the cells in the fibrous layers are perfectly normal, and fully show that bone lacuns, with their characteristic canaliculi, are nothing less than these mesoblasted cells, with their wavy processes anastomozing with each other.

The Limbs. Soon after the shield begins to form, and the feet begin to show external signs of the toes, (Pl. 25, fig. 11, and p. 565, the bones of the feet, or rather their cartilaginous matrices, are quite conspicuons. The terminal or claw bones have not yet appeared. The matrix of each bone is composed of very irregular cartilage cells (Pl. 21, fig. 22, 24). Those in the centre are set at a considerable distance from each other, but as they approach the surface of the matrix they approximate, and at the same time gradually assume the smaller size and form of those in the surrounding tissue (fig. 25). Each cell contains fine granular contents and a large, round, clear mesoblast, which contains one or two entoblasts (fig. 22a). A short time before the Turtle is latched, the 
terminal bones (Pl. 21, fig. 21) of the feet lave not yet assumed the cartilaginous state, but are composed of sharply polygonal cells (fig. 21a) in contact with each other. Each cell contains a lurge mesoblast occupying half its diameter, and numerous entoblasts. Just before hatching, the centre of the bones of the limbs contains pure cartilage cells (Pl. 22, fig. 5, 6, 6a, 6b). The intercellular substance, or blastema, $(a$,$) so called, occupies a laigre amount of space, when contrasted with$ the size of the cells (b). These cells are very irregular in shape, varying from spherical, semiglobular, trianguloid to elongate-oval, and each one contains a large, faint mesoblast. The principal point of interest is the granular basis for lime deposits in the form of a central heap, with branches stretching out in various directions. Some of the cells (fig. 6) also contain faint granules throughout their whole length and breadth. The application of alcohol brings out more clearly the faint granules, (fig. 6a,) and also those arranged in a branching manner. In some instances, the cells thus treated shrank away from the surface of the cavity of the blastema (fig. $6 \mathrm{a}, c, 6 \mathrm{~b}$ ).

The Skin. At the time the branchial fissures begin to form, and the eye to develop, (Pl. 12, fig. כ, 8, 9, 9a, 11,) the surface of the tail consists of hyaline, oval cells, (Pl. 19, fig. 2, ) each one of which contains a small, sharply defined, single mesoblast. A little later, the cells on the head, near the eye, are large, cylindrical, thin walled, and hyaline, and appear to have no contents whatever that may be seen, not even a mesoblast. They form but a single stratum, and have scattered between them minute hyaline granules. Considerably later than this, (Pl. 14, fig. 2, 2a, ) the cells of the dermal layer (PI. 19, fig. 4, f) are globular, hyaline, and contain each a single, dark mesoblast (see fig. $7, b$ ). ${ }^{1}$ When water is applied to these cells, the mesoblast becomes resolved into two bodies, one very transparent, and the other dark and granular (fig. 4, a). When the toes begin to develop, (Pl. 25, fig. 11,) the cells of the surface of the feet are globular, faintly granulated, and contain a large, single, clear mesoblast, and a single entoblast (Pl. 21, fig. 23). The internal tissue of the feet is composed of cells similar to those of the shield (fig. 26). At this time, the cells of the skin of the carapace are elongated, irregular, finely granulated, and each contains a large mesoblast and a central, single entoblast (Pl. 21, fig. 26). That portion of the skin which is metamorphosed into claws (Pl. 21, fig. 20, a) is composed of very large, transparent, irregularly polygonal cells, each one of which contains a minute, irregular mesoblast, situated at its surface, and a dot-like entoblast (fig. $20 \mathrm{a}, 20 \mathrm{~b}, 20 \mathrm{c}$ ). The cells (fig. 20,b) beneath this horny sheath and at the base of the toe $\left(b^{\prime}\right)$ are large, (fig. 20d,) but yet much smaller than those of

1 Although this is a bloot corpuscle, it is apparently ilentical with the cells of the dermal layer. 
the claw (fig. 20, a). They are sharply polygonal, and contain minute scattered granules, a single, large, round mesoblast, and a minute entoblast (fig. 20d). In the last phase, just before the Turtle is hatched, the cells of the epidermis of the shell are (Pl. 20, fig. 18, on the right) sharply polygonal; they have very thick walls, and appear to be perfectly homogeneous. Underneath these are very large, hyaline, excessively thin-walled, polygonal cells (fig. 18, on the left). Each cell contains a central heap of very dark granules, which extend in a scattered manner to the walls of the cell.

The Eye. Soon after the eye has begun to develop, (Pl. 12, fig. 6; p. 550,) the cells of the retina (Pl. 21, fig. 28, a) are columnar, narrow, elongated, and arranged with their longer axes trending perpendicularly to the parietes of the cavity which they surround. Each cell occupies the whole thickness of the retinal layer. At a much later period, when the shield has become quite conspicnous, (Pl. 14, fig. 1,) and the toes begin to protrude from the paddle-shaped feet, the cells (Pl. 21, fig. 30) of the crystalline lens are excessively hyaline, and have homogeneous contents without a trace of a mesoblast. They are arranged in lines, which run from the anterior to the posterior side of the lens, and converge around a centre $(a)$ where the cells are smallest, so that a fibre of the lens may be said to be an exceedingly long, fusiform body, composed of cells arranged in a single line. A short time before the Turtle is hatched, (P1. 15, fig. 1, 2, 3, ) the membrana pupillaris is composed of very large, polygonal cells (Pl. 21, fig. 29, a). The crystalline lens (fig. 32) is composed of long, ribbon-shaped, flat fibres, (fig. 32b, 32c, containing scattered, faint granules. Each fibre runs from the anterior to the posterior side of the lens, those at the centre in a straight line, and those exterior to them more and more in a curve, according as they are nearer the surface. Every one is composed of excessively transparent, thick-walled, quadrilateral cells, (fig. 32a,) to display which requires the agency of water, since in a fresh state they cannot possibly be detected, except that portion of the wall which forms the edge of the fibre (fig. 32b, 32c). A few exceedingly transparent, large, globular bodies are scattered among the fibres; but even these must be brought out by the agency of water. By the continued action of water, the cells swell up enormously (fig. 31, 32d). This can only be accounted for by the thickness of the walls of the cells, in a natural state, which allows such great extension without tearing. At the time the Turtle is hatched, the retina is nearly as complicated as in the adult. A section of the thickness of the retina was made at a point half-way between the crystalline lens and the back of the eye.

Immediately behind the hyaloid membrane, (PI. 22, fig. 8, $k_{9}$ ) the surfice of the retina is covered by a thin layer (fig. $S, i$ ) of excessively elongated fibres, which 
seem to run from the entrance of the optic nerve (fig. 8, $h^{1}$ ) to the anterior edge $\left(i^{1}\right)$ of the retina. In the section, (PI. 21, fig. 33,) these fibres were found to be slender, tail-like prolongations of the cells $(b)$ next to the inner surface of the retina. The whole thickness of the retina is made up of five apparently distinct layers of cells; but this is true only in a certain respect, as the following separate description of each of them will show. The innermost layer $(b, c)$ is about one quarter as thick as the whole retina, and is composed of large, hyaline cells, each containing a large mesoblast. The general contour of these cells is globular, but either the outer or the inner end, and sometimes both, are prolongred into tail-like processes, which, in the case of those on the inner surface of the retina, form the fibrous layer above mentioned, or project $(c)$ so far into the next outer layer $(d)$ as, at times, almost to reach the layer beyond $(e, f)$. The next outer layer $(d)$ is only two thirds as thick as the first. It is composed of excessively thin-walled cells, which are hardly larger than the mesoblasts of the cells in the inner layer. Exterior to this, the third layer $(e, f)$ is a little thicker than the innermost one, $(b$,$) and appears to be identical in structure with it,$ except that the cells are a little more elongated, and spindle-shaped. Its cells send projections $(e)$ both into the second layer $(d)$ and $(f)$ into the next outer or fourth one $(g)$. The fourth layer $(g)$ is about as thick as the second, $(d$, and, except that the cells are much smaller, they are just like those of the first $(b)$ and third $(e, f)$ layer. Here and there the tail-like prolongations of these cells project, $\left(i_{,}^{\prime}\right)$ even to the outer surface of the membrana Jacobi $(h, i)$. The outermost layer, the membrana Jacobi, $(h, i$,$) is composed of two kinds of cells:$ the first kind are those $(i)$ which resemble the cells in the next inner layer, $(g$, except that no mesoblast is visible, and they send tail-like prolongations (i) into the layer next within, and also outwardly to the surface of the layer to which they belong; the other kind of cells do not project into the layer beneath. They are long and club-shaped ( $h$, fig. $33 \mathrm{a}, a, b, c$ ); some of them terminate suddenly in a thick end, (fig. $33 \mathrm{a}, b, c$, ) where a large yellow or orange mesoblast is situated; others have a long, slender projection at both ends, $(a$,$) and the yellow$ mesoblast is situated at the thickest part of the cell. These last are by far the most numerons cells in the layer. The colored mesoblasts are so situated that they are all on the same level; and they vary in intensity of color, from almost white to the deepest orange red. In no instance has it been possible to find the acells of the retina forming a continuous fibre, extending from the inner to the outer surface, as has been observed by Kölliker and H. Mïller in Mammalia. (Compare Wagner's Icon. Phys. 3d Lief. 1854.) In the adult Turtle, the cells of the retina are very similar to those just described, except that their prolongations are more slender. 
The Ear. Soon after the ear has begun to develop, (Pl. 12, fig. 6, the cells (Pl. 21, fig. 27) of the cup-shaped tympanic cavity are identical, in every respect, with those of the eye (fig. 28).

The Intestine. A short time before the Turtle is hatched, the mucous layer of the oesophayns is composed of two layers of cells. 'The superficial ones ( $\mathrm{Pl}$. 21, fig. 1, fig. 5, a, fig. 6) are simply irregularly oval, or round, and have faint, granular contents. Their free surfaces are furnished with numerous vibratile cilia. By the application of water, the single mesoblast, and the single, double, or triple entoblast are brought out, (fig. 7, and 8,) and the mesoblast of the columnar cells may be recognized through the superior layer (fig. 8). The inferior layer (fig. 5, b) consists of long, cylindrical cells, (fig. 2, fig. 5, b, with seattered granular contents, and a single, homogeneous, hyaline mesoblast, situated near the broader end. Whilst in place, these cells are prismatic from mutual pressure, but being set free, they assume an irregular, club-shaped or spindle form (fig. 2). The superficial epithelial cells (fig. 14e) of the stomach, when seen endwise, appear sharply polygonal, of moderate size, and filled by densely packed granules, which almost obscure the large, single, oval mesoblast (fig. 14d). When seen in profile, they are deeper than broad (fig. 14c). By the action of water, these cells swell, and the granules are scattered (fig. $14 \mathrm{f}, 14 \mathrm{~g}$ ) so as to expose the dark, granulated mesoblast. By rolling these cells along the field of the microscope when they are very much swollen by water, it may very readily be seen that the mesoblast is attached to the wall of the cell (fig. $14 \mathrm{~g}, a$ ). By careful manipulation it was ascertained that the vibratile cilia on these cells are not scattered promiscuously all over the free surface, but form a crown to each one (fig. 3, and 4) along the line, where each cell touches its neighbor. The elongated cells of the thick intestine are arranged end to end, in three layers (fig. 34). They contain numerous, minute gramules, and, when seen endwise, appear sharply polygonal (fig. 34a). If slightly acted upon by water, the large mesoblast is brought out quite clearly.

The glands of the stomach appear as more or less elongated openings on the inner surface of the mucous membrane (fig. 14, a, 14a, 14b, 15, 15a). Around each opening a dark ring may be seen; every ring touching its neighbor: this is the outline of the gland seen through the thickness of the epithelium. By plunging the microscope deeper, toward the outer surface of the stomach, the elongated, oval cells (fig. 15, 15a, b, 16a) of the glands may be seen radiating from around the central cavity. Each glind is about four times as deep as broad, and consists of but one layer of cells (fig. 16b). These cells, in a view of the exterior surface of the gland, are irregularly polygonal; they contain a few scattered granules, and each a large, round, dark mesoblast in the 
centre. In a profile riew they appear elongated, with the longer diameter trending in the direction of the thickness of the wall. At the time the animal is latched, the epithelium, (fig. 10, at the base of the tongue, is a layer of rather irregular, polygonal cells, containing a moderate sized mesoblast, and a minute, granule-like entoblast. These cells vary considerably in size, and so does the mesoblast. In a transverse section of a fold of the oesophagus, (fig. 11, we have, first, on the surface, a layer of epithelial cells $(a)$ that are broader than deep, and each one of which is crowned with a row of vibratile cilia (fig. 12) arranged along the line of contact with the neighboring cells, so that their free surface is naked. Next beneath these is a thick layer of long, irregular, columnar cells, (fig. 11, b, the longer diameter of each occupying the whole thickness of the layer; and, outside of these, irregularly rounded, homogeneous, transparent cells, $(c$, which fill up the space in the angle of a fold, and also form a thin layer between the columnar cells $(b)$ and the muscular coat $(d)$. The cells of the muscular coat (fig. 13) of the oesophagus are excessively long, slender, and spindleshaped, and lie so closely pressed together that their long, slender ends cannot be well seen, unless they are separated (fig. 13a). With a magnifying power of eleven hundred diameters, the cell wall appears only as a rather thick, dark line. The mesoblast occupies nearly or altogether the whole breadth of the cell; it has a quite thick wall, $(a$,$) and contains a sharply defined, single ento-$ blast (b).

The mucous membrane of the stomach is made up of at least four layers of cells, (fig. $17, a$, piled one above the other, so as to resemble columnar cells. Those next the imner surface of the stomach are the largest; and, proceeding thence outwardly, they grow smaller. The mucous membrane of the thick intestine is composed of no less than six layers of cells (Pl. 21, fig. 18, $a-a^{\prime}$ ). In those cells which are next to the surface, $\left(a^{\prime},\right)$ the mesoblast is very easily seen; but in the other more exterior cells it is very faint. By separating a few columns of cells, (fig. 18a, 18b, not only may their relations be better shown, but the clear, round mesoblast, and its sharply defined entoblast also become visible. These cells are placed so regularly one above the other, that they resemble a long columnar cell. When seen in a mass, through considerable depth, they appear oval, with the longer diameter of each trending in the same direction as the columns (fig. 18); but, taken singly at a fixed focus, their more or less polygonal shape (fig. 18a) may be recomnized. Those at the surface (fig. $\left.18, a^{\prime}\right)$ are the largest, and those at the outermost side, $(a$,$) nearest the muscu-$ lar layers, $(c, d$,$) are a great deal smaller; and between these two extremes there$ is a regular gradation. Here and there a few cells were found in a state of selfdivision (fig. 18c, a, b); some (a) had two distinct mesoblasts and a strong median 
constriction, made more conspicuous by the total absence of granules at that point, and others (b) had but a single, clear, distinct mesoblast, probably the old one, near one end, and at the other, on the opposite side of the constriction, a very faint one, without doubt just forming. By this we may very readily account for the fact that there are but two layers of cells (fig. 11, $a, b$ ) in the aesophagus; while there are four layers (fig. 17, a) in the stomach, either four or five (fig. 19, $a, a$ ) in the long intestine, and six here (fig. 18, $a, a^{\prime}$ ). Directly beneath the mucous membrane is a layer of rounded, loosely packed cells, $(b$, identical, to all appenrance, with those seen in the same relation in the oesophagus (fig. 11, c). Next, and farther outward, is the layer of constrictor muscles, $(c$,$) composed of elongated, fusiform cells, similar to those of the same layer$ in the asophagus, (fig. 11, $d$, ) which trend in a direction transverse to the axis of the intestine. Just exterior to this is another layer of muscle, $\left(d_{9}\right)$ which is composed of similar cells, but they trend at right angles to the last, and therefore along the intestine. In a transverse section of the intestine, these cells are cut across, so that their shorter diameters are exposed. A thin, apparently amorphous membrane $(c)$ incloses the whole intestine. The mucous membrane (fig. 19, a) of the long intestine, at a point about one third of its length behind the stomach, hardly differs from that of the thick intestine, (fig. 18, $a, a^{\prime}$ ) except that the layers of cells are only four or five in number, and the cells a little smaller. The rounded, loosely packed cells (b) just outside of the mucous membrane $(a)$ are also a little smaller than in the thick intestine; but the muscular layers $(c$, and d) and the enveloping membrane (e) do not appear to differ. The grlands of the stomach are very much elongated, and more or less convoluted (fig. 17, $b$, $c, d)$. Their walls are composed of cells, which are identical in every respect with those of the mucous membrane, $(a$,$) of which they are a direct continuation.$ When the gland is perfectly straight, the cells $(c)$ on its inner surface are as large as those $(a)$ on the surface of the stomach; but where the gland bends, those in a similar position at the inner angle of the bend $(d)$ are compressed, whilst those at the outer convex surface of the curve are the largest. The cavity $(b)$ of the glands is very narrow, from its opening to its bottom.

The Allantois. A short time before the young are hatched, the allantois is composed of two layers. At a point near the body of the embryo, the inner one (Pl. 9a, fig. 30) of the two is made up of rather large, thick-walled, irregularly polygonal cells, filled by minutely granular but transparent contents. The outer layer (fig. 30a) is distinguishable only on account of its numerous dark granules, which are arranged in heaps; the cells which, in all probability, surrounded them, could not be discovered. At a point more distant from the embryo, the cells of the inner layer (Pl. 1Sa, fig. 3) are larger and more elongated, and 
lozenge-shaped, and have thicker walls. The outer, granular layer is very distinct, and contains the bloodvessels.

The Urinary Bladder. At the time of hatching, the mucous membrane of the bladder is composed of five layers of cells, (PI. 20, fig. 13, 13a,) very similar to those of the long intestine, (PI. 21, fig. 18, 18i, 18b, the only difference being that there is one layer less, and that the cells of the several layers are more strictly on a level with each other (Pl. 20, fig. 13a). When seen from the inside of the bladder, the superficial cells (fig. 15) appear more or less polygonal, but yet their walls are slightly rounded. The mesoblast of some of them is elongated, and contains two entoblasts, an arrangement which is often indicative of a tendency to a self-division of the cell. In an expanded state of the bladder, the cells lose in a measure their polygonal shape (fig. 13). The muscular coating (fig. 16) is a mesh-work of superposed fibres, which run in every possible horizontal direction. These fibres are composed of elongated, fusiform cells, (fig. 14, 14a,) of variable length, according to their position. The outermost fibre cells are lozengeshaped, about twice as long as broad, and excessively transparent. The large, round mesoblast is not so faint as the cell, and the entoblast, sometimes double, is sharply defined. The rest of the whole muscular system is composed of elongated, spindle-shaped cells, (fig. 14, with faint, granular contents and a large mesoblast occupying nearly the whole width of the cells, which have none of the long, thin, tail-like prolongations seen in the oesophagus (Pl. 21, fig. 13, 13a).

The Lungs. At the time the lungs have fairly separated from the intestine, (Pl. 24, fig. 2, $t, t^{\prime}$, and fig. 2a,) the inner wall, or mucous membrane, (Pl. 20, fig. 12, b, ) is composed of a single layer of broad, cylindrical cells, with rounded outer ends. A short time before birth, the mucous membrane is composed of a single layer of cells, ( $\mathrm{Pl} .20$, fig. $7,9, a, 11, a)$ of variable size, in different portions of the lung. They contain very scattered, granular contents, and vary in shape; some being broader than deep, (fig. 9, $a, 11, a$, ) and others (fig. 7) much deeper than broad. The contractile tissue (fig. 10, b, 11, b) is a delicate, fibrous mesh, forming, with the mucous membrane, (fig. 11, $a_{2}$ ) the walls of the cavities. The bloodvessels (fig. 10, c) do not follow the trend of the fibres of the mesh, but run at various angles across them, and in close proximity to the mucous membrane (fig. 7). The outer surface of the lung is covered by a thin layer of very pale, round cells, (îg. 9a, 11,) which do not touch each other, but are separated by numerous dark granules. Besides these, the surface is mottled, principally over the course of the bloodvessels, (fig. 5,) by numerous pigment cells, (fig. 8, 9a, 11, which are nothing more than the pale cells, around which much darker granules are densely packed, in such a manner as to assume the appearance of an irregular two, three, four, or five-rayed star. 
The Tiachea. A short time before birth, the cartilage rings of the trachea, (Pl. 24, fig. 6) are composed of quite thick-walled cells, which contain numerous minute, dark granules (Pl. 20, fig. 6). The cells are as yet in close contact with each other, and have sharp, polygonal contours. At birth, the cartilage cells (fig. 3, b) are widely separated from each other by the development of an amorphous, intercellular substance. At the middle $(b)$ of the ring, these cells are more or less rounded; but, as they approximate the fibrous bands $(a)$ which alternate with the rings, they gradually flatten, and diminish in size, till, at the edge $(c)$ of the layer, they are mere thick, dark lines. The fibrous bands $(a)$ consist of very fine threads, or strings, of granules, interwoven, and oftentimes crossing each other at very broad angles.

The Liver. A short time before the Turtle is hatched, and about the period when the allantois has surrounded the whole yolk sac, the cells (Pl. 19, fig. 32) of the liver are moderate in size and polygonal. They are filled by densely crowded, dark granules, in the midst of which is a clear, round mesoblast. When separated from each other and immersed in water, they assume a spherical form $\left(a, b, b^{\prime}, c, c^{\prime}\right)$. Just before birth, the liver cells are much larger than those mentioned here. They are more or less polygonal, and contain a crowded mass of coarse, dark, oily looking granules and a bright yellow mesoblast, with a minute, sharply defined entoblast (fig. 31, a). When isolated (b) from each other, and treated with a little water, they show that they have $(a)$ very thin walls and a rather opaque but bright yellow mesoblast.

The Gall Cyst. At the last stage mentioned, the wall of the gall cyst is a single layer (Pl. 19, fig. 29) of cylindrical, wedge-shaped cells, with the broader ends next to the outer surface $(\alpha)$ of the wall. They are very transparent, and contain scattered, faint granules and an excessively hyaline mesoblast near the broader end. Seen endwise, they appear polygonal (fig. 29a).

The Bloodvessels. Just after birth, a bloodvessel that had been isolated from the pia mater had an excessively thin wall, (Pl. 19, fig. 14, which appeared to be built up of excessively hyaline, polygonal cells, each one of them containing a large but rather faint mesoblast and perfectly homogeneous contents. In some places, the mesoblast appeared in profile $(a, b)$; yet outside of it no wall, but that of the cell, could be detected.

The Genital Organs. Just before the Turtle is born, the ovary (see p. 573 and Pl. 25, fig. $7, n$ ) is composed of moderately large, polygonal, and extremely transparent cells, (Pl. 19, fig. 30, each one of which contains a large, densely granulated mesoblast.

The Kidncys. By the time the embryo can freely move its eyes, jars, and toes, (see p. 565, and Pl. 18a, fig. 2 and 3,) the Malpighian bodies (Pl. 20, 
fig. 2) of the kidneys are pretty far advanced. The bloodvessels (b) do not form a convoluted glomerulus in the end of the urimiferous tube, $\left(a, a^{\prime}, a^{\prime \prime},\right)$ but in a swelling situated at a certain point in its track. The cells of the wall of the Malpighian body are short and broad, and form only a single layer $\left(a, a^{\prime \prime}\right)$. The bloodvessels in the glomerulus are very closely crowded, and tortuous. Only a single vessel, whether artery or vein could not be determined, was seen in connection with the glomerulus.

The Wolffan Bodies. A short time before birth, the uriniferous tubes of the Wolffian bodies are composed of very large, irregularly polyhedral cells, arranged in one layer (PI. 20, fig. 1, 1a, 1b) around a rather large, central channel (fig. 1, a). In a transverse section, these cells appear broadly wedge-shaped, with the narrower end next to the central channel (fig. 1, 1a). Where the tube bends upon itself, the cells all converge around one point, so that the inner ends of some may be seen in the centre, (fig. $1 a_{\text {, }}$ ) and the channel in the distance. At this stage, the uriniferous tubes are very long and slender, and may be very easily traced from the central canal, or duct, (Pl. 25, fig. 5, c,) to the point $(a)$ where they bend upon themselves, at the parietes of the Wolffian body, and return to the channel whence they started. The uriniferous tubes (b) of the kidneys are very short and thick, and are much less numerous than those of the Wolffian bodies. They also run outward, and back toward the duct, $(c$,$) but we are$ not sure that they empty into it.

The Blood. About the time the heart begins to lose its tubular character, and the eyes and ears have become decidedly marked and conspicuous, (PI. 12, fig. 6c, and p. 550,) the blood corpuscles are mere globular, minute, transparent cells (Pl. 19, fig. 6, 7, $a, b){ }^{1}$ This shape and size they retain for some time, at least until the allantois has nearly covered the embryo, (Pl. 14, fig. 2, 2a, ) and the lungs (Pl. 24, fig. 2, 2a) have become separated from the intestine, and begun to assume a sac-like shape. In a natural state, these corpuscles (PI. 19, fig. $7, a, b)$ are perfectly globular and transparent, and each contains a large, apparently granulated mesoblast attached to the wall $(a)$. By the application of water, the mesoblast bursts, $(c, d, c, f, g, k, i, j$,$) and the whole granular contents$ come out, but still retain their globular state, and appear to have a membrane about them $(j)$. From this it would seem that the apparently granular contents of the mesoblast constitute, in reality, an entoblast which fills the mesoblast. The blood corpuscles do not attain to the characteristic oval and flattened shape of the adult (fig. 8, a to $i$ ) until very late. At a certain stage, (see Pl. 15, fig. 1, 2, 3, and

1 Fig. $7, a, 8$ belong to a little later stage; but, tical with those of this stage, it would be superfluous as the blood corpuscles which they represent are idento repeat the figures. 
p. 570, there is a mixture of oval, flat, disc-formed corpuscles (Pl. 19, fig. 12, $a, b$ ) with those which are oval and partially flattened, (fig. 9, 10, $a, b, c, c^{\prime}$ ) whilst others, although oval, are not flattened in the least (fig. 11, $a, b, c, d, e$ ). These last (fig. 11) are evidently derived from the elongation of the globular corpuscles of earlier stages (fig. 7); for, except in shape and a little difference in size, the two kinds differ but very little. An end view (fig. 11, $c, d$ ) of the oval corpuscles is not distinguishable from that of globular forms, (fig. 7.) except that in the oval ones the mesoblast is not lateral, but central. In order to become disciform, as in the adult, the corpuscles gradually flatten, (fig. $9,10, a, b, c, c^{\prime}$ ) until the two opposite sides almost touch each other (fig. 12, $a, b$, fig. 13, 13a, 13b, 13c). At this period, they have a remarkably plastic nature, and, when in contact, mutually flatten against each other, (fig. 13, 13a,) or stretch out to a considerable extent, (fig. 13b,) if they catch against any thing whilst floating on the stage of the microscope. The mesoblast is very faint and perfectly homogeneous in the most advanced phase, a short time before the birth of the Turtle. Finally, in the adult, the blood corpuscles (fig. 8, a to $i)$ are quite flat $(c)$; but the centre is not depressed, as would appear from a side view $(a, b)$. The clear, homogeneous, light mesoblast contains a much darker entoblast. In water, the walls of the parent cell, the ectoblast, $(i$,$) col-$ lapse, and the mesoblast and entoblast blend into one darker mass. By drying, the thickness of the parent cell $(h)$ becomes sharply defined, and very conspicuous.

The Inuscles. A short time before the Turtle is hatched, the muscles differ in the degree of development to which they have arrived in various parts of the body. At the point where the dorsal muscles are attached to the arch of the vertebra, they consist of a mass of spindle-shaped cells, attached obliquely to each other, (Pl. 19, fig. 23, b, ) or of very long, slender cells $(a)$. The former $(b)$ resemble the cells of the dorsal arch, $(c$, ) and have a large, oval mesoblast, which contains numerous granules; the latter have lost their mesoblast, and have become so intimately united to each other as to obliterate the intervening walls, and thus assume the appearance of long, slender cells. Some of the mesoblasted cells are thus united to those without mesoblasts. The granular contents of these united cells have a more or less linear arrangement. Presently we shall see what this peculiarity tends to. In the foreleg, the muscular fibres have all the characteristic appearances of the adult. The longitudinal and the transverse strix of the fibres are readily seen (PI. 19, fig. 25, a). The fibrilla (fig. 25, b) which constitute the fibres $(a)$ are mere strings of very minute granules, such as we saw in another part (fig. 23, $a, b$ ) of the body, near the dorsal arch. Here, however, they are more regularly arranged in lines, but have not lost their gran- 
ular, rounded appearance. By maceration in water, the membranous sheath of the fibres (fig. 24, and a) becomes quite conspicuous, and distends so as to leave the mass of disturbed fibrilla floating free in the centre. Just before birth, the muscular fibres of the upper retractor muscle of the head are very transparent (fig. 27). When the fibrille are not disturbed, they are excessively transparent, and represented by the light spaces between the faint, parallel, longitudinal lines which may be seen in every part of the fibre; but where they are displaced, their component granules are separated or dislocated, and thrown into zigzag lines (fig. 27a). The granules are then easily recognizable. Treated with very weak alcohol, the undisturbed fibrilla gradually display their component granules in close and continued series. Where the granules had been disturbed and separated from each other, before the application of alcohol, spaces were left between them, as the application of this reagent proved.

The Tondons. A short time before birth, the tendons of the foreleg consist of very slender, spindle-shaped cells, packed closely together (fig. 26, 26a). They do not appear to have united, as yet, to form the slender fibrilla of the adult tendon.

\section{SECTION $\mathrm{X}$.}

\section{CHRONOLOGY OF THE DEVELOPMENT OF THE EMBRYO}

In the higher Vertebrata, the progress of the embryo is generally so regular, that the investigator, knowing the period of gestation or of incubation, is at the same time certain to find the different parts of the germ proportionally developed. This is not the case with the Testudinata, at least not so strictly; since the embryonic growth may be retarded for weeks, and the period of hatching postponed for months. In order, therefore, that the reader may see at a glance what figures belong to any particular phase, we give below a list of our figures, arranged according to their actual degree of development, in stages, and have affixed the dates of the time when the eggrs were laid, and when they were opened and drawn. By this, it may be seen that age tells very little respecting the real degree of development of the embryo; but that the actual inspection of the structure of the organs is necessary, in order to ascertain whether any two or several embryos are equally developed. The duration of the growth of the ovarian eggs has already been discussed. (See p. 490 and 496.) For the names of the different species, see the Explanation of the Plates.

First Stage. Pl. 10, fig. 12, taken from the oviduct and drawn at once, June 
4, 1852; fig. 13, and 14, taken from the oviduct and drawn at once, June 3, 1852; fig. 15, and 15a, taken from the oviduct and drawn at once, May 29, 1854. Pl. 9a, fig. 34, date of laying not known, opened June 12, 1854. Pl. 9e, fig. 1; (see Pl. 10). - p. 535 .

Second Stage. PI. 11, fig. 1, and 1a, laid June 21, opened June 26, 1855; fig. 6, and 6a, laid and opened July 3, 1855. Pl. 9e, fig. 2; (see Pl. 11, fig. 6).p. 536 .

Third Stage. PI. 11, fig. 2, no date, ${ }^{1}$ opened June 15, 1854; fig. 7, 7a, and 7b, laid July 2, opened July 3, 1855; fig. 8, and 8a, laid July 10, opened July 12, 1855; fig. 9, 9a, and 9b, laid and opened July 4, 1855; fig. 10, 10a, 10b, and 10c, laid July 2, opened July 3, 1855. - p. 537.

Fourth Stage. Pl. 11, fig. 3, and 3a, no date, opened June 12, 1854. P1. 9e, fig. 3, and 3a; (see Pl. 11). - p. 538, and 543 .

Fifth Stage. Pl. 11, fig. 4, $4 \mathrm{a}$, and $4 \mathrm{~b}$, no date, opened June 12, 1854. p. 538, and 543 .

Sixth Stage. Pl. 11, fig. 5, 5a, 5b, and 5c, laid June 23; fig. 5, opened June 26 ; fig. 5a, opened June 27, 1855. Pl. 9e, fig. 4, 4a, and 4b; (see Pl. 11). p. 539 , and 543 .

Seventh Stage. Pl. 12, fig. 1, and 1a, laid June 12, opened June 28, 1855. PI. 9d, fig. 1; (see Pl. 12). Pl. 9e, fig. 5; (see PI. 12). Pl. 24, fig. 13, 13a; (see Pl. 12). - p. 544.

Eighth Stage. Pl. 12, fig. 2, laid June 12, opened June 26, 1855. PI. 9e, fig. 6; (see Pl. 12). - p. 546.

Ninth Stage. Pl. 12, fig. 3, 3a, 3b, and 4, no date, opened June 24, 1852.p. 547.

Tenth Stage. Pl. 12, fig. 7, no date, opened July 28, 1852. - p. 547.

Elerenth Stage. Pl. 12, fig. 5, no date, opened June 25, 1854; fig. 8, laid July 18, opened July 30, 1852; fig. 9, and 9a, laid July 15, opened July 26, 1852; fig. 11, laid July 11, opened July 22, 1852. Pl. 14, fig. 12, no date, opened June 25, 1854. Pl. 19, fig. 2, (see Pl. 12, fig. 11, and fig. 3, 5c, and 22, laid July 18, opened July 27, 1852. - p. 548.

Twelfth Stage. Pl. 12, fig. 10, 10a, 10b, and 10c, laid July 18, opened July 27, 1852. Pl. 13, fig. 10, and 11, laid June 18, opened July 11, 1855. Pl. 14, fig. 11, no date, opened July 11, 1855. - p. 549.

I No date means that the date of laying could not be ascertained. Eggs were frequently obtained from the ficlds under eircumstances which made it impossible to ascertain the precise period when they were laid. They were nevertheless very uscful, as they exhibited a most striking general coincidence with those raised in confinement, and, on that account, added to the value of these in the investigation. 
Thirtenth Stage. Pl. 12, fig. 6, no date; opened July 28, 1852; fig. 13, laid July 18, opened July 28, 1852. Pl. 19, fig. 1, 6; (see Pl. 12, fig. 13). Pl. 21, fig. 27, and 28; (see Pl. 12, fig. 13). Pl. 9a, fig. 28; (see Pl. 12, fig. 6). - p. 550.

Fourtcenth Stage. Pl. 9e, fig. 7; (see Pl. 18). Pl. 18a, fig. 11, and 12, laid July 14, opened Aug. 2, 1852; fig. 13, laid July 15, opened July 26, 1852; fig. 14, laid July 10, opened July 20, 1852. Pl. 18, fig. 5, and 7, laid July 11, opened July 22, 1852. Pl. 24, fig. 8, laid June 22, opened July 22, 1852. - p. 551.

Fifteenth Stage. Pl. 18a, fig. 14, laid July 10, opened July 20, 1852. PI. 19, fig. 5, 5a, 5b, and 5d, laid July 10, opened July 20, 1852.- p. 552.

Sixtcenth Stage. Pl. 13, fig. 2, no date, opened Aug. 3, 1852; fig. 3, laid June 18, opened July 10, 1855; fig. 8, laid June 12, opened July 11, 1855; fig. 12, laid June 18, opened July 10, 1855. Pl. 14, fig. 6; (see Pl. 13, fig. 12). Woodcut 1. - p. 553 .

Seventeenth Slage. PL. 24, fig. 7, and 7a, no date, opened July 30, 1852; fig. 14, laid July 14, opened August 2, 1852; fig. 15, no date, opened July 31, 1852. Pl. 18a, fig. 11, 12; (see Pl. 24, fig. 14). - p. 554.

Eightecnth Stage. PL 14, fig. 5, laid June 18, opened July 17, 1855. Pl. 17, fig. 5; (see Pl. 24, fig. 9, and 9a). Pl. 24, fig. 1, and 1a, no date; fig. 9, 9a, and 12, no date, opened August 6, 1852, p. 555.

Nincleenth Stage. PI. 14, fig. 4, laid June 20, opened July 18, 1855. - p. .5.

Tiwenticth Stage. Pl. 16, fig. 6, 6a, laid June 20, opened July 17, 1855. - p. .5.

Ticenty-first Stage. Pl. 14, fig. 2, and 2a, laid June 22, opened July 17, 1855 ; fig. 3, laid June 18, opened July 25, 1855. Pl. 18, fig. 8, no date, opened August 21, 1852. Pl. 18a, fig. 6, 7, 7a, 8, and 9, laid June 18, opened July 25, 1855; fig. 10, laid June 13, opened July 17, 1855. Pl. 20, fig. 12; (see Pl. 24). Pl. 24, fig. 2, and 2a, laid June 21, opened July 31, 1855. Pl. 22, fig. 9, no date. Pl. 9e, fig. 8, 8a, 9, and 9a; (see Pl. 14, fig. 2, 2a). Pl. 19, fig. 4, 7, about 18 days old. - p. 558.

I'uenty-second Stage. Pl. 24, fig. 3, and 3n, laid June 23, opened July 30, 1855. - p. 561 .

T'wenty-third Stage. Pl. 15, fig. 13, laid June 18, opened July 31, 1855; Pl. 24, fig. 4, laid June 12, opened July 29, 1855; fig. 11, laid June 21, opened August 8, 1855. Pl. 16, fig. 3, laid June 16, opened August 1, 1855. Pl. 18a, fig. 4, and 5; (see Pl. 24, fig. 4). - p. 561.

T'uonty-fourth Slage. Pl. 14, fig. 1, laid June 23, opened July 31, 1855. PI. 15, fig. 11, laid June 10, opened August 2, 1855; fig. 12, and 12a, laid June 10, opened August 1, 1855. Pl. 17, fig. 4, 4a, no date, opened September 17, 1855; 
fig. 6, oviduct, ${ }^{1}$ July 20, opened September 17, 1855. PI. 16, fig. 5, no date. PI. 21, fig. 22, 22 a, 23, 24, 25, 26, and 30, no date, opened in September, 1852. Pl. 25, fig. 11, no date. P1. 23, fig. 1, and 1a, laid June 23, opened August 22, 1855. - p. 564 .

Tiwenty-fifth Slage. Pl. 18a, fig. 2, and 3, laid July 20, opened September 19, 1855. Pl. 17, fig. 2, laid July 20, opened September 19, 1855; fig. 3, 3a, and 7, laid June 10, opened September 18, 1855. Pl. 19, fig. 13, 13a, 13b, and 13̉c, laid June 12, opened August 16, 1855. Pl. 23, fig. 2, 2a, 2b, 2c, 2d, 2e, 2f, 2g, and 2h; (see Pl. 19). Pl. 18, fig. 1; (see Pl. 17, fig. 3 and 7). Pl. 24, fig. 5, laid June 23, opened August 7, 1855. Pl. 25, fig. 4, laid June 12, opened August 13, 1855. Pl. 20, fig. 2; (see Pl. 25). Wood-cut 2.-p. 565.

Twenty-sixth Slage. Pl. 15, fig. 4, 5, and 5a, laid June 18, opened September 6, 1855; fig. 6, oviduct, June 20, opened September 4, 1855; fig. 10, oviduct, July 20, opened September 19, 1855. Pl. 13̂, fig. 1, laid June 18, opened September 6, 1555. Pl. 16, fig. 2, 2a, and 2b, laid June 21, opened September 1, 1855. Pl. 18, fig. 9, and 9a, no date, opened August 23, 1852. Pl. 25, fig. 2, laid June 18, opened September 4, 1855; fig, 6, 6a, and 6b, laid June 12, opened August 29, 1855; fig. 8; (see Pl. 15, fig. 4, 5, 5a, and 6). Pl. 9c, fig. 3 ; (see Pl. 15, fig. 4). - p. 567 .

Tucnty-seventh Slage. Pl. 14, fig. 13, laid June 12, opened September 1, 1855. Pl. 15, fig. 7, laid June 21, opened September 21, 1855; fig. 8, and 8a, no date, opened August 22, 1852; fig. 9, no date, opened August 21, 1852. Pl. 18a, fig. 1; (see Pl. 15, fig. 7). PI. 20, fig. 4 and 4 a, laid June 18, opened September 3, 1855. Pl. 23, fig. 3, laid June 12, opened August 28, 1855. P1. 24, fig. 10, 10a, and 10b, laid June 18, opened September 3, 1855. - p. 568.

Twenty-eighth Stage. Pl. 16, fig. 1, laid June 21, opened October 23, 1855. Pl. 25, fig. 10, (see Pl. 16, fig. 12, no date, opened August 25, 1852. - p. 569.

Thenty-ninth Stage. Pl. 15, fig. 1 and 2, laid June 10, opened September 20; fig. 3, laid June 10, opened September 21, 1855. Pl. 18, fig. 3, no date, opened August 27, 1852. Pl. 9a, fig. 30 and 30a; (see Pl. 15, fig. 1 and 2). Pl. 19, fig. 9 to 12, no date, opened August 25, 1852; fig. 16b, 16c, 18, 18a, 19, 20, 21, 24, 25, 26, 26a, and 32, no date, opened September 6, 1852; fig. 23, no date, opened August 25, 1852. Pl. 20, fig. 1, 1a, 1b, no date, opened August 31, 1855; fig. 5, and 6, no date, opened September 2, 1852; fig. 9, 9a, 10, 11, 7, and S, no date, opened August 28, 1852. Pl. 21, fig. 1, 2, 3, 4, 5, 6, 7, 8, and 9, no date, opened August 30,1852 ; fig. 14, 14a, and 14b, no date, opened September 9, 1852; fig. $14 \mathrm{c}$ to

1 Oriduct, means that the egrgs were taken from the oviduct at the time indicated; but many of these eggs were raised with those laid in the natural way, and sometimes not opened until long afterwards. 
14g, 15, 15a, 34, 34a, 16, 16a, and 16b, no date, opened August 30, 1852; fig. 20 to 20d, 21, and 21a, no date, opened August 25, 1852; fig. 29 and 31, no date, opened in August, 1852; fig. 32 to 32d, no date, opened September 9, 1852. Pl. 24, fig. 6, no date, opened September 2, 1852. PI. 25, fig. 1 to $1 d$, no date, opened August 30, 1852; fig. 5, no date, opened August 31, 1852. - p. 570.

Thirtieth Stage. All just hatched or hatching. Pl. 18, fig. 2, 4, and 4a, no date; fig. 10, 10b, and 10c, no date, opened August 31, 1855; fig. 10a, 10d, 10e, and 10f, no date, opened September 5, 1855. Pl. 25, fig. 3, 3a, 7, and 7a, no date; fig. 9; (see Pl. 18, fig. 10d). Pl. 19, fig. 27 and 27a, laid June 21, opened October 19, 1855; fig. 29, 29a, 30, 31, and 33, no date; fig. 34, laid June 21, opened October 17, 1855; fig. 35, and 35a, see Explanation of Plates. Pl. 20, fig. 18, laid June 21, opened October 17, 1855. Pl. 22, fig. 5, 6, 6a, and 6b, no date. Pl. 9e, fig. 11 and 11a, no date. Pl. 9a, fig. 31 and 31a, laid June 21, opened October 25, 1855. - p. 572.

Thirty-first Stage. All hatched in October, 1555. Pl. 17, fig. 1, no date. Pl. 19, fig. $14,15,16,16 \mathrm{a}$, and 17 to $17 \mathrm{~b}$, no date. Pl. 20, fig. 3, 13, 13a, 14, 14a, 15, 16, and 17 , no date. Pl. 21, fig. 10, 11, 12, 13, 13a, 17, 18, 18a, 18b, 18c, 19, 33, and 33a, no date. Pl. 22, fig. $1,1 \mathrm{a}, 1 \mathrm{~b}, 2,3,3 \mathrm{a}, 4,4 \mathrm{a}, 8$, and $8 \mathrm{a}$, no date. Pl. 23, fig. 4, 4a, 5, 6, 7, 8, 9, 10, and 11, no date. Pl. 9e, fig. 12, no date. - p. 575.

A careful preliminary comparison of these references with the Explanation of the Plates will greatly facilitate the reading of the text. 


\section{EXPLANATION OF THE PLATES.}

[Diam. stands for diameters, and the figures for the number of diameters any object is magnified; i. e., 500 diam. after fig. 1, Pl. 8, means that all the objects represented in that figure are magnified 500 times their natural diameter, etc.]

\section{PLATE I.-VIIa.}

[All the figures of these Plates were drawn from nature, by A. Sonrel.]

These Plates require no special explanation. PI. 1 to 6 represent young Turtles in their natural size at the time of hatching, or soon afterwards. Most of them are represented from three sides, in profile, from above and from below ; and frequently a front view of the head, and occasionally of the whole animal, is added. The attitudes are all natural, and in most cases copied from the living animal. Pl. 6, fig. 10-12 represent an embryo of Ozotheca odorata from the middle period of incubation; fig. 17 , a transverse section of the body of a young Thalassochelys Caonana; $e$, is the spinal marrow; $l d$, the neural arch; $t^{\prime}$, the lungs; $t$, the windpipe; $m p$, the pectoral muscle; $r$, the liver; $h^{\prime}$, the aorta ; $n^{4}$, the cesophagus; $m s$, the shoulder muscles; $r c$, the body of the vertebra; fig. 18-32, a series of embryos of Thalassochelys Caouana; fig. 30-32, a week old; fig. 28 , and 29 , two weeks old; fig. 26 , and 27 , three weeks old; fig. 24 , and 25 , four weeks old ; fig. 22 , and 23 , five weeks old; fig. 20 , and 21 , six weeks old ; fig. 18, and 19 , seven weeks old. PI. 7 , and $7 \mathrm{a}$, represent the mature egrgs of many species, with fragments of the shell magnified.

\section{PLATE VIII.}

[.All the figures of this Plate were drawn from nature, by H. J. Clark. ]

Fig. $1, a, b, c, c^{1}, d, e, f, g, h, i, j, k, l, m, n, o, p$. Ovarian egrgs of Chrysemys picta. All except $c, 500$ diam., and $c, 1100$ diameters.
Fig. 1, $h^{1}, o^{1}$. Two Graafian follicles of $\mathrm{Ch}$. picta, containing each an egg, 500 diam.

Fig. 2, 3, 3a, 4, 6, 6a, 7, 8, 8a, 9a, 10. Ovarian eggs of $\mathbf{C h}$. picta; fig. 8, 25 diam.; the others, 500 diam.

Fig. 5. Graafian follicle inclosing an egg of $\mathrm{Ch}$. picta; 500 diam.

Fig. 9. Same as fig. 5. Ch. picta, and Nanemys guttata; 500 diam.

Fig. 11. Ovarian egg of Ch. picta, 25 diam.; fig. $11 \mathrm{~b}$, the same as fig. 11 , natural size; fig. 11 ả, the same, 500 diam.; $a$, its yolk granules, 1100 diam.

Fig. 12. Graafian follicle inclosing an egg of $\mathrm{Ch}$. picta, 300 diam.; $a$, stroma; $b$, tunica granulosa ; $c$, zona pellucida; $d$, embryonal membrane; $e, f$, the yolk.

Fig. 13, and 13a. Ovarian eggs of Ch. picta, and Nanemys guttata; fig. 13, 25 diam.; fig. 13a, 500 diam.

Fig. 14. Graafian follicle and egg, 25 diam.; fig. 14a, Purkinjean vesicle of the same, 500 diam.

Fig. 15. Ovarian egg of Ch. picta, 500 diam. Fig. 15a, $a, b, c, d, c, f, f^{1}$, mesoblasts of the l'urkinjean vesicle ; $a$ to $f, 1100$ diam. ; $f^{1}$, the same as $f$ on an exagrerated scale.

Fig. 16. Ovarian egg, 25 diam.; fig. 16a, the same, 40 diam.; fig. 16b, albuminous globule of fig. $16 \mathrm{a}$, 500 diam. Ch. picta.

Fig. 17, 17a. Ovarian eggs, 25 diam.; fig. 17b, yolk granules of fig. 17,500 diam.; fig. $17 \mathrm{c}$, same as fig. 17 , natural size. Ch. picta, and Nanemys guttata.

Fig. 18. Ovarian egg, nat. size; fig. 18a, the same, 25 diam. ; fig. $18 \mathrm{~b}$, yolk of the same, 500 diam. Ch. picta.

Fig. 19. Orarian egrg, 25 diam.; fig. $19 \mathrm{a}$, the yolk, 500 diam.; fig. $19 \mathrm{~b}$, the egg, natural sizc. Ch. picta. 
Fig. 20. Ovarian eggg, natural size; fig. 20a, its yolk, 500 diam. Ch. picta.

Fig. 21. Ovarian egcg, natural size; fig. 21a, its yolk, 500 diam. Ch. picta.

Fig. 22. Ovarian egg; $a$, natural size; $b$, the finer yolk, 500 diam.; $c$, one of the large yolk cells, 500 diam.; $d$, the same, 1100 diam.; e, Purkinjean vesicle, 500 diam. Ch. picta.

Fig. 23. Ovarian egg, natural size; fig. 23a, granular yolk, 500 diam.; fig. $23 \mathrm{~b}, a$, yolk cell, 500 diam.; $b$, the same. 1100 diam.; fig. 23c, $a$, yolk cell, 500 diam.; $b$, the same, 1100 diam.; fig. 23d, yolk cells, 500 diam.; $a, b$, angular mesoblasts. Ch. picta.

Fig. 24. Ekgg, natural size; fig. 24a, granular yolk, 500 diam.; fig. 24b, the Purkinjean vesicle, 500 diam.; $a, a$, altered mesoblasts. Nanemys guttata.

Fig. 25. Figg, natural size; $a, b, c, d, e$, its yolk cells, 500 diam. Ch. picta.

\section{PLATE IS}

[From nature, by H. J. Clark.]

Fig. 1. Ovarian egg, natural size; fig. $1 \mathrm{a}$, the same, 25 diam. ; $a$, zona pellucida; $b$, Prurkinjean vesicle. Ch. picta.

Fig. 2. Egg, natural size; fig. 2a, $a, b, c, d$, yolk cells, 500 diam. Ch. picta.

Fig. 3. Egg, natural size ; fig. $3 a, a, b, c, d, e, g$, yolk cells, 500 diam. Ch. pieta.

Fig. 4. Egg, nat. size; fig. 4a, its Purkinjean vesicle, 500 diam.; fig. 4 b, the same as fig. $4 \mathrm{a}$, burst open by water, 500 diam. Nanemys guttata.

Fig. 5. Egg, nat. size; fig. 5a, Purkinjean vesicle, 40 diam.; fig. $5 \mathrm{~b}$, another view of the same as fig. $5 \mathrm{a}$; fig. $5 \mathrm{c}$, the same as fig. $5 a$, and fig. $5 \mathrm{~b}, 500$ diam.; $\alpha$, its granular contents; $b$, yolk granules.'

Fig. 6. Egg, nat. size; fig. $6 a, a$ ta $r$, yolk cells, 500 diam. ; fig. 6 b, yolk cells, near the l'urkinjean vesicle, 500 diam. Ch. picta.

Fig. 7. E⿺g, nat. size; fig. 7a, Purkinjean vesicle, 40 diam.; fig. $7 \mathrm{~b}$, contents of the resicle, 500 diam.; fig. $7 \mathrm{c}, 7 \mathrm{~d}$, $7 \mathrm{e}$, if, ig, yolk cells acted upon by water, 500 diam. Ch. jicta.

Fig. 8. Egg, nat. size; fig. $8 \mathrm{a}, \boldsymbol{\Lambda}$ to $\mathrm{N}$, yolk cells; $J, \mathbf{K}$, $\mathbf{L}^{\prime}, \mathbf{L}, \mathbf{L}^{\prime}, 1100$ diam., the others, 500 diam. In all the

1 Some of the yolk granules which surround this l'urkinjean resicle are drnwn upon its edge, between the outline and fig. 5 . figures, $a$ is the ectoblast, $b$ the mesoblast, $c$ the entoblast. Ch. picta.

Fig. 9. Emy, nat. size ; fig. 9a, Purkinjean vesicle 40 diam.; fig. $9 \mathrm{~b}$, another view of the same; fig. $9 \mathrm{c}$, the same as fig. 9a, 500 diam. ; 2 a, $b$, granular contents. Ch. picta.

Fig. 10. Emg, nat. size; fig. 10a, Purkinjean resicle, 40 diam.; fig. $10 \mathrm{~b}$, another view of fig. $10 \mathrm{a}$; fig. $10 \mathrm{c}$, the same as fig. $10 a ; a, b$, granular contents, 500 diam. $^{3}$ Ch. picta.

Fig. 11. Eggr, nat. size; fig. $11 \mathrm{a}$, l'urkinjean vesicle, 40 diam.; fig. $11 b$, the same as fig. $11 a, 500$ diam.; $a, b$, its granular contents; fig. $11 \mathrm{c}$, yolk cells around the Purkinjean vesicle, 500 diam.; fig. $11 \mathrm{~d}$, the same as fig. 11c ; fig. 11e, yolk cells, $x^{3}$ of an inch below the Purkinjean vesicle, 500 diam.; fig. $11 \mathrm{f}$, yolk cells, $\frac{1}{8}$ of an inch below the Purkinjean vesicle; fig. 11 g, yolk cells, from the centre of the egrg, 500 diam.; fig. 11 , yolk cells pressing against each other, 500 diam." Ch. picta.

Fig. 12, $a, b, c, e, f$; mesoblasts, altered by water, of yolk cells of an egg from the oviduct that had its shell; $d, d^{\prime}$, pieces of the walls of the mesoblast. Ch. picta.

\section{PLATF IX̃a.}

[Fig. 32, 32a, from nature, by A. Sonrel, the others by H. J. Clark.]

Fig. 1. Yolk cells from an egg in the oviduct, 500 diam. Chrysemys picta.

Fig. 2, 2a, 2d. Yolk cells, 500 diam., from an eggg laid June 12, opened June 26, 1852. Nanemys guttata.

Fig. 3. Yolk cells from the germinal layer, 500 diam. Egg laid June 15, opened June 16, 1854. Chelydra serpentina.

Fig. 4. Yolk cells from the germinal layer. Sec fig. 2, $2 a$, $2 d$, for their age. ${ }^{5}$

Fig. 5. Ileaps of mesoblasts in the germinal layer, 250 diam.; fig. $5 \mathrm{a}$, one of these heaps, 500 diam. For age, see fig. 2 , etc.

a One half only of this Purkinjean resicle is drawn; its outline passes by fig. $9 c$, and its contents are represented on the right side, along the frame of the Plate.

a Here also the outline of one half only of the vesicle is dram, passing by fig. $10 \mathrm{c}$, and the contents on the right along the frame of the Plate.

- The yolk cells, fig. $11 \mathrm{~d}$ to $1 \mathrm{hh}$, scatterel over the I'urkinjean resicle, fig. 11b, in order to save room, are, of course, out of place there, but those on its edge, fig. 11c, are in place.

s This, and similar references to other figures, are intended to point out the connection between the diljerent objects represented. 
Fig. 6. IIeaps of mesoblasts, lower side of embryonic dise, 250 cliam. For age, see fig. 2.

Fig. 7. Yolk cells from the lower side of the embryonic disc ; $a, b$, mesoblasts; fig. 7a, the same as fig. 7 , burst by water; 500 diam. From the oviluct.

Fig. 8. Mesoblasts on the upper surface of the embryonic disc, 500 diam. For age, see fing. 2.

Fig. 9, $a, b$. Yolk cells from the lower surface of the embryonic disc; $a^{\prime}$, the mesoblast, acted upon by water; 500 diam.; $a^{\prime \prime}$, the same as $a^{\prime}, 1100$ diam. From the oviduct. Chrysemys picta.

Fig. 10, and 11. Graafian follicles, 500 diam. Ch. pieta.

Fig. 12. Orarian egrg, nat. size; fig. 12a, cells of the zona pellucida; 500 diam.; fig. $12 \mathrm{~b}$, cells of the tunica granulosa, 800 diam. Ch. picta.

Fig. 13. Piece of the Graafian follicle (see Pl. 8, fig. 12); fig. $13 a$, surface view of the polygonal cells of the tunica granulosa; 300 diam.

Fig. 14. Piece of the tunica granulosa, and stroma $(a)$ of the Graafian follicle; fig. 14a, tunica, surface view; 500 diam. Ch. picta.

Fig. 15. Embryonal membrane from an ovarian eggr (see fig. 16).

Fig. 16. Ovarian egg, nat. size; the Purkinjean vesicle appears like a black dot. Fig. 16a, portion of the Graafian follicle around fig. $16 ; a$, stroma; $b$, tunica granulosa; $c$, zona pellucida; $d$, yolk; 500 diam. Chrysemys picta, and Nanemys guttata.

Fig. 17. Portion of Graafian follicle inclosing an egg; $a$, the yolk; $b$, zona pellucida; $c$, tunica granulosa; $d$, stroma; 500 diam. Ch. picta, and N. guttata.

Fig. 18. Ovarian egg, nat. size; fig. 18a, portion of the Graafian follicle; $a$, stroma; $b$, tunica granulosa; $c$, vitelline sac; $d$, yolk; $e$, zona pellucida; 500 diam. Ch. picta.

Fig. 19. Piece of the zona pellucida, 500 diam. From an ovarian egg (sce fig. 20). Ch. picta.

Fig. 20. Ovarian eggo, nat. size; fig. 20a, $a, b$, embryonal membrane, 500 diam. Ch. picta.

Fig. 21. Ovarian egg, nat. size; fig. 21a, its embryonal membrane, 500 diam. Glyptemys insculpta.

Fig. 22, and 22a. Embryonal membrane from a full-grown ovarian eng, 500 diam. Chrysemyss picta.

Fig. 23. Embryonal membrane. For age, sec 11. 11, fig. 3. Chelydra serpentina.

Fig. 21. Embryonal membrane, 500 diam.; fig. 2ta, the same as fig. 24, 1100 diam. For age, see P'. 11, fig. 1. Chrysemys picta.

Fig. 25. Embryonal membrane, 500 diam. For age, sec Pl. 11, fig. 2. Ch. picta.
Fig. 26. Embryonal membrane, 500 diam. From the oviduct. For age, see Pl. 11, fig. 2. Ch. picta.

Fig. 27. Embryonal membrane, 500 diam.; the egr had been laid about 18 days.

Fig. 28. Amnios, 500 diam. For age, see Pl. 12, fig. 6.

Fig. 29. Embryonal membrane, surface view ; fig. $29 \mathrm{a}$, profile; $a$, yolk; $b$, cells of the embryonal membrane; 500 diam. Chelydra serpentina. For age, see fig. 25 , and Pl. 11, fig. 2.

Fig. 30. The allantois, inner surface; fig. 30a, outer surface ; $a$, cells of the inner surface; 500 diam. Chelydra serpentina. For age, see Pl. 15, fig. 1, 2, 3.

Fig. 31. The embryonal membrane, $\left(a_{9}\right)$ the amnios, $(b$, and the allantois $(c)$ of an egrg from which the young turtle is about hatching; fig. $31 \mathrm{a}$, a single cell of each of these membranes; view from the outside of the exg; 500 diam. Chelydra serpentina. Laid June 21, opened Oct. 25, 1855.

Fig 32. A full-grown ovarian egg of Cistudo virginea, 3 diam.; to show the convergence of the bloodressels around a central area and the Purkinjean vesicle on the left of it; fig. 32a, the Purkinjean vesicle as scen at the surface of the mature egg, 5 diam.

Fing 33. Yolk cell, and its segmenting mesoblast; fig. 33a, yolk cell almost filled by its mesoblast; fig. $33 \mathrm{~b}$, yolk cell filled by its mesoblast; 500 diam. From the oviduct; Aug. 7, 1856. Cinosternum pennsylvanicum.

Fig. 34. Germinal layer; $a$, the outer surface; $b$, underside; 500 diam. Chelydra serpentina. For age, see Pl. 11, fig. 3. An alcoholic preparation.

Fig. 35. Surface of the embryonic area; fim. 35a, germinal layer; 500 diam. From the oviduct; the egro had just commenced to segment; see Pl. 10, fig. 1, and 2; an alcoholic preparation. Glyptemys insculpta.

Fig. 36, 36a, 36b, 36c. Yolk cells from close beneath the segmenting embryonic area (see Pl. 10, fig. 1, and 2). Fig. $37,37 a, 37 b, 37 \mathrm{c}, 37 \mathrm{~d}$, yolk cells from the side of the same engr ; 500 diam.; from the oviduct. Glyptemys insculpta. Fig. 38, 38a, 38b, 38c, 39, 39a, 39b, 39c, 39d, yolk cells; 500 diam. Ozotheca odorata, laid and opened Aug. 4, 1852. Fig. 40, 40a, 40b, 40 , $40 \mathrm{~d}, 40 \mathrm{e}$, $40 \mathrm{f}, 40 \mathrm{~g}, 40 \mathrm{~h}, 40 \mathrm{i}, 40 \mathrm{j}, 40 \mathrm{k}, 40 \mathrm{l}$, yolk cells of Chelydra serpentina, laid June 20, opened Aur. 20, 1856; 500 diam. In all the figures from 36 to $401, a$ is the ectoblast, $b$ the mesoblast, $c$ the entoblast.

Fig. 41. Profile, and fig. 41a, view from above, nat. size of an egrg of Ozotheca odorata. Laid and opened Aug. 4 , $185 \%$.

Fig. 42. Surface of egroshell, 40 diam.; fig. 43 , section of the thickness of the egg-shell and its membrane; $a, a^{\prime}$, 
calcareous nodules; $b$, base of the sanie; $c, d$, shell membrane; 500 diam, fig. $43 \mathrm{a}$, a nodule seen from the outsile, 500 diam. ; fir. $43 \mathrm{~b}$, piece of a nolule in profile, 500 diam.; fig. $43 \mathrm{c}$, organic matrix of nodule, the lime dissolved out; $a$, its surface ; $b$, its base ; 500 diam.; fig. 44 , rows of nodules of a partially formed shell, 20 diam. ; fig. $44 \mathrm{a}$, lreaps of young nodules, 500 diam.; fig. 45 , inner surface of shell membrane, 500 diam. Chelydra sexpenlina.

Fig. 46. Openings in the egr-shell of Ozotheca odorata, 20 diam.

\section{PJATE IXT,}

[Figs. $9,9 n$, and 10, from unture, by A. Sonrel; the other figures by H. J. Clark.]

Fig. 1. Egr of Nanemys guttata, nat. size, from above; from the oviduet; for age, see P'l. 11, fig. 3.

Fig. 1a. Egg of Nanemys guttata, nat. size, from above from the oviduct, June $3 \mathrm{~d}, 1854$; for age, see Pl. 10, fig $12,13,14,15$

Fig. 2. 1'rofile, and fig. 2a, from above. Clirysemys picta nat. size; from the oviduct, June $3 \mathrm{~d}, 1852$; for embryo see $\mathbf{P}^{\prime}$ ]. 11, fig. 2 .

Fig. 3. I'rofile of an erg of Cinosternum pennsylvanicum, nat. size; from the oviduct, July $3 \mathrm{~d}, 1856$. Alcoholic preparation. Fig. $3 a$, one of the layers of albumen; $a$, the surfaces in profile; $b$, the interior; 25 diameters.

Fig. 4. Profile, and fig. $4 \mathrm{a}$, from above; nat. size; from the oviduct, June $2 \mathrm{~d}, 1854$. 'Glyptemys insculpta. Alcoholic preparation; for embryo, see Pl. 11, fig. 6.

Fig. 4b. View from above of an egg without a shell, nat. size; from the oviduct. Glyptemys insculpta. Alcoholic preparation.

Fig. 5. I'rofile of the egg of Chelydra serpentina, nat. size; from the oviduct, June 12, 1854 .

Fig. 6. Egrg of Platypeltis ferox; from the oviduct, Aurg. 20,1856 ; nat. size. Alcoholic preparation. Fig. 6a, portion of a layer of albumen; $a$, surfaces in profile; $b$, the interior; 20 diam. Fig. $6 \mathrm{~b}$, albumen from the decper layers; $a, b, c$, the oval granules, trending in three different directions; 500 diam. Fig. $6 \mathrm{e}$, inner layer of shell membrane; $a, b$, the oval, elongated granules, trending in two diflerent direetions; 500 diam. Fig. $6 \mathrm{~d}$, shell membrane, just outside of the inner layer (fig. 6e); $a$, granules in strings; $b$, finer granular strings; 500 diam. Fig. $6 \mathrm{e}, a, b, c$, three layers from the midule of the thickness of the shell membrane; 500 diam. Fig. $6 f$, from the middle of the membrane; $a$, seprarate granules; $b$, fine fibres; 500 diam. Fig. $6 \mathrm{~g}$, shell membrane next to the shell, 500 diam.

Fig. 7. l'rofile and fig. 7a, from above; nat. size; just lail, date lost. Thalassochelys Caouana. Alcolsolic preparations.

Fig. 8. From above; nat. size; one week since laid; the same species as fig. 7 .

In all the figures of these egrgs, from fig. 1 to fig. 8 , a designates the albumen outside of the yolk sac, $a^{3}$ the albumen inside of the yolk sac, $s$ the shell, $y$ the yolk, $y^{1}$ the surface of the yolk, $c$ the embryonic disc, $v a$ the vascular area.

Fig. 9. Portion of the oviduct containing an egg, nat size; $m a$, its mesenteric peritoneum ; fig. 9a, slightly magnified portion of the oviduct to show the numerous bloodressels, and the pigment following their courses. Glyptemys insculpta.

Fig. 10. 'The left ovary and oviduct, from below, nat. size; $o v, o v^{1}$, the oviduct; $o v^{2}$, its posterior end; $p$, the pavilion, or anterior opening; pr, ramifications of pigment cells; $b l$, the urinary bladder. Chrysemys picta.

Fig. 11. Right ovary and oviduet, seen from below, nat. size; $i$, the intestine; $c l$, the corpora lutea, or cicatrices; $m$, the mesenteric peritoneum of the oviduct; $p$, the pavilion; $e, e, e, e$, four eggs covered by the oviduct. Glyptemys insculpta; opened May 20, 1854.

\section{PIA'TE IXY.}

[Figs. 1, 2, 3, from nature, by H. J. Clark, the others by A. Sonrel.]

Fig. 1. The same as I'l. 8, fig. 12, on a larger scale. $a, a^{1}$, the two layers of the stroma; $b$, tunica granulosa; $c$, zona pellucida; $d$, embryonal membrane; $d^{1}$, profile of $d ; 2 \cdot s$, yolk sac; $e$, outer layer of fine yolk granules; $f$, inner layer of coarse yolk granules; $g$, Purkinjean vesicle.

Fig. 2. Diagramic profile of an egg after the albumen has become partially absorbed. The same as 1'.11, fig. 4, 4a. $a$, the shell; $b$, shell membrane; $b^{\prime}$, albumen; $b^{\prime \prime}$, innermost and densest layer of albumen; $c$, zona peliucida; $d$, embryonal memuraue; $e$, germinal layer; $e^{\prime}$, embryonic disc; $j$, surface of the yolk; al, albumen within the yolk sac.

Fig. 3. Actual view of the interior of the embryo and its envelopes, seen from the front, to show the relations of the rascular system. 'The red color corresponds to the ventricle $(p)$ and the arterial system of the boty and yolk; the blue to the auricles $(r)$ and the venous system of the body and yolk; the yellow to the arterial system 
of the allantois; the green to the renous system of the allantois. $a$, the shell; $b$, shell membrane; $c$, zona pellucida (sce p. 485); $d$, embryonal membrane; $e$, outer peripheric portion of the amnios (see p. 541);f, $h, m, l$, the allantois; $m, m$, edges of its superior folds; $h$, its lower border; $l$, its peduncular base ; - - - - - , its posterior portion next to the yolk on the right side; $k, k^{\prime}$, amnios; $(k ;)$ its umbilicus; .... embryonal membrane lining the amniotic sac, $\left(k, k^{\prime}\right)$ and covering the shield of the embryo, here represented by a transverse, triangular section; $g$, vascular area; $i$, its lower border; $i^{\prime}$, subsidiary layer, in which run the omphalo-meseraic arteries $\left(q^{\prime}\right) ; j$, yolk; $n$, intestine; $o$, allantoidian arteries; $o^{\prime}$, the same passing close to the body, and then more outwardly; $p$, ventricle with aorta (darker red) in the middle; $p^{\prime}$, branchial arteries; $p^{\prime \prime}$, dorsal artery foreshortened; $p^{\prime \prime}$ to $q$, single omphalo-meseraic artery passing down behind the heart $(p, r) ; q$, two branches of the same; $q^{1}$, omphalo-meseraic arteries of the yolk, which anastomoze with the veins at $i ; r$, the double ventricle; $r^{\prime}$, omphalo-meseraic veins ramifying through the mass of the yolk; $s$, abdominal veins foreshortened, in part, and turned in to enter the auricles $(r) ; \ell$, allantoidian reins, foreshortened in part, which run along the sides of the body, and pass in behind, and into the rentricle $(r) ; t^{\prime}$, allantoidian veins, which run on the outer folds; $t^{\prime \prime}$, the same as $t^{\prime}$, running along the inner folds, close against the body, and then on the outer folds. Chelydra serpentina, about 4 diam., corresponds to Pl. 15 , fig. 4, 5, 5a, and to Pl. 16, fig. 2, 2a, 2b.

Fig. $9,10,11,12,15,16,17,13,14,4,5$, and 6 represent a series of embryos of Chelydra serpentina, from the time the shield begins to be distinet to the moment of hatehing. Fig. 6 represents a young just breaking through the egg-shell. All in their natural size.

Fig. 7, and 8. Ozotheca odorata; fig. 7, head from below; fig. 8 , young breaking through the egg-shell; nat. size.

Fig. 22, 23, 18, 19, 20, and 21, represent a series of embryos of Chrysemys picta; nat. size.

\section{PLATE IX'l.}

[Drawn by H. J. Clark.]

Fig. 1. An actual longitudinal section of an embryo, 40 diam. The embryo is nearer to the yolk $(y k)$ than is natural. The tro opposite sides of the lateral halves of the yolk are approximated here for want of room, but the level of the vitelline surface is kept in its proper relation to the position of the embryo. a, $a^{1}, a^{2}, a^{5}, a^{6}$, the amnios; $a$, its peripheric part; $a^{1}, a^{2}$ above, the elge of its dorsal aperture; $a^{2}$ at the tail, to $a^{2}$ above, the caudal hood; $a^{b}, a^{5}, a^{1}$, the cephalic hood; $a^{3}, a^{4}$, the area pellucida of the subsidiary layer $\left(n, o^{1}\right) ; c, c$, the area pellucida; $d, d$, its periphery; $e, e^{1}, e^{2}, e^{3}, e^{4}, e^{b}$, spinal marrow; $e$, edge of the channel of the spinal marrow ; $e^{7}$, floor of the same; $e^{1}, e^{2}$, edge of the broad channel of the brain; $e^{3}$, point where the edges touch; $e^{6}$, lower floor of the brain; $e^{4}$, posterior end of the germino-spinal layer; $f^{1}$, vertebral layer; $f$, vertebre ; $g$, anterior end of the chorda dorsalis ; $\eta^{1}$, its posterior end ; $h$, heart; $i^{\text {t }}$, incipient vena terminalis; $j^{2}$, cavity between the vertebra $\left(f^{\prime}\right)$ and the subsidiary $(n)$ layer; $n$, intestino-subsidiary layer; $o^{2}$, peripheric part of the subsidiary layer; - ......, point where the lower half of the egg joins the serment of the upper part; $y k$, the yolk (its cells are magnified just as much as the embryo); al, albumen; $r s$, yolk sac, or rather zona pellucida; ...., embryonal membrane. Chelydra serpentina; the same as 1'l. 12, fig. 1, 1a.

Fig. 2. An actual section of the walls of the Graatian follicle, and of a full-grown egg, 500 diam. $a, a^{1}$, the two walls of the stroma; $b$, tunica granulosa; $c$, zona pellucida; $v \&$, vitelline or yolk sac; $d^{1}$, embryonal membrane; $e$, yolk cells about the Purkinjean vesicle $(g) ; v^{c} c$, yolk cells from the centre of the yolk. Chrysemys picta. Compare fig. 11b, Pl. 9.

Fig. 3. View from above of fig, 2, Pl. 9c; the letters are the same.

Fig. 4. Profile of an egg of Ozotheca odorata, nat. size; the shell broken open at the side to expose the yolk; $e$, embryonic disc.

Fig. 5. The albumen of a hen's egg, at the point where resorption is going on, showing the exposed edges of all the layers of altumen, down to the yolk.

\section{I'LATE IXe.}

[Drawn by H. J. Clark.]

Fig. 1 to fig. 9a are. longitudinal and transverse sections of the embryo. The same parts are lettered alike in all; ...., embryonal membrane; al, albumen; $y k$, yolk; $a$, germinal layer; $a^{2}$, fold of the cephalic hood; $a^{2}$, foll of the caudal hood; $a^{3}$, the subsidiary layer in the area pellucida about the head; $a^{4}$, the same about the tail; $a^{5}$, cephalic hood; $a^{0}$, base of attachment of the cephalic hood; $b$, primitive furrow; $c$, area pellucida; $c^{1}$, cavity 
between the germino-amniotic $(a)$ and subsidiary $\left(o^{2}\right)$ layers in the area pellucida; $d$, periphery of the area pellucida; $e$, edge of the primitive furrow, or of the spinal channel ; $e^{1}$, cephalic region of the spinal nervous system ; $e^{3}$, spinal marrow closed over; $e^{4}$, caudal portion of the same; $e^{p}$, lower floor of the spinal canal; $f$, vertebra; $f^{1}$, vertebral layer; $f^{\prime}$, lower edge of the vertebrs; $f^{4}$, upper edge; $f^{5}$, outer or lateral limit of the vertebrx; $g$, chorda dorsalis; $\imath^{1}$, incipient vena terminalis; $j^{2}$, dorsal artery; $n$, intestino-subsidiary layer; $n^{2}$, stomach; $n^{4}$, cesophagus ; $n^{6}$, mesenterium of the intestine; $o^{1}$, subsidiary layer; $p$, musculo-cutaneous layer ; $p^{2}$, musculo-costal layer; $q$, Wolfian bodies; $q^{2}$, their ducts; $r$, liver; $w$, the feet.

Fig. 1 corresponds to Pl. 10, fig. 12, 13, 14, 15. An ideal section.

Fig. 2 corresponds to 1'l. 11, fig. 1, 6, 6a; 25 diam. An actual longitudinal section.

Fig. 3 corresponds to Pl. 11, fig. 3. Ideal longitudinal section. Fig. 3a, ideal transverse section of fig. 3.

Fig. 1 corresponds to Pl. 11, fig. 5, 5a. Ideal longitudinal section. Fig. $4 \mathrm{a}$, ideal transverse section of fig. 4, through the point $e^{\top}$. Fig. $4 \mathrm{~b}$, another transverse section through the point $b$, so as to include the upper and lower bend of the body.

Fig. 5 corresponds to Pl. 12, fig. 1, 1a. An ideal transrerse section at about midway between head and tail. (In this figure, the dots from the letter $e$, on the right, should extend to the next inner line, which runs close to $f^{2}$.)

Fig. 6. An actual transwerse section close behind $a^{1}$, fig. 2, Pl. $12 ; 40$ diam.

Fig. 7 corresponds to Pl. 18, fig. 7. Actual transverse section, near the posterior end of the body.

Fig. 8 corresponds to Pl. 14, fig. 2, 2a. Actual transverse section of the embryo of Thalassochelys Caouana, just behind the fore legs, about 5 diam.

Fig. 8a. The same as fig. 8. Aetual transverse section through the middle region of the body.

Fig. 9. The same as fig. 8, 8a. Actual transverse section just behind the opening of the wophlagus. Nanemys guttata, 12 diam.

Fig. 9a. The same as fig. 8 and 9. Actual section across the root of the tail, 12 diam.

F"ig. 10 to $10 \mathrm{~d}$. Spermatic particles from the testicle of an adult turtle. Chrysenays picta ; fig. 10, 10a, 500 diam.; fig. $10 \mathrm{~b}$ shows the swelling $\left(a^{1}\right)$ at the base of the socalled head $(a)$; b, the tail; fig. $10 \mathrm{c}$, another view of $10 \mathrm{~b}$, showing that the swelling $\left(a^{3}\right)$ is on one side. The origin of this swelling has not been traced in turtles; but, from its similarity to what has been seen in several other animals, we have no hesitation in pronouncing it to be the remains of the cell in which the particle was developed; fig. 10d, a perfectly mature particle, the most numerous and lively of all, free from the remains of the parent cell; figs. $10 \mathrm{~b}, 10 \mathrm{c}, 10 \mathrm{~d}, 1100$ diam.; April 8 , 1856.

Fig. 11. Longitudinal section of the right branches of the lower jaw; $a$, channel of the nerve; $b$, lateral cavities connecting with $a$; $d$, teeth of the suture; fig. 11a, transverse section of fig. 11 ; the letters $a, b$, the same; $c$, cartilaginous strip in the sulcus inframaxillaris; *.....**, line through which the longitudinal section was made. About 12 diam. Chelydra serpentina, just ready to be hatched.

Fig. 12. Transverse section of a rib and of the shield, 40 diam.; $a, a^{\prime}$, cartilaginous part of the rib; $b$, its wings; $c$, the corium; $c^{\prime}$, corium below the rib; $d$, fibrous lining of the shicld; $e$, epidermis. Chelydra serpentina, just hatched.

\section{PLATE X.}

[Fig. 2, 3, 4, 12, 13, 14, from nature, by H. J. Clark; the others by $\mathrm{A}$. Sonrel. Excepting fig. 12, 13, 14, all were taken from the oviduct of Glyptemys insculpta.]

In all the figures, $a$ marks the region immediately around the emuryonic area; $a^{2}$, the "cones;" $b$, the space where segmentation is roing on; $c$, the yolk; $d$, the albumen; $e$, the segment masses beyond the embryonic disc.

Fig. 1. The whole eng, the shell being removed, 3 diam., seen from above; fig. $1 \mathrm{a}$, the same, nat. size. This was the anterior or first erg in the left oviduct.

Fig. 2. Deeper view of fig. 1.

Fig. 3. Anterior or first erg in the right oviduct.

Fig. 4. Second egg in the right oviduct.

Fig. 5. Third erg in the right oviduct.

Fig. 6. Third egg in the left oviduct.

Fig. 7. Second egr in the left oviduct.

Fig. 8. Fourth ener in the left oviduct.

All the eggs represented in fig- 1 to 8 were taken from the same turtle, May 27, 1854.

Fig. 9. Fourth egg in the right oviduet.

Fig. 10. Second egg in the left oviduct.

Fig. 11. First egrg in the right oviduct, 25 diam.

Fig. 11a. 'The whole egrg, without the shell, nat. size. The same as fig. 11.

Fig. 11b. 'The same as fig. 11. The whole egg, 3 diam.

All the egres represented in fig. 9 to $11 \mathrm{~b}$ were taken from one turtle, May 28, 1854. 
Fig. 12. Embryonic disc, about 5 diam. Nanemys guttata; from the oriduct, June 4, 1852 .

Fig. 13. The same as fig. 12; from the oviduct, June 3, 1852 .

Fig. 14. Embryonic dise, 12 diam. ; from the oviduct, June 3, 1852. Cliryseny's picta.

Fig. 15. Embryonic disc, about 3 diam.; from the oviduct, May 29, 1854. Glyptemys insculpta. Fig. 15a, the same as fig. 15 ; the yolk, seen from above, nat. size.

\section{PLATE XI.}

[Fig. 1, 1a, 2, 3, 3a, 4, 4a, 4b, 5, 5b, 5c, from nature, by A. Sonrel; fig. $6 a, 6,6 a, 7,7 a, 7 b, 8,9,9 a, 9 b, 10,10 a, 10 b, 10 c$, by H. J. Clark.]

In all the figures, $\boldsymbol{a}$ is the region about the embryonic disc; $a^{1}$, the cephalic hood; $a^{2}$, the caudal hood; $a^{3}, a^{4}$, see $P^{3}$. $9 \mathrm{e}, \mathrm{fig} .4,4 \mathrm{a}, 4 \mathrm{~b}, a^{3}, a^{4} ; a^{5}$, the end of the head; $b$, the primitive furrow; $c$, the area pellucida; $d$, the area vasculosa.

Fig. 1. Embryo of Chelydra serpentina, 20 diam.; fig. 1a, the same as fig. 1, yolk and inner layer of albumen in profile, nat. size. Laid June 21; opened June 26, 1855.

Fig. 2. Embryo of Chelydra serpentina, 20 diam.; period of laying unknown; opened June 16, 1854.

Fig. 3. Ch. serpentina, 20 diam.; period of laying unknown, opened June 12, 1854 (in this figure, $a$ should be $d$, as in fig. 2); fig. $3 a$, the same as fig. 3 , yolk and inner layer of albumen in profile, nat. size.

Fig. 4. Ch. serpentina, 20 diam.; period of laying unknown, opened June 12, 1854. Fig. 4a profile, and $4 \mathrm{~b}$ from above, jolk and inner layer of albumen, nat. size.

Fig. 5. Ch. serpentina, from above, fig. $5 \mathrm{a}$ from below; 20 diam.; laid June 23, 1855, at $9 \frac{1}{2}$ o'clock, A. Mr.; fig. 5 opened June 26, 1855, at 4 P. .r., fig. 5a opened about 3 A. M., June 27,1855 ; fig. $5 \mathrm{~b}$, profile of the whole egr of fig. 5 and $5 \mathrm{a}$, nat. size; fig. $5 \mathrm{c}$, the same as fig. $5 \mathrm{~b}$, seen as if cut through the middle to show the concave surface of the yolk, nat. size.

Fig. 6. Malacoclemmys palustris, 18 diam.; laid and opened July $3 \mathrm{~d}, 1855$; fig. $6 \mathrm{a}$, actual longitudinal section of fig. $5 ; 25$ diam.

Fig. 7. Malacoclemmys palustris, from above; fig. 7a, the sane as fig. 7 , from below; 20 diam.; fig. $7 \mathrm{~b}$, longitudinal section of fig. 7 and $7 a, 25$ diam.; laid July 2 , opened July 3, 1855.

Fig. 8. Ozotheca odorata, from below; fig. 8a, anterior end of fig. 8, from above, 30 diam. ; laid July 10, opened July 12, 1855.
Fig. 9. Oz. odorata, from abore; fig. $2 \mathrm{~b}$, actual longitudinal section of fig. 9 ; fig. $9 \mathbf{a}$, actual transverse section across the middle of fig. $9 ; 26$ diam.; laid and opened July 4, 1855.

Fig. 10. Malacoclemmys palustris, from abore; fig. 10a, from below; fig. $10 \mathrm{~b}$, actual longitudinal section; fig. $10 \mathrm{c}$, view of fiy. 10 from front; 26 diam.; laid July 2 , opened July 3,1855 .

\section{I'LATE XII.}

[Figs. 2, 3, 3a, 3b, 4, 5, from nature, by A. Sonrel; the others by H. J. Clark.]

In all the figures of this Plate, $a$ designates the amnios; $a^{1}$, the posterior bend of the cephalic hood; $a^{2}$, the caudal hood; $a^{3}$, the point of disjunction of the subsidiary layer and of the germino-amniotic layer; $a^{5}$, the cephalic hood; $a^{6}$, the basis of the cephalic hood; $c$, the area pellucida; $d$, the area vasculosa; $e$, the spinal marrow; $e^{2}$, the upward folding borders of the brain; $e^{2}$, the edge of the open medulla oblongata; $e^{3}$, the point where the brain is closed over; $e^{4}$, the caudal portion of spinal marrow; $f$, vertebre; $f^{1}$, the rertebral layer; $g$, the chorda dorsalis; $h$, the heart; $i$, the rena afferens; $i$, the rena terminalis; $j$, the branchial arteries; $k$, the eyres; $l$, the cars; $m$, the branchial fissures; $o$, the abdoninal aperture, and the basis of attachment to the amnios; $p$, the musculo-cutaneous layer.

Fig. 1, from above; fig. 1a, from below; 25 diam. (In this figure, $c^{\prime}$ should be $e^{\prime}$.) Chelydra serpentina; laid June 12, opened June 28, 185.

Fig. 2, from abore, 25 diam. Chelydra serpentina; laid June 12, opened June 26, 1855.

Fig. 3, from below, on partially darkened background; fig. $3 a$, the same as fig. 3 , by transmitted light; fig. $3 \mathrm{~b}$, from above; 20 diam. Ch. serpentina; period of laying unknown, opened June 24, 1854.

Fig. 4, from below, 22 diam. Ch. serpentina; period of laying unknown, opened June 21, 1854.

Fig. 5. Three quarters view from below, 22 diam. $\mathrm{Ch}$ serpentina; period of laying unknown, opened June 25, 1854 .

Fig. 6. Right side and in profile, 21 diam. Nanemys guttata; period of laying unknown, opened July 28, 1852.

Fig. 7 , from below, 5 diam. Nanemys guttata; period of laying unknown, opened July 28, 1852.

Fig. 8, from above and to the left, 21 diam. N. guttata; laid July 18, opened July $30,1852$. 
Fig. 9, from abore and to the left, 26 diam. N. guttata; laid July 16, opened July 26, 1852 .

Fig. $9 a$, from above, the same as fig. 9.

Fig. 10, from below, 20 diam.; fig. 10a, the same as fig. 10, from above; (in this figure, $a^{4}$ should be $a^{1}$; correct also the same mistake in the text, p. 541 , line 16 ;) fig. $10 \mathrm{~b}$, the same as fig. $10 \mathrm{a}$, seen more from the front; fig. $10 \mathrm{c}$, the same as fig. 10 , scen directly from the front N. guttata ; laid July 18, opened July 27, 1852.

Fig. 11. Posterior half, from above, 20 diam. N. guttata; laid July 11, opened July 22, 1852.

Fig. 12. Posterior half, from the left side, 26 diam. N. guttata; laid July 18, opened July 29, 1852.

Fig. 13. Posterior half, from below and to the left, 25 diam. N. guttata ; laid July 18, opened July 28, 1852.

\section{PLATF XIIII.}

[Fig. 4 from nature, by H. I. Clark; the others by A. Sonrel.]

Fig. 1. Interior view of the egg, the shell being taken off, and the shell membrane varnished; $o$, the allantoidian vessels; $h$, the upper surface of the yolk sac; $r$, the vena afferens, 2 diam. Chelydra serpentina; laid June 18, opened Sept. 6, 1855.

Fig. 2. Embryo and vascular area, from above; the arrows inlicate the direction of the currents of blood; about 6 diam. Ch. serpentina; period of laying unknown, opened Aug. 3, 1852.

Wood-cut 1, p. 553 , represents parts of the same figure $; f$, vertebre; $i^{2}$, allantoidian artery, running along the side of the body ; $j^{2}$, abdominal or dorsal artery; $n^{6}$, allantois.

Fig. 3, from below, about the same diam. as fig. 2. Ch. serpentina; laid June 18, opened July 10, 1855; q, point from which the omphalo-meseraic arteries radiate.

Fig. 4, 5, 6, 7, 8, 9. Views in profile and from above of the egg, with the shell partially taken off, to exhibit the extent of the circulation of the blood, nat. size. $\mathrm{Cl}_{2}$. serpentina; all laid June 12, and opened July 11, 1855.

Fig. 10, and 11. Laid June 18, and opened July 11, 1855. Ch. serpentina, nat. size.

Fig. 12. Laid June 18, and opened July 10, 1855. Ch. serpentina, nat. size. (See p. 599.)

\section{PLATE: XIV}

[Fig. 1, from nature, by II. J. Clark; the others by A. Sonrel.]

All the figures are of Chelydra serpentina.

Fig. 1. Embryo from the left side, about $3 \frac{1}{2}$ diam.; laid June 23, opened July 31, 1855.
Fig. 2. From above, about 3 diam.; tho allantois nearly covers the embryo." $r$, vena afferens; $r^{2}$, vena terminalis; laid June 23, opened July 18, 1855.

Fig. 2a. From above, about 5 diam.; laid June 23, opened July 17,1855 .

Fig. 3. From below, about 5 diam.; laid June 18, opened July 25,1855 .

Fig. 4. From the right side, about 5 diam. o, allantoidian artery; $t$, allantoidian vein running along the side of the abdominal opening. 'Taken from the oviduct June 20, and opened July 18,1855 .

Fig. 5. From above, about $2 \frac{1}{2}$ diam.; laid June 18 , opened July $17,1855$.

Fig. 6. From above, about $1 \frac{1}{2}$ diam. ; laid June 18 , opened July 10,1855 .

Fig. 7. From above, about $1 \frac{1}{2}$ diam. ; laid June 23, opened July 10,1855 .

Fig. 8. From above, about $1 \frac{1}{2}$ diam.; taken from the oviduct, June 20, and opened July 10, 1855 .

Fig. 9. From above, about $1 \frac{1}{2}$ diam, ; laid June 18 , opened July $10,1855$.

Fig. 10. From above, about $1 \frac{1}{2}$ diam.; taken from the oviduct, June 20, and opened July 10, 1855.

Fig. 11. From abore, about 2 diam.; laid June 18, opened July $11,1855$.

Fig. 12. From above, about 2 diam.; period of laying unknown, opened June 25, 1854.

Fig. 13. From above, nat. size; laid June 12, opened September 1,1855

PLATE IV.

[Drawn from nature, by A. Sonrel.]

All the figures are of Chelydra serpentina.

Fig. 1. From the right; fig. 2 , from the left side, the shell being taken off; fig. 3 , the allantois and amnios cut away; nat. size; fig. 1 and 2, laid June 10, opened Sept. 20, 1855; fig. 3, laid June 10, opened Sept. 21, 1855.

Fig. 4, 5, 6. From above, nat. size; fig. 4, outer folds of the allantois cut away, leaving the inner folds with their bloodvessels running over the amnios; fig. 5 , to the right the whole allantois is lifted ofl and cut away so as to expose the radiating vessels of the vascular area; laid June 18, opened Sept. 6,1855 ; fig. 6 , the allantois entire; taken from the oviduct June 20, opened Sept. 4, .1855 ; fig. $5 \mathrm{a}$, a portion of the large vena afferens of fig. 5 , and the two omplalo-meseraic arteries at the point where they begin to branch, about 5 diam.

Firg. 7 . From the right side, the allantois and amnios cut away; laid June 21, opened sept. 21, 1855. 
Fig. 8 . From the right side; the shell is removed; $i$, edge of the vascular area; fig. $8 \mathrm{a}$, the same as fig. 8 , from the left side, on the right the allantois is cut away to show the edge of the shield more distinctly, 2 diam.; period of laying unknown, opened Aug. 22, 1852.

Fig. 9. From abore, the shell partially remored, 2 diam.; period of laying unknown, opened Aug. 21, 1852.

Fig. 10. Twins, nat. size; the shell is removed; taken from the oviduct, July 20, opened Sept. 19, 1855 .

Fig. 11. From above, the shell mostly cut away; laid June 20, opened Aug. 2, 1855.

Fig. 12. From above, the allantois drawn back; fig. 12a, the same as fig. 12, the embryo from behind, to show the extent of the rascular area on the lower side of the yolk; laid June 10, opened Aug. 1, 1855.

Fig. 13. Embryo with its allantois, taken out of the shell, about 3 diam.; laid June 18, opened July 31, 1855.

\section{PLATE XYI.}

[Fig. 4 from nature, by H. J. Clark, the others by A. Sonrel.]

Fig. 1. The allantois and amnios removed. Chrysemys picta, nat. size. Laid June 21, opened Oct. 23, 1855.

Fig. 2. From above, the shell cut away, nat. size; fig. 2a, the same as fig. 2, from below, about 2 diam, the shell being remored to show the superficial extent of the vascular area; $r^{\mathrm{r}}$, rena afferens; fig. $2 \mathrm{~b}$, the same as fig. 2 , and $2 a$, the allantois and amnios cut away, and the embryo turned back and exposed from below; $r^{2}$, the point where the vena afferens enters the yolk mass. Chrysemys picta. Laid June 21, opened Sept. 1, 1855.

Fig. 3. From above, 5 diam.; $r^{1}$, vena atferens. Chrysemrs picta. Laid June 16, opened Aug. 1, 1855.

Fig. 4. Seen obliquely from above and to the right, about 2 diam. Period of laying unknown, opened Sept. 17, 1852. Ch. pieta.

Fig. 5. From above, a little more than 3 diam. The allantois is drawn back. Ch. picta. Date of laying unknown, opened Aug. 2, 1855.

Fig. 6. From above and to the right; fig. 6a, the same from the left, without the rascular area; about $\&$ diam. Laid June 20, opened July 17, 1855. Nanemys guttata.

\section{PLATE XYVII.}

[. III the âgures of this Plate are drawn from specimens of Chelydra serpentina; fig. 5, by A. Sonrel, the others by 11. J. Clark.]

Fig. 1. Portion of the intestine and of the adherent yolk sac, about 5 diam. The rena afferens on the right; in, the midule the omphalo-meseraic artery. Hatched in October.

Fig. 2. Portion of the intestine to show its opening into the yolk sac, 5 diam. On the right the afferent rein; in the middle the omphalo-meseraic artery. Taken from the oviduct, July 20, opened Sept. 19, 1855.

Fig. 3. Portion of the vascular area, just below the surface. The large ressel on the left is an omphalo-meseraic artery, the others are omphalo-meseraic veins; the arrows indicate the course of the blood, 250 diam.; fig. $3 \mathrm{a}$, large, transparent cells from fig. 3, 500 diam. Laid June 10, opened Sept. 18, 1855.

Fig. 4. Portion of the allantois, 20 diam.; fig. 4 a, portion of the same as fig. 4,40 diam. Period of laying unknown, opened Sept. 17, 1855.

Fig. 5. Part of the elge of the vascular area, 5 diam. Period of laying unknown, opened Aug. 6, 1852.

Fig. 6. Strip of the vascular area, from the first part of the omphalo-meseraic artery to the vena terminalis, 5 diam. Taken from the oviduct, July 20, opened Sept. 17, 1855.

Fig. 7. Portion of the nearly parallel ompbalo-meseraic arteries, and the very crooked omphato-meseraic reins, 5 dianı. Laid June 10, opened Sept. 18, 1855.

\section{PLATE XVIII.}

[Fig. 1, 2, 3, 4, 4a, 5, 7, 9, 11, 11a, 11b, from nature, by H. J. Clark. Fig. $6,8,9 \mathrm{a}, 10,10 \mathrm{a}, 10 \mathrm{~b}, 10 \mathrm{c}, 10 \mathrm{~d}, 10 \mathrm{e}, 10 \mathrm{f}$, by A. Sonrel.]

Fig. 1. Omphalo-meseraic rein with a very thick wall, 500 diam.; the same as Pl. 17, fig. 3, and 7. Ch. serpentina.

Fig. 2. Omphalo-meseraic artery, 500 diam. Embryo just hatched.

Fig. 3. Piece of the allantois with a bloodvessel, 500 diam. Period of laying unknown, opened Aug. 27, 1852.

Fig. 4. Mesh of bloodressels covered by yolk, 20 diam.; fig. $4 \mathrm{a}$, a single ressel in its sheath of yolk, 500 diam. Ch. serpentina. Just hateled.

Fig. 5. Posterior end of the dorsal artery and the neighboring omphalo-meseraic arteries. Magnified from fig. 7 . Nanemys guttata. Laid July 11, opened July 22, 1852.

Fig. 6. The fork of the vena terminalis, 12 diam.; the same as fig. 7 .

Fig. 7. From below, 5 diam.; the same as fig. 5 , and 6 .

Fig. 8. From above, $3 \frac{1}{2}$ diam. Nanemys guttata. Period of laying unknown, opened Aug. 21, 1852.

Fig. 9. From above, 2 diam. Ozotheca odornta. Period of laying unknown, opened Aur. 23, 1852; fig. 9a, the same as fig. 9. The embryo and allantois drawn to one sille. 
Fig. 10. From the right side; fig. 10a, from above; fig. $10 \mathrm{~b}$, from below; fig. $10 \mathrm{c}$, from the left side, the allantois partly opened; fir. 10d, the same, the allantois being cut away; fig. 10e, the same, from behind; fig. 10 , the same as $10 \mathrm{~d}, 10 \mathrm{e}$, from above. Cistudo virginea, nat. size. Just ready to hatch. P'eriod of laying unknown; fig. 10, 10b, 10c, opened Aug. 31, 1855 ; fig. 10a, 10d, 10e, 10f, opened Sept. 5, 1855.

Fig. 11, 11a, 11b, $a, b$. Crystals of nitrate of lime. Sce p. 508 , on the structure of the egr-shell.

\section{PLATE XVIIIa.}

[Fig. 1, 2, 3, from nature, by A. Sonrel, the others by H. J. Clark.]

Fig. 11, 12, 13, 14. Naneny's guttata, the others, Chelydra serpentina. Throughout the Plate the letter $a$ designates the amnios; $a^{2}$, the cephalic hood; $a^{2}$, the caudal hood; $e^{1}$, the medulla oblongata; $e^{3}$, the corpora quadrigemina; $e^{5}$, the choroid plexus; $f$, the vertebrx; $h$, the heart; $h^{2}$, the aorta, or aortic bulb; $h^{2}$, the branchial aorta; $h^{3}$, the auricle; $l^{4}$, the ventricle; $i$, the vena afferens; $i^{2}$, the allantoidian vein; $i^{3}$, the abdominal vein; $i^{4}$, the junction of the allantoidian and abdominal vein; $i^{5}$, the cephalic vein; $j$, the eephalic artery; $j$, the dorsal artery $; j^{3}$, the allantoidian artery $; j^{\ddagger}$, the omphalo-meseraic artery $; j^{3}$, the junction of the abdominal or dorsal artery and the omphalo-meseraic artery $; j^{6}$, the junetion of the aludominal and allantoidian arteries; $k$, the cyes; $l$, the ears; $m$, the branchial fissures; $n^{\prime}, n^{2}$, the intestine; $n^{2}$, the stomach; $n^{3}$, the junction of the allantois and intestine, except in fig. 5 , where it refers to the œsophagus; $n^{4}$, the cosophagus; $n^{5}$, the anus; $q$, the Wolttian bodies; $r$, the liver; $t$, the windpipe; $t$, the lungs ; $u$, the gall cyst; $v$, the nostrils.

Fig. 1. Head of Pl. 15 , fig. 7,4 diam. $; j^{2}$, cephalic arteries

Fig. 2. Young turtle from above, $2 \frac{1}{2}$ diam. Taken from the oviduct, July 20, opened Sept. 19, 1855.

Fig. 3. From below, 2 diam. Laid open to expose the organs; the same as fig. 2.

Fig. 4. Wollian body, intestine, liver, and bloodvessel dissected out; the anterior end is on the right; about 5 diam. Laid June 12, opened July 29, 1855.

Fig. 5. Heart, vessels, liver, intestine, dissected out; the anterior end is to the left; the same as fig. 4 .

Fig. 6. IIeart and branchial aorta, about 10 diam. Laid June 18, opened July 25, 1855.

Fig. 7. Anterior end of fig. 8, from above; fig. 7 a, posterior end of fig. 8 , and 9 , from below, laid open. Where the allantoidian arteries $\left(j^{3}\right)$ join the abdominal artery, $\left(j^{2}\right.$, the intestine $\left(n^{2}\right)$ is cut away.

Fig. 8. This figure, the largest of the Plate, is erroneously marked 2 in most copies. The same as fig. $6,7,7 \mathrm{n}, 9$, from the right side. The Wolflian boly $(q)$ is drawn down a little, to expose the dorsal artery $\left(j^{2}\right)$; about 10 diam.

Fig. 9. The same as fig. 8 , from below, about 5 diam. Laid open before and behind, and the allantois, the amnios, and the yolk sac turned aside.

Fig. 10. Heart, and adjoining vesse's, dissected out; 10 diam. Laid June 13, opened July 17, 1855.

Fig. 11. Heart, and branchial arteries from the right side; 25 diam. Laid July 14, openerl Aug. 2, 1852.

Fig. 12. Heart, from the left side; the same as fig. 11.

Fig. 13. Anterior part of the boty from the right side, 12 diam. Laid July 15, opened July 26, 185̃2. The dotted lines which should connect the letters $h^{3}$ and $h^{1}$ are unfortunately omitted; $h^{3}$ should go to the dark hole in the heart, which is nearest to the letter, and $h^{1}$ to that part of the aorta which is just below the longest branchial fissure, $(m$, that runs from the ear $(b)$ downwards. The $i$ nearest to the letter $\iota^{3}$ should be $i^{\text {? }}$.

Fig. 14. From the left side. The amnios, $(a$,$) behind the$ head, laid open; 12 diam. Laid July 10, opened July 20, 1852. The first letter to the left of $k$ should be $e^{3}$ instead of $e^{1}$.

\section{PLATE XIX.}

[Drawn from nature, by H. J. Clark.]

Fig. 1, 2, 3, 4, 5 to $5 d, 6,7,8,22$ are from Nanemys guttata, the others from Chelydra serpentina.

Fig. 1. Cells on the surface of the head near the eye, 300 diam. Laid July 18, opened July 28, 1852.

Fig. 2. Surface cells of the tail, 500 diam.; $c$, profile; $a$, a cell; $b$, its mesoblast. Laid July 11 , opened July 22 , 1852.

Fig. 3. A rertebra, 500 diam. Laid July 18, opened July 27,1852 .

Fig. 4. Transverse section across the mildle region of the body, and between the vertebra, 40 diam.; ( $a$, cells from the dermal layer, $\left(f, 500\right.$ diam.); $a^{\prime}$, spinal tube; $b$, chorla dorsalis; $c$, dorsal artery; $d$, Wollian bodies; $e$, duct of $d ; f$, musculo-cutancous layer $g$, mesenterium of the intestine. About 18 days old.

Fin. 5. Surface view of the anterior end of the chorda dorsalis; $a$, cell in profile; fig. $5 a$, surface view near the posterior end; $a$, cell in profile; fig. $5 b$, middle region; $a$, view of the surface; $b$, of the interior; 500 diam.; fig. 
$5 d$, chorda, entire, 25 diam. Laid July 10, opened July 20,1852 .

Fig. 5c. Chorda, near the anterior end, 500 diam. The same as fig. 3.

Fig. 6. Blood corpuscles from the vena terminalis, 40 diam. Laid July 18, opened July 28, 1852.

Fig. 7. Blood corpuscles; $a, b$, in a natural state; $c$ to $j$, altered by water; $a$ to $i, 500$ diam. $j, 1100$ diam. About 18 days old.

Fig. 8. Blood corpuscles from an adult; $a, b, c, d, e$, in a natural state; $h$, altered by water, and dried; the others in water; $a, b, c, 1100$ diam.; the others, 500 diam.

Fig. 9, 10, 11, 12. Blood corpuscles; fig. 9, from the yolk; fig. 10 , from the allantois; $a, b$, end views; $c, c^{\prime}$, side views, showing the thickness; 500 diam.; fig. 11, from the body: $a, 1100$ diam., as thick as broad; $b$, the same as $a, 500$ diam.; $c, d$, end views; $e$, with two mesoblasts ; 500 diam.; fig. 12, flat corpuscles from the allantois: $a, 1100$ diam.; b, 500 diam. Period of laying unknown, opened Aug. 25,1852 .

Fig. 13 to $13 \mathrm{c}$. Blood corpuscles, 500 diam.; fig. 13, flattened against each other; fig. 13a, a corpuscle squeezing between two others; fig. 13b, drawn out; fig. 13c, in a natural state, the left one seen edgewise, the middle one, from the side, the right one seen endwise. Laid June 12, opened Aug. 16, 1855.

Fig. 14. Bloodressel from the pia mater, 500 diam.; $a, b$, mesoblasts in profile. Hatched in Oct. 1855.

Fig. 15. Cells of the olfactory nerve, close to the Schneiderian membrane, 500 diam.; $a, b$, nearly perfect nerve tubules. Hatched in Oct. 1855.

Fig. 16. From the hemisphere of the brain, section in profile, 500 diam.; $a$, outer stratum; $b, c$, inner strata of the cells of the pia mater; $d$, blood corpuscles; $e$, cells of the hemisphere; the same as fig. 15.

Fig. 16b. Cells at the surface of the hemisphere in profile; fig. $16 \mathrm{c}$, cells of the hemisphere from the interior; $a$, single cells; $b, b^{\prime}, c, c^{\prime}$, altered by water; $b$, and $c$, the same cell seen from two different points of view, and magnified 1100 diam.; the others, 500 diam. Period of laying unknown, opened Sept. 6, 1852 .

Fig. 17, 17a, 17b. Cells of the olfactory nerve, just before the olfactory lobe; fig. 17 , cells at various depths; fig. $17 \mathrm{a}$, at one focus, the surface of the cells; fig. 17b, a little deeper, so as to show the thickness of the walls; 500 diam.; the same as fig. 15.

Fig. 18. Cells of the olfactory lobe; $\alpha$, caudate cell, 500 diam. ; the same as fig. $16 \mathrm{~b}$; fig. $18 \mathrm{a}$, cells of the pia mater of fig. $18 ; 500$ diam.

Fig. 19. Cells of the Schneiderian membrane; $a$, in a nat- ural state; 19, altered by water; $b$, single cells of 19 500 diam.; the same as fig. $16 \mathrm{~b}$.

Fig. 20. Cells of the medulla oblongata ; $a, a$, caudate cells $b$, nearly filled by the mesoblast; 500 diam.; the same a fig. $16 \mathrm{~b}$.

Fig. 21. Cells from the spinal cord, just behind the medula oblongata, 500 diam.; the same as fig. $16 \mathrm{~b}$.

Fig. 22. Chorda dorsalis, 500 diam. Laid July 18, opened July $27,1852$.

Fig. 23. Passage of muscles into cartilage, from the dorsal arch ; $a, b$, muscle; $c$, cartilage cells; 500 diam. Perior of laying unknown, opened Aug. 25, 1852.

Fig. 24. Muscular fibre macerated in water; $a$, transverse section; 500 diam.; the same as fig. 25.

Fig. 25. Muscular fibre from the foreleg; $a$, fibre; $l$, beaded fibrills; 800 diam.; the same as fig. $16 \mathrm{~b}$, etc.

Fig. 26. Tendinous fibrill $;$ f fig. $26 \mathrm{a}$, in a contracted state; 500 diam. ; the same as fig. $16 \mathrm{~b}$.

Fig. 27. Muscular fibre from the upper retractor muscles of the head, 800 diam.; fig. $27 \mathrm{a}$, a beaded fibril, 1100 diam. Laid June 21, opened Oct. 19, 1855. No fig. 28. Fig. 29. Cells of the gall cyst, in profile; $a$, outer surface; $b$, single cell; fig. 29a, surface view; 500 diam. Period of laying unknown. Just hatched.

Fig. 30. Cells of the ovary; 500 diam. Period of laying unknown. Just hatched.

Fig. 31. Cells of the liver; $a$, group; $b, b$, single cells; 500 diam. Period of laying unknown. Just hatched.

Fig. 32. Liver cells; $a$, single cells; 32 , a group, 500 diam.; $b, c$, in water, 500 diam.; $b^{\prime}, c^{\prime}, 1100$ diam.; the same as fig. $16 \mathrm{~b}$.

Fig. 33. Contents of the gall cyst, 500 diam. Period of laying unknown. Just hatehed.

Fig. 34. Contents of the gall cyst, 500 diam. Laid June 21 , opened Oct. 17,$1855 ; a$ to $h$, blood corpuscles, in various stages of development; $i$, decomposing globules.

Fig. 35. First frecal discharge, 36 hours after hatching, 500 diam:; fig. $35 \mathrm{a}$, erystals of uric acid in the frees, color greenish-yellow, 800 diam.; $a, b, c, d, e, f$, various combinations of crystals.

\section{PLATE XX.}

[Drawa from nature, by II. J. Clark.]

All the figures are from Chelydra serpentina.

Fig. 1, 1a, 1b. Urinifurous tube; fig. 1, seen endwise; fig. $1 \mathrm{a}$, seen at the bend; fig. $1 \mathrm{~b}$, at the side; 500 diam. Period of laying unknown, opened Aug. 31, 1853 
Fig. 2. Malpighian body from the kidney, 500 diam.; $a$, wall of uriniferous tube ; $a^{\prime}$, its cavity; $a^{\prime \prime}$, glomerule; $b$, bloodvessel, artery"? Laid June 12, opened $\Lambda$ ug. 13, 1855.

Fig. 3. Windpipe, 500 diam.; $a$, fibrous connective tissue; $b, c$, ring of cartilare; $b$, central cells; $c$, cells at the edge. Period of laying unknown. Hatched in Oct.

Fig. 4. Portion of the lung, 250 diam.; $a$, outer wall; $a^{\prime}, a^{\prime}$, partitions; $b, b$, bloodressels; $c$, interior wall of the partitions; $c^{\prime \prime}$, incipient partition in profile ; $e$, mucous membrane ; $e^{\prime}, e^{\prime}$, mucous membrane of an incipient partition; $f$, lateral and downward projection of the larger partitions; fig. $4 a, a$, surface of the lung; $b$, bloodvessel; $d$, incomplete large partition; 250 diam. Laid June 18, opened Sept. 3, 1855.

Fig. 5. End of the lung, showing the pigment cells following the courses of the bloodvessels, 25 diam. Period of laying unknown, opened Sept. 2, 1852.

Fig. 6. Cartilage cells from the windpipe of fig. $5 ; 500$ diam.

Fig. 7. $\Lambda$ bronchiole of the lung surrounded by bloodressels, 500 diam. Period of laying unknown, opened Aug. 28,1852 .

Fig. 8. Pigment cells from the surface of the lung, 500 diam.; the same as fig. 7 .

Fig. 9. $\Lambda$ bronchiole of fig. $5 ; a$, cells of the mucous membrane; fig. $9 a$, the same, seen through the round cells on the surface of the lung; 500 diam.

Fig. 10. Portion of fig. $5 ; a$, bronchioles; $b$, musculofibrous partitions; $c$, bloodvessels; 300 diam.

Fig. 11. Portion of fig. 5 still more magnified, 500 diam.; $a$, cells of the mucous membrane; $b$, a partition nearest to the surface of the lung; $b^{\prime}$, a partition lying deeper.

Fig. 12. Lnd of the lung when very young, 250 diam.; $a$, outer wall ; $b$, mucous membrane. Laid June 21, opened July $31,1855$.

Fig. 13, and 13a. Cells of the mucous membrane of the urinary bladder, 500 diam.

Fig. 14. Cells of the interior muscular layers of the urinary bladder (fig. 13 and 13a); fig. 14a, outermost cells of the museular layers, 800 diam.

Fig. 15. Inner ends of the cells (fig. 13, 13a) of the mucous membrane, 500 diam.

Fig. 16. Mesh of muscular filses of the urinary bladder, 40 diam.

Fig. 17. Contents of the bladder, 500 diam.

Fig. 13 to 17 are drawn from the same specimen, just hatched, the period of laying of which was unknown.

Fig. 18. Cells of the epidermis on the right, and the pigment layer on the left; from beneath, 500 diam. Laid June 21, opened Oct. 17, 1855.

\section{PLATE XXI.}

[Urawn from nature, by II. J. Clark.]

Fig. 22, 23, 24, 25, 26, 30, from Chrysemys picta; fig. 27 , and 28, from Nanemys guttata; the others from Chelydra serpentina.

Fig. 1. Profile of the inner cells of the mucous membrane of the csophargus, 500 diam.

Fig. 2. Columnar cells of the mucous membrane of the œsophagus, 500 diam.

Fig. 3. Surface of the cells of the mucous membrane of the stomach, 800 diam.

Fig. 4. Single cells of fig. 3, 800 diam.; fig. 1 to 4 , from the same animal; age not ascertained.

Fig. 5. Section of the mucous membrane of the oesophagus, 500 diam.; $a$, inner cells; $b$, columnar cells. Period of laying unknown, opened Aug. 30, 1852.

Fig. 6. Inner surface of the æesoplaagus, 500 diam.; the same as fig. 5 .

Fig. 7. Single cells of fig. $5, a, 500$ diam.

Fig. 8. Group of cells from fig. 6 , in water, 500 diam.

Fig. 9. Profile outline of fig. 8 , to show the relations of the two strata of cells, 500 diam.

Fin. 10. Epithelial cells at the base of the tongue, 500 diam. Period of laying unknown. Just hatched.

Fig. 11. Transverse section of a fold of the csophagus, 500 diam.; $a$, inner cells; $b$, columnar cells ; $c$, round cells; $d$, inner muscular coat; the same as fig. 10 .

Fig. 12. Surface cells of osophagus, with vibratile cilia, 800 diam.; the same as fig. 10.

Fig. 13. Very elongated cells from the muscular coat of the œsophagus, 800 diam. ; fig. 13a, a single cell of fig. 13, 1100 diam.; the same as fig. 10 .

Fig. 14. Inner surface of the stomach, 300 diam. ; $a$, entrance to the glands; $b$, outlines of the glands; fig. $14 a$, open aperture of one of the glands, 500 diam.; fig. $14 \mathrm{~b}$, the same shut, 500 diam. Period of laying unknown, opened Sept. 9, 1852.

Fig. 14c. Profile of the epithelial cells of the stomach, 500 diam.; fig. $14 d$, and 14 e, surface riew of fig. $14 c, 500$ diam.; fig. $14 f$, and $14 \mathrm{~g}$, the same as fig. $14 d$, altered by water; $14 \mathrm{~g}, a$, a single cell with its lateral mesoblast, 500 diam. Periol of laying unknown, opened Aug. 30, 1852.

Fig. 15. Surface of the stomach, looking into the glands, 300 diam.; fig. $15 \mathrm{a}$, mouth of a gland, 500 diam.; $\alpha$, epithelial cells of the stomach; $b$, mouth; fig. 16 , lower half of a gland, outside view; fig. 16a, transwerse section of fig. 16 ; fig. $16 \mathrm{~b}$, longitudinal section of fig. 16 ; 500 diam. ; the same as fig. 1 to 5 . 
Fig. 17. $\Lambda$ gland of the stomach in profile; $\alpha$, surface of the stomach; $b$ above, openiug of the gland; $b$ in the middle and below, its cavity; $c, d$, its walls; 500 diam. Just hatched.

Fig. 18. Section across the thick intestine, 500 diam.; $a$, $a^{\prime}$, columns of cells of the mucous membrane; $b$, stratum of round cells; $c$, inner, and $d$, outer muscular coats; $e$, thin membrane inclosing the whole intestine; fig. 18a, the same as fig. 18, $a$, and $a^{\prime}$, being seen in one focus; fig. $18 \mathrm{~b}$, two columns of cells separated so as to disclose the mesoblasts; fig. 18c, $a, b$, cells of fig. 18 , segmenting; the same as fig. 17 .

Fig. 19. Section across the long intestine, 500 diam.; $a, b$, $c, d, e$, as in fig. 18 ; the same as fig. 17.

Fig. 20. One of the claws, 25 diam.; $a$, horny sheath; $b$, interior cells of the claw; $b^{\prime}$, cells at the base of the claw; fig. 20a, cells of the horny sheath, 500 diam., in profile; fig. $20 \mathrm{~b}$, the same as fig. $20 \mathrm{a}$, view perpendicular to the surface; fig. 20c, cells at the end of the borny sheath, 500 diam.; fig. 20d, cells of the skin of the next joint, just beneath the sheath, 500 diam. Period of laying unknown, opened Ang. 25, 1852.

Fig. 21. The bone of the claw, 40 diam.; fig. 21 a, cells at the surface of fig. 21, 500 diam.; the same as fig. 20.

Fig. 22. Cartilaginous matrix of a bone of the toe, 500 diam.; fig. 22a, separate cells of fig. 22. Period of laying unknown, opened in Septo, 1852.

Fig. 23. Cells at the surface of the foot, 500 diam; the same as fig. 22.

Fig. 24. Piece of the bone of the toe, 500 diam.; the same as fig. 22.

Fig. 25. Interior cells of the foot, 500 diam, the same as fig. 22.

Fig. 26. Cells of the shield, 500 diam.; the same as fig. 22.

Fig. 27. Cells of the ear, 300 diam. Laid July 18, opened July 28, 1852.

Fig. 28. Cells of the eye, 300 diam.; $a$, cells of the retina; $b$, skin of the head; $c$, passage-way to the brain; the same as fig. 27.

Fig. 29. Crystalline lens taken out of the eye with the surrounding membranes, 40 diam. ; $a$, membrana pupillaris; $b$, pigment layer on the zonula Zinnii (c). Period of laying unknown, opened in Aug. 1852.

Fig. 30. Portion of the crystalline lens, 300 diam.; $a$, the converging ends of the fibres $b$; the same as fig. 22.

Fig. 31. The converging ends of the fibres of the crystalline lens, 300 diam。; the same as fig. 29.

Fig. 32. Part of a section throumh the centre, from front to back, of the crystalline lens; $a$, the ends of the fibres, 40 diam.; fig. 32a, $a, b, c, d$, four fibres of fig. 32, 500 diam.; fig. $32 \mathrm{~b}$, large globules interwixed with the fibres, 500 diam.; fig. 32c, portion of a fibre tristed so as to show a combined view of the edge and of the flat side, 500 diam.; fig. 32 d, ends of fibres swollen by water, 500 diam. Period of laying unknown, opened Sept. 9, 1852.

Fig. 33. Section of the thickness of the retina at a point midway between the front and back of the eye, 500 diam.; $b, c$, cells of the inner or first layer; $d$, second layer; $e, f$, third layer; $g$, fourth layer; $h, i$, membrana Jacobi; $i^{\prime}$, outer prolongations of $h$ and $i$; fig. $33 \mathrm{a}$, cells of the membrana Jacobi, with their yellow and orange mesoblasts, 1100 diam. Hatched Oct. 1855.

Fig. 34. Profile of the mucous membrane of the thick intestine, 500 diam.; fig. $34 a$, surface view of fig. 34, altered by water; $b$, a group; $c$, single cell; 500 diam.; the same as fig. 15. These tro figures are between fig. 14 and fig. 15 , and erroneously marked 20 and $20 \mathrm{a}$.

\section{PLATE XXII.}

[Drawn from nature, by H. J. Clark.]

Fig. 1, from Thalassochelys Caouana ; fig. 7, from Trachemys serrata; all the others from Chelydra serpentina.

Fig. 1. Obliquely transverse section of a rib, 500 diam.; $a$, innermost cartilage cells; $a^{1}, a^{3}, a^{3}$, successively nearer to the surface of the bone; $b$, innermost layer of the fibrous layer next to the cartilage cells; $b, c, d, e, f, g$, successirely nearer to the surface of the bone; $h$, corium; $g^{1}$, granular, hardened fibrillx of the outer layer of the bone: $l^{1}$, similar soft fibrilla of the corium; fig. 1a, a single cartilage cell, 800 diam.; $a$, parietes of the blastematous carity; $b$, cell wall shrunk; $c$, mesoblast; fig. $1 \mathrm{~b}$, the same as fig. 1a, 1100 diam. Just hatched.

Fig. 2. Transrerse section of a rib; the letters are the same as in fig. 1.

Fig. 3. Strip from the inferior face of a vertebra, 500 diam., view from within; $a$, fbres running in the direction of the length of the rertebra; $b$, more interior layer: $c$, still deeper; $d$, innermost layer; fig. $3 a$, granular fibrillæ of fig. $3, b, 800$ diam. Just hatehed.

Fig. 4. Transverse section of the interior portion of the ventral half side of a rertebra, 500 diam.; $a, b$, granular lining of cells ; $c$, ossification encroaching upon the cells; $d$, coarse granular ossification; $e$, mesoblast of the cells: the same as fig. 3 ; fig. 4a, $a, b$, crystals of nitrate of lime.

Fig. 5. Transwerse section of the cartilage cells of the coracoid bone, 500 diam.; $a$, blastema; $b$, cells. Just ready to hatch.

Fig. 6. Longitudinal section of fig. $5 ; a, b$, the same as in 
fig. 5 ; fig. $6 a$, in alcohol, $c$, the cell wall has shrunk; fig. $6 \mathrm{~b}, \mathrm{a}$ single blastematous cavity $(a) ; b$, the cell wall shrunk; $c$, the mesoblast; the same as fig. 5 .

Fig. 7. Part of a longitudinal section through the middle of the eye of an adult 'Trachemys serrata, 10 diam.; $a$, sclerotic portion of the conjunctiva; $a^{1}$, conjunctiva; $a^{3}$, fold where $a$ and $a^{2}$ join ; $b$, sclerotica; $c$, sclerotic squamula; $c^{2}$, cornea ; $c^{2}$, base of iris; $d$, pigment layer ; $e$, choroidea ; $e^{1}$, iris; $e^{2}$, posterior lining of the iris, or ciliary process $; e^{3}$, posterior border of the ciliary process; $f, f^{2}$, pigment layer lining the choroidca $(e) ; g$, membrana Jacobi; $g^{2}$, anterior border of $g ; h$, retina; $i^{7}$, anterior edge of $h ; i$, fibrous layer; $k$, membrana hyaloidea; $k^{1}$, prolongation of $k$ over the back of the crystalline lens $(l) ; h^{3}$, fold where $k$ recurves; $l$, crystalline lens; $m, m^{\prime}$, triple wall of the capsule of the lens; $n$, the membrana pupillaris; $n^{1}$, border of $n$.

Fig. 8. Longitudinal section through the middle of the left eye of a Turtle just hatched, about 10 diam. The optic nerve $\left(h^{1}\right)$ is introduced here out of place, to show its relation to the retina. The letters are the same as in fig. 7 , to which are added: $l^{2}$, continuation of the sclerotica orer the optic nerve; $d^{2}$, posterior termination of the pigment layer which covers the choroidea $(e) ; e^{4}$, (this letter is erroneously marked $e^{\prime}$ in the plate, near $h^{\prime}$, ) continuation of the choroidea (e) over the optic nerve, $h^{1}$; fig. $8 \mathrm{a}$, portion of fig. 8 , about 20 diam., to show more distinetly the different membranes and layers of the eye bulb. The letters are the same as in fig. 8 .

Fig. 9. Transverse section of the head through the eyes, 10 diam., date not noticed; $a$, musculo-cutaneous layer; $b$, corpora quadrigemina; $c$, eye; $c^{1}$, aqueous humor; $c^{2}$, crystalline lens; $d$, vitreous humor ; $d^{\prime}$, retina; $e$, anterior half of the orbit of the eye, empty; $b^{2}$, hemispheres; $l^{2}$, the separate edges of $b^{1}$.

\section{PLATE XXIII.}

[Drawn from nature, by II. J. Clark.]

All the figures are from Chelydra serpentina. Fig. 1, 1a, 2, $2 \mathrm{a}, 2 \mathrm{~b}, 2 \mathrm{c}, 2 \mathrm{~d}$, and 3 , are all lettered alike: $a$, hemispheres; $b$, corpora quadrigemina; $c$, olfactory bulb; $c^{\prime}$, Schneiderian membrane; $c^{\prime \prime}$, the same as $c^{\prime}$ cut across; $c^{\prime \prime \prime}$, septum marium; $d$, pineal gland; $e$, cerebellum; $e^{\prime}$, edge of the still open portion of the spinal tube $; f$, upper wall of the spinal tube $g$, vascular pia mater $; g^{\prime}$, choroid plexus over the medulla oblongata $(p) ; h$, the eyes; $i$, spinal tube; $k$, optic lobes; $h$, optic nerre; $l$, auditory nerve; $m$, opening on the inner face of the hemispheres; $n$, commissure of the hemispheres; $a$, floor of $b$, the socalled pons Varolii ; $o^{x}$, fourth rentricle; $p$, medulla oblongata; $p^{\prime}$, commissure of the optic lobe; $p^{\prime \prime}$, auterior end of the commissure of the optic lobe.

Fig. 1. View of the left side of the brain and part of the spinal tube, about 3 diam. Laid June 23, opened $A$ ug. 22,1855 ; fig. $1 \mathrm{a}$, the same as fig. 1 , a longitudinal me. dian section; alout 4 diam.

Fig. 2. Left side of the brain and part of the spinal tube, 3 diam. Laid June 12, opened Aug. 16, 1855. Fig. 2a, view from above of fig. $2 ; 3$ diam. From $c$ to $c^{\prime}$, the olfactory nerve and the Schneiderian membrane are raised up higher than is natural. Fig. $2 b$, longitudinal median section of fig. 2 and $2 a$; nearly 6 diam. (In this figure $p$ should be $k$, and $k$, just before it, should be $k^{\prime}$ ) Fig. 2c, transverse section of the Schneiderian membrane; 10 diam. Fig. 2d, longitudinal and horizontal section of the hemisphere, exposing the interior and the corpora striata $(r)$; $a$, walls of the hemispheres; $c$, olfactory lobe; $c^{\prime \prime}$, olfactory nerve. Fig. 2e, the choroid plexus taken out from the hemisphere, 20 diam. Fig. 2f, small tuft of fig. 2e. Fig. $2 \mathrm{~g}$, profile of fig. $2 \mathrm{f} ; s$, a single vessel from which several are budding. Fig. 2h, end of one of these vessels; $a$, inner wall, formed of long columnar cells; $b$, outer wall, formed of short and broad cells; the centre is full of blood corpuscles; 500 diam.

Fig. 3. Iongitudinal section of the brain and the skull, 5 diam.; 1 , designates the crest of the occipital bone; 2 , the base of the skull; 3 , the ethmoid ; 4 , the end of the skull; 5 , the end of the vomer; 6 , the sphenoid; 7 , the vertebræ of the neck; 8 , the cartilaginous upper maxillary; 9, the entrance to the nostrils. Laid June 12, opened Aug. 28, 1855.

Fig. 4 ; compare wood-cut 3, p. 576. Longitudinal section of the head of a 'Turtle just hatched; 5 diam. An alcoholic specimen was used on account of the hardening of the brain; $a$, entrance to the nasal cavity; $b$, nasal cavity around which the Schneiderian expands; $c$, olfactory nerve; $d$, olfactory lobe; $e$, hemisphere with an opening on the inner face next to the commissure for the passage of the bloodvessel, $\left(e^{\prime},\right)$ which expands in the interior into a vascular plexus in the form of a tuft; $f$, pineal gland, its superior or outer commissure $\left(f^{7}\right)$ cut through; $g$, corpus quadrigeminum, cut at the commissure so as to allow an interior view. The outlines of the surface of the right lobe may be seen in the distance under the rascular membrane $\left(g^{\prime}\right)$; $g^{\prime \prime}$, bloodressel of the enveloping membrane, (pia mater, ) which plunges between the corpora quadrigemina and the cerebellum $(k)$; the same passes backwards into the 
great plexus $\left(h^{\prime}\right)$ in the cerebellum; $h$, optic lobe, its commissure cut through, both at the front and hind side; $h^{\prime}$, optic nerve; $i$, anterior wall of the fourth ventricle cut through; $i$, point where the medulla oblongata suddenly narrows and passes into the spinal tube $(l) ; k$, cerebellum terminating suddenly behind, against the choroid plexus $\left(l^{\prime}\right) ; h^{\prime \prime}$, vascular membrane (pia mater) continuous from $l^{\prime}$ over the brain; $l$, spinal tube; the upper half of the tube suddenly thins out $\left(l^{\prime}\right)$ as it reaches the medulla oblongata; $m$, the partition between the eyes; $n$, the upper wall of the cranium; $n^{\prime}$, the ossified portion; $n^{\prime \prime}$, ethmoid bone; 0 , muscular layer, which passes within and upon the inner surface of the upper wall of the cranium; $o^{\prime}$, dorsal arch of the first vertebra cut through; $o^{\prime \prime}$, dorsal arch of the second rertebra cut through ; $p$, os dentatum, cut through the axis ; $p^{\prime}$, its ligamentous attachment to the base of the skull $(r) ; p^{\prime \prime}$, $p^{\prime \prime \prime}$, the atlas; $p^{\prime \prime \prime}$, the upper half of the ring; $p^{\prime \prime}$, the lower half; $q$, second vertebra; $r$, basal occipital bone; $r^{\prime}$, sphenoid bone; $r^{\prime \prime}$, vomer; $s$, fibrous layer of the roof of the mouth; $s$, interior portion of $s$, where it hangs down loosely, and is more open, network like; $t$, anterior commissure of the upper jart, quite hard from the considerable amount of ossification; $t^{\prime \prime}$, termination of the horny layer prolonged from the beak $\left(l^{\prime}\right) ; u$, fibro-muscular tongue; $u^{\prime}$, commissure of the lower jaw; this part is not yet ossified, but the darker part below is quite gritty with lime; $u^{\prime \prime}$, opening of the larynx $(v)$; the darker transverse lines are the tracheal rings; $u$, tongue bone, not yet ossified.

Fig. 4a; compare wood-cut 4, p. 576 . A brain like fig. 4, the olfactory and cerebral lobes cut open, and the right pineal gland and the right half of the corpora quadrigemina cut through more to the right than in fig. $4 ; 5$ diam.; $c$, tube of the olfactory nerve exposed; $d$, olfactory lobe with rery thick walis and a small cavity; $e$, carity of the cerebral lobe nearly filled by the choroid plexus; $e^{\prime}$, main ressel of the choroid plexus where it enters the cavity of $e ; f$, pineal gland; $g$, corpus quadrigeminum of the right side cut through, considerably to one side of its commissure, to show the very thick upper wall; $k^{\prime \prime}$, choroid plexus of the fourth ventricle partly cut away, to show the lamellx of which it is composed; $l$, the upper edge of the open medulla oblongata. For the other parts compare fig. 4 .

Fig. 5; compare wood-cut 5, p. 576. Transverse section through the anterior end of the medulla spinalis, the atlas, and a portion of the os dentatum, and also through the posterior end of the occipital crest; about 15 diam. Corresponds to the line $\mathbf{F}$, in w-c. 3, p. 576 ; compare also fig. 4 : $a, a^{\prime}$, medulla spinalis; $b$, narrow furrow along the upper surface of $a ; c$, medullary canal, with a ring of gray substance around it; $d$, pia mater; $d^{\prime}$, bloodvessel; $e_{\text {, }}$ arachnoid; $f$, dura mater; $g$, vessels from the dura mater filling the vertebral canal; $h$, cervical muscles; $i$ processus dentatus, from the second vertebra; $i$, the canal in the atlas for the passage of $i ; j$, atlas, the dark part still soft and gelatinoid, the dead white $(k, k)$ morc cartilaginous; $l$, a small portion of the atlas ossified; $m$, $m^{\prime}$, occipital crest; $m$, the yet cartilaginous part; $m^{\prime}$, part where a bony deposit has taken place; $n$, muscle running close to, and parallel with, the crest; 0 , dorsal muscles of the neck; $p$, musculus intertransversalis; $p^{\prime}$, musculus retractor capitis.

Fig. 6 ; compare wood-cut 6, p. 576. Transverse section through the posterior edge of the cerebellum, the choroid plexus over the fourth ventricle, the medulla oblongata and the lower jaw ; 5 diam. Corresponds to the line $\mathbf{E}$, in W-c. 3, p. 576 ; compare also fig. $4: a$, cerebellum, just in front of its posterior edge; $a^{\prime}$, the same in the distance, where it descends to join (at $a^{\prime \prime}$ ) the corpora quadrigemina; $b, b$, choroid plexus cut obliquely to the trend of its oblong mass, showing the lamellar structure; $c$, right, and $c^{\prime}$, left half of the medulla oblongata; $c^{\prime \prime}$, furrow (in $c, c^{\prime}$ ) which leads to the canal of the spinal tube; $c^{\prime \prime \prime}$, cavity of the fourth rentricle; $d$, pia mater; $d^{\prime}$, arachnoid; $d^{\prime \prime}$, dura mater; $e$, restibule exposed, and here and there cut across; $e^{\prime}$, tympanic carity; $f$, still cartilaginous cranium; $g$, muscles attached to $f ; h$, fibro-spongiform mesh between $g$ and $i$; $i$, membrane of the palate; $i^{\prime}$, fibro-muscular membrane of the floor of the mouth; $j$, windpipe; $k$, hyoid bone; $l$, left branch of the lower jaw; $m$, bloodvessels cut across; $n$, muscles; 0 , lateral muscles of the jaw ; $p$, muscles from the neck; $q$, deep fold of the skin cut across; $r$, dense fibrous corinm.

Fig. 7 ; compare rood-cut 7, p. 577. Transwerse section through the corpora quadrigemina, the third ventricle, the cochlea of the ear, the tympanic carity, and the lower jaw; 5 diam. Corresponds to the line D, in $\pi-c .3$, p. 576 ; compare also fig. 4 . This view is from the front, looking backwards. $a$, the right, and $a^{\prime}$, the left half of the corpora quadrigemina; $b$, the eavity of $a, a^{\prime}$, communicating through a narrow space $\left(b^{\prime}\right)$ with the fourth ventricle, $\left(b^{\prime \prime},\right)$ which has its commissure just before this point; $c$, the right, and $c^{\prime}$, the left fourth rentricle; $d$, inferior commissure of $c, c^{\prime}$, a portion of the fourth ventricle being cut aray to expose the origin of the auditory nerve, $\left(e^{\prime}\right)$ which expands $\left(e^{\prime \prime}\right)$ in the carity of the restibule; $f$, prolongation of the pia mater over the nerve 
$e^{\prime}$, and $f^{\prime}$, over its expansion; $g, a$ branch of the restibule cut across; $h, h^{\prime}$, the cartilarinous crunium; $i$, tympanic carity; $k$, pia mater; $k^{\prime}$, bloodvessels from $k$ plunging into the mass of the brain; $l$, dura mater; $m$, ressels of the median sinus; $n$, fibrous membrane of the palate; $n^{\prime}$, lateral sinus of the fibro-muscular membrane of the mouth; $o$, windpipe; $p$, os byoides; $q$, muscular bundles; $r$, adductor museles of the neek; $r^{\prime}$, muscles of the lower jaw ; $s$, bloodvessels cut across; $t$, dense white fibrous corium; $u$, epidermis very much wrinkled.

Fig. 8; compare wood-cut 8, p. 577. Transverse section through the hemispheres, the optic lobe, and the lower jaw, just behind the opening of the windpipe; 5 diam. Corresponds to the line $\mathrm{C}$, in w-c. 3 , p. 576 ; compare also fig. 4. View from before, looking backwards; $a$, left hemisphere, the rudimentary corpus striatum lies at the point where the letter is placed; $a^{\prime \prime}$, crura corcbri ; $b, b^{\prime}$, interior face of the hemispheres; $b$ is partly cut away to expose the bloodvessel $\left(c^{\prime}\right)$ going to the choroid plexus, $(d$,$) which enters by the foramen at this point; c$, bloodressel which enters at $c^{\prime} ; d$, choroid plexus; $e$, third ventricle in the distance; $f, f$, optic lobes; $g$, inferior commissure of $f$ and $f^{\gamma} ; h$, parictal bone of the skull; $h^{\prime}$, frontal bone; $i$, sphenoid bone; $j$, cavity of the mouth; $k$, fibro-muscular layer of the floor of the mouth; $k^{\prime}$, roof of the mouth; $l$, windpipe; $m$, middle part of the hyoid bone; $n$, bloodressels; 0 , muscular bundles; $p$, $p^{\prime}, p^{\prime \prime}$, three parts of the lower jaw, $p$ still cartilaginous, the two others quite gritty with lime; $q$, filbrous corium.

Fig. 9 ; compare wood-cut 9, p. 577. The same section as fig. 8 , looking forward on the opposite side of the eut toward the olfactory lobes; 5 diam. ; $l^{\prime \prime}$, open communication between the hemispheres; $d^{\prime \prime}$, narrow passage in the olfactory lobe in the distance; $e^{\prime}$, anterior commissure of the optic lobes. The other letters as in fig. 8 .

Fig. 10; compare wood-cut 10, p. 577. Transverse section through the anterior end of the olfactory lobe and a portion of the surrounding tissues, seen from behind; 15 diam. Corresponds to the line $B$, in $w-c .3, p$. 676 ; compare also fig. $4: a$, the right olfactory lobe, marked by concentric layers of alternately white and gray substance, the white being much thicker than the gray; $b$, ventricle in the centre of the lobe; $c$, the rascular pia mater; $d$, arachnoid membrane, or network of ressels counecting the pia mater (c) to the dura mater $\left(d^{\prime}\right)$; $e$, interorbital septum ; $f$, frontal bone; $g$, fabrous corium; $h$, layer of pigment under $i$; $i$, the epidermis.

Fig. 11; compare wood-cut 11, p. 557. Transwerse section through the nasal cavity, seen from behind; 5 diam. Corresponds to the line $\Lambda$, in w-c. $3,11.576$; comprare also fig. 4: a, right Schneiderian membrane; that part which is below the palate bone $(f)$ is not seen in the longitudinal section, (fig. 4, ) which is made through the midule line of the head; $b$, septum narium; $U^{\prime}$, the irregular dotted line next to $a$ indicates a dense layer of black pigment; $c$, frontal bone; $d$, ethmoid; $d^{\prime \prime}$, upper edge of the intermaxillary bone, os incisivum; $e$, corium; $f$, vomer; $g$, palate; $h$, inner edge of the horny layer of the mandible, where it mects the mucous membrane (i) of the palate $(g)$.

\section{P'LATE XXIV.}

[Fig. 7, 7a, 9, 9a, 15, from nature, by A. Sonrel; the others by H. J. Clark.]

Fig. 8 and 14 are from Nanemys guttata; the others from Chelydra serpentina.

Fig. 1, 1a, 2, 2a, 3, 3a, 4, 5, 7, 7a, 8, 9, 9a, 11, 12, 13, 13a, 14, 15 , are all lettered in the same manner: $a$, amnios; $a^{2}$, caudal hood; $e$, edge of the channel of the spinal marrow; $e^{3}$, edge of the open part of the brain; $e^{3}$, brain closed over; $e^{5}$, constriction between the corpora quadrigemina and the optic lobes; $f$, vertebra; $f^{1}$, vertebral layer; $f^{2}$, lower edge of $f^{\prime} ; f^{3}$, lower edge of $f^{1} ; f^{4}$, upper edge of $f ; h^{1}$, aortic bulb; $h^{3}$, auricle ; $h^{4}$, ventricle; $i$, vena afferens; $i^{3}$, abdominal veins; $i^{5}$, eephalic reins; $j$, cephalic artery; $j$, dorsal artery; $k$, the whole eye, or the outer layer of the retina; $h^{\prime}$, the inner infolded layer; $l^{2}$, passage to the brain; $l^{3}$, crystalline lens; $l^{4}$, point where the inner wall $\left(k^{1}\right)$ folds upon the outer $(k)$; $l$, ear ; $m$, branchial fissures; $n$, intestino-subsidiary layer; $n^{2}$, stomach $; n^{4}$, œsophagus; $n^{5}$, anus; $n^{6}$, allantois ; 0 , edge of the abdominal aperture; $p$, musculo-cutaneous layer; $r$, liver; $t$, windpipe; $t$, lungs; $v$, nostrils; $w$, fore legs; $w^{1}$, hind legs; $x$, mouth; 1 , outer wall of the lungs; 1 ', outer wall of the esophagus behind the lungs; 1 ", outer wall of the oesophagus before the lungs; 1 'll, outer wall of the windpipe; 2 , mucous membrane of the lungs; 2 ', mucous membrane of the œsophagus belind the lungs; 2 ", mucous membrane of the csophagus before the lungs; 2 'I', mucous membrane of the windpipe; 3 , opening of the windpipe; 5 , open communication between the widpipe and the osophagus; 6, part of the trachea of the right lung; 7 , a broncliole trending transversely to the broad face of the lung.

Fig. 1. The lungs, and part of the esophagus, from below, 40 diam., date not ascertained; fig. 1a, interior walls of fig. $1 ; 250$ diam.

Fig. 2. Lungs and stomach, from below, about 5 diam.; laid 
June 21 , opened July 31,1855 ; fig. 2a, a lung from fig. 2, 40 diam.

Fig. 3. Lungs and windpipe, from below, slightly magnified; fig. $3 a$, the same as fig. 3 , one lung is turned so as to show the broad side, 40 diam.; laid June 23 , opened July 30,1855 .

Fig. 4. Left lung and the windpipe, in profile, 25 diam.; laid June 12, opened July 29, 1855.

Fig. 5. Left lung, the side next to the œsophagus, 25 diam.; laid June 23, opened Aug. 7, 1855.

Fig. 6. Part of a trachea close to the lung, 40 diam.; period of laying unknown, opened Sept. 2, 1852.

Fig. 7. Left side of the head and shoulders, 25 diam. ; period of laying unknown, opened July 30,1852 ; fig. $7 \mathrm{a}$, head of fig. 7 , seen from the end.

Fig. 8. The right eye, 40 diam.; laid June 22, opened July 22, 1852 .

Fig. 9 and $9 \mathrm{a}, 25$ diam.; period of laying unknown, opened Aug. 7, 1852. Fig. 9a, head, heart, and shoulders from below; fig. 9 , region of the heart of fig. $9 \mathrm{a}$, the right side. (In this figure, $i^{3}$ should be $j^{3}$, and $j^{3}$ should be $i^{3}$.)

Fig. 10, 10a, 10b. The heart, 5 diam.; fig. 10, the ventral face; fig. 10a, the dorsal face; fig. $10 \mathrm{~b}$, the ventral face, the rentricle $\left(h^{4}\right)$ cut open. In all three figures, $h^{1}, h^{1}$, indicates the pulmonary arteries; $h^{3}, h^{3}$, the auricles; $h^{4}$, the ventricle; $p a$, the left aorta; the double vessel without letters is the right aorta; vo, valvular opening betreen the auricles and rentricle; $v l$, valves of $v o$; laid June 18, opened Sept. 3, 1855.

Fig. 11. The head, from below to show the mouth, 3 diam. ; laid June 21, opened Aug. 8, 1855.

Fig. 12. The head of fig. 9a cut off and seen from behind, about 5 diam.

Fig. 13. Posterior end of Pl. 12, fig. 1, from above, 250 diam.; fig. 13a, surface of fig. 13.

Fig. 14. Posterior end of the left side of the body, 25 diam., seen on dark ground; laid July 14, opened Aug. 25, 1852.

Fig. 15. Posterior end of the left side of the body, 8 diam.; period of laying unknown, opened July 31,1852 .

\section{PLATE XXY.}

[Fig. 2, 8, 9, 10, from nature, by A. Sonrel; all the others by H. J. Clark.]

Fig. 9, Cistudo virginea; fig. 10, 11, Chrysemys picta ; fig. 12, Ozotheca ollorata; the others, Chelydra serpentina.

Fig. 1, 1a, 3, 3a, 9, 10, are lettered in the same manner: $b k$; beak; $h$, heart; $h^{\prime}$ aorta ; $n^{2}$, intestine ; $n^{3}$, stomach ; $n^{4}$, œsophagus; $n^{5}$, anus; $n^{6}$, urinary bladder, or in fig. 3 , allantois; $n^{7}$, remains of the neck of the yolk sac, or in fig. 3 and $3 a$, the whole yolk sac; oh, hyoid bone; $q$, Wolffian bodies; $r$, liver; $t$, windpipe; $t^{\prime}$, lungs; $v$, nostrils; $x$, lower jaw in fig. $1 \mathrm{a}$, opening of the mouth in figr. 9 and 10.

Fig. 1. Intestines, heart, and liver, seen from below, $2 f$ diam.; period of laying unknown, opened Aug. 30, 1851. Fig. 1a, intestine stretched out, nat. size; fig. $1 \mathrm{~b}$, junction of the oesophagus and intestine, cut open, seen from within, 5 diam.; fig. $1 \mathrm{c}$, piece of the long intestine laid open, 5 diam.; fig. $1 \mathrm{~d}$, piece of the thick intestine laid open, 5 diam.

Fig. 2. See below, after fig. 3 and $3 a$.

Fig. 3. Cut open from below, nat. size, just hatched; fig. $3 a$, cut open from above; the yolk sac $\left(n^{2}\right)$ has lost part of its contents, and shrunk; the dotted line indicates its outlines when uninjured.

Fig. 2, 4, 5, 6, 6a, 7, $7 \mathrm{a}$, are lettered in the same manner: $a$, the Wolffian bodies; $a^{\prime}$ in fig. $6 \mathrm{~b}$ is the same as $d ; b$, kidneys; $b^{\prime}$, posterior, and $l^{\prime \prime}$ anterior end of $b ; c$, duct of Wolftian body; $c^{\prime \prime}$, posterior opening of $c$; $d$, abdominal reins, see also $a^{\prime}$ above, in fig. $6 \mathrm{~b} ; e$, ureters of the kidneys; $f$, vas deferens of the testicle $(n) ; g$, anal pouches; $g^{\prime}$, aperture of $g ; h$, dorsal or abdominal artery, or in fig. 2 , the heart; $h^{\prime}$, arteries going to the hind legs; in fig. 2 it is the aorta; $i$, vena afferens; in fig. 6 and 7 , it is put by mistake for the vessels which go to the Malpighian corpuscles; $j^{4}, j^{4}$, forks of the omphalo-meseraic artery; $k$, intestine ; $l$, cloaca ; $m$, anus; $m^{\prime}$, opening of the intestine into the cloaca; $n$, genital organ; $n^{\prime}$, anterior prolongation of $n ; o$, allantois; $r$, liver; $u$, gall cyst.

Fig. 2. Heart, liver, Wolltian bodies, and kidneys, seen from the right side, 6 diam.; laid June 18, opened Sept. 4,1855 .

Fig. 4. Left Wolfian body in profile, 6 diam, ; laid June 12, opened Aug. 13, 1855.

Fig. 5. Piece of the left Wolfian body and kidney, 12 diam.; period of laying unknown, opened Aug. 31, 1852.

Fig. 6. Wolffian bodies and kidneys, from above, 6 diam.; fig. $6 \mathrm{a}$, the same as fig. 6 , from below ; fig. $6 \mathrm{~b}$, transverse section of fig. 6, and 6a; laid June 12, opened Aug. 29, 1855.

Fig. 7. Left Wolfian body and kidney, from below, 5 diam.; fig. $7 \mathrm{a}$, upper side of fig. 7 , the upper end is the anterior. Just hatchel.

Fig. 8. An embryo deprived of its envelopes, 2 diam.; the same as Pl. 15, fig. 4, 5, 5a, 6.

Fig. 9. Ilead of Pl. 18, fig. 10d, $3 \frac{1}{2}$ diam. 
Fig. 10. Head of Pl. 16, fig. 1; 4 diam.

Fig. 11. Left anterior foot, 25 diam.; periol of laying unknown.

Fig. 12. Left fore foot, from above, 10 diam.; period of laying unknown, opened Aug. 25, 1852.

Fig. 13. Brain of an adult Chelyula serpentina, from above; fig. $13 a$, the same as fig. 13 , seen in profile from the left side, slightly magnified; $c$, cerebellum; $h$, hemispheres; $i$, pituitary body; $n$, nostrils; sm, Schneiderian membrane; *, cut edge of the cartilaginous box surrounding the nasal cavity; on, olfactory nerves; ob, olfactory bulb; $p g$, pineal gland; $c q$, corpora quadrigemina; $p c$, plexus choroidous; no, optic nerve. A comparison of these two figures with those of Plate 23 will readily show the remarkable changes which the brain undergoes, even after its parts are well defined. A further comparison of these figures with those of Plates 12, 18a, and 24, will exhibit the whole range of the transformations of that organ, from its first appearance to its complete growth.

\section{PLATE XXVI, and XXVIL}

[Painted from nature, by J. Burkhardt.]

These two Plates exhibit the range of variations of the colors in one and the same species, and the successive changes in their distribution, as well as in the tints. It is the Emys rubriventris Auct., rugosa Shaw.

Pl. 26, fig. 1 to 4, represents a young Ptychemys rugosa in four different views, just hatched: fig. 5 to 7 , three different specimens, three or four years old, in profile, and from above, two thirds the natural size; fir. 8 , specimen five or six years old, reduced nearly one half, from below; fig. 9 , specimen about 7 years old, reduced one third; fig. 10 and 11, half grown specimens, about ten or tirelve years old, reduced one half.

Pl. 27, fig. 1 to 3. Full-grown sprecimens, reduced one half; fig. 4 , the eye, natural size; fig. 5 , front view of the head, reduced one half. 


\section{A P PENDIX AND ERRATA.}

WInLE the first volume was passing through the press, Dr. John E. Gray published a highly valuable and rery important contribution to the Natural History of the Testudinata, under the title of "Catalogue of Shield Rieptiles in the Collection of the British Museum," a copy of which I have lately received through the kindness of the author. This work is accompanied with a large number of remarkably well executed plates. A fer additional remarks upon the North American species are rendered necessary by its appearance.

Dr. Gray supposes that the hind lobe of the sternum may be movable in the females of all the species of genuine Testudo; and on that account he objects to the genus Chersus of Wagler. In the species of our Southern States, this is certainly not the case. I have seen several specimens lay eggs in my garden, the sternum of which was as immovable as that of the males.

Dr. Gray still unites the Chelydroidx and Cinosternoidx with the Emydoidx. I hold this to be an oversight of their true relations.

Under the generic name of Geoclemys, Gray unites three of our North American species, - which I have referred to the genera Glyptemys, Calemys, - and Nanemys, with three Asiatic species, which certainly are not very closely allied to them, if I may judge by his figure of Geoclemys Reevesii. These Asiatic species seem rather to belong to the genus Graptemys.

Contrary to the law of priority, Dr. Gray does not retain the name of Enys for the European Testudo Lutaria, but applies it nearly in the same way as Duméril and Bibron. Among his North American Emys, there are several which are only nominal species. I trust that the evidence I have adduced in the case of Ptychemys rugosa is sufficient to show, that, in some types, the color does not afford specific characters. This is the case, to the same extent, with Ptychemys concinna, which is mentioned under four different names by $\mathrm{Dr}$. Gray, - as Emys ornata, E. floridana, E. ansulifera, and Pseudemy's concinna. P'tychemys mobiliensis appears twice, - as Emys mobiliensis and as E. rentricosa. Ptychemys rugosa also appears twice, - as Enys rivulata and Pseudemys serrata. These facts are sufficient to show that Gray's genus Pseudemys is not well founded, as the two species which he himself had an opportunity of examining are only, varieties of other species which he refers to the old genus Emys. I am unable to refer his Emys venusta with certainty, as his figure, though very well drawn, does not exhibit the generic characters. I believe it, horever, to be one of the many rarieties of Ptychemys concinaa. The same remark applies to Emys callirostris. As stated p. 435, Emys Holbrookii Gray is Emys elegans $N_{e}$-WVied, a western species, which Gray was unable to refer. It belongs to the genus Trachemys.

Among the species requiring further examination, Gray mentions Enays reticularia or reticulata. As I have stated p. 441, this is a very distinct species, the type of a distinct genus, which I hare named Deirochelys. Emys mobiliensis is also a distinet species, belonging to the genus Ptychemys; and so in Emys labyrinthica, Emys Troostii comes nearest to Emys seabra, the Lmys serrata of the North American IIerpetology, but it is quite distinct, and belongs, with the latter, to the genus Trachemys.

I do not know Gray's Lmys olivacea, and doubt its being a North American species. I have, at least, never seen a Turtle like that in the United States. 
Gray is certainly mistaken in referring Emys oregonensis as synonyme to Chrysemys Bellii. Through the kindness of my friend, James II. Barnard, I have lately received a dozen living specimens of Chrysemys oregonensis, - or rather Nuttalii, as I would now call it, - and feel satisfied that it is distinct from Ch. 1Bellii, of which I have also seen a large number of living specimens. 'They differ not only in the pattern of their color, but they occupy also different tracts in the western Fauna. Chr. Nuttalii is a more northern species. This species is inscribed in our lierpetological works as Emys oregonensis; but as there is no cvidence of its occurrence in Oregon besides the alleged indication of Mr. Nuttal, who probably collected it on this side of the locky Mountains, where it is common in Mlinesota and westward to the junction of the Yellowstone and Missouri, I propose henceforth to call it Chryseny's Nuttalii, in commemoration of its distinguished discoverer.

Should the fossil Turtle described by I'omel as $1^{2}$ tychemys prove to constitute a natural genus, I propose, for our living species, to change the name of I'tyehemys to Nectemys.

I am glad to find that Dr. Gray has himself giren up the genus Onychotria, against the adoption of which I have raised objections, (p. 445.) It remains now to be ascertained whether the Mlexican three-toed Cistudo differs from that of our Southern States.

Gray describes two Cinosternums from North America as new species, founded upon young specimens. I confess my inability to distinguish them from Cin. pennsylvanicum; Cin. punctatum seems to me to be a young male, and Cin. Ilippocrepis.a young female, with a rather narrow hind lobe of the sternum, as is occasionally the case in Cin. pennsylvanicum. I have seen such large numbers of Cinosternum pennsylvanicum, that I feel little doubt upon this point. It is gratifying to me to see that Gray has arrived at the same conclusion as I have expressed (p. 428) respecting his Cin. oblongum. $\Lambda$ s to Cinosternum scorpioides, cruentatum, Doubledayi, and leucostomum, I refer simply to what I have already stated p. 426, note 1, and p. 429 .

The genus Aromochelys Gray embraces the two genera which I have distinguished as Ozotheca and Goniochelys. Ilis Aromochelys odorata is the same as my Ozotheca odorata, and his Aromochelys carinata is identical with my Goniochelys triquetra. Gray's genus Macroclemys is also identical with my Gypochelys.

The British Museum must be very indifferently provided with specimens of North American Trionychidx, since Dr. Gray has failed to perceive the generic and specific differences which exist among them, and which his extensive knowledge of this family would at once have pointed out to him. $\Lambda \mathrm{s}$ it is, he confounds the southern Trionyx ferox with the northern spinifur, and considers Trionyx muticus as a very doubtful species. I have shown (p. 398-405) that they belong to three different genera, and that three other species of this family, found in the rivers of North America, havo remained unnoticed to this day.

\section{VRRATA IN THE TEXT.}

Page 11, 2d line, instead of $\mathbf{I}$ sluall consider, real is to be considered.

- 18, note, $2 \mathrm{~d}$ col., line 10, instead of Naturwissenhaft, read Naturwissenschaft.

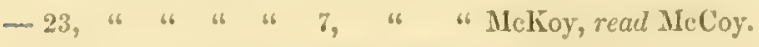

- 29, 30th line, instead of the studies of which, read whose studies.

$-34,18$ th " for has, read have.

$-35,30$ th " "is, read are.

$-41,15$ th " " insertiverous, read insectivorous.

$-43,12$ th "6 " amimals, read animals.

$-43,17$ th " "Betrachians read Batrachians.

- 52, note $2 \mathrm{~d}$ col., 8 th line, instead of to deny, read in denying. 
l'age 53, line 1, for Itunth, read Kunth.

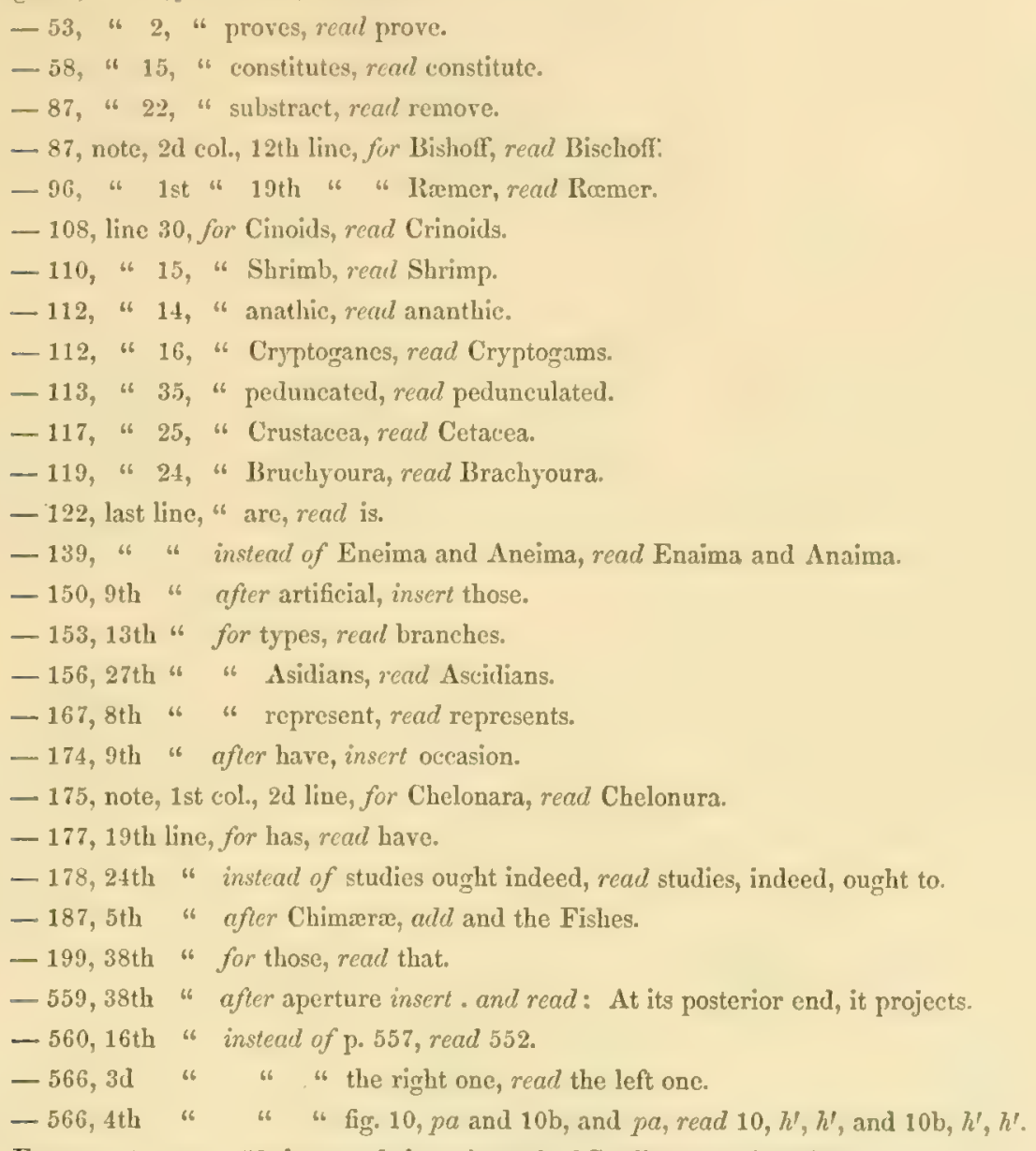

From p. 451 to p. 458 , here and there instead of Graffian read Graalian.

\section{IN TIIE PLATES.}

Plate 9e, fig. 5. The dots from the letter $e$ on the right should go to the next inner line, which runs close to $f^{2}$.

-11, " $3 ; a$, must be $d$, as in fig. 2 .

-12 , " $19 ; c^{\prime}$, must be $e^{\prime}$.

-12 , " $10 \mathrm{a} ; a^{4}$, must be $a^{\prime}$; correct the same, p. 511 , line 16.

$-18 a$; fig. 2 in profile, should be fig. 8.

- 18a, fig. 13, $h^{3}$, and $h^{1}$. From $h^{3}$, a dotted line should go to the dark hole in the nearest part of the heart, and from $h^{\prime}$ to the part of the aorta which is just below the longest branchial fissure, $(m$,$) that runs from the ear (b)$ downward. The letter $i$, nearest to the letter $h^{3}$, should be $i^{\prime}$.

- 18, fig 14. The first letter to the left of $k$ should be $e^{3}$, instead of $c^{\prime}$.

- 21, fig. 20, 20a, near fig. 14, should be fig. 34, and $34 a$.

$-22, " 8$; the letter $e^{\prime}$, near $h^{\prime}$, should be $e^{*}$.

- 23, " $2 \mathrm{~b} ; p^{\prime}$ should be $k$, and the $k$ just before it clranged to $k$ \%

- 24, " $9 \mathrm{a} ; i^{3}$ should be $j^{3}$, and $j^{2}$ should be $\imath^{3}$. 


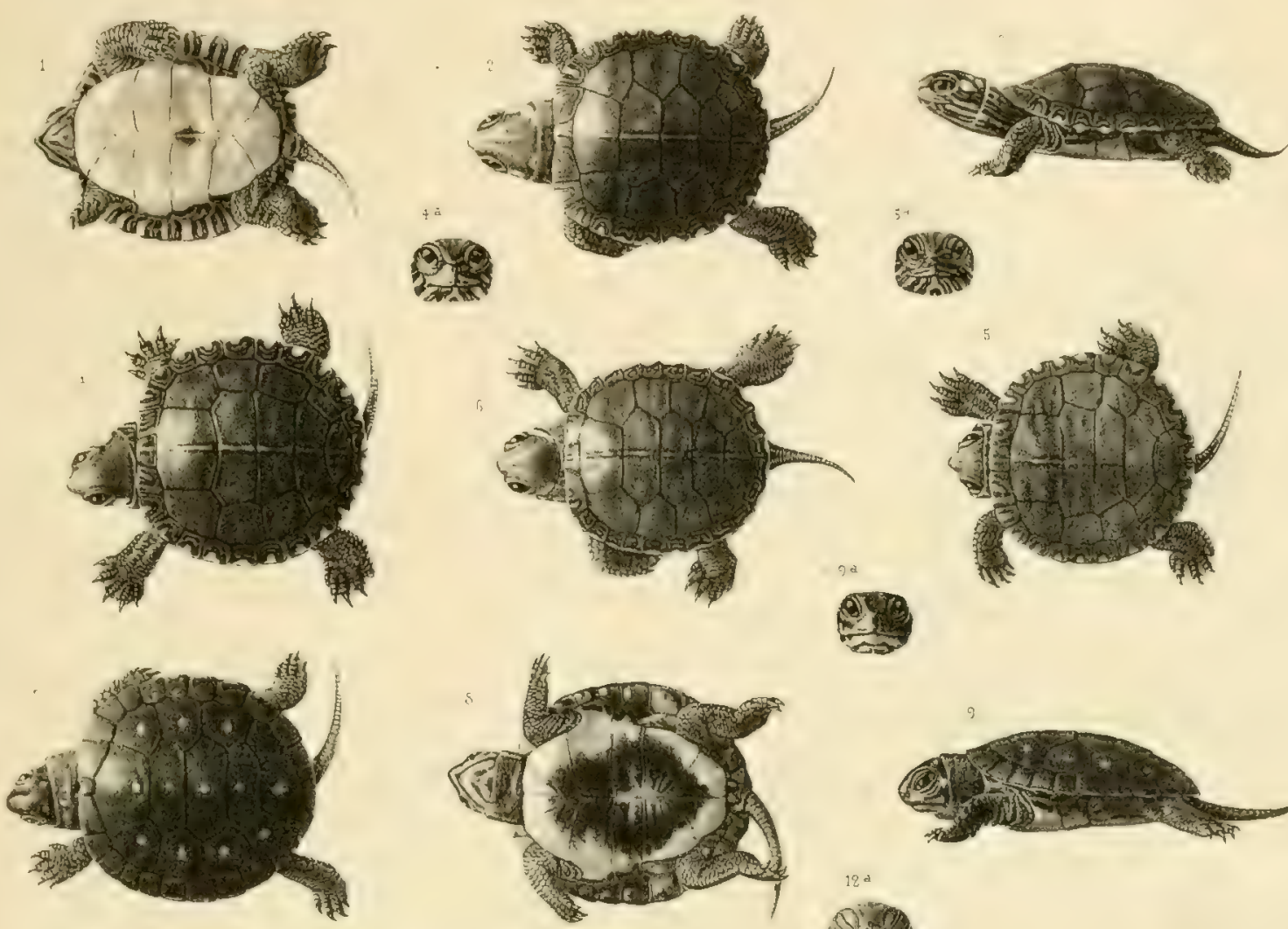

$\lim _{\infty}$
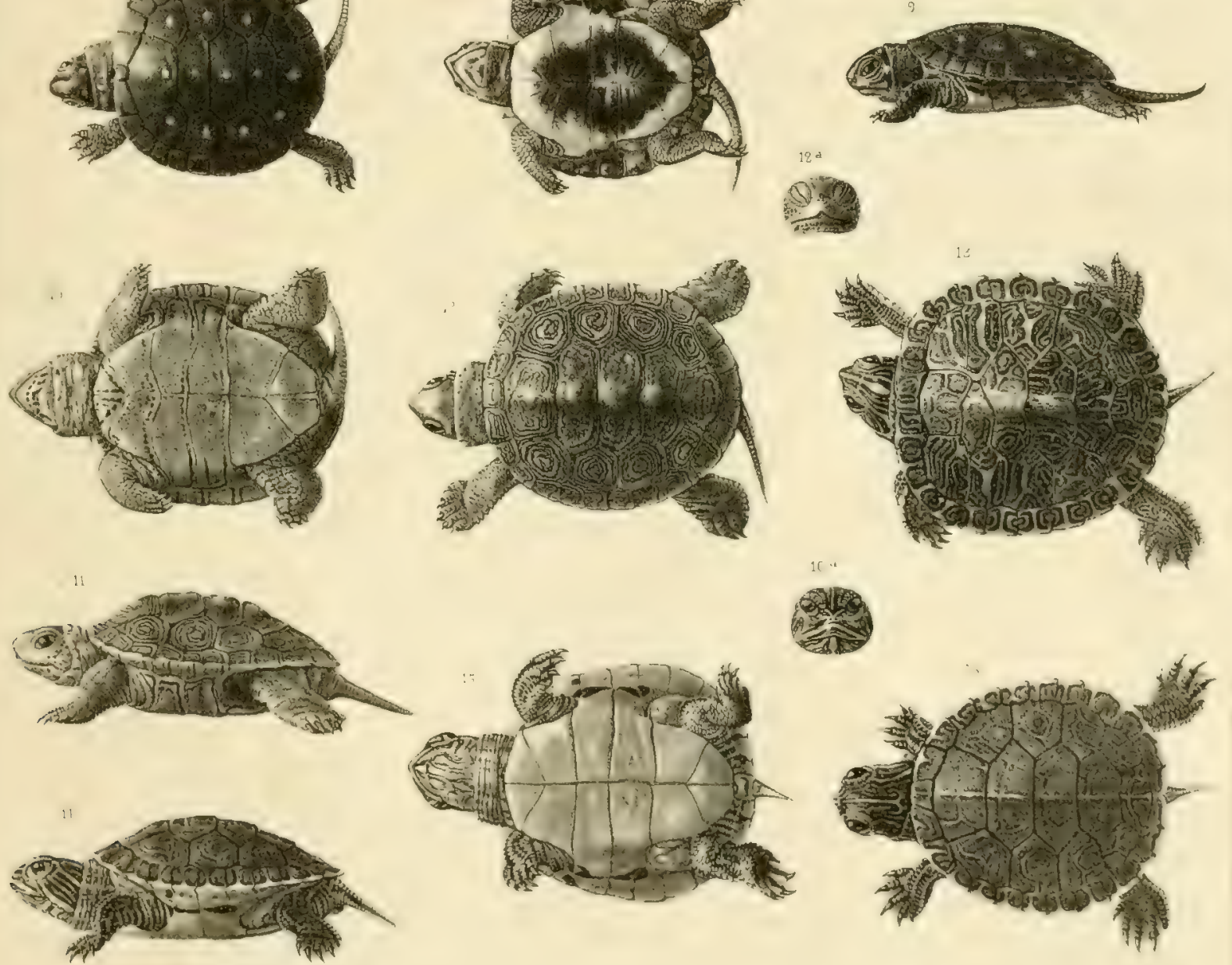


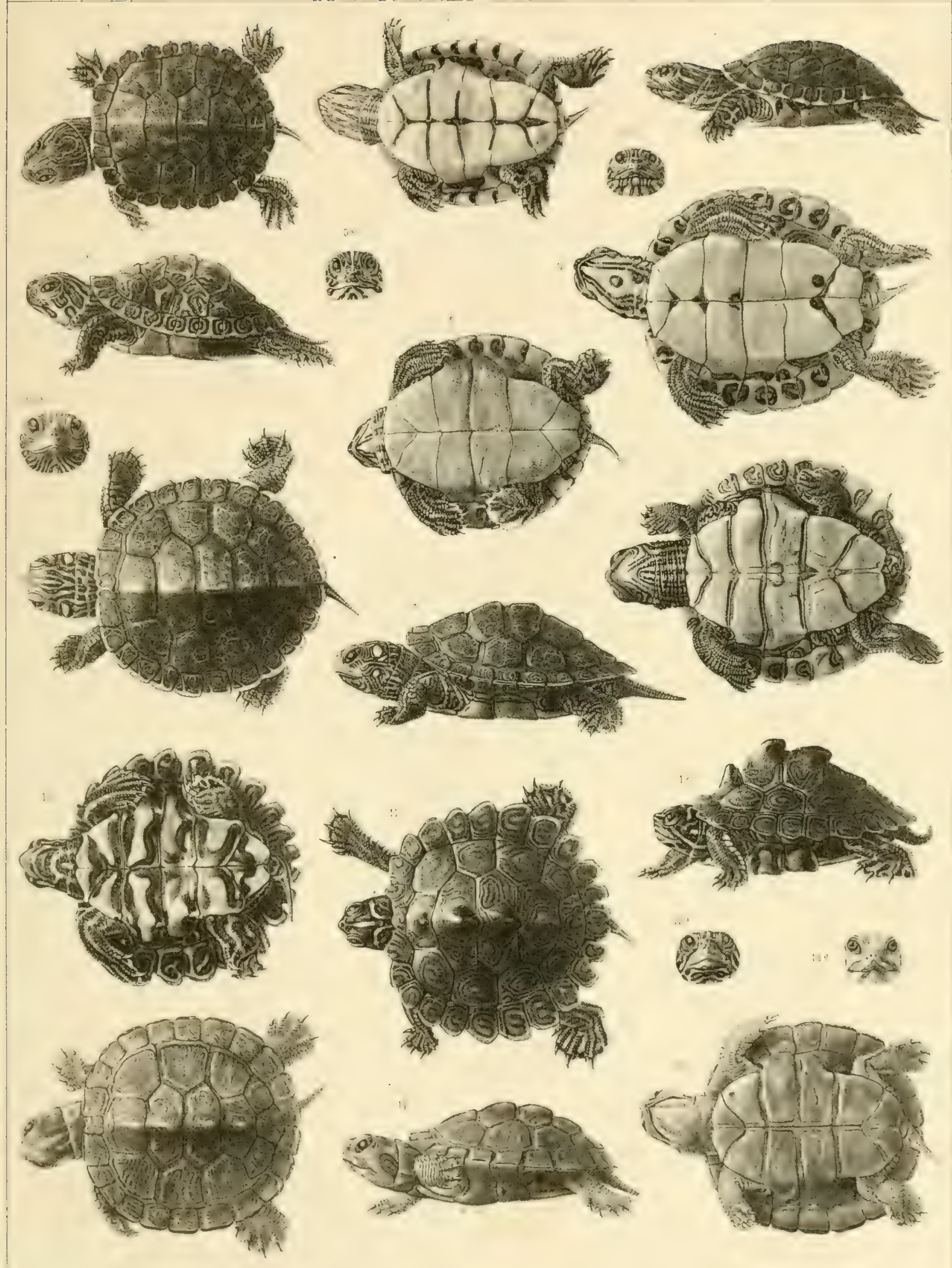



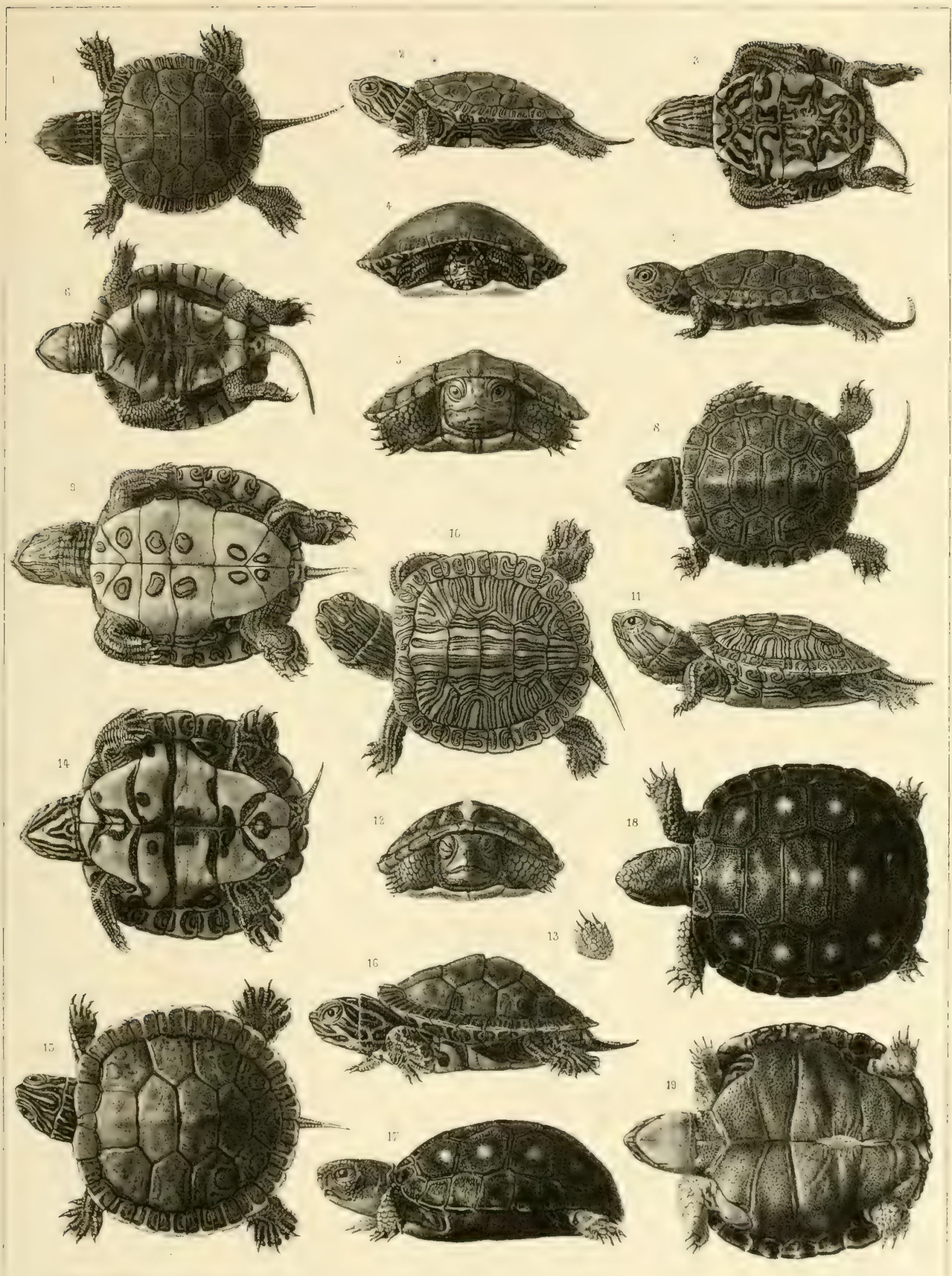





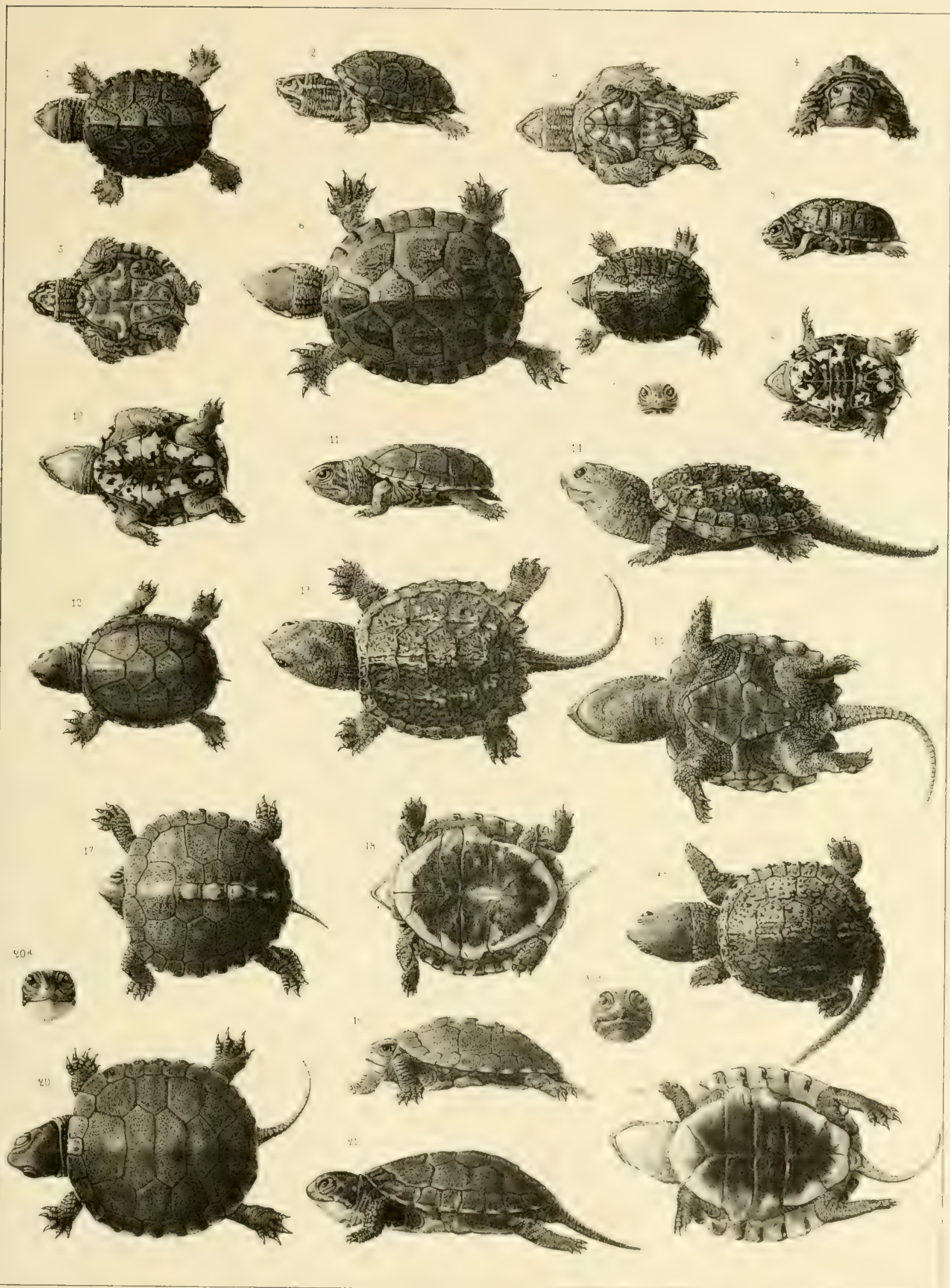

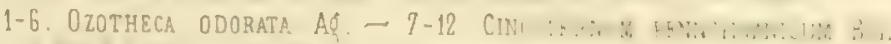





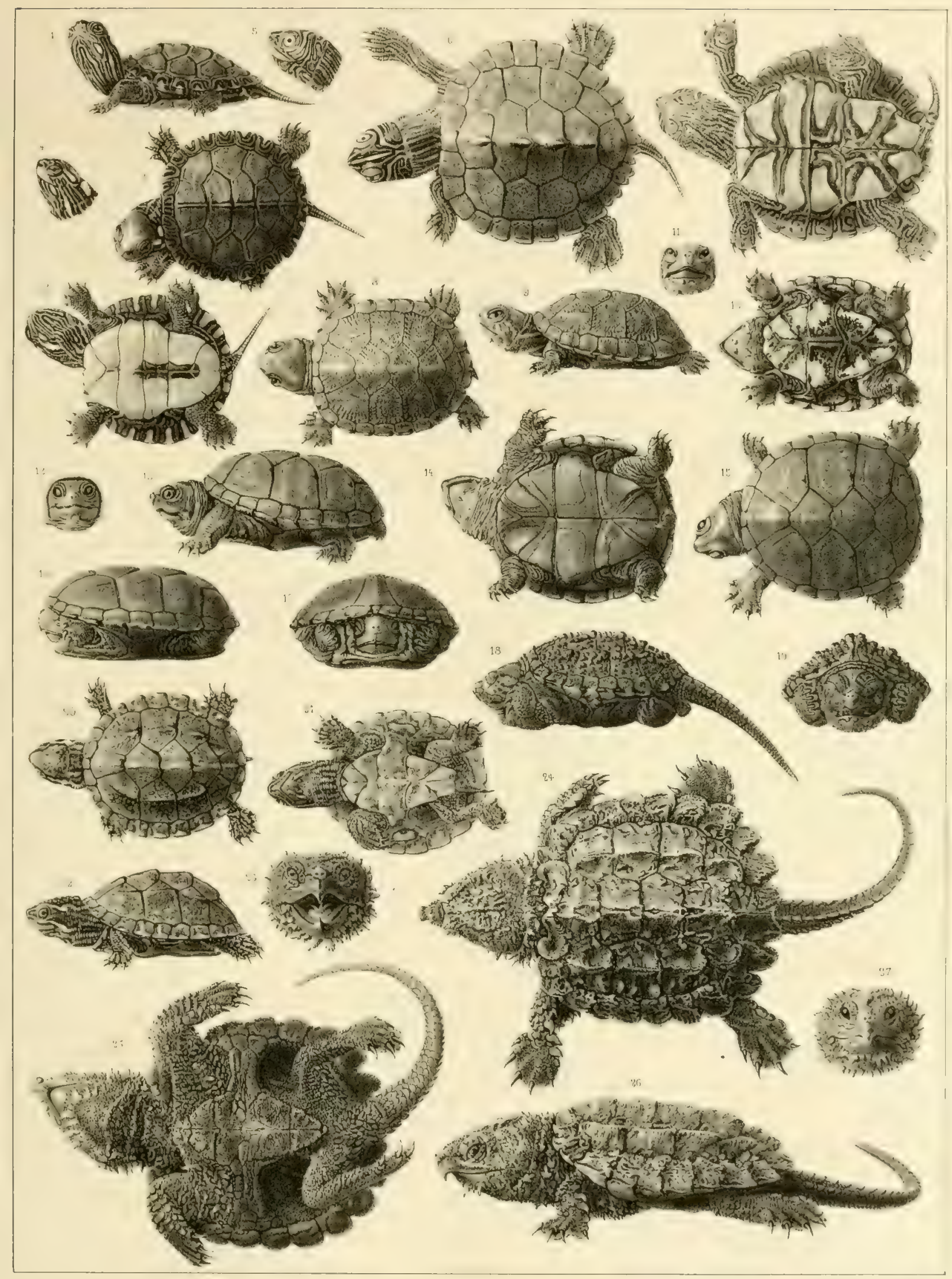

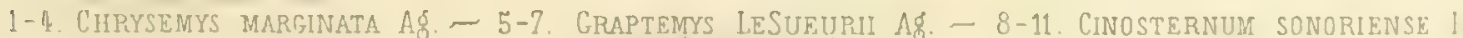

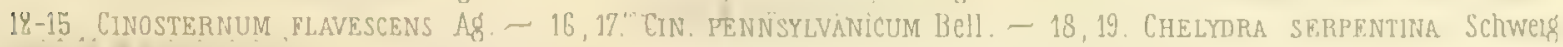

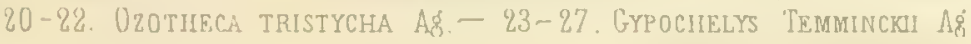



YOUNG TURTLE: ;, 19

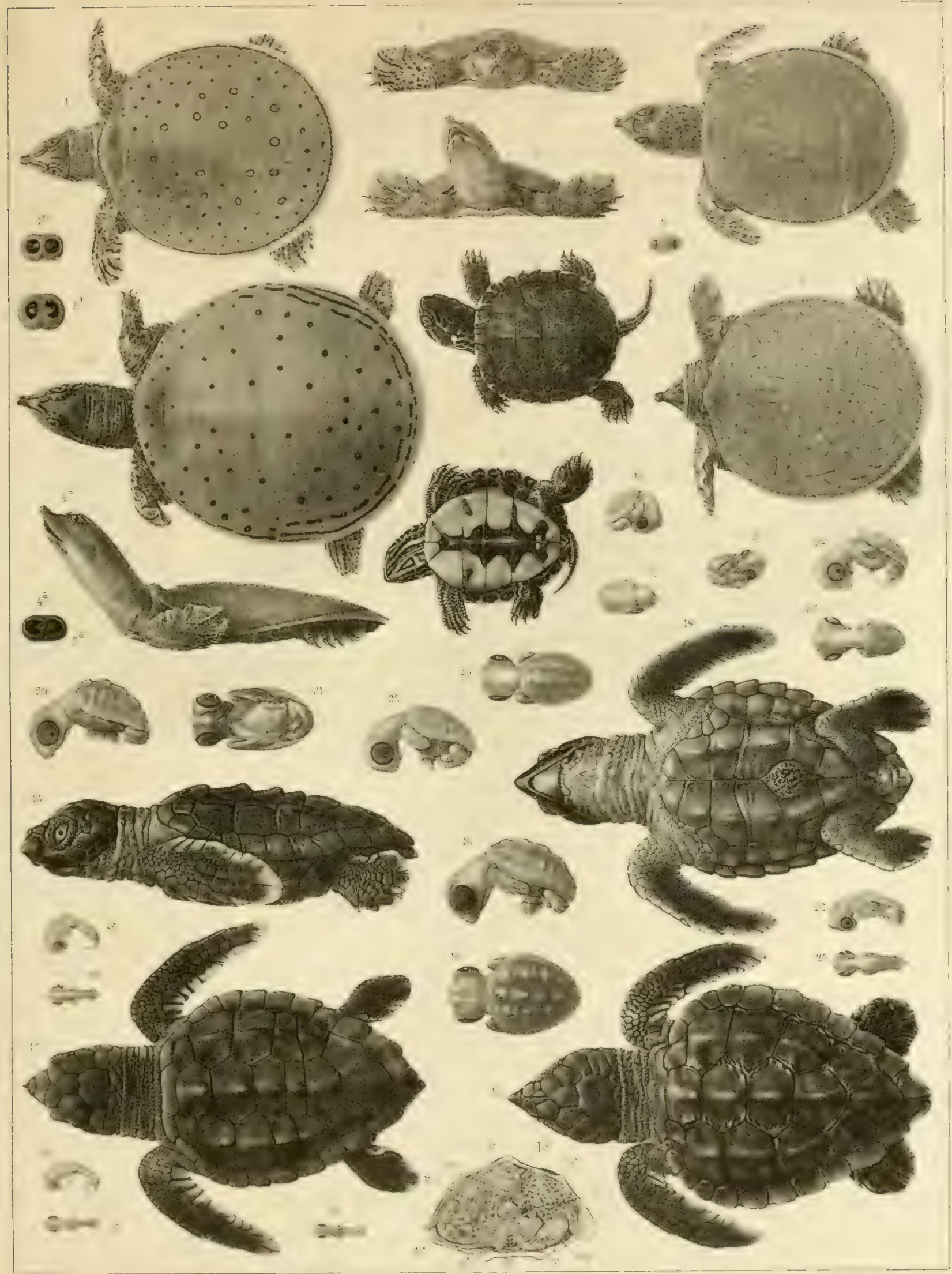





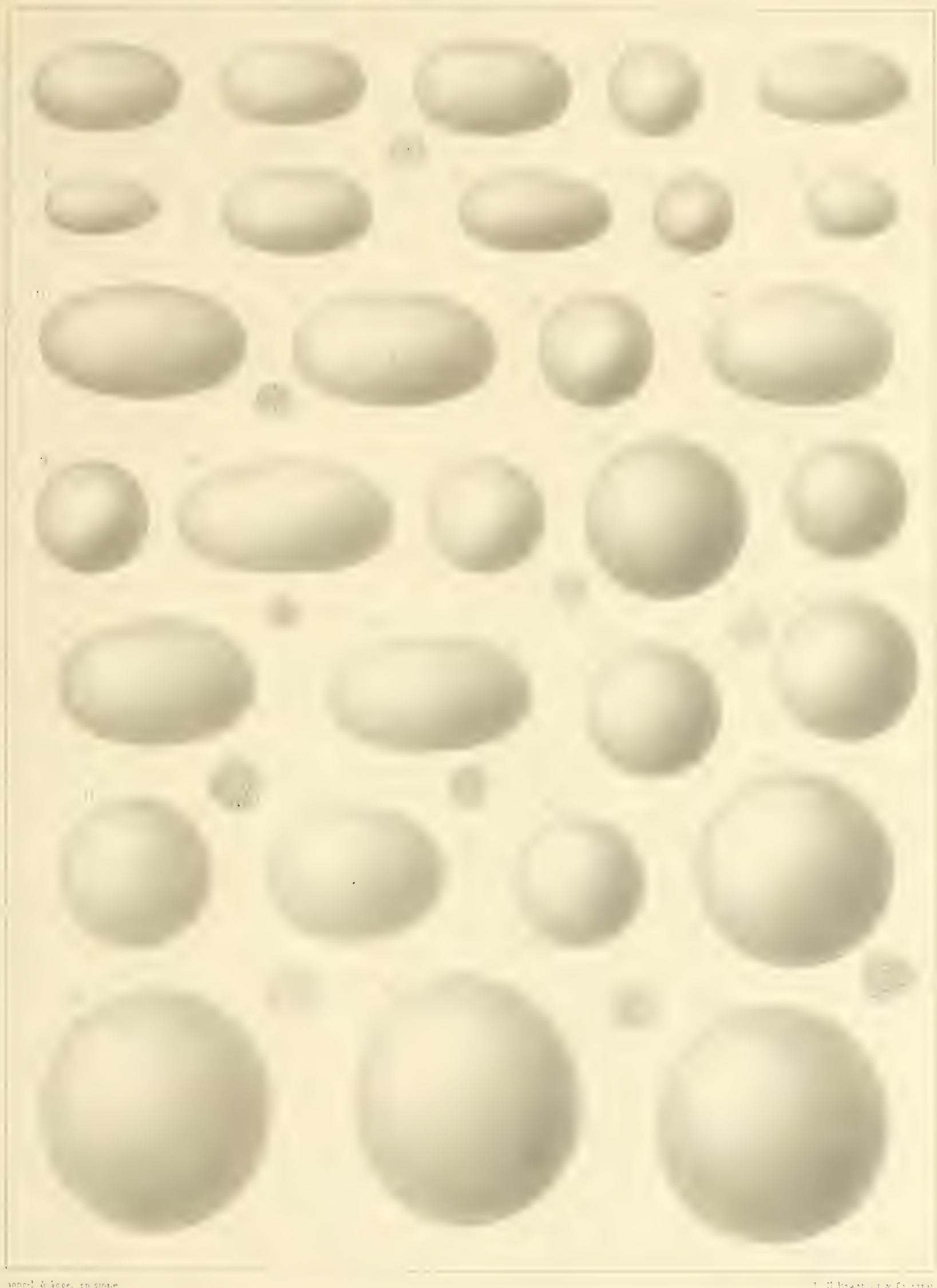

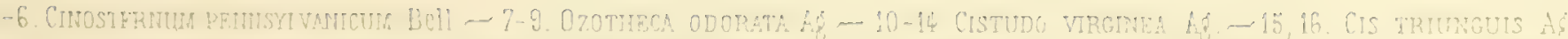

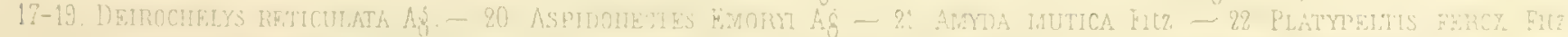

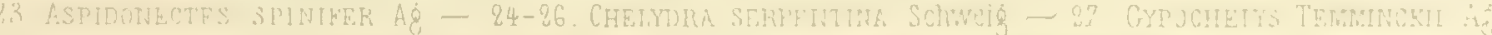

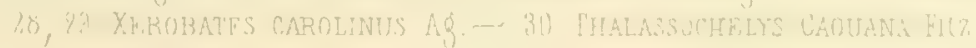





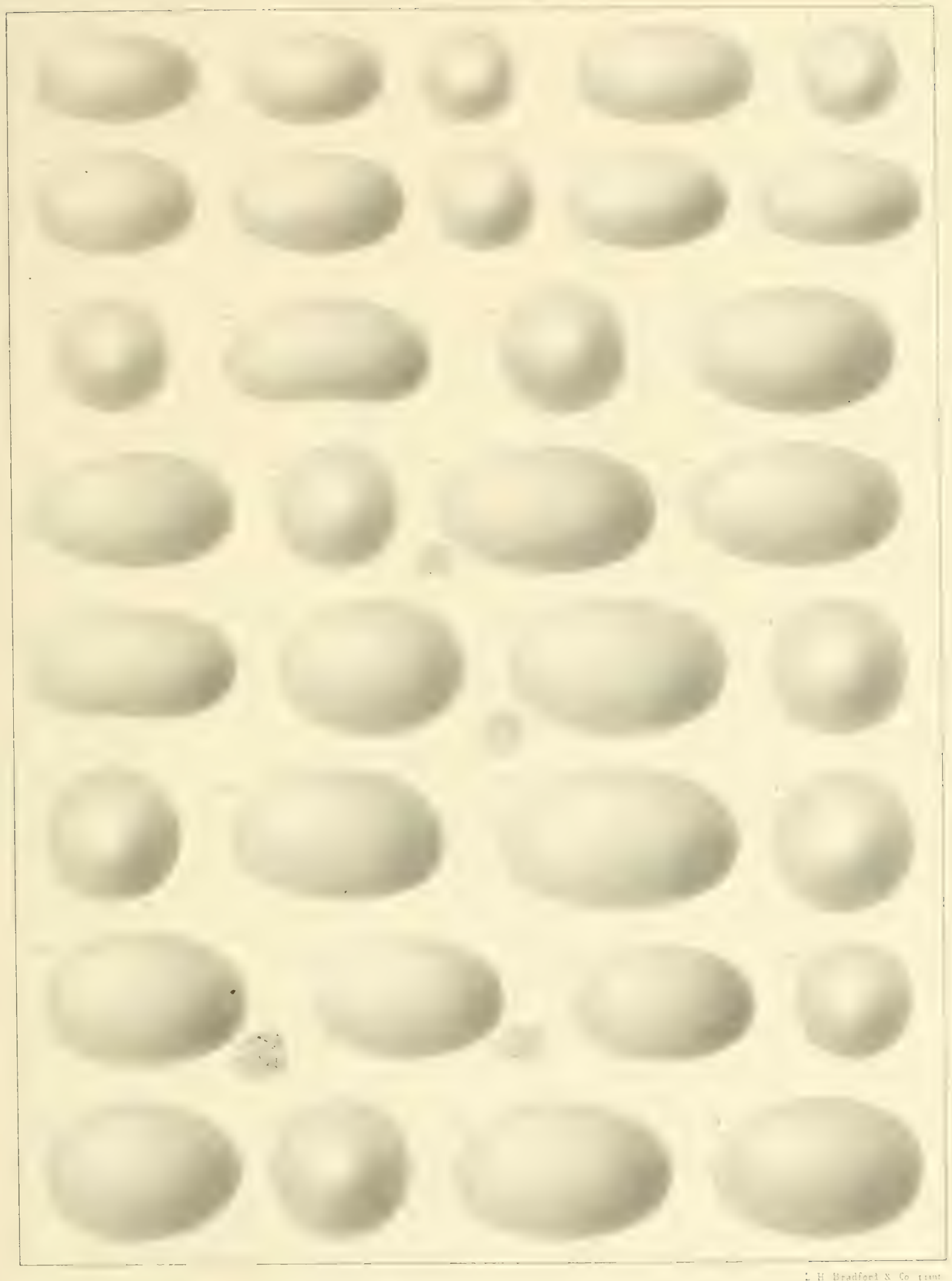

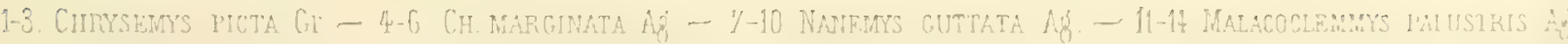

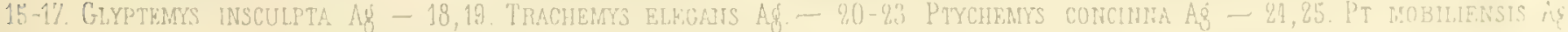

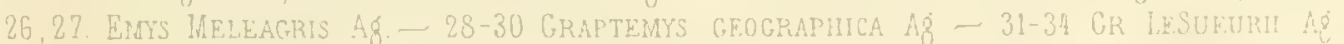





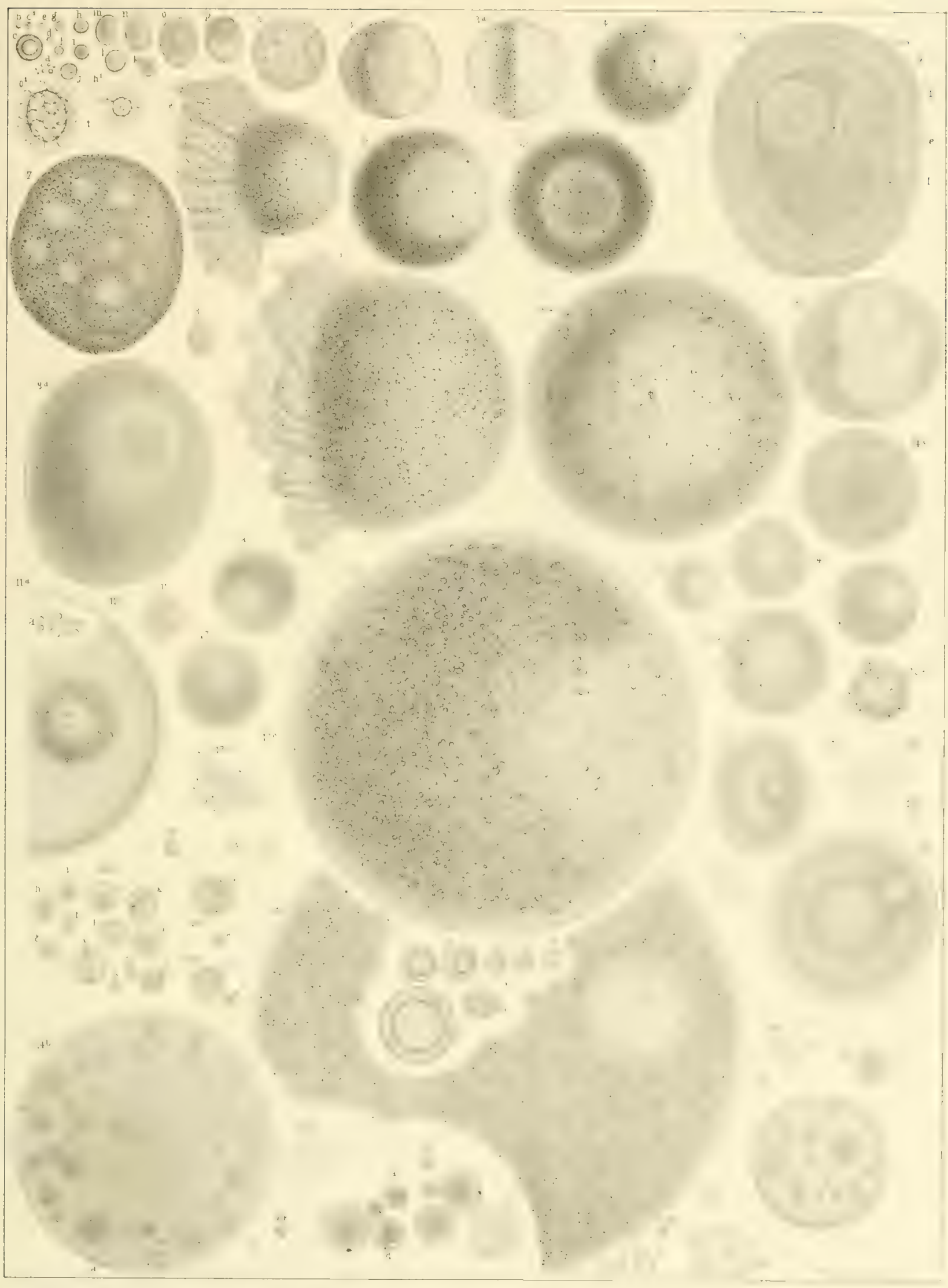

Clark from nac Sonsel on slorte 



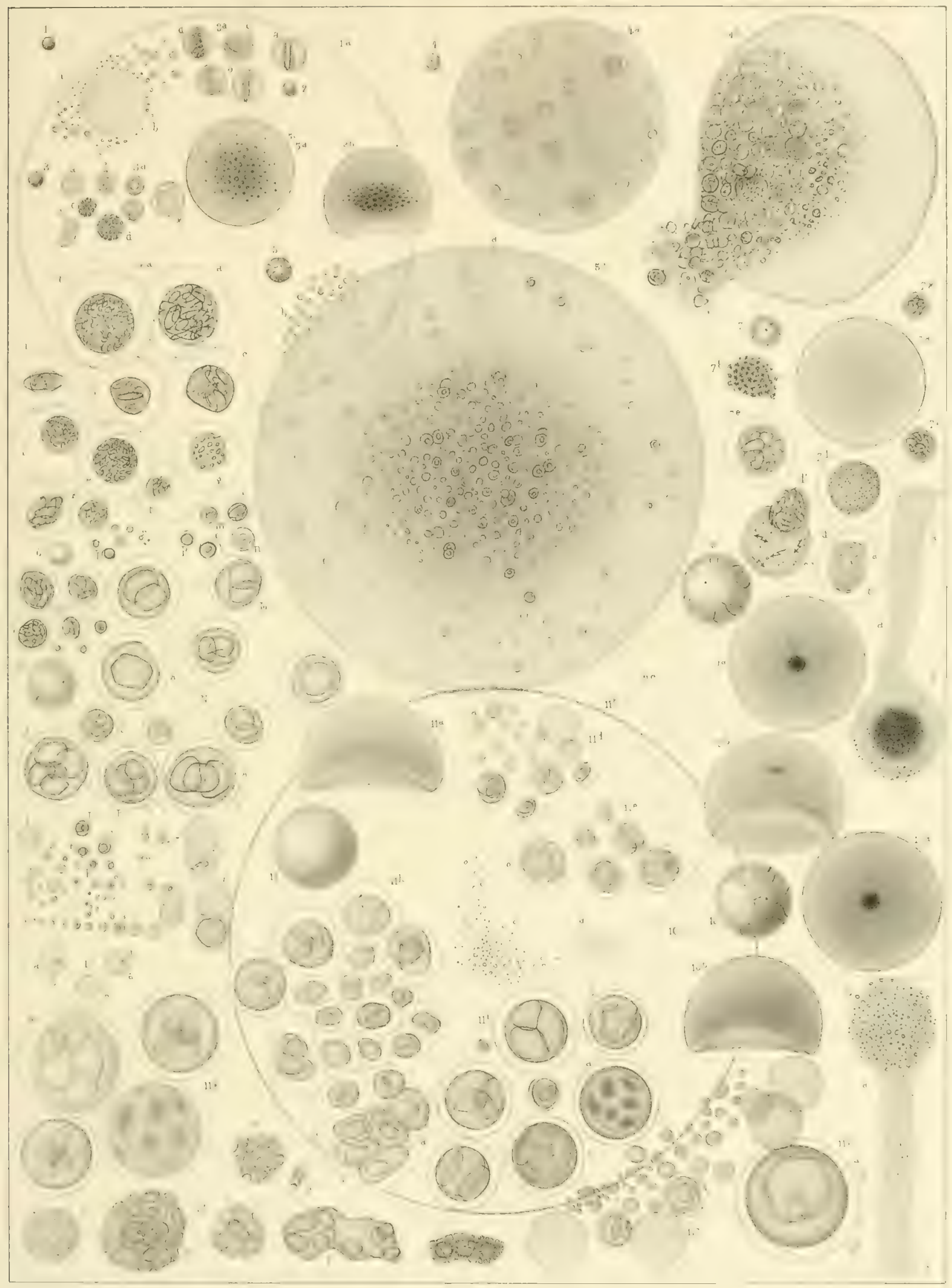





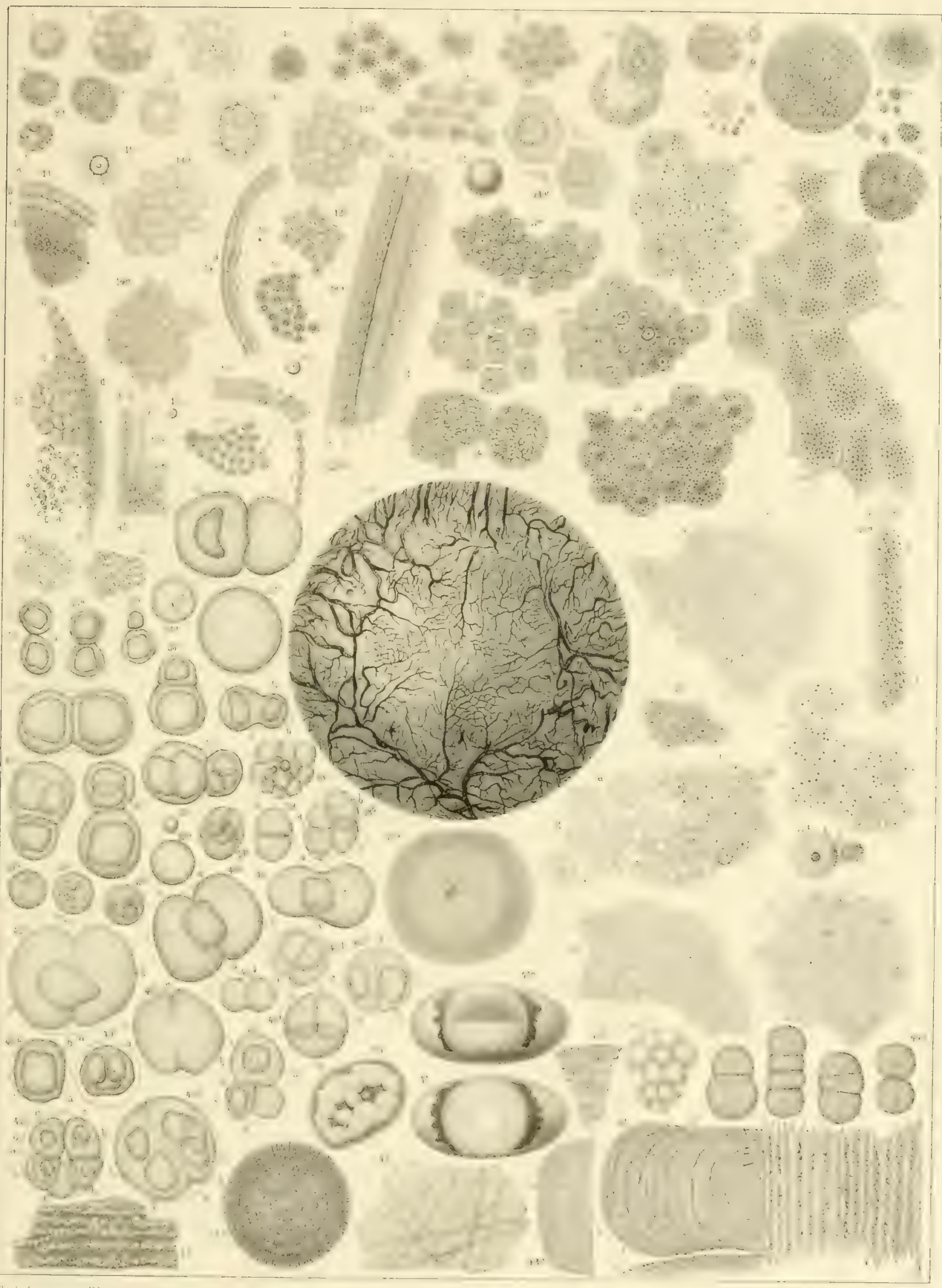





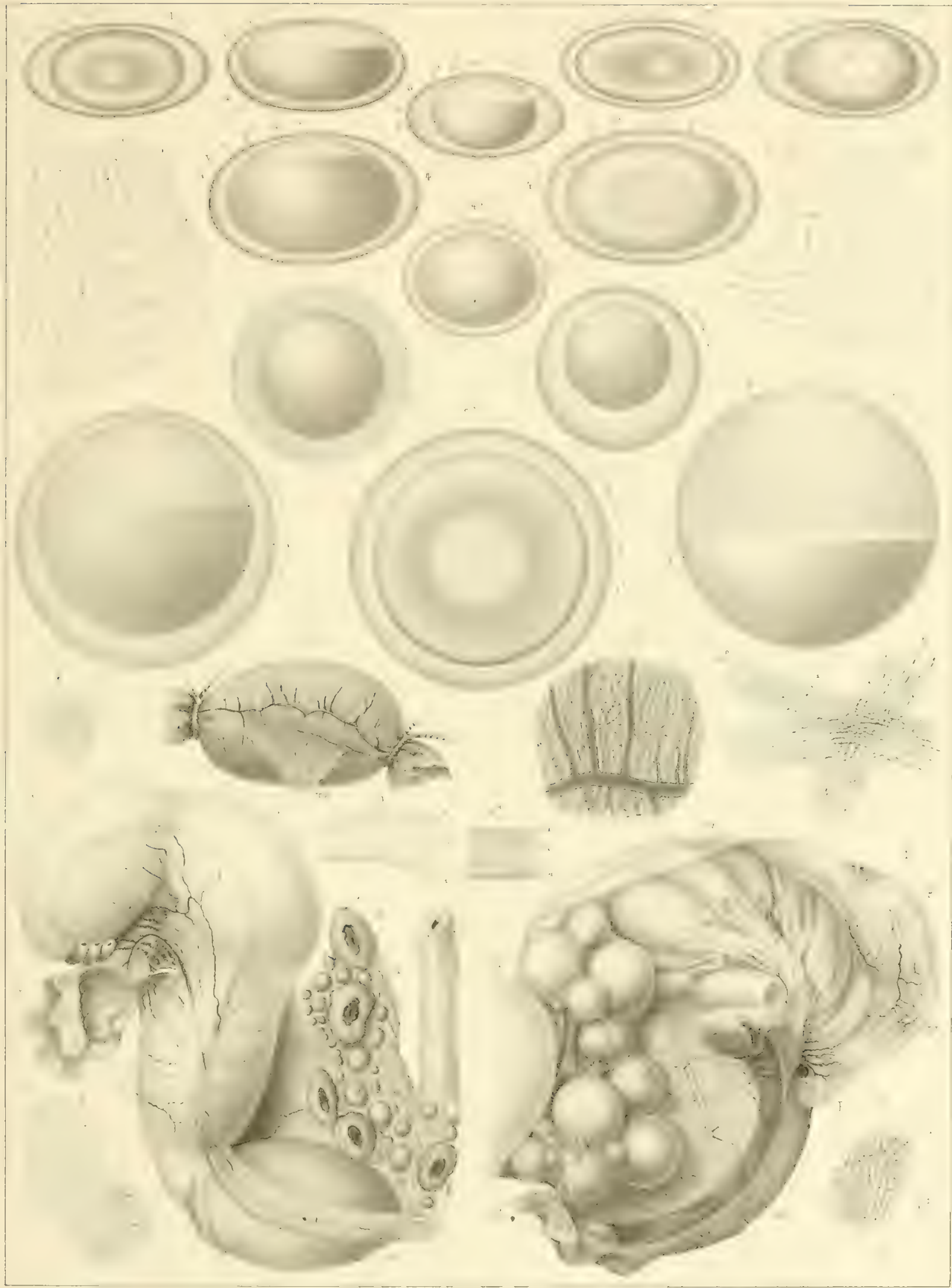





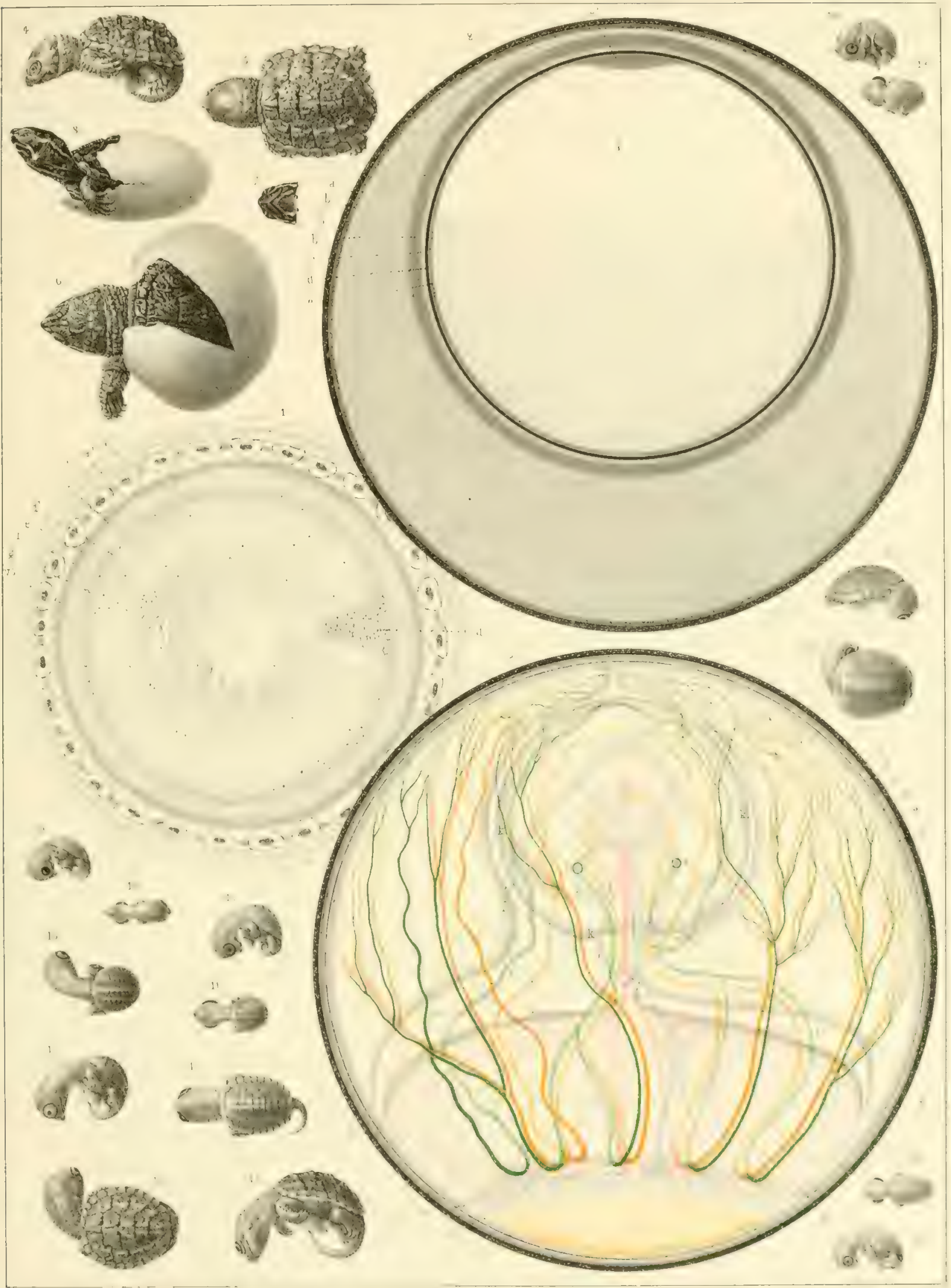





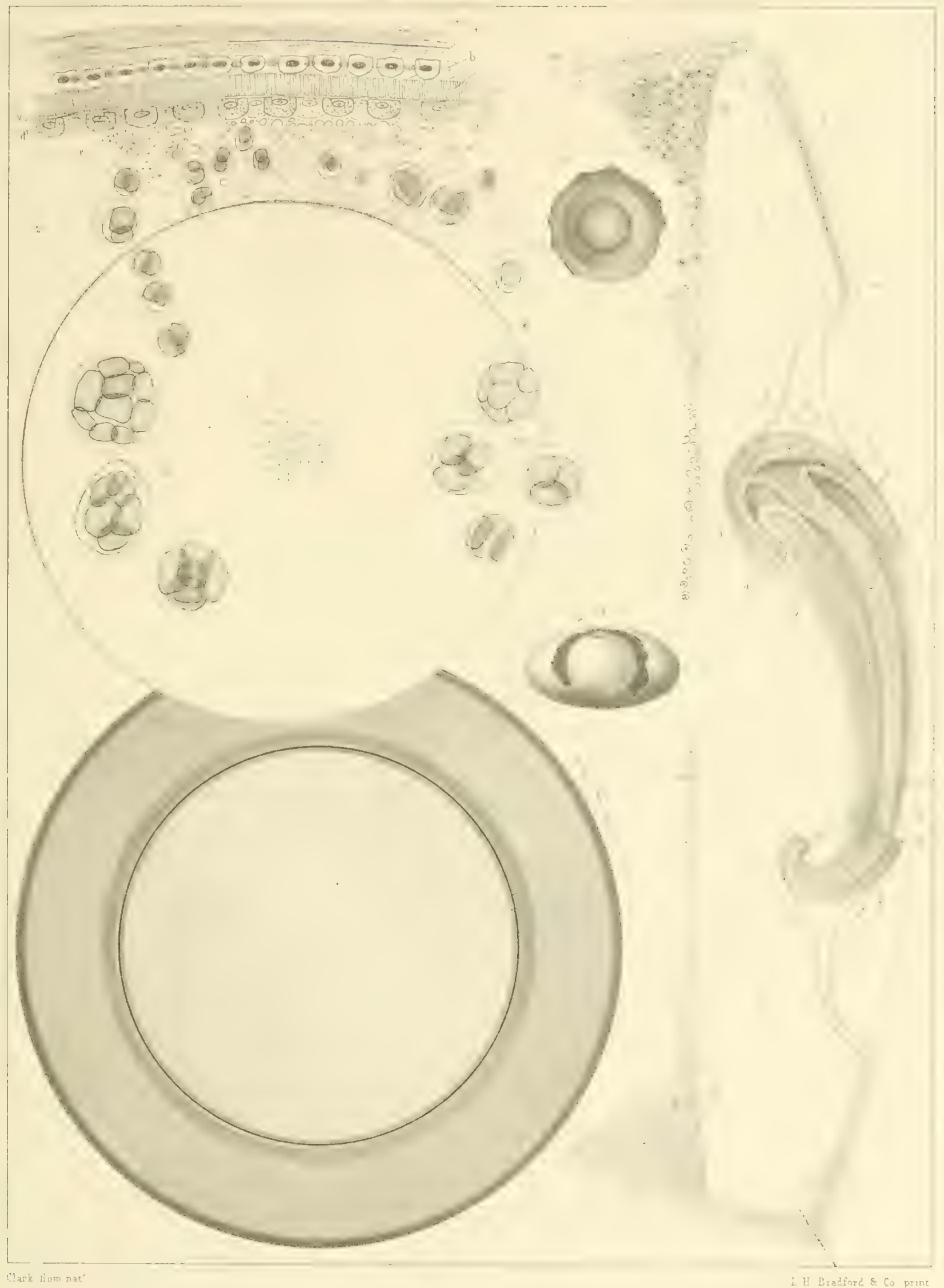

SECTIONS OF THE, VGG AND OF TIE FMBRYQ? 





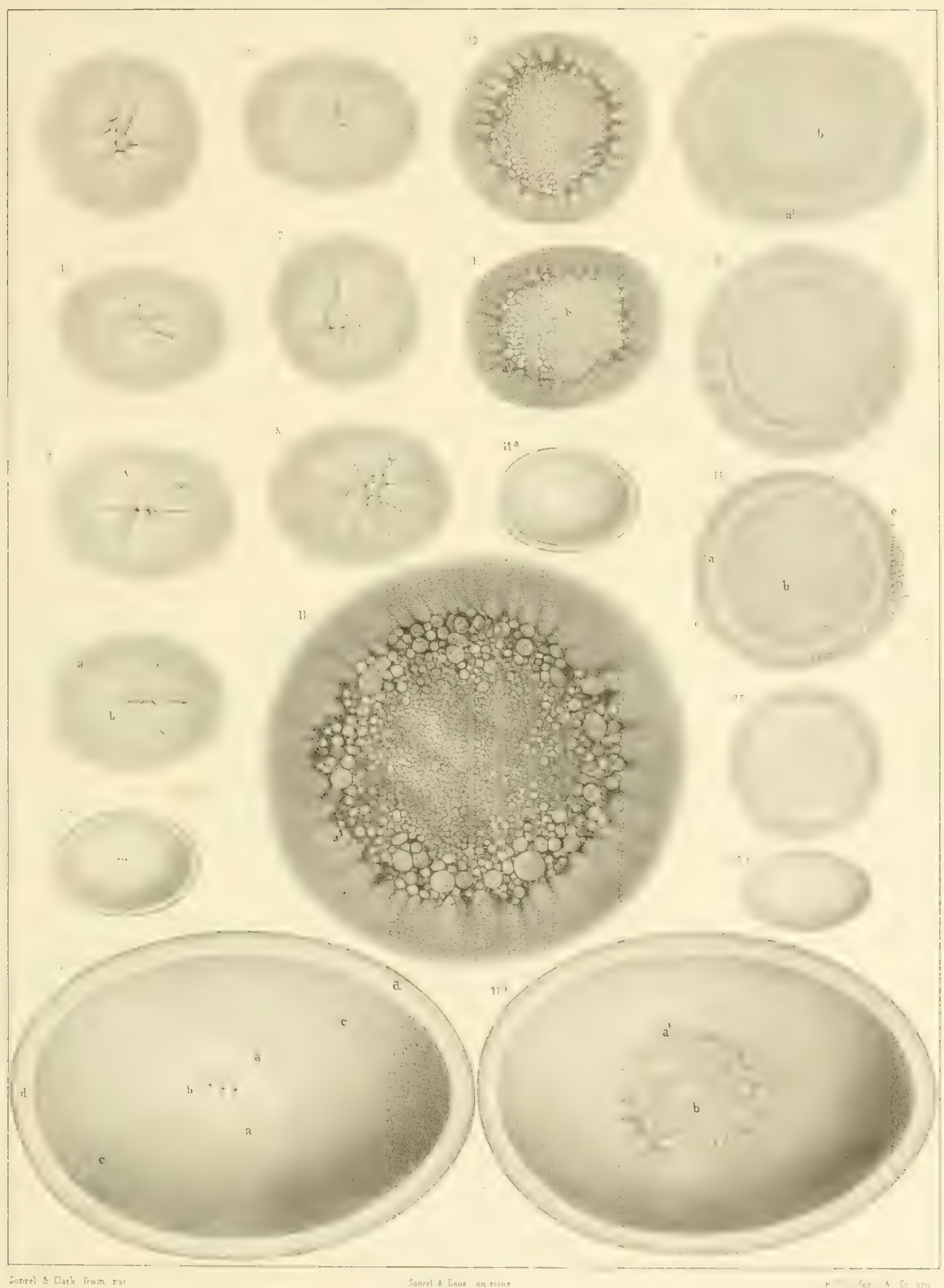

GCMENTATION OF THE YOLK 

EMBRYOLOGY OF TURTLES

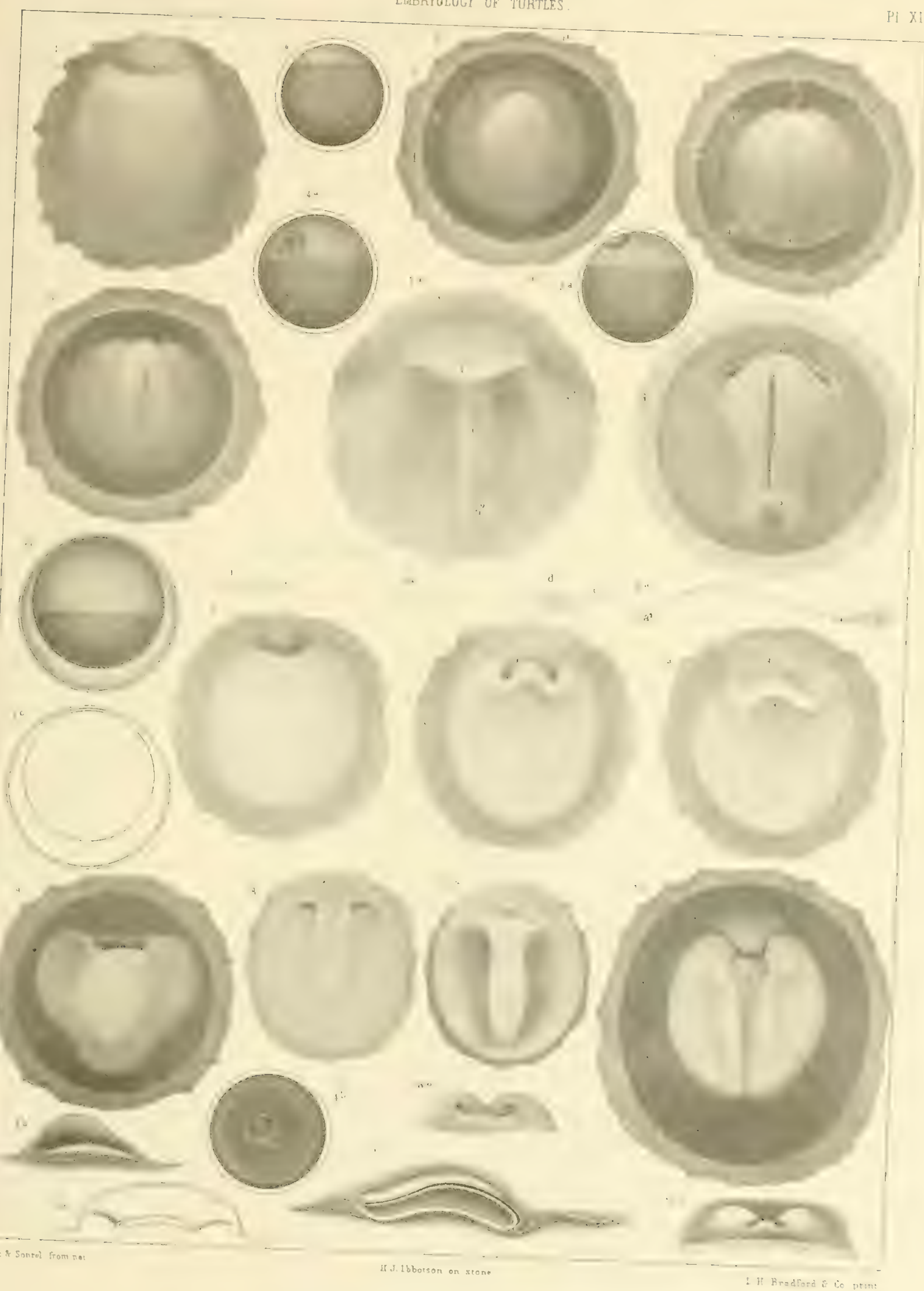

FOIDING OF THE BIASTODERMA 



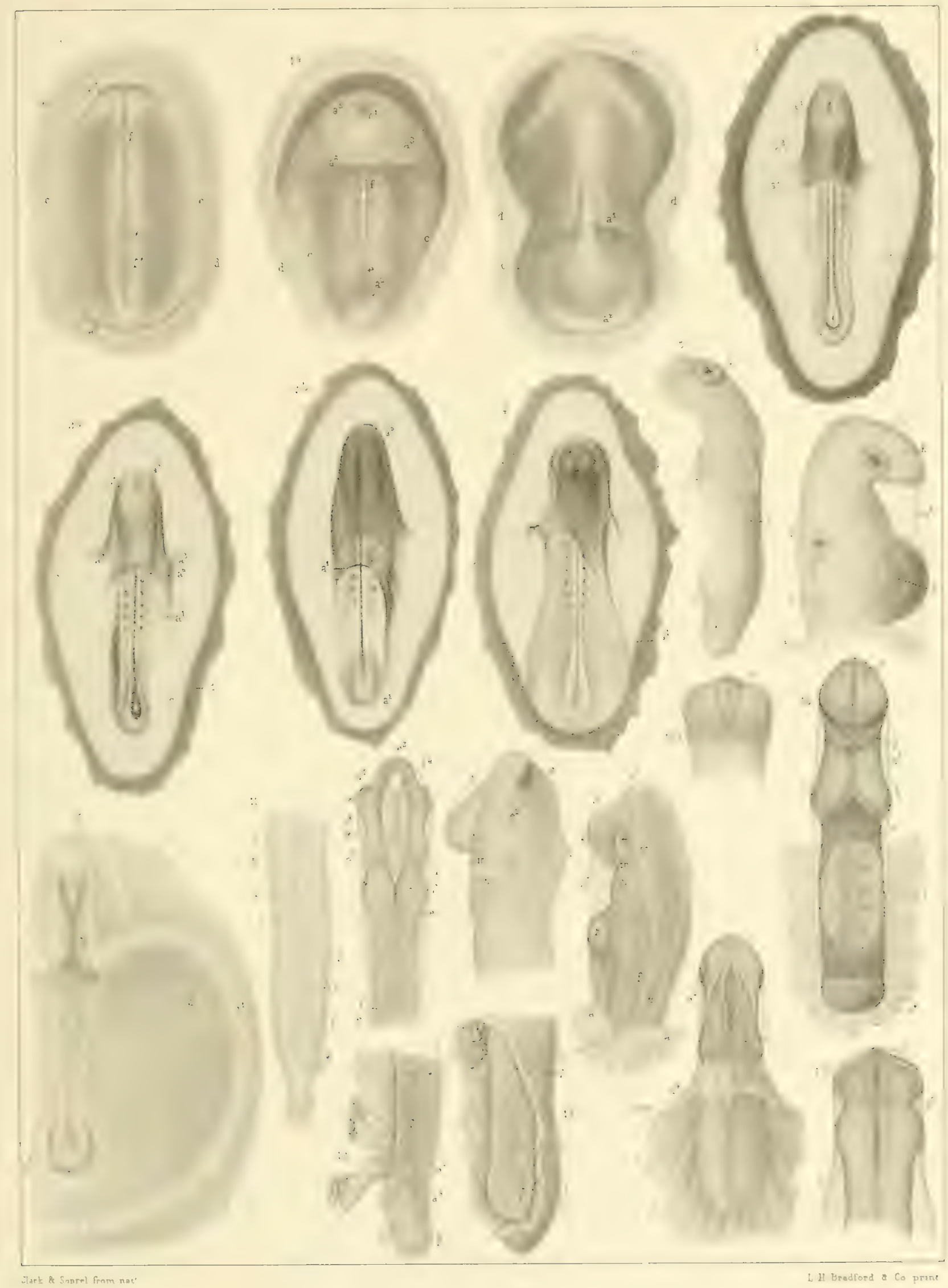

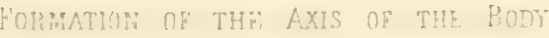





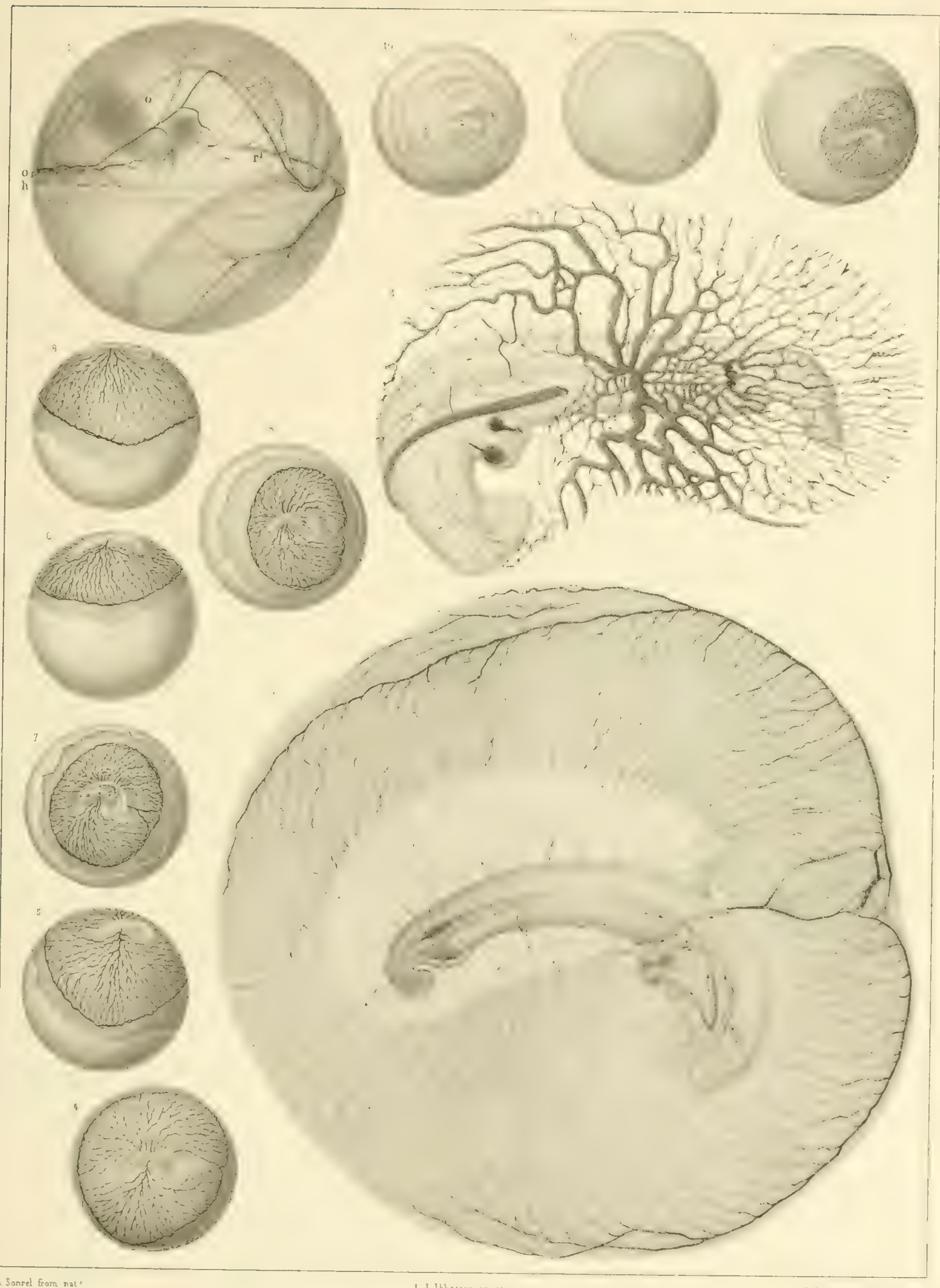

Vitelline and allantojdian circulation 



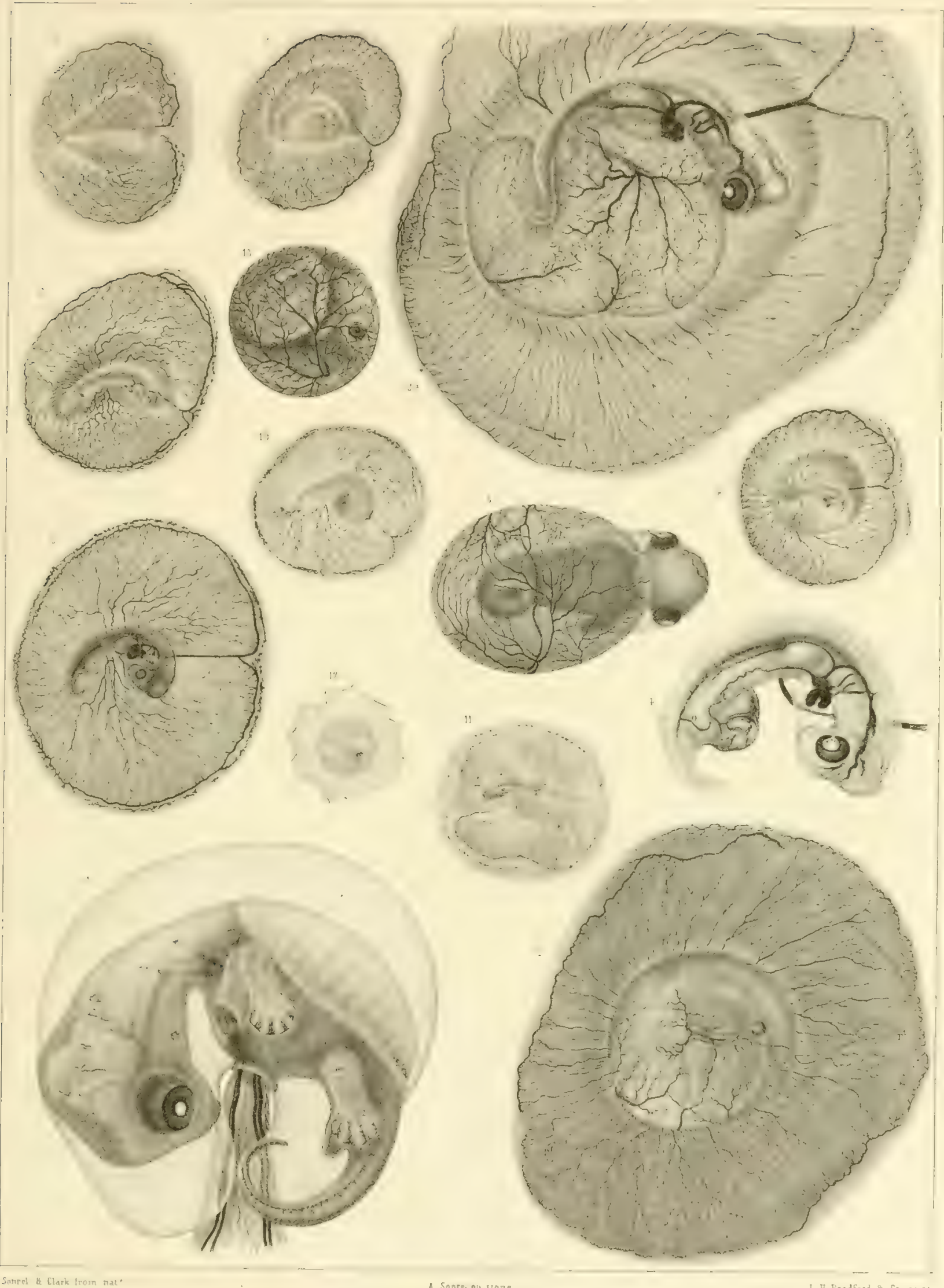

VitelLiNf, ANo ALLANTOIDIAN CIRCULATIO: 



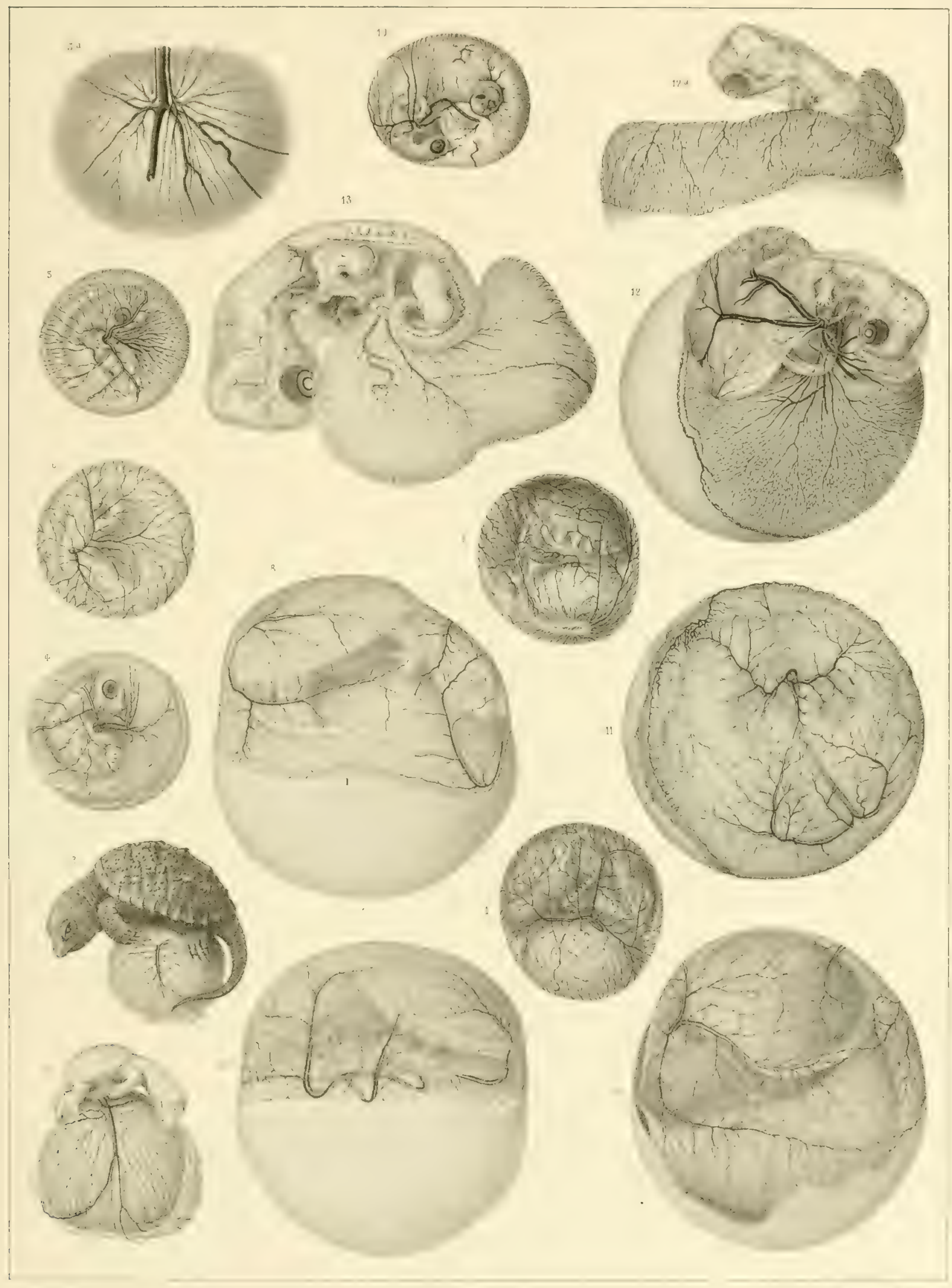



EMBRYOIOGY OF THITTISS

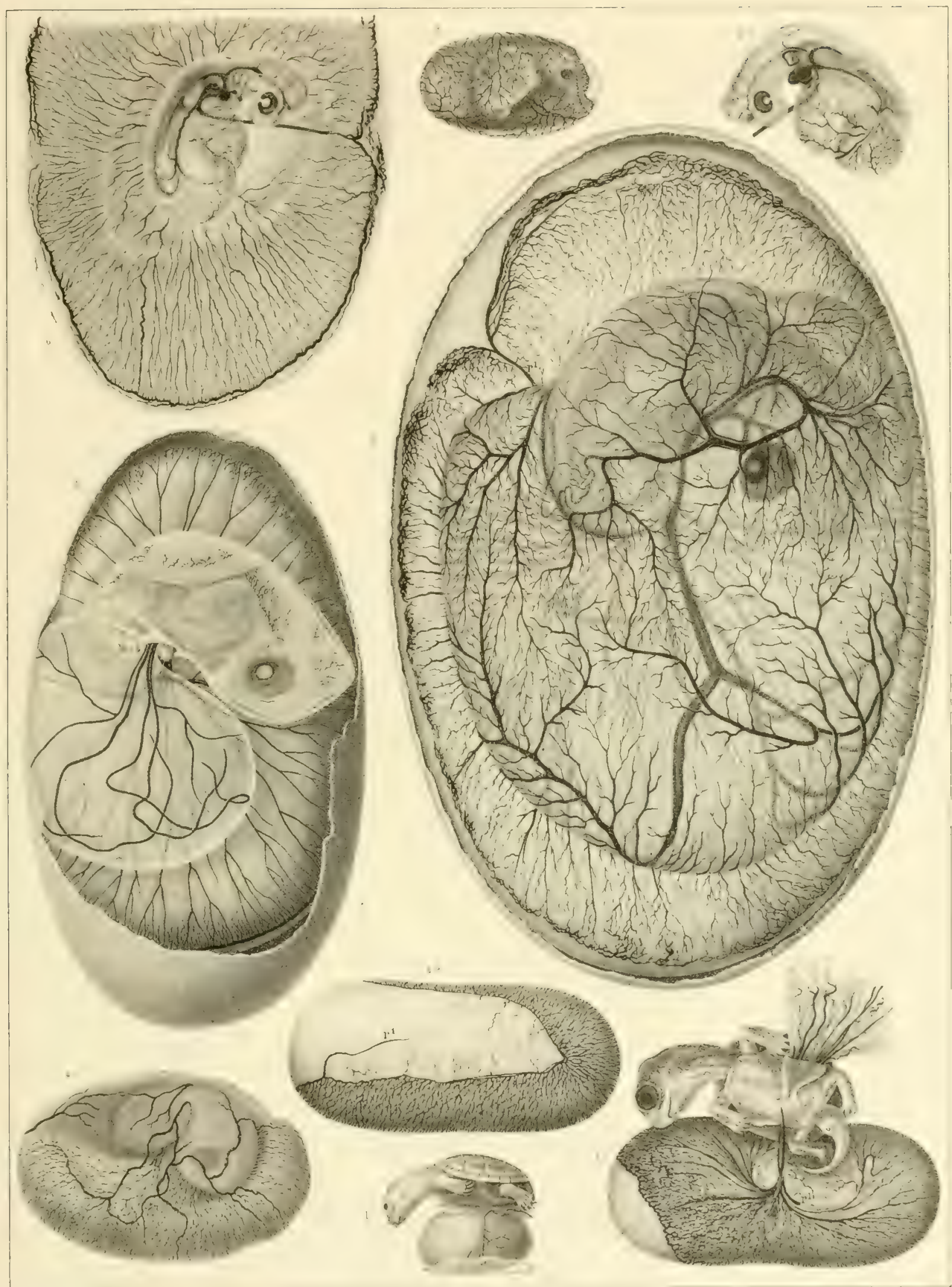



EMBRYOIDG OF TURTIES

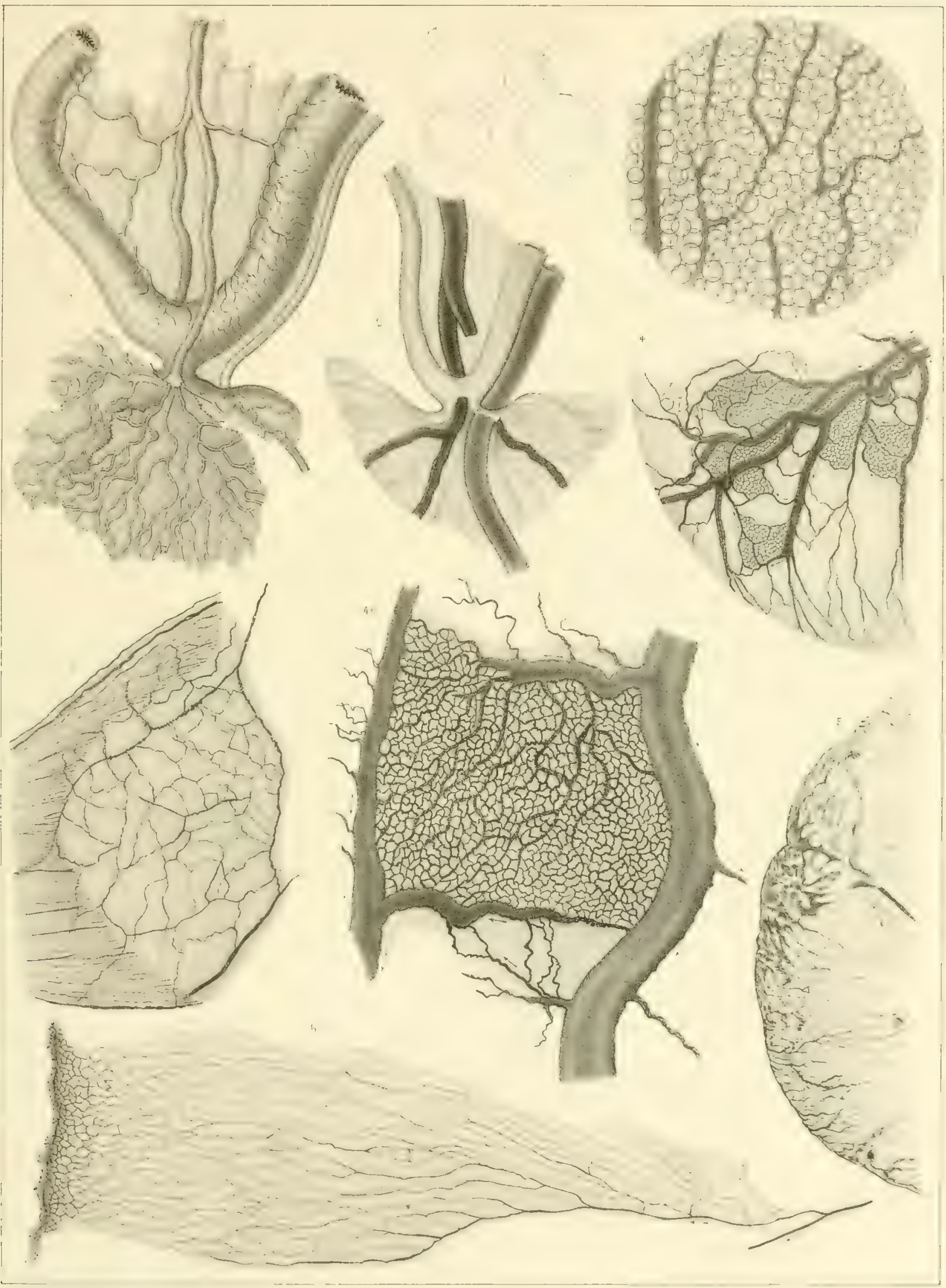





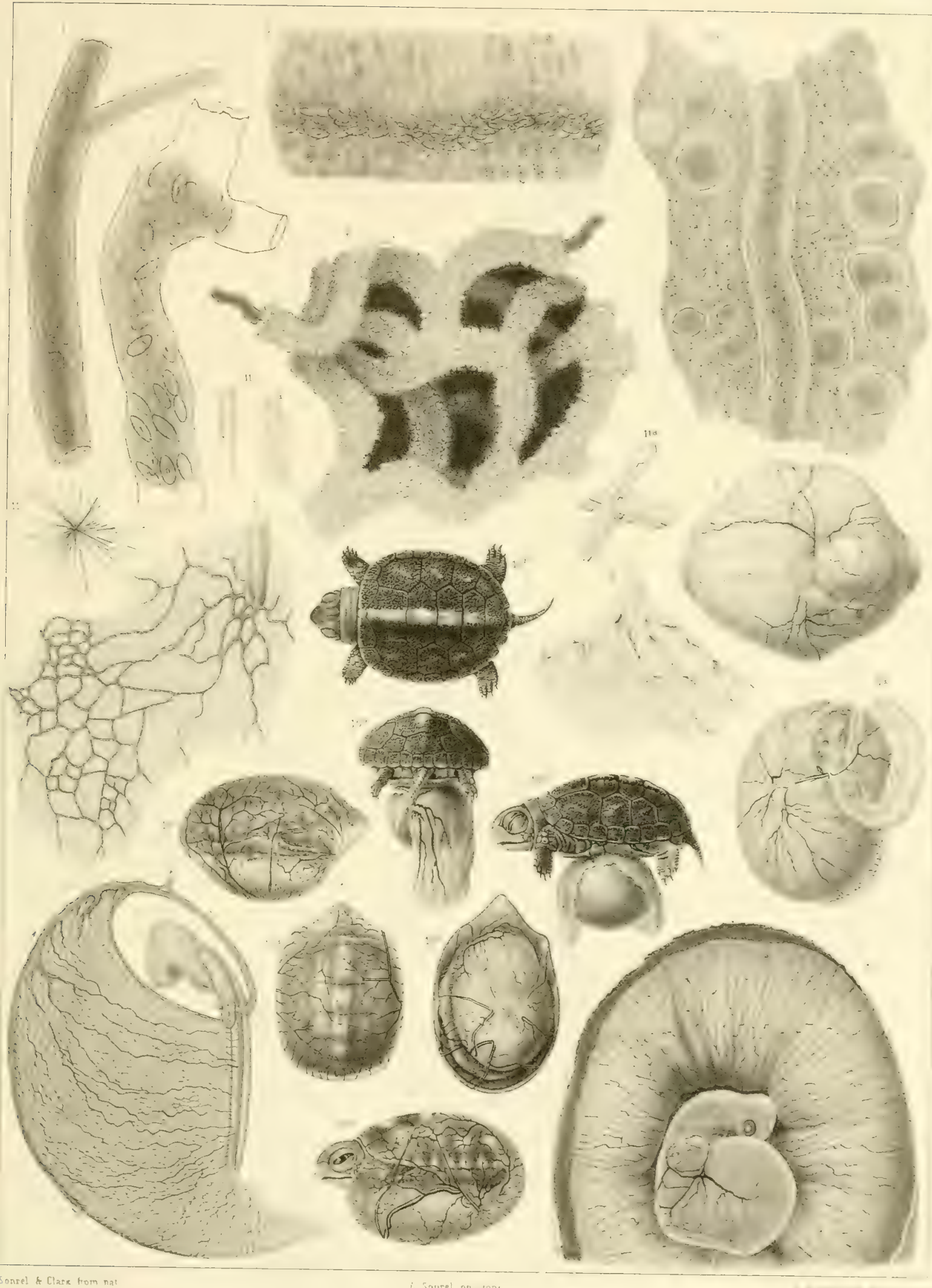

JITELLINE AND ALLANTOIDIAN CIRCULATINA 



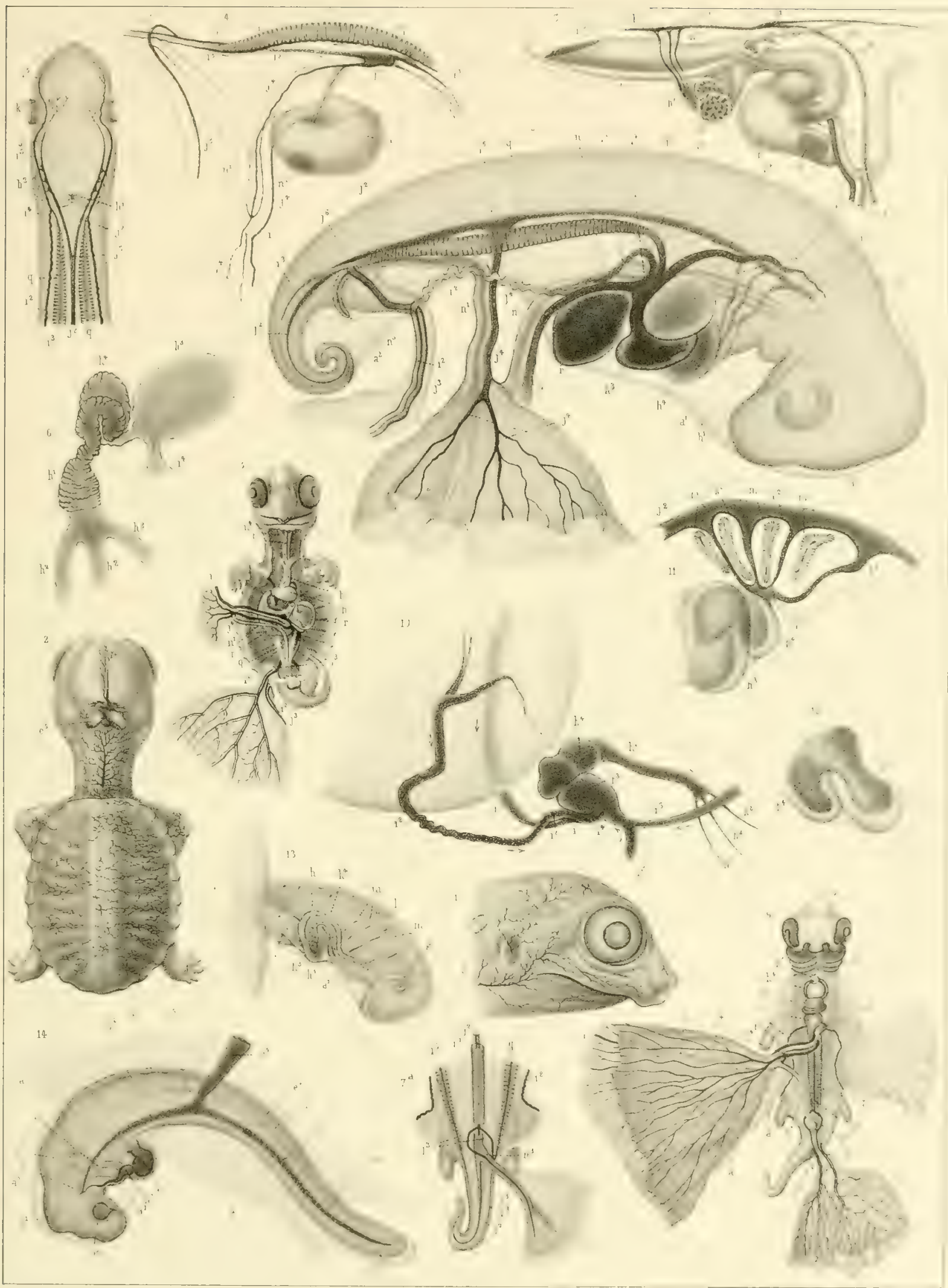





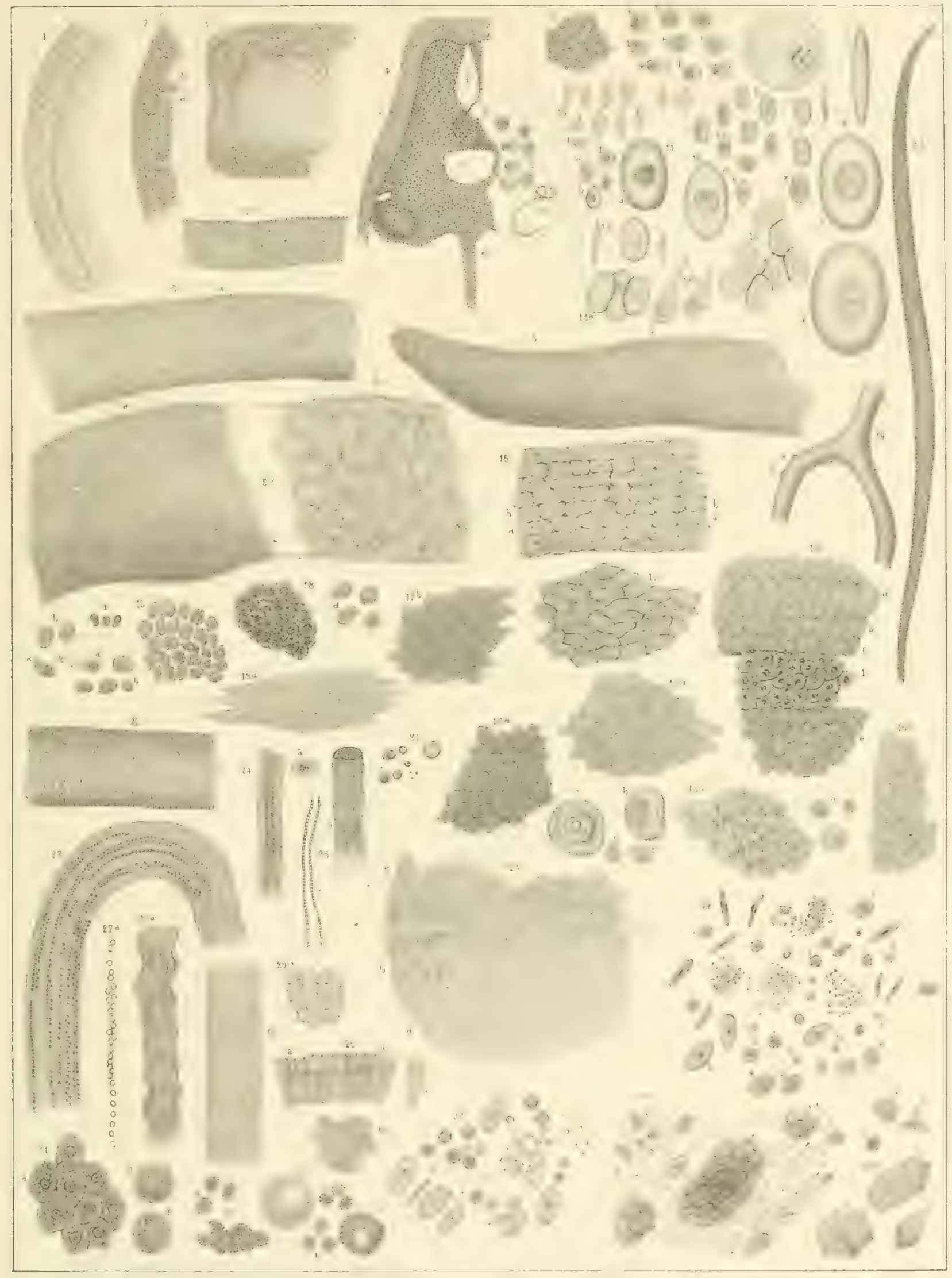





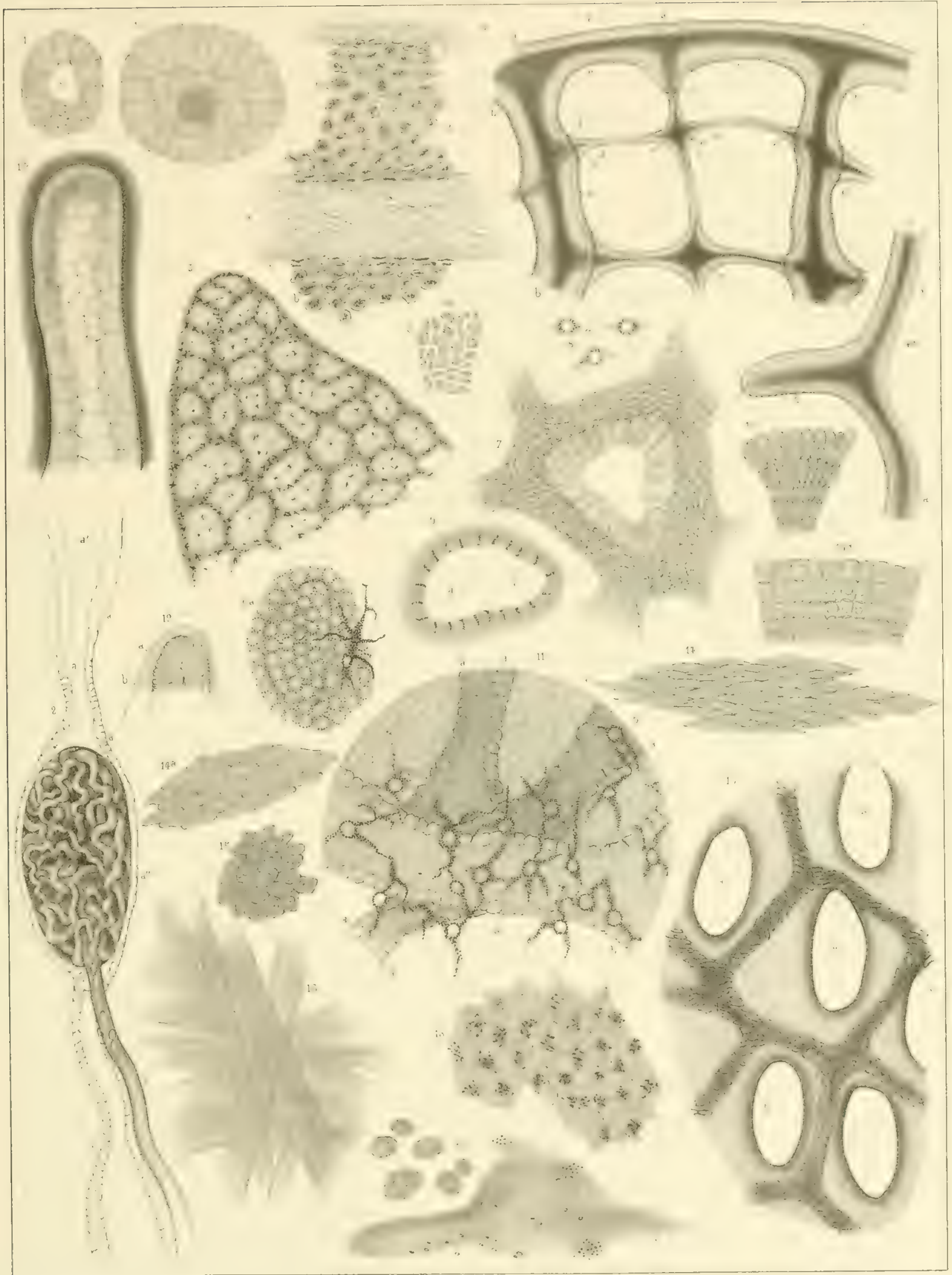





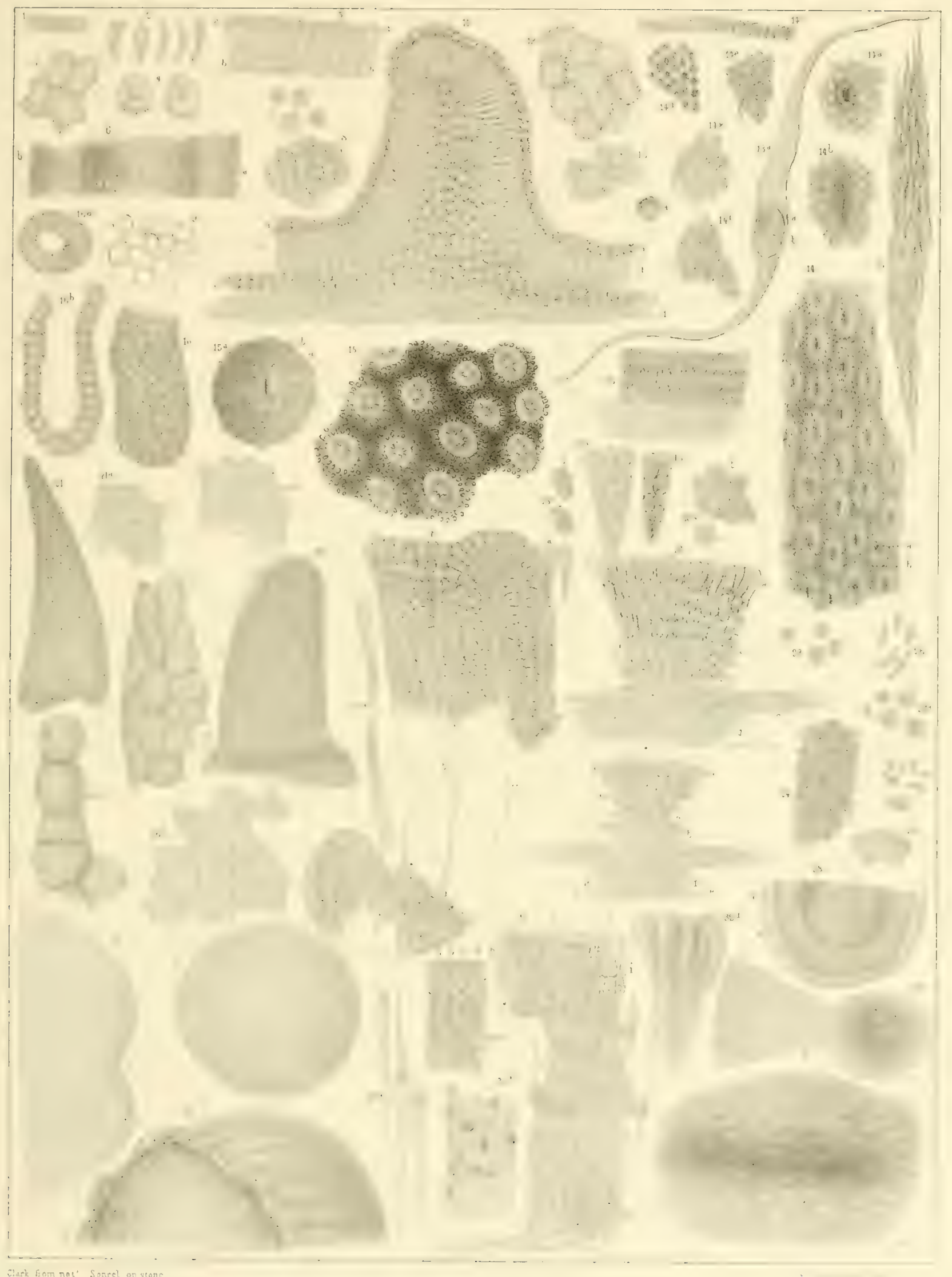





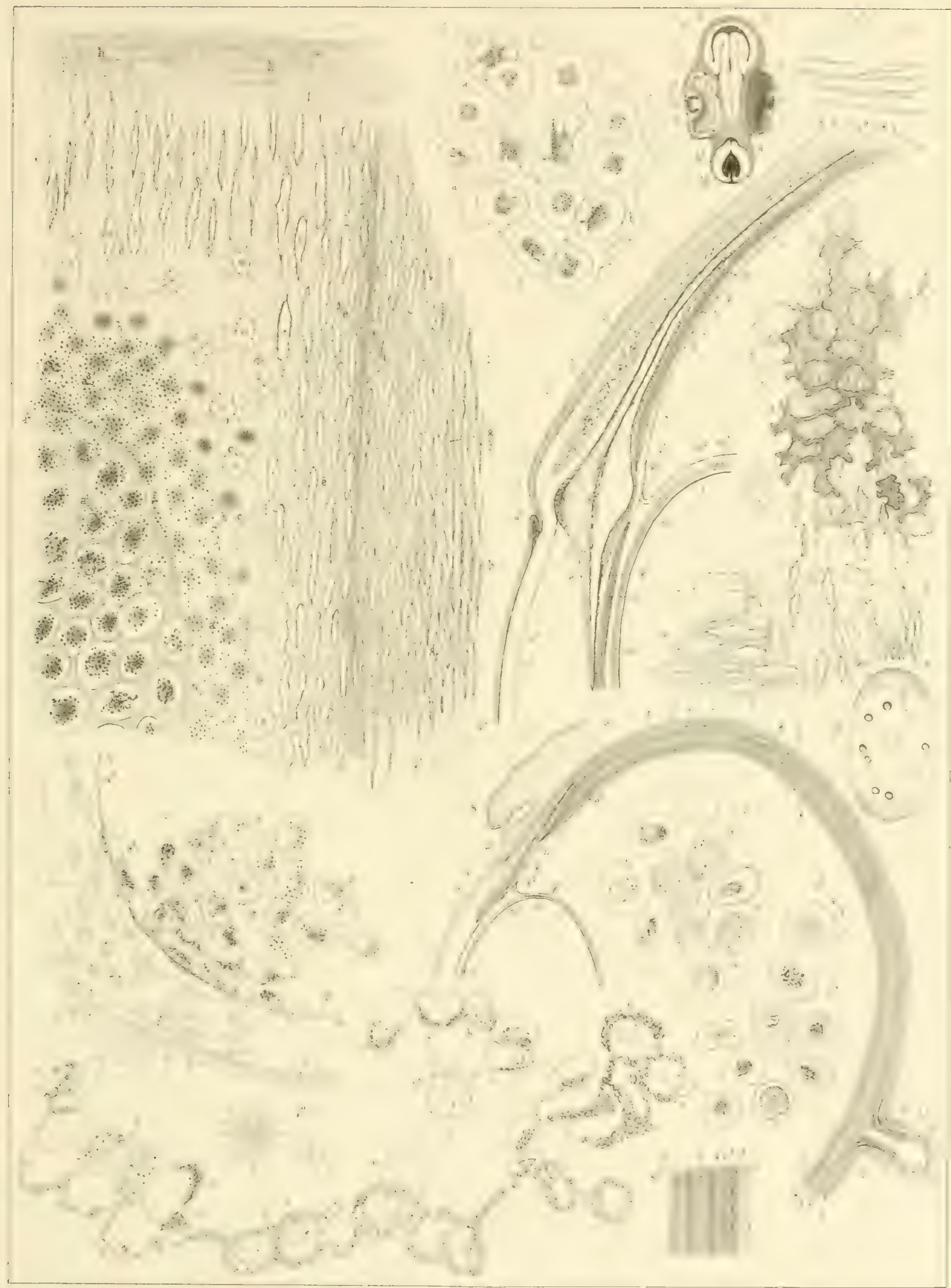





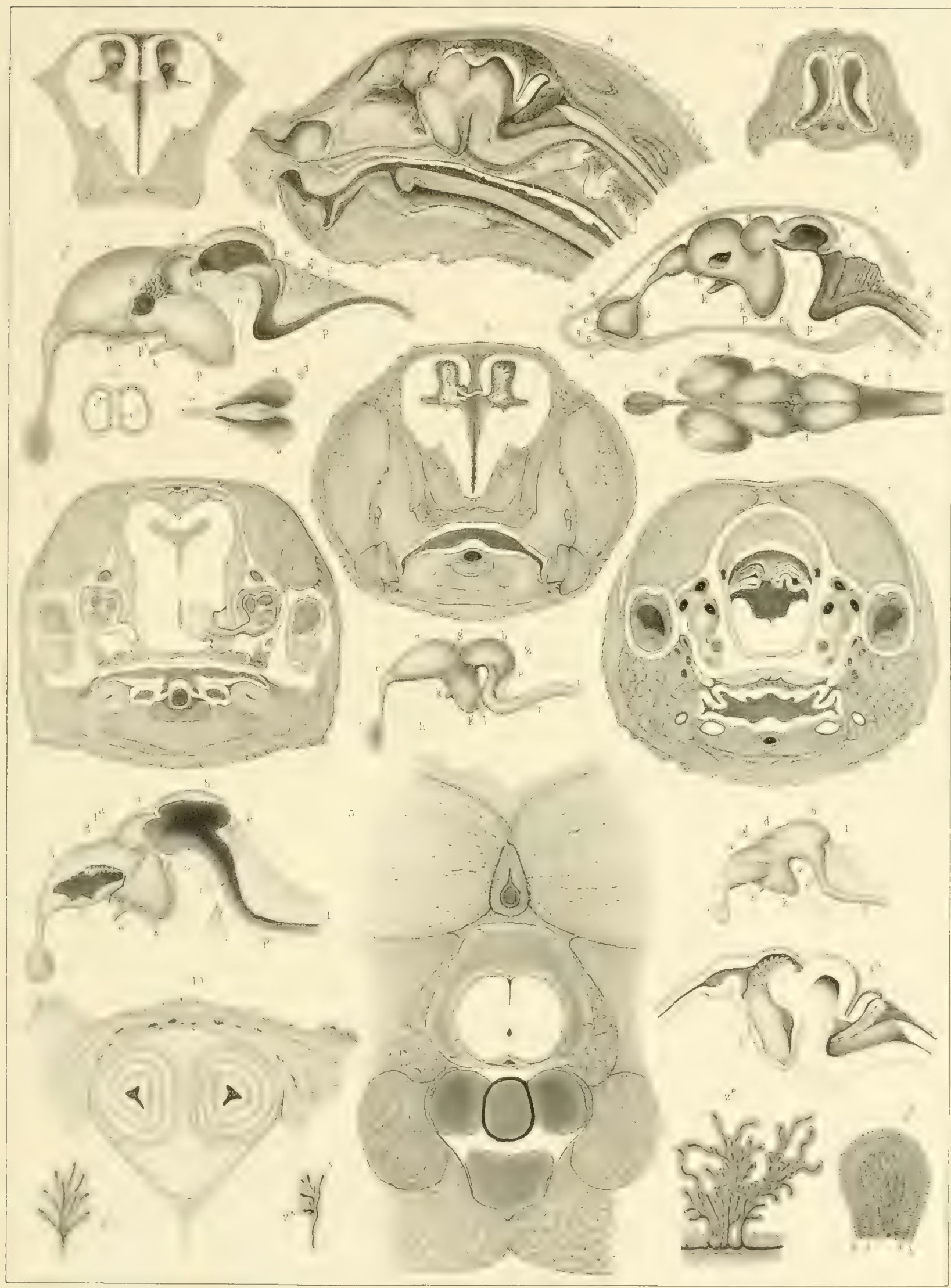





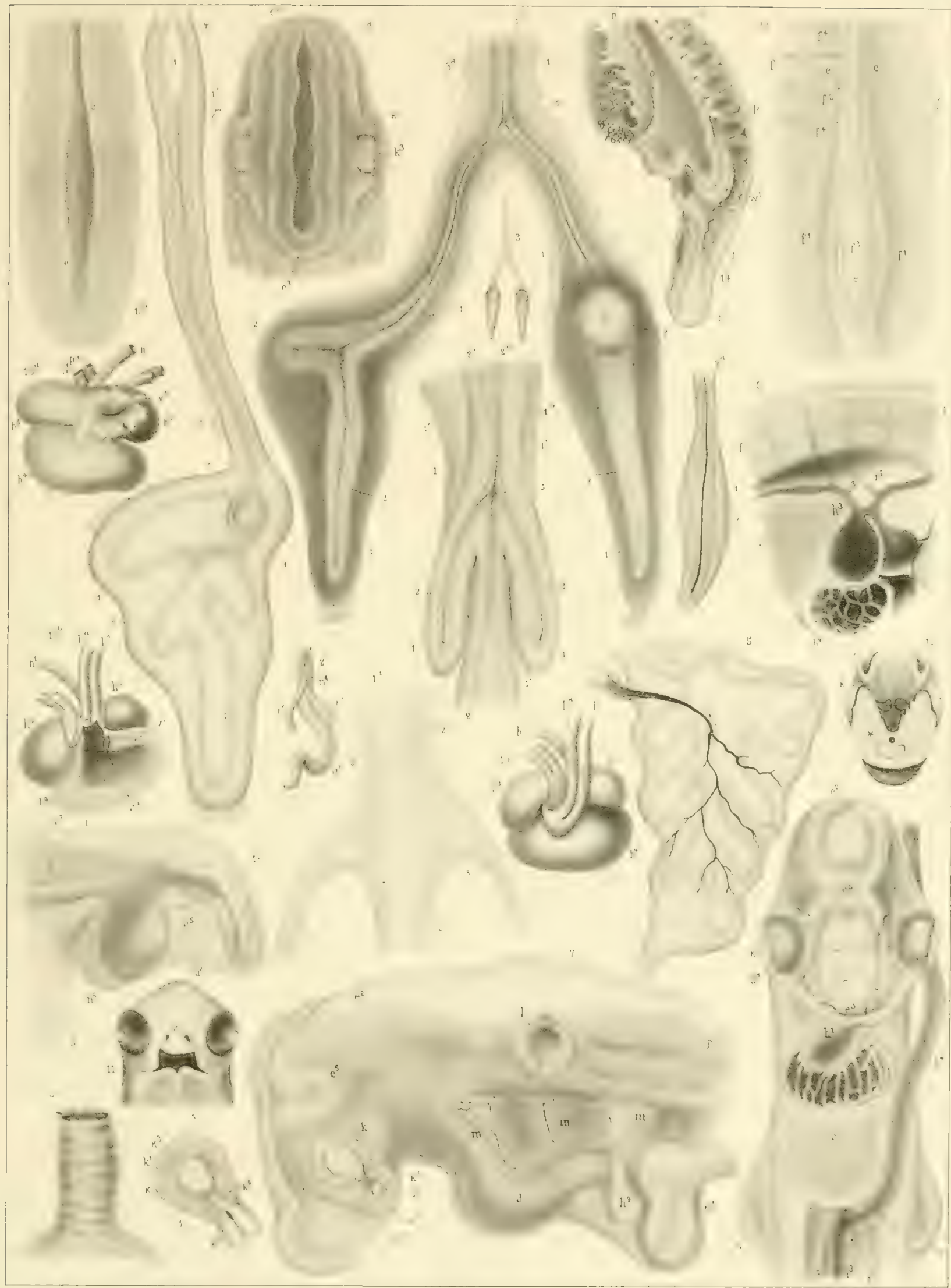

VORMATION DF URCANS 



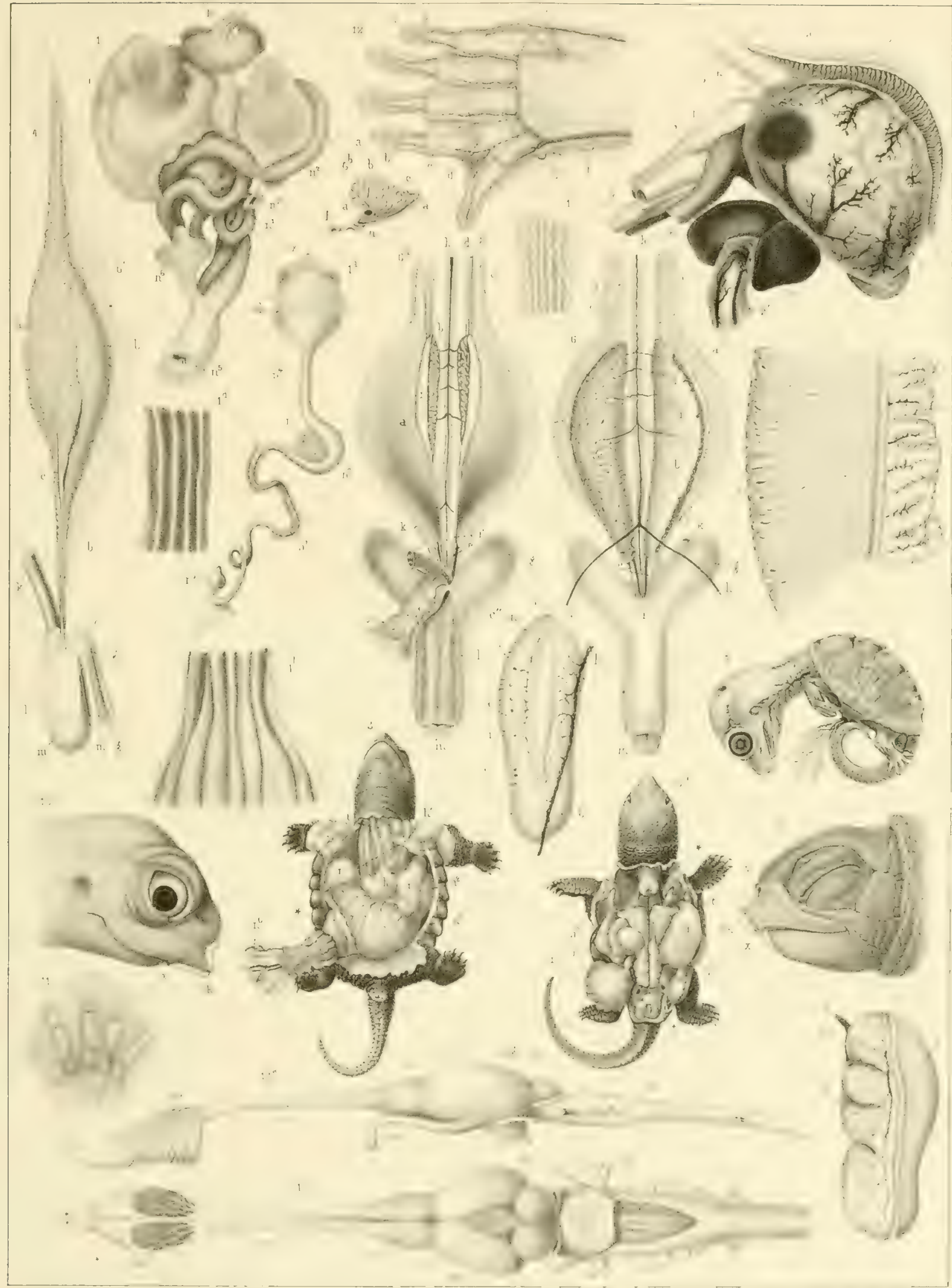




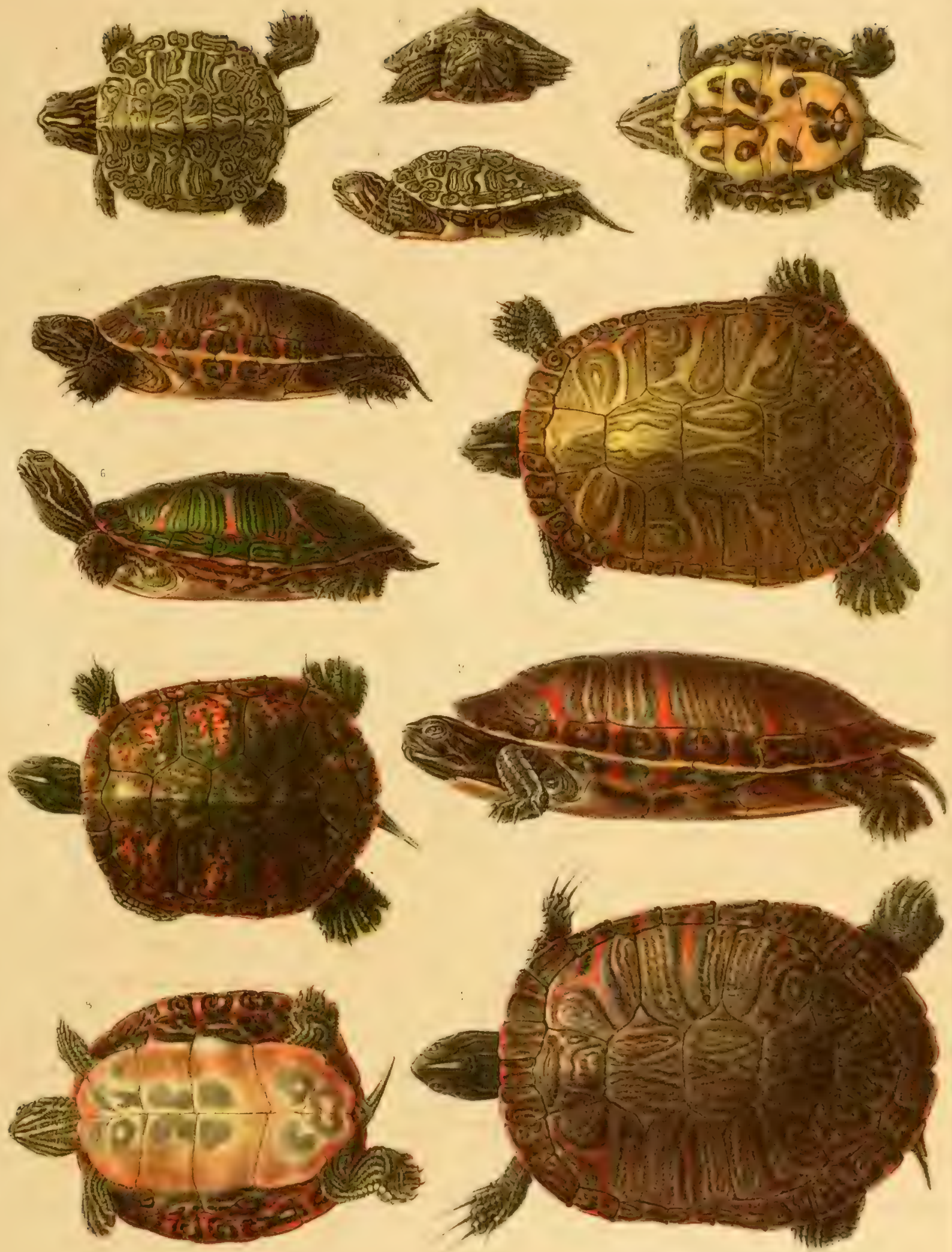



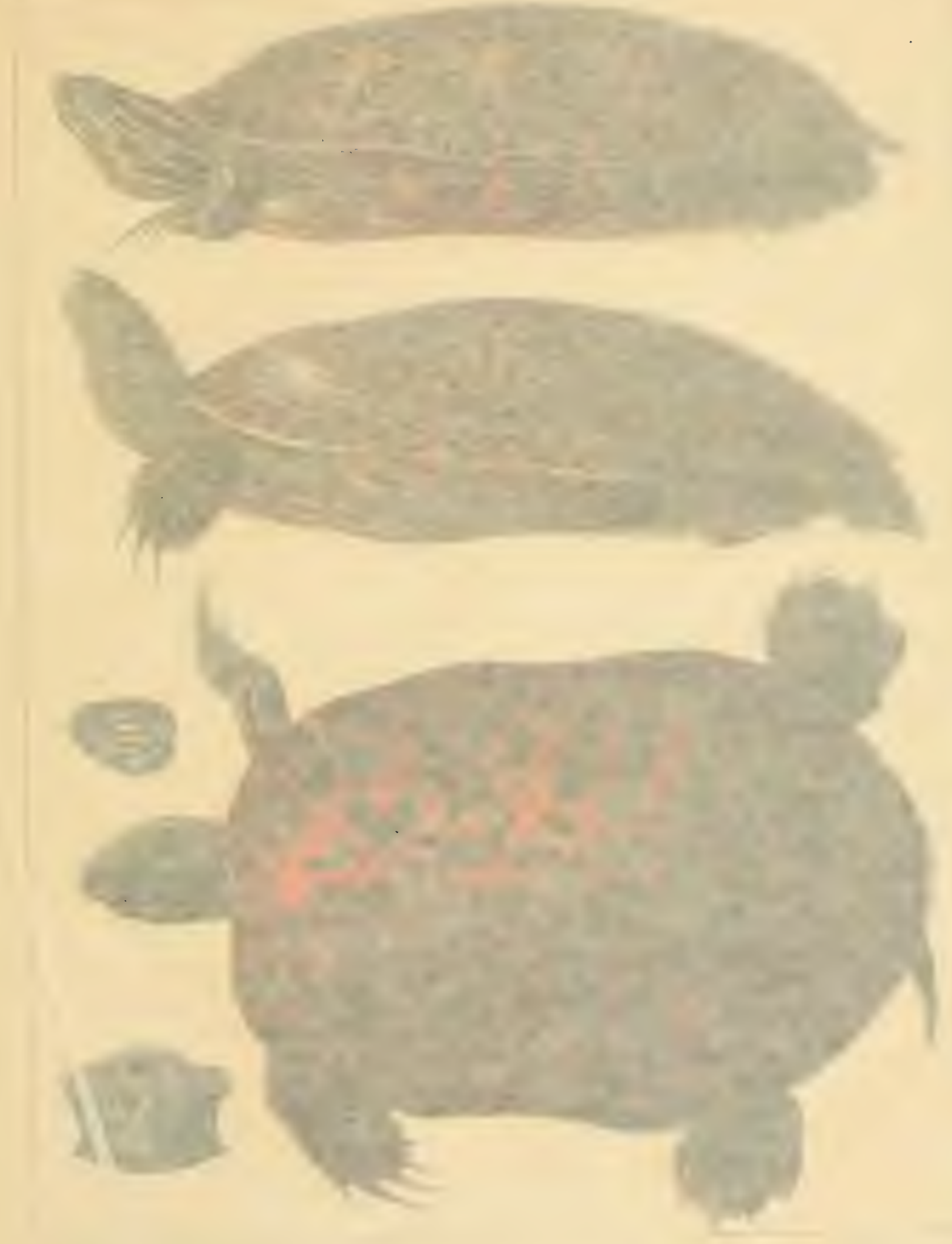





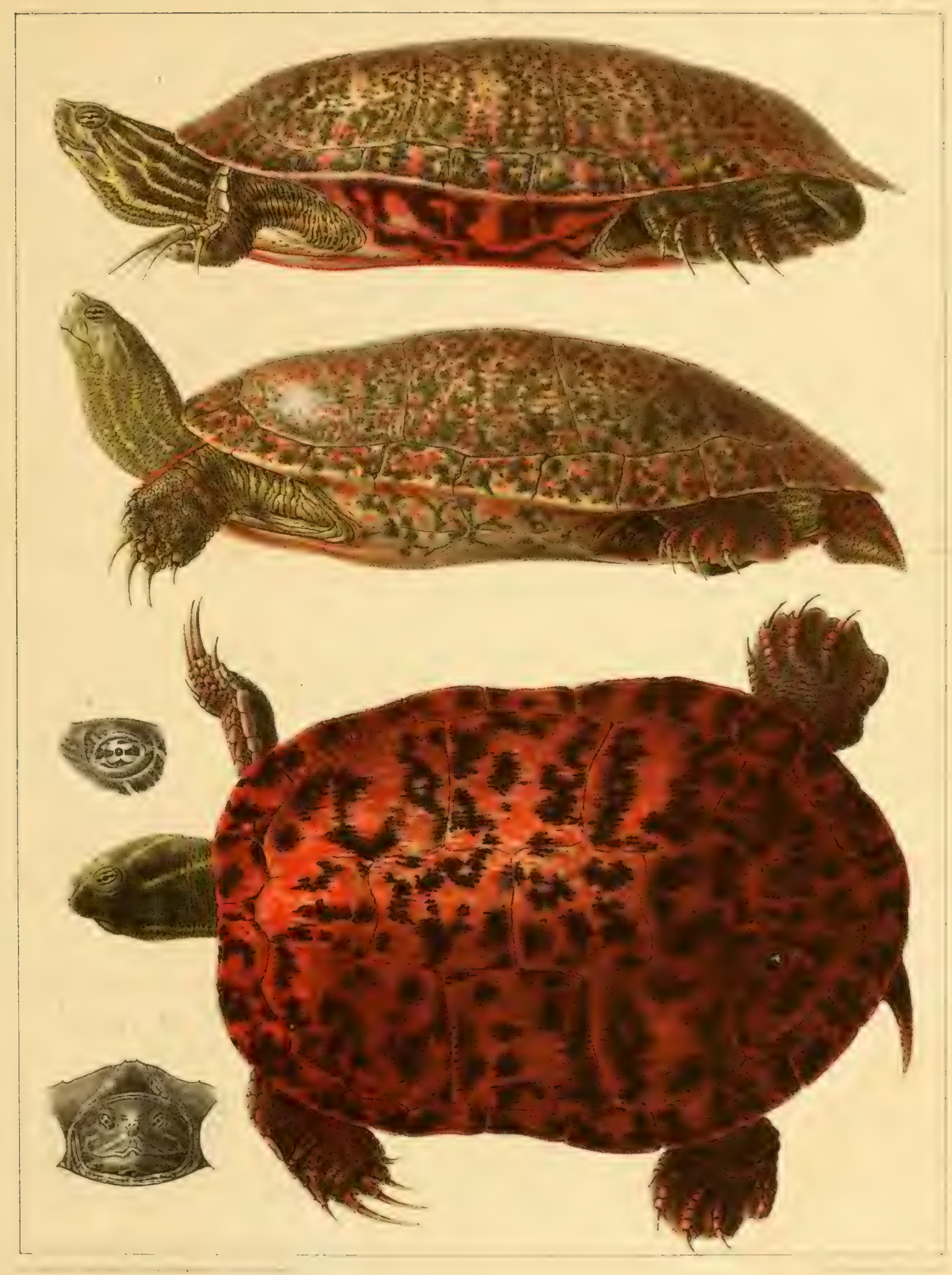



Agassiz" Correspondents (Contr. vol.2)

1. Abbott, Dr. R.0.: Camp Yuma on the Gila River

2. Abert, S. Th.: Wilmington, North Carolina

3. Baird, Prof.: Alleghany River, Vest Pennsylvania

4. Barnard, James M.: White Bear Lake, Minnesota

5. Benedict, Dr. : Now Orleans

6. Cary, T.G. Jr.: San Francisco, California

7. Chase, B.

8. Chilton, Prof.: New Orleans

9. Clark, George of Tolodo: Iraumec River, Ohio

10. Clarke, Jos, of Cincinnati

11. Copes : New Orleans

12. Cunningham, Dr. Samuel of Jonosboro", Tennossee

13. Dariell, W.B.: Savannah. p. 401

14. Eppes, lir. : Trillahasseo

15. Fontaine, Prof. Edw. of Austin, Texas

16. Gardiner, Robert H.: Southwest Georgia

17. Gerhardt, Al.: Georgia

18. Gessner, Dr. : of Columbia, Georgia - West Georgia and West. Florida

19. Hill, Franklin: Delphi, Indiana [Arkansas and Texas]

20. Hoy, P.R. of Racine, Hisconsin

21. Hunter, Dr. C.L.: North Carolina

22. Joffries: Pensacola, Florida

23. Kennerly: San Antonio - Ledina River, Texas

24. Korr, ".C.: North Carolina

25. Kirkland, Dr. : of Rockport, C:. : 

20. Lapham, J.1T. of Milwauke, Hisconsin

27. Ie Conte, Maj.: Uppor Darby, Pa. Lake Erio ¿e Ontario, P. 400; St. John's River, Florida, p. 401

28. Lindsley, Prof. of Nashville, Tennessee

20. Miles, Dr. Manly of Flint, Michigan

EO llott, Dr. : llobile, Pensacola

31. Owen, Richard: ilabash

iz. Pratt, II.A. Jr.: Roswell, Georgia

33. Putnan, Fr. i..: Florida

3.. Rauch, Dr. J.: Burlington, Iowa

35. Sager, Dr. A. of Ann Arbor

86. Sargent, Vinthrop of Natchez

37. Savage, Th. S.

38. Stein, Albort: Pensacola

50. Stolley, G.: Osage River, Missouri - Williamson Co., Tezas in stream emptying into Osage [Arkansas and Texas]

40. Tonney, S.: Lancaster, liassachusetts; Naine

11. Thompson, Zedd.: Lake Champlain

42. Wailes, B.L.C. of Washington, Mississippi

43. Watson, Dr. : Quincy

4. Winchell, Prof. Alex. of Ann Arbor 

Actinonge 64

$$
\text { maracrete } 44 \%
$$

Anvie 590

$$
\text { mutics } 580
$$

asper, Ampidoncotes 405

Aspidoncotos 405

asper 405

moryt 407

nwohelis 406

goinifer 603

bollii, Chyrewge 150

berlandieri, Xoroinatec $4 \Delta 7$

Calomere 445

fullenivercis $\leq \leq s$

carolinus, throivetes 447

Chelyare 416

serpontine 417

chelyiroidas 408

Chryearve 130

$$
\begin{aligned}
& \text { bellil } 430 \\
& \text { orocoursele } 630 \\
& \text { picta 450 }
\end{aligned}
$$

Cinostemoicuo 413, 4xo

Cinoeternou 4EC

Cistudinieno A4.

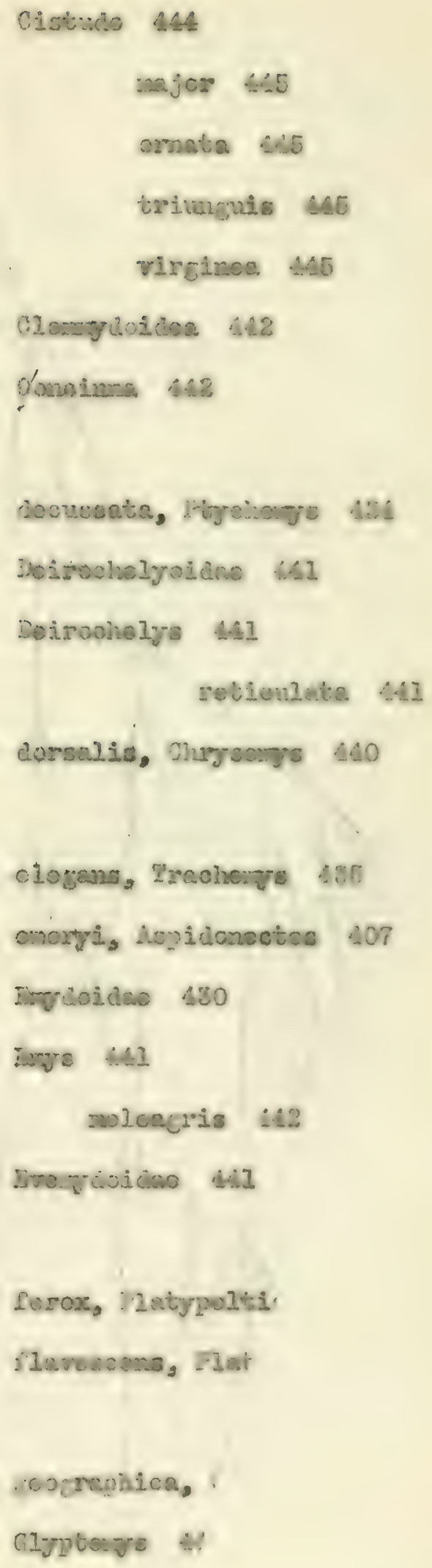




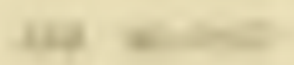

at ous

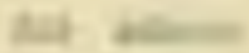

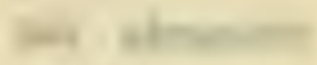

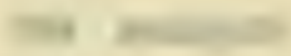

mas

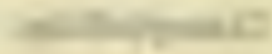

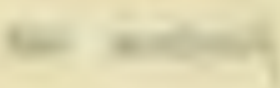

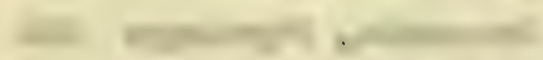

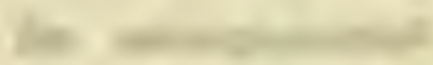

int ex an.

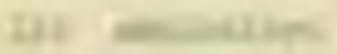

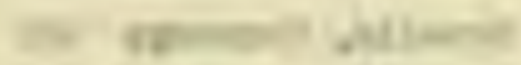

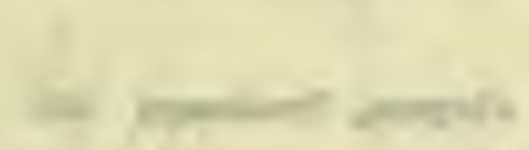

Then

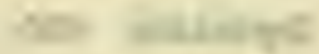

$$
\begin{aligned}
& \text { tar wou }
\end{aligned}
$$

314 basese

Der anis nom

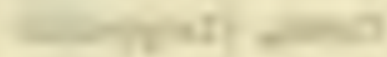

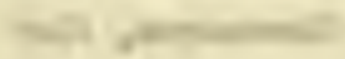

$$
\begin{aligned}
& +20-20
\end{aligned}
$$

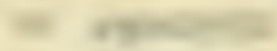

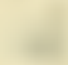

nes

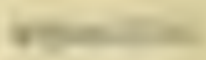

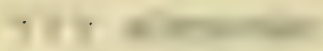

nas now

nar.

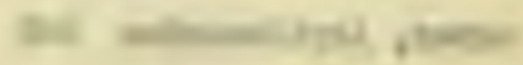

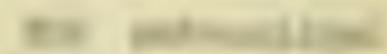

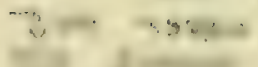

20 10

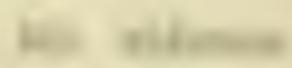

con astakt a

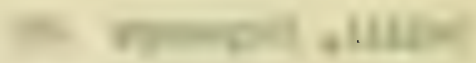

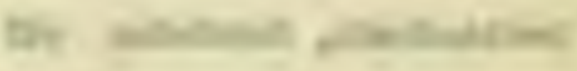

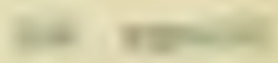

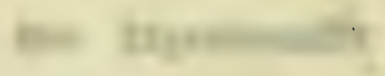

R. ninge nostives tel ousal

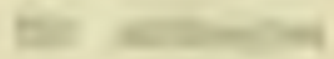

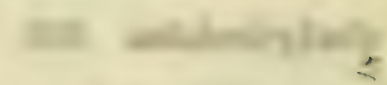

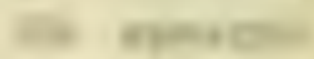

c․ Imin

ne slowaneso

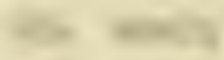

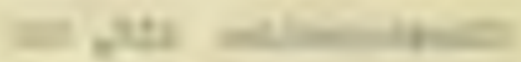

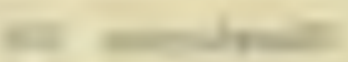

bit wat nutis 
Goniosincirs 105

minor 404

trlquotre 425

Craptomes 450

coojraplios 456

leswourls ASO

Gypochelys 413

lacortina 414

hicroclyphica, Ptyohome SDA

Insculpte, Glypte:-ge $\mathrm{CH}$

integrm, Cinostorman 420

lacortina, Cypochelys 414

lesveuri, Craptente ses

ranjor, Cistudo 4A5

Inalscoelenass 487

palustris 687

marginate, Cluryceners 48

murmorate, ictinengs LCA

meloagris, Durs 112

nobiliensis, Htycivens 455

mihlenbergi, Calergs 4

entice, sutin 393
Henenge 402

guttalo as:

tho bormilo1dae 451

auchalis, Lopicansctes con

aucreto, Cectlmse ase

orogononsts, Gurynorys 440

omate, Cistudo wh

Ocothocs en:

clerebe 4:24

trictyole $6: 34$

Oevilnocolces tas

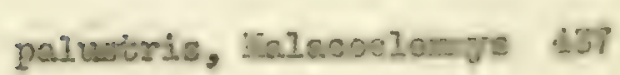

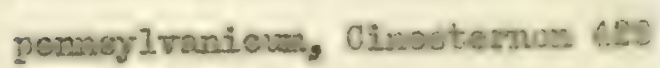

picta, chryecurge 4ab

letypoltis 400

Corot 402

In:ytigre 459

\section{Marescens ENo}

Pty encters 481

concine als

decuseats ast

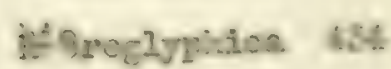

-obicisenode ass

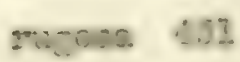


Wh nener

10 - nome

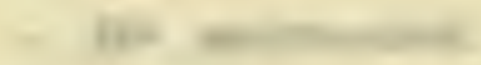

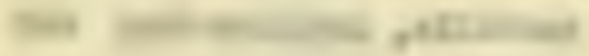

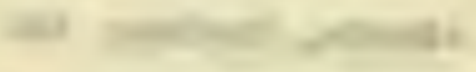

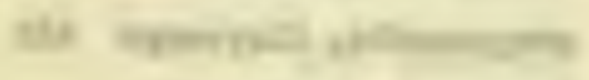

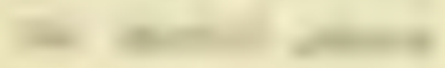
nas neme

a

- optant

an - nim

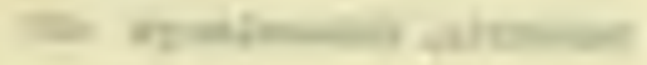

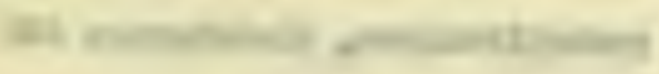

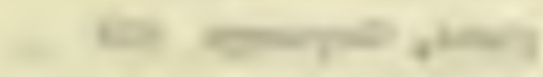

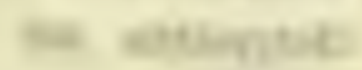

int ans

$$
\text { momin }
$$

at nom art

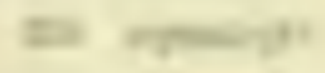

In

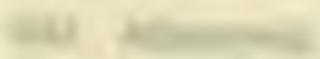

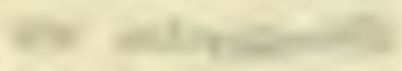

ant shourno

$=\operatorname{mos}$ res ratenes: no $\cos$

an mowi

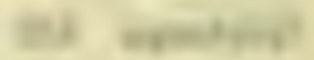

ina indingers

ais chenes

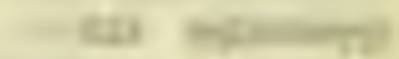

$4 \mathrm{n}$ anstonat

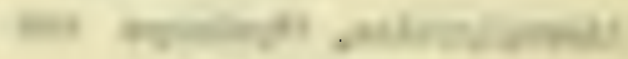

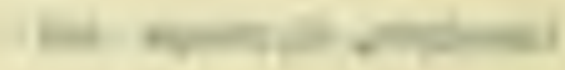

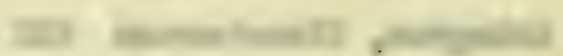

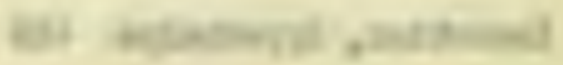

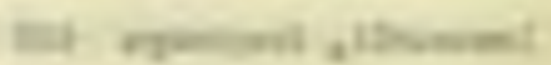

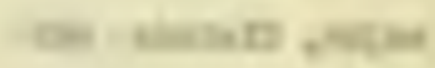

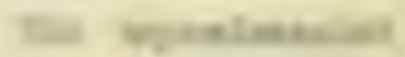

Firtede

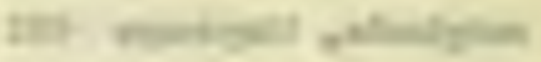

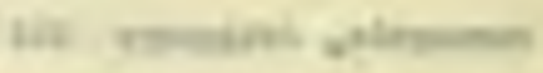

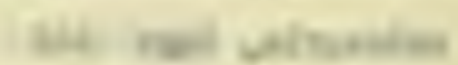

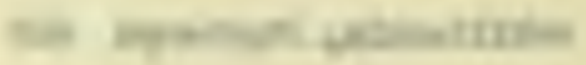

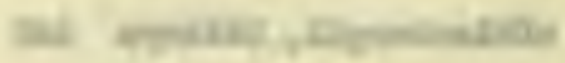

masion olne 
reticulata, Deiroolnelyo MI

Lenivatue $\leftrightarrow$ beu'?ouciord $\quad$ SCT carclinene las

scabra, Traolwave 4S

serpenting, Cholyure 417

sonorieuso, flyrosternum $\leqslant 28$

spintifer, Aspilionectea AOS

Ioctudinine $\leq 46$

Fiprostemu 427

interman 420

pennsylvenioum 423

sonoricnse 420

Trachergs 434

elecoms 455

rugoen 436

seabra 434

troostii $\mathbf{4 3 5}$

Trichychidoe ses

tristyeha, Deotileca 4P.

triunguis, Cintails we

troostil, Tracherre 435

Fircinos, Cisture cas 


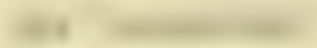

nivis

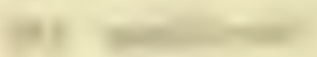

nat

vefingeure

20

woment pas

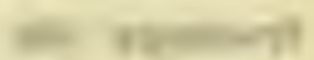

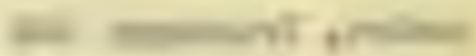

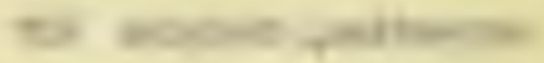

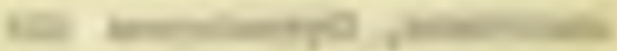

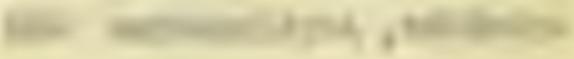

mat

Vate

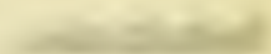

2. noment?

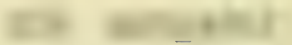

10

mons

14

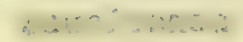

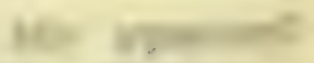

ath no no

nets ins

ats $=0$

tor homest

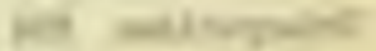

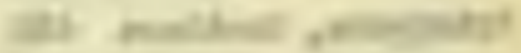

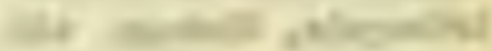

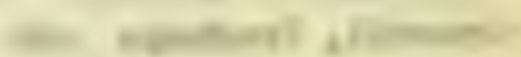

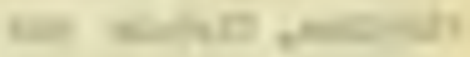





